\title{
RELATIONSHIP DEVELOPMENT OF FOREIGN FIRMS OPERATING IN CHINA
}

\author{
By
}

Yang Yu

\begin{abstract}
A thesis
Submitted to the Victoria University of Wellington in fulfilment of the requirements for the degree of

Doctor of Philosophy

in International Business
\end{abstract}

Victoria University of Wellington

2010 



\section{Abstract}

In a networked market, firms build and develop their relationships with surrounding exchange partners. Despite extensive research on relationships, there is still great potential for researchers to undertake a novel approach to address issues in the field. This study explores the relationship development process of foreign firms operating in China. A fundamental claim of the study is that although the economic and social contents in business relationships are outlined in the extant literature, empirical research treating them as distinguishable and examining them in a separate manner remains uncommon. In response to this, a two-dimensional view is presented to understand relationships and their development processes, by analysing the economic and social aspects separately. Particularly, the study focuses on comparisons between Asian firms and Western firms, between small and large firms, and between manufacturing and service firms, and investigates their differences in developing the economic and social dimensions in the relationship development context.

The study contains two phases, Phase 1 and Phase 2, undertaking qualitative and quantitative approaches, respectively. In Phase 1, the two-dimensional view is examined in the Chinese setting, and results show that foreign firms put different emphases on the economic and social aspects in developing their local relationships; in Phase 2, it is found that some of the underlying assumptions from the literature that are associated with the three comparisons noted above need to be reconsidered. For example, Western foreign firms appear to emphasise the social aspect of their relationships more than their Asian counterpart at the start of the relationship. Similarly, larger firms and manufacturing firms nurture social content more than their smaller and service counterparts, respectively. These findings are contrary to some of the accepted orthodoxies in regard to firms' relationship development. 
The results from these two phases respond to the two research questions underpinning the study: 1) Do foreign firms operating in China emphasise their economic ties and social bonds differently in developing business relationships?

2) Are there any differences in the relationship development process of firms that have different nationality and size, and which operate in different industry sectors, with respect to the economic ties and social bonds? If yes, then what are these differences? Discussion of the results for these two questions ties back to the broad research problem of the study - how do foreign firms develop their business relationships in China with local actors? In presenting the findings and insights, the study contributes to the literature in a number of ways that are outlined in the thesis. Most notably, it makes a contribution to the relationship literature, by proposing and confirming the two-dimensional approach to relationship formation and development. Secondly, by exploring foreign firms' relationships in China, the study contributes to the international business literature, providing insights into differences between different types of foreign firms. 


\section{Acknowledgement}

Many would say writing a doctoral thesis is a lonely journey. I have to disagree with this because in my case, the thesis was by no means a one man's battle, but involved invaluable helps from many people.

I would not have made this far without these people. I like to begin by thanking Associate Professor Valerie Lindsay, my primary supervisor, who has been truly generous with her time and attention, always behind me, and extremely patient for my all sorts of questions. For many times, her encouragement and counsel gave me the determination of continuing this thesis. I would also like to thank Professor Elizabeth Rose, my secondary supervisor. Despite the geographical distance between us she always gave me timely feedbacks and comments, and her expertise on research benefited me enormously in terms of designing the study, analysing the empirical data and writing up the results. As a matter of fact, without my two supervisors, I would not have even begun this journey at the first place. Certainly, I could never forget other senior academics who always expressed their warm concerns about my research progress. They are Professor Peter Dowling, Dr. Audra Mockaitis and Professor Nick Ashill.

Many thanks also go to the School of Marketing and International Business which offered the financial assistance to my field work in China. Besides, I am extremely grateful for Jacqueline Cheung and Yiwan Chen who helped me during the data collection process, which, otherwise, could never have been accomplished. In addition, I thank my former fellow David St. George who is now pursuing his photography career passionately. Sharing an office room with him for three years was part of my memory about the journey of writing this thesis.

The greatest appreciation also goes to my dearest family. My parents gave me the opportunity to come to New Zealand and ask for no return. I hope I could spend more time with them in the future, as a good son should do. Also, my wife, Lucy Zhang, has been waiting for me patiently to complete this journey for the last three years. We married in October 2009, but had to be apart three months later, in order for me to continue writing the thesis. I am deeply indebted to her, and appreciate what she has sacrificed for me. Also, thank you, my parents-inlaw, for your understanding and support.

Last but not least, I would like to express my gratitude to anyone who has ever encouraged me during the past four years, even though I cannot name them all in this short acknowledgement.

So, it wasn't a lonely journey indeed. 


\section{Table of Contents}

Chapter One Introduction 1

1.1 Chapter Objectives 1

1.2 Research Problem and the Literature Background 1

1.2.1 Research problem 1

1.2.2 Literature background 3

1.3 Conceptual Approach to Examining Relationship Development 5

1.3.1 Relationship development as a process 5

1.3.2 The economic and social contents in business relationships 6

1.3.3 A two-dimensional view of analysing business relationships 8

1.4 Research Questions and the Intended Contributions of the Study 9

1.5 Research Approach 11

1.6. Organisation of the Thesis 14

Chapter Two Literature Review 16

2.1 Chapter Objectives 16

$\begin{array}{ll}2.2 \text { Business Networks } & 16\end{array}$

2.2.1 The concept of business networks 16

2.2.2 Structural and relational level analysis $\quad 20$

2.2.3 Defining networks for research 23

2.3 Economic and Social Contents of Business Networks 26

2.3.1 Economic perspective of networks 26

2.3.2 Social perspective of networks 28

2.3.2.1 Embeddedness theory $\quad 29$

2.3.2.2 Social capital theory $\quad 31$

2.3.2.3 Relationship marketing $\quad 34$

2.3.2.4 Section summary $\quad 37$

2.4 Measurement of Business Relationships 38

2.4.1 A brief review of relationship constructs 38

2.4.2 Themes of relationship measurement 41

2.5 Effects of Business Networks on Firms 44

2.5.1 The positive effects $\quad 44$ 
2.5.2 The negative effects

2.5.3 The mediators and contingent value of networks 48

2.6. Network Development 48

2.6.1 Interactive nature between firms and networks 49

2.6.2 Factors influencing network development 51

2.6.3 Network structure evolution $\quad 52$

2.6.4 Evolution of dyadic relationships in networks $\quad 54$

2.6.4.1 The stages model $\quad 54$

2.6.4.2 Alternative models and perspectives $\quad 57$

2.6.5 Network dynamics evolution of entrepreneurial firms 61

2.6.6 Section remark 63

2.7 Networks and Relationships in International Business 65

2.7.1 External network and internal network of MNCs 65

2.7.2 MNC subsidiary networks in foreign markets 67

2.7.3 Social networks in China $\quad 69$

2.7.3.1 Guanxi in business networks $\quad 69$

2.7.3.2 Guanxi and relationships development $\quad 72$

2.8. Chapter Summary 73

Chapter Three Conceptual Development, Research 76 Questions and Hypotheses, and Research Design

3.1 Chapter Objectives $\quad 76$

3.2 They Study of Relationships in Networks 76

3.3 Defining and Examining 'Process'

3.4 The Nature of Relationships and Their Development 79

3.5 A Two-dimensional View for Analysing Relationships and 85

Relationship Development

3.6 Research Problem and Research Questions $\quad 88$

$\begin{array}{ll}3.7 \text { Hypotheses Development } & 90\end{array}$

3.7.1 Comparison between Asian and Western foreign firms 90

3.7.2 Comparison between small and large foreign firms 94

3.7.3 Comparison between manufacturing firms and service firms 97

3.8 The Two-phase Design and Mixed Methodology 101

$\begin{array}{ll}3.9 \text { Chapter Summary } & 103\end{array}$ 


\section{Chapter Four The Qualitative Phase of the Study}

4.1 Chapter Objectives 105

4.2 Qualitative Methodology 105

4.2.1 Objective and design in Phase One 105

4.2.2 Sampling and firm recruitment 106

4.2.3 Research instrument and the interview process 109

$\begin{array}{ll}\text { 4.2.4 Business relationships of the firms } & 110\end{array}$

4.3 Coding and Data Interpretation 112

4.3.1 Data reduction (coding) 112

4.3.2 Data interpretation $\quad 114$

4.4 Qualitative Findings 115

4.4.1 Distinctive emphasises on the economic and social dimensions 115

4.4.2 Four categories of relationships 117

4.4.2.1 Relationships with weak economic ties and social bonds $\quad 117$

4.4.2.2 Relationships with strong economic ties and weak social 119 bonds

4.4.2.3 Relationships with weak economic ties and strong social 121 bonds

4.4.2.4 Relationships with strong economic ties and strong social 123 bonds

4.4.3 Additional findings on economic ties and social bonds 124

4.5 Discussion of the Four Relationship Categories $\quad 125$

$\begin{array}{ll}4.6 \text { Chapter Summary } & 129\end{array}$

Chapter Five Quantitative Methodology 130

5.1 Chapter Objectives 130

5.2 Objective and Research Design 130

5.3 Measures for Economic Ties and Social Bonds 132

5.3.1 Refine relationship constructs by the economic and social aspects 133

$\begin{array}{ll}\text { 5.3.2 Economic constructs and the items } & 134\end{array}$

5.3.2.1 Economic interaction $\quad 135$

5.3.2.2 Economic communication 136

5.3.2.3 Economic trust 137

5.3.2.4 Economic commitment 140

5.3.3 Social constructs and items 142 
5.3.3.4 Social commitment

5.3.3.5 Norms and values

5.3.4 Section remark

5.4 Variables and Analysis Strategy for Multiple Regressions

5.4.1 Dependent variables for the economic ties and social bonds

5.4.2 Dependent variables for the economic and social constructs

5.4.3 Explanatory variables

5.4.3.1 Firm size

5.4.3.2 Nationality

5.4.3.3 Industry sector

5.4.4 Control variables

5.4.4.1 Ownership structure

5.4.4.2 Influence from the foreign headquarters

5.4.4.3 Presence of other subsidiary/ries in China

5.4.4.4 Relationship benefit and relationship dependence

5.4.4.5 Relationship duration

5.4.4.6 Relationship satisfaction

5.4.5 Analysis strategy for regression modelling

5.5 The Survey Instrument and Data Collection

5.5.1 The survey instrument

5.5.2 Data collection methods and the sample

\section{Chapter Six Quantitative Data Analysis and Results}

6.2 Data for the Variables

6.2.1 Data for the explanatory variables

6.2.2 Data for the dependent variables

6.2.3 Data for the control variables 
6.3.1 Development of the economic ties and social bonds

6.3.1.1 Economic ties at relationship formation

6.3.1.2 Social bonds at relationship formation

189

6.3.1.3 Change in economic ties after relationship formation

6.3.1.4 Change in social bonds after relationship formation

6.3.1.5 Summary of findings in the analysis of economic ties and social bonds

6.3.2 Changing status of economic and social constructs

6.3.2.1 Economic constructs at relationship formation

6.3.2.2 Social constructs at relationship formation

6.3.2.3 The degree of change in economic constructs

6.3.2.4 The degree of change in social constructs

\section{Chapter Seven Discussion and Conclusions}

7.1 Chapter Objectives 250

7.2 Discussion of the Findings 250

7.2.1 Discussion of the qualitative findings 250

7.2.1.1 Early stage in relationship development 251

7.2.1.2 The subsequent relationship development 252

7.2.2 Discussion of the quantitative findings 255

7.2.2.1 Comparison between Western and Asian firms (Hypotheses 255 $1 a, 1 b, 1 c$ and $1 d)$

7.2.2.2 Comparison between small and large firms (Hypotheses $2 a, \quad 260$ $2 b$ and $2 c$ )

7.2.2.3 Comparison between manufacturing and service firms (Hypotheses $3 a$ and $3 b$ )

7.2.2.4 Control variables

7.2.3 Contributions to the literature 274

7.2.3.1 Understanding the two-dimensional nature of business 275 relationships

7.2.3.2 Considering relationship development from the twodimensional perspective

7.2.3.3 Relationship constructs and measurement 280

7.2.3.4 Relationship development of foreign firms in China 282 
7.2.4 Contributions to research methodology

7.2.4.1 Relationship development from a process-based view

7.2.4.2 The two-phase research design

7.2.4.3 Data collection in China

7.2.5 Section summary

7.3 Conclusions of the Study

7.3.1 Summary of key research findings

7.3.2 Limitations and future research

7.3.3 Implications for Practitioners

7.3.3.1 Manage relationships by the economic and social dimensions

7.3.3.2 Relationship development for foreign Western and Asian firms in China

7.3.3.3 Relationship development for foreign small and large firms in China

7.3.3.4 Relationship development for foreign service firms in China

\section{APPENDIXES}

Appendix 1: Research Information Sheet for Interviews

Appendix 2: Interview Consent Form

Appendix 3: Background of the Interviewed Firms

Appendix 4: Interview Guideline

Appendix 5: Factor Analysis Results for Economic Constructs

Appendix 6: Factor Analysis Results for Social Constructs

Appendix 7: Research Information Sheet for Survey

Appendix 8: Survey Questionnaire 


\section{List of Tables}

Table 2-1 Distinguishing Attributes of Market, hybrid and hierarchy 28

Table 2-2 An Example for Examining Relationships in a Continuum 43

Table 2-3 Comparison Between Guanxi and the Western Relational 70

Exchange

Table 4-1 Characteristics of the Interviewed Firms 108

Table 4-2 Relationships Discussed in Interviews 112

Table 4-3 A Summary of Qualitative Findings on Economic and Social 125 Elements

Table 5-1 Items for Economic Interaction 135

$\begin{array}{lll}\text { Table 5-2 Items for Economic Communication } & 137\end{array}$

Table 5-3 Items for Economic Trust 139

$\begin{array}{lll}\text { Table 5-4 Items for Economic Commitment } & 141\end{array}$

Table 5-5 Items for Social Interaction 143

Table 5-6 Items for Social Communication 144

$\begin{array}{lll}\text { Table 5-7 } & \text { Items for Social Trust } & 146\end{array}$

$\begin{array}{lll}\text { Table 5-8 Items for Social Commitment } & 147\end{array}$

$\begin{array}{lll}\text { Table 5-9 } & \text { Items for Norms and Values } & 149\end{array}$

Table 5-10 Summary of the Economic and Social Constructs 150

Table 5-11 Summary of Dependent Variables in the Construct-level 153

Table 5-12 Items for HQs' Managerial Influence 156

Table 5-13 Items for Relationship Benefit 157

Table 5-14 Items for Relationship Dependence 157

Table 5-15 Items for Relationship Satisfaction 159

Table 5-16 Regression Modelling for the Economic Ties and Social 161 Bonds

Table 5-17 Regression Modelling for the Economic and Social 163

$\begin{array}{lll}\text { Table 5-18 } & \text { Survey Responses in Phase } 2 & 168\end{array}$

$\begin{array}{lll}\text { Table 5-19 Examples of Previous Surveys in China } & 169\end{array}$

Table 5-20 Types of Relationships in the Survey 170

Table 5-21 Demographic Information of the Respondents 170

Table 6-1 Nationality, Size and Industry of the Sample Firms 174 
$\begin{array}{lll}\text { Table 6-2 Explanatory Variables Used in Regression Modelling } & 175\end{array}$

Table 6-3 Descriptive Statics of Economic Constructs and Items 177

Table 6-4 Descriptive Statics of Social Constructs and Items 178

Table 6-5 T-tests for Means of Relationship Constructs between Time 1 and Time 2

$\begin{array}{lll}\text { Table 6-6a Descriptions of the Control Variables (1) } & 184\end{array}$

$\begin{array}{lll}\text { Table 6-6b Descriptions of the Control Variables (2) } & 185\end{array}$

Table 6-7 Regression Results for Economic ties at Relationship 188

$\begin{array}{lll}\text { Table 6-8 Regression Results for Social Bonds at Relationship } & 190\end{array}$

Table 6-9 Regression Results for the Degree of Change in Economic 193 Ties

Table 6-10 Regression Results for the Degree of Change in Social Bonds 195

Table 6-11 Summary of the Regression Results at the Level of Economic 197 ties and Social Bonds

Table 6-12a Regression Results for Tangible Economic Interaction at 203

Relationship Formation

Table 6-12b Regression Results for Intangible Economic Interaction at 204

Relationship Formation

Table 6-12c Regression Results for Economic Communication at

Relationship Formation

Table 6-12d Regression Results for Competence Trust at Relationship Formation

Table 6-12e Regression Results for Contractual Trust at Relationship Formation

Table 6-12f Regression Results for Economic Commitment at Relationship Formation

Table 6-13a Regression Results for Social Interaction at Relationship Formation

Table 6-13b Regression Results for Social Communication at Relationship Formation

Table 6-13c Regression Results for Social Trust at Relationship

Table 6-13d Regression Results for Social Commitment at Relationship Formation

Table 6-13e Regression Results for Norms and Values at Relationship Formation 
Table 6-14a Regression Results for the Degree of Change in Tangible

Economic Interaction

Table 6-14b Regression Results for the Degree of Change in Intangible

Economic Interaction

Table 6-14c Regression Results for the Degree of Change in Economic

Communication

Table 6-14d Regression Results for the Degree of Change in Competence

Trust

Table 6-14e Regression Results for the Degree of Change in Contractual Trust

Table 6-14f Regression Results for the Degree of Change in Economic Commitment

Table 6-15a Regression Results for the Degree of Change in Social Interaction

Table 6-15b Regression Results for the Degree of Change in Social Communication

Table 6-15c Regression Results for the Degree of Change in Social Trust

Table 6-15d Regression Results for the Degree of Change in Social Commitment

Table 6-15e Regression Results for the Degree of Change in Norms and Values

Table 6-16a Summary of the Significant Results for Relationship Formation at the Construct Level

Table 6-16b Hypothesis Testing Results for Relationship Formation at the Construct Level

Table 6-17a Summary of the Significant Results for the Degree of Change at the Construct Level

Table 6-17b Hypothesis Testing Results for the Degree of Change in

Relationships at the Construct Level 


\section{List of Figures}

$\begin{array}{lll}\text { Figure 2-1 A Network Identified in China } & 24\end{array}$

Figure 2-2 Characteristics of Business Relationships 41

Figure 2-3 An Integrated View on Closure and Structural Hole 53

Figure 2-4 The Development of Buyer-seller Relationships 55

Figure 2-5 The Relationship Development Process 56

Figure 2-6 A Cycle Framework of Relationship Development 58

$\begin{array}{lll}\text { Figure 2-7 The States Model of Relationship Development } & 60\end{array}$

$\begin{array}{lll}\text { Figure 2-8 Evolutionary Paths of Relationship Governance } & 61\end{array}$

$\begin{array}{lll}\text { Figure 2-9 Evolutionary Processes of Relationships } & 63\end{array}$

Figure 3-1 A Continuum View to Analysing Business Relationships 81

Figure 4-1 A Generic Representation of Firms' Egocentric Business 111 Network

Figure 4-2 Defining Relationships by the Economic and Social 126 Dimensions

Figure 6-1 Scatterplots for the Relationships in the Survey at Time 1 181

Figure 6-2 Scatterplots for the Relationships in the Survey at Time 2 181

Figure 7-1 Illustration of the Relationship Development Patterns for 257

Figure 7-2 Illustration of the Relationship Development Patterns for 262 Larger and smaller firms

Figure 7-3 Illustration of the Relationship Development Patterns for 267 manufacturing and service firms

Figure 7-4 Conceptual Framework Illustrating the Relationship 278 Development Process via Changes in the Economic and Social Dimensions 



\section{Chapter One Introduction}

\subsection{Chapter Objectives}

The relationship development process of foreign firms operating in China is explored in this study. Chapter 1 begins with stating the overarching research problem, and then describes the background literature. After introducing the conceptual approach undertaken to examine firms' relationship development, the chapter then presents the specific research questions and the intended contributions of the study. Thereafter, methodological aspects are explained along with the research approach, followed by an outline of the entire thesis.

\subsection{Research Problem and the Literature Background}

The broad research problem of the study is stated in this section, followed by a brief description of the related literature.

\subsubsection{Research problem}

A network consists of a set of actors and relationships connecting those actors (Van Wijk, Van den Bosch and Volberda, 2003). The application of this basic concept to the business context elicits the idea of interfirm business networks which has attracted a great deal of attention in the literature and become one of the most notable research topics in the last two decades. Scholars who advocate business networks perceive that firms in the market do not exist in a vacuum but are connected with each other via different types of exchanges, or business relationships (Jarillo, 1988; Thorelli, 1986). By embracing the business network concept, they believe that researchers are empowered with a very effective tool to study the interconnected market system between and among individual firms.

In the international business field, network-related studies have developed into an important research stream. Following Johanson and Mattsson's $(1987,1988)$ classic work, researchers adopt a business network perspective and explain how firms' external networks with suppliers, buyers and other alliances may affect 
their business activities and performance in the internationalisation process (e.g. Chen, Chen and Ku, 2004; Coviello and Munro, 1995, 1997; Ellis, 2000; Ellis and Pecotich, 2001; Harris and Wheeler, 2004; Wong and Ellis, 2002). Drawing from a number of theoretical perspectives, scholars have suggested that firms should continue to establish and nurture their networks with the local business actors after their arrival in a foreign country. For example, London and Hart (2005) theorise that developing local network embeddedness should be an important strategic issue for multinational corporations (MNCs). Others underline the necessity of fostering social capital in local networks after MNCs arrive in new countries (Hitt, Lee and Yucel, 2002; Rauch, 2001).

Networks are studied at the structural or relational level, and the analysis of relationships is a central part of network research, as relationship building is the fundamental way of networking (Todeva, 2006). The study is concerned with foreign firms operating in China and their relationship development with the local business actors, given the important role of China in today's global economy. The overarching research problem, therefore, is: how do foreign firms operating in China develop business relationships with local actors? The study is meaningful because relationship development is an important issue for foreign firms operating in China. First, Luo (2007) has argued that China should no longer be considered as only a world manufacturing factory, because its fast growing domestic middleclass has made the market increasingly crucial for foreign MNCs' global success. This may also be echoed by the historical high foreign direct investment inflows to China in 2008, which reached USD 1,083 billion (www.stats.govt.cn). Theoretically, foreign firms operating in China are likely to encounter a high requirement on local network development (London and Hart, 2004), suggesting the importance of relationship building. Second, China's culture is featured by the emphasis on social networking - guanxi (Luo, 1997, 2003; Park and Luo, 2001; Xin and Pearce, 1996), which implies that firms operating in this market would need to pay strong attention to relationship building, especially the social elements, with surrounding business actors. However, as Wu and Choi (2004) mentioned, 
despite extensive studies about China how foreign firms actually develop networks and build relationships in this market remains somewhat unclear. In addition, China's market and social environments are evolving continuously, and therefore deserve constant research input to ensure an up-to-date knowledge base (Luo, 2007).

In the following section, the literature on relationship development, especially with regard to MNCs' subsidiaries in host countries and the Chinese setting, is introduced briefly.

\subsubsection{Literature background}

Network development is a recent topic and still relatively under-researched (Gulati and Gargiulo, 1999; Kim, Oh and Swaminathan, 2006). According to Borgatti and Foster (2003), this is because much attention in the early network literature was given to the issue of how networks can affect individual actors, for the purpose of legitimate network theory by seeking evidence of 'network consequence'. From the 1990s onwards, in line with Nohria's (1992) recommendation, scholars began to shift their interest to network development, because knowledge in this regard can help firms to make better use of their networks for business purposes (Coviello, 2006; Koka, Madhavan and Prescott, 2006). Also, from the firms' point of view, "managers who understand the potential of business networks for their firms would naturally like to know how to build one in practice" (Andersson, Hakånsson and Johanson, 1994:13).

The literature on network development remains somewhat controversial. From a structural perspective for example, although traditionally cohesive networks are favoured (Coleman, 1988), others argue for loosely structured networks featured by weak ties (Burt, 1997). As far as relationship development is concerned, strong and close relationships were traditionally favoured, and previous scholars present a well-known stages model for developing such relationships (Dwyer, Schurr and Oh, 1987), which predicts that relationships evolve along a linear process. Lately, 
however, scholars from various theoretical perspectives point out that, firms should be cautious of these strong business relationships, due to potential negative effects resulting from the social elements embedded in the relationships (Anderson and Jap, 2005; Gargiulo and Benassi, 2000; Molina-Morales and Martínez-Fernández, 2009; Uzzi, 1997). In the meantime, the stages model has also been questioned by many researchers who, based on their empirical findings, argue that many relationships do not evolve linearly as the model predicts (e.g. Batonda and Perry, 2003a; Beloucif, Donaldson and Waddell, 2006).

With regard to MNCs' subsidiaries in host countries, a group of Uppsala scholars point out that subsidiaries should be cautious of the locked-in situation emerging from their local networks, and the resulting constraint on their coordination and cooperation with the headquarters and other MNC units (Forsgren, Holm and Johanson, 2005). In order to address this issue, Andersson, Forsgren and Holm (2001) suggest that a subsidiary's local network in its host country should be composed of both highly embedded relationships and a number of arm's-length relationships with other business actors. Their view points towards the complexity of business relationship development of subsidiaries in foreign markets. However, empirical research investigating this issue remains limited.

As far as China is concerned, the literature highlights the importance for firms to engage in social networking, or guanxi building, with their local exchange partners (e.g. Chen and Chen, 2004; Luo, 1997; Park and Luo, 2001; Wu and Choi, 2004; Wu and Leung, 2005; Xin and Pearce, 1996). Nonetheless, this does not necessarily mean that foreign firms operating in China would all have to nurture strong social relations with their exchange partners when developing the business relationships. First, one original motive for firms to build guanxi is to substitute the under-developed institutional environment (Peng and Heath, 1996; Xin and Pearce, 1996). Since China has made significant progress in its economic and political environment in recent years, guanxi might have become less influential. From an institutional theory perspective, Peng $(2002,2003)$ considers 
that in a transitional economy like China, the constantly improving institutional environment could make social relations less important and therefore, business networks become more transactional and contractual based. Second, scholars have noticed the negative effects of guanxi on business firms (Chen and Chen, 2009). To avoid the dark side of guanxi, which includes reciprocal obligations and collective blindness ( $\mathrm{Gu}$, Hung and Tse, 2008), firms are likely to focus less on the social relations in developing business relationships. As Lovett et al. (1999) predicted, due to the constraint posed by guanxi, with time goes by, Chinese firms may emphasise more on partners' ability other than guanxi, for the purpose of being more competitive.

Overall, it can be seen that relationship development of foreign firms operating in China can be very dynamic. The study aims to address this topic. The following section explains the approach undertaken in the study to investigate firms' relationship development.

\subsection{Conceptual Approach to Examining Relationship Development}

In this study, relationship development is investigated by unfolding the evolving nature of relationships, with respect to two components - economic and social. This conceptual approach is explained in the following sub-sections.

\subsubsection{Relationship development as a process}

Networks and relationships are essentially process-based (Hite and Hesterly, 2001; Larson and Starr, 1993), so is relationship development. However, as Coviello (2006) noted, research on how networks and relationships develop over time in terms of their characteristics remains surprisingly little. To address this, relationship development is perceived as a process-based concept in the study. Van de Ven (1992) concludes that one of the definitions for 'process' refers to a category of concepts that can be further operationalised as constructs of the subject. In line with this definition, a process is revealed by measuring the representative constructs before and after, to identify the degree to which the focal 
subject has evolved within a focal timeframe. The method adopted in the study to investigate relationship development echoes this definition. Particularly, relationships are the subject and perceived as being represented by a number of constructs which reflect the characteristics or nature of the relationships. Hence, from an operational perspective, the study investigates the relationship development process by examining how relationships, by their nature, have evolved over time. Notably, the study is in response to the statement made by the IMP (International Marketing and Purchasing) scholars Turnbull, Ford and Cunningham (1996) who consider that an effective angle to unfold the dynamic relationship development process is focusing on the subtle changes of the relationship nature. Some early scholars, for example, Stern (1979) adopted such an approach, by emphasising a concern with change through analysing the evolving characteristics of the focal inter-organisational relationships. However, as just indicated, research undertaking such an approach is limited in the literature.

\subsubsection{The economic and social contents in business relationships}

The process-based approach sheds light on the nature of relationships. The nature of relationships helps to understand how actors are linked or connected to each other (Turnbull et al., 1997). It has attracted a great deal of attention in the past, and been discussed in various forms of relational attributes, including those such as strength, quality and closeness (Tangpong, Michalisin and Melcher, 2008), which generally refer to the degree or the magnitude of relationships (Bove and Johnson, 2001; Golicic et al., 2003). Recently, research interest in this area has gained further momentum. According to Brass, Galaskiewicz, Greve and Tsai (2004: 809), the literature shows an increasing interest in firm-level network dynamics, and a clear shift has emerged from "binary consideration, such as the existence or non-existence of a relationship, to consideration of distinction, such as the strength and content of the relationship".

The current body of knowledge on the nature of business relationships is gained from two broad perspectives - economic and social. To begin with, in order to 
form a business relationship, two actors must be engaged in business exchanges involving aspects of transactions of assets, resource and knowledge sharing, and so on (Forsgren, 2004). This type of economic content exists in business relationships in a quite explicit way, and traditionally, draws attention from the economists who, from the transaction cost point of view (Williamson, 1991) consider that firms' behaviours in network relationships are driven largely by their perceived economic gains. Such an economic view of business networks and relationships, as Jones, Hesterly and Borgatti (1997) pointed out, primarily focuses on profit-oriented business interactions. It attempts to explain relationships based on cost-benefit analysis, and regards firms' behaviours as highly opportunistic and calculative.

In the meantime, a number of theories arising from the sociology literature highlight the non-economic or social aspect of business networks and relationships, including social exchange theory (Bagozzi, 1975; Ferrell and ZeyFerrell, 1977), relational exchange theory (MacNeil, 1980), embeddedness theory (Granovetter, 1985) and social capital theory (Coleman, 1984, 1988, 1990). Essentially, these themes indicate that in a relationship, two firms carry out not only economic exchanges, but also socialising activities. They may be concerned about each other's welfare, and have strong emotional attachment consisting of for example trust, commitment, goodwill and reciprocity. Importantly, these social contents may exert influence on the firms' business activities, which cannot be sufficiently explained by the economic view mentioned above.

The 1980s witnessed a debate between economics and sociology, and an outcome from this debate was the re-drawing of boundaries between these two theoretical disciplines by scholars in both fields (Swedberg, 1990). With such a background, an integrated view to understanding firms' networks and relationships has emerged. Now, it is acknowledged that both economic and social contents together provide a theoretical foundation to comprehend firms' business networks. With regard to relationships in particular, scholars suggest that the essence of 
measuring relationships is to capture the economic and social contents connecting two actors (Donaldson and O'Toole, 2000), and the growth of economic and social elements gives rise to the two primary themes in relationship development (Larson and Starr, 1993; Ring and Van de Ven, 1994).

\subsubsection{A two-dimensional view of analysing business relationships}

Drawing on economic and social contents highlighted in the extant literature, as described in the previous section, a two-dimensional view is proposed in the study to analyse business relationships by their nature. Specifically, economic ties and social bonds are defined as the two primary dimensions of business relationships ${ }^{1}$, representing the economic and social contents. The former is concerned with two firms' mutual engagement to accomplish their central business tasks and pursue anticipated economic benefits; the latter concerns firms' social attachments, indicating the levels of cohesive social capital and relational embeddedness. These two dimensions are considered to be distinguishable in a relationship, despite being interrelated and intertwined under particular circumstances. For instance, they do not necessarily have equal weighting; a relationship can have strong economic ties and strong social bonds, whereas it can also be featured by strong economic ties and weak social bonds.

This two-dimensional view addresses an underlying issue in the relationship literature. Although researchers take both the economic and social contents into consideration while measuring relationships, they rarely differentiate between them and examine them separately (e.g. Perry-Smith and Shalley, 2003). From such a perspective, researchers could obtain an overall impression about the relationships. Yet, they may not be able to evaluate the nature of relationships more in-depth, and fail to reveal the diversity of relationships, including for instance those 'economically close but adversarial' (Mudambi and Mudambi, 1995) and 'durable arm's-length' relationships (Dyer, Cho and Chu, 1998). As Donaldson and O'Toole (2000: 494) noted, "a relationship may be very co-

\footnotetext{
${ }^{1}$ In this thesis, the terms 'social dimension' and 'social bonds' are used interchangeably, as are 'economic dimension' and 'economic ties'.
} 
operative and open but not have strong economic ties, or a relationship may have strong economic ties through dependency but be very uncooperative and forced".

With regard to relationship development, the two-dimensional view further suggests that researchers need to scrutinise the evolution of the economic ties and social bonds separately, in order to capture the dynamics in the development process. This is because these two dimensions could evolve differently in a relationship. For example in entrepreneurial firms' networks, research shows that a relationship originated from family ties could become arm's-length, indicating decreasing social bonds but increasing economic ties in the relationship (Coviello, 2006; Hite, 2003, 2005). Also, in recent years, scholars suggest deliberately managing the degree to which the social content needs to be developed (MolinaMorales and Martínez-Fernández, 2009), which is especially the case for firms operating in China (Björkman and Kock, 1995). This implies that it may be meaningful to examine the development of the social dimension separately from the economic dimension.

In short, it is argued that by undertaking a two-dimensional view and analysing the economic and social dimensions separately, the researcher is able to understand relationships and their development processes more fully.

\subsection{Research Questions and the Intended Contributions of the Study}

As discussed in the previous section, the co-existence of economic and social contents of business relationships is widely acknowledged by scholars, but empirical research that addresses them separately while investigating relationships and the relationship development process remains uncommon. The study is intended to address this issue. To begin with, it aims to explore the extent to which foreign firms operating in China differentiate between the economic and social dimensions in developing their business relationships. Furthermore, considering the variety of foreign firms operating in China, the study is intended to find out whether, and how, these firms differ from each other in terms of their 
relationship development processes, with respect to the economic and social dimensions. Specifically, foreign firms in this study are categorised by their nationality, size and industry sector for the comparisons between Asian firms and Western firms, between small firms and large firms, and between manufacturing firms and service firms. This is because the literature has suggested differences between these types of firms from the network relationship perspective. The relevant literature will be addressed in detail in Chapter Three, along with the three respective sets of hypotheses.

Accordingly, the two research questions of the study are as follows:

1) Do foreign firms operating in China emphasise their economic ties and social bonds differently in developing business relationships?

2) Are there any differences in the relationship development process of firms that have different nationality and $\operatorname{size}^{2}$, and which operate in different industry sectors, with respect to the economic ties and social bonds? If yes, then what are the differences?

In regard to the second question, the study undertakes the 'process' approach described earlier (Van de Ven, 1992), and examines the relationship development process by measuring if and to what extent the social and economic dimensions of a relationship may change, as the relationship develops over time.

The above two research questions are both refined from the research problem and are interrelated. The first research question allows the researcher to comprehend firms' relationship development in regard to their economic and social dimensions in the Chinese research setting. The second research question builds on this foundational two-dimensional view established in response to Research Question 1. In other words, the findings associated with the first research question allow the

\footnotetext{
${ }^{2}$ In this study, firm size is compared based on the focal subsidiary, instead of the whole MNC.
} 
relationship development process to be investigated in more depth - specifically with respect to the ways in which the economic and social dimensions are developed by different types of foreign firms in China. The study, is, therefore, expected to provide insights into the extent to which foreign firms in China undertake distinct relationship building approaches with respect to their local business partners.

Hence, by addressing these two questions, the researcher is able to obtain a comprehensive understanding of the research problem. The study, therefore, attempts to contribute to the literature in two main ways. First, business relationships are complex. Especially in China, interfirm business relationships are perceived as an integration of traditional social based managerial ties and modern management philosophies (Li, 2005). Drawing on the two-dimensional view, the study may produce detailed insight in the dynamics of foreign firms' relationship development, and further add to the existing research stream in this respect (Lee, Pae and Wong, 2001; Park and Luo, 2001; Wu and Choi, 2004). Second, through comparing foreign firms in China by their nationality, size and industry sector, the study adds specifically to the body of knowledge about how these firms may undertake distinctive approaches to develop relationships with local Chinese business actors. Overall, the study responds the call for network studies in the cross-cultural setting (Parkhe et al., 2006), and its detailed findings could enrich the research stream on MNCs networking in China in the international business field. Answers to the two research questions provide up-todate insights in the MNCs' relationship building approaches, which are meaningful for both researchers and practitioners.

\subsection{Research Approach}

The two research questions are addressed in two sequential phases in this study, Phase 1 and Phase 2, respectively. The unit of analysis for this study is the firm, specifically foreign firms operating in China. Particular focus is given to these firms' business relationships with their local network actors. 
Phase 1 is intended to address the first research question, by exploring whether and how foreign firms operating in China place different emphases on the economic and social dimensions of relationships in the relationship development setting. A qualitative approach is chosen because it can produce rich and contextual data that allow the researcher to gain a fundamental understanding of relationships and relationship development process, as demonstrated in many previous studies (Doz, 1996; Hite, 2003; Koza and Lewin, 1998, 1999; Larson, 1992; Larson and Starr, 1993; Mouzas and Naude, 2007; Numagami, 1998; Tyler, Stanley and Brady, 2006). Phase 1 also contributes to the conceptual basis of the study, as its empirical data may provide evidence of the uneven development of firms' economic ties and social bonds in their relationships, which could further support the two-dimensional view. This is crucial before the study moves on to address the second research question, which focuses on differences between different types of foreign firms in their relationship development processes, with respect to the economic and social dimensions.

Between March and April 2008, fieldwork was conducted in China, and the senior managers from eight foreign firms located in Shanghai and Nanjing were interviewed face-to-face. The central inquiry for the interviews was how these firms' relationships with the local business actors were developed with respect to their economic and social contents. During the interviews, close attention was paid to the nature of these firms' business relationships and their managerial practices related to the economic ties and social bonds. The computer software, NVivo 8.0, was used to assist the qualitative data analysis.

The quantitative data in Phase 2 provide further support for the two-dimensional view at the level of the economic and social dimensions. The focus of Phase 2, however, is on addressing the second research question. The hypotheses arising from this research question compare different types of foreign firms' relationship development processes in China with local customers, along the economic and 
social dimensions. The three pairs of comparisons, as mentioned earlier, are: Western foreign firms vs. Asian foreign firms, small foreign firms vs. large foreign firms, and foreign manufacturing firms vs. foreign service firms.

These hypotheses are explained in detail in Chapter 3. They are tested using multiple regression analysis. The explanatory variables in the regression modelling pertain to firms' nationality, size and industry sector. The dependent variables pertain to the evolving economic and social nature of firms' relationships. The regression analysis is conducted at multiple levels. First, it is concerned with the development of the economic ties and social bonds; the second level of analysis is concerned with the evolving status of each relationship construct adopted in this study for measuring the economic ties and social bonds. This is a more in-depth investigation of the hypotheses, because these constructs represent distinctive economic and social aspects of relationships, as discussed in Chapter 5. A number of control variables relating to the foreign firms and their relationships are also included in the analyses. In addition, the regression modelling is conducted based not only on the full-sample using the complete dataset from all the responses, but also on split-samples stratified by the three categorical explanatory variables. This split-sample analysis is expected to produce more detailed results for the hypothesis testing.

To collect the quantitative data for the analysis, a survey was conducted in China between October and December 2008. It produced 118 returned questionnaires, and 96 of them were useable. All the respondents were the senior managers of foreign firms operating in China. In the questionnaire, these respondents were requested to identify the important and currently active customers of their firms, and then provide the data about the relationships with the chosen customers with respect to two time points: the relationship formation stage (defined as Time 1), and the time of the survey completion (defined as Time 2), so that the evolving nature of the relationships could be captured. The programme SPSS 17.0 was used to analyse the quantitative data. 
Overall, the study utilises a two-phase design, similar to that described by Creswell (1994), and employs mixed methodology to address the two research questions, for deep understanding of the research problem. Further explanation on the methodological aspects of the study is provided in the following chapters of the thesis.

\subsection{Organisation of the Thesis}

The thesis is organised into seven chapters, including the current chapter Introduction. The following Chapter Two presents an in-depth review of the relevant literature. The review is carried out with the fundamental purpose of understanding business networks and relationships, and encompasses a number of issues relevant to the research problem. Although the study is primarily concerned with relationships, the current knowledge relating to relationship development is reviewed within, rather than being isolated from, a network context. Then, the literature is reviewed in the context of international business, since this field is directly relevant to the empirical setting for the study - that is, foreign firms operating in China. Finally, the literature relating to the Chinese environment is reviewed, in order to provide contextual knowledge for the study.

Chapter Three focuses on business relationships and establishes the conceptual basis of the study. It explains the process-based view of investigating relationship development, and introduces the two-dimensional view of assessing relationships by economic and social aspects separately. On this basis, a conceptual approach is built to examine the relationship development processes along the two dimensions. In line with the research problem stated in this chapter, research questions are presented, followed by the development of the respective hypotheses that are drawn from the existing literature on the comparison between Asian and Western firms, between small and large firms, and between manufacturing and service firms. The chapter concludes with a section describing the two phase research design, as well as the rationale for the mixed methodology adopted in the study.. 
Chapter Four sheds light on the qualitative Phase 1. It describes the research setting, highlights the research objective, and reports the data collection procedure and the sample profile. Thereafter, the data from the qualitative sample are analysed, and the findings for relationships featuring distinctive economic ties and social bonds are highlighted. At the end of this chapter, a conceptual framework in the form of a matrix is presented to illustrate these findings, which underpins the two-dimensional view.

Chapter Five shifts the focus onto Phase 2 of the study. The quantitative research methodology adopted in this phase is explained in detail. The constructs and measurements for the economic and social dimensions are derived from the existing literature. Then, variables used in the data analysis and the analysis strategy are introduced in this chapter, followed by the report on the data collection procedure and the sample characteristics. In Chapter Six, the quantitative data collected in Phase 2 are analysed. The chapter begins with presenting the descriptive results for the data. Particularly, it sheds light on the uneven development of the economic ties and social bonds, and the positive growth of the sample relationships from the time of formation (Time 1) to the time of survey completion (Time 2). Then, the chapter reports the statistical analysis relating to the hypotheses, and summarises the significant results in a series of tables.

Chapter Seven provides an in-depth discussion of the qualitative and quantitative results and underlines the contributions of the study. A framework describing the relationship development process is presented based on the conceptual approach of the study and the relevant findings. Then, the chapter concludes the entire thesis by summarising the key findings, and acknowledging the limitations, as well as presenting recommendations for future research. Implications for managers in foreign firms operating in China are also highlighted, followed by concluding remarks for the study. 


\section{Chapter Two Literature Review}

\subsection{Chapter Objectives}

This chapter reviews the literature related to the fundamental issue of the research - relationship development from a process perspective. In this study, relationships are understood in the network context. The chapter contains five components. First, it outlines a number of general issues in the network literature, including the basic concept of networks, relational and structural perspectives of networks, and how to define networks for research purposes. Second, the chapter sheds light on the economic and social contents of business networks and relationships. It also describes how relationships are measured on this basis. Third, the chapter addresses how networks may impact firms, which is an important topic studied by many scholars. Fourth, the chapter shifts emphasis on network development and pays particular attention to the relationship evolutionary process. The interactive nature of firms and their networks is described. Different schools of thought and models are then introduced, followed by a section remark that highlights some of the key arguments. The fifth component of the chapter aims to present contextual knowledge about the present research setting, by highlighting MNCs' networks in the international business literature, as well as networks in China.

\subsection{Business Networks}

This section introduces the concept of business networks, and underlines the differences between structural and relational analysis usually seen in the literature. An operational issue - how to define networks for an empirical research - is also addressed in this section.

\subsubsection{The concept of business networks}

Despite many attempts to define networks, the most straightforward way of describing this phenomenon is perhaps by its physical composition - a network consisting of actors and the relationships connecting the actors (Van Wijk et al., 2003). By applying this basic concept to various settings, different types of 
networks can be identified, with the 'actors' referring to various subjects including for example, persons, teams, groups, organisations and even nations (Tichy, Tushman and Fomburn, 1979). The present study is concerned with interfirm business networks. Actors are, therefore, individual and autonomous firms that control their own business activities and are connected to each other in a network (Forsgren, 2004). These firms form "a structure of relationships between heterogeneous actors interacting for a business purpose" (Todeva, 2006: 1); that is, a business network.

The strong academic interest in business networks is fundamentally driven by the belief that firms do not exist in a vacuum in a market, but are engaged in production, distribution and use of goods and services in an industrial system (Johanson and Mattsson, 1987). These economic exchanges take place along with coordination and cooperation between and among individual firms, which means that no one can achieve outstandingly on their own (Moran and Ghoshal, 1999). As Jarillo (1988: 32) suggested, firms must develop their networks based on "long-term, purposeful arrangements among distinct but related for-profit organisations that allow those firms to gain or sustain competitive advantage visà-vis their competitors outside the network". From a resource-based view, the network is a type of external resource, which entails firms achieving competitive advantages in the marketplace (Dyer and Singh, 1998).

Interfirm business networks have been studied in various theoretical fields, such as sociology, organisation theory, strategic management, and marketing (Heracleous and Murray, 2001). Different terms like 'interlock', 'industrial complex', 'system' and 'bloc' were used in the early literature to refer to similar phenomena, but network becomes the mostly accepted word for its flexibility of usage (Mattsson and Johanson, 2006). For example, scholars use networks to refer to a variety of forms of cooperative arrangements, such as joint ventures, partnerships, strategic alliances, collaborations and consortia (Brass et al., 2004) or they may regard networks specifically as constellations of organisations that 
join together through relational agreements rather than legally binding contracts (Barringer and Harrison, 2000). In essence, as concluded by Provan, Fish and Sydow (2007), networks are usually discussed by scholars as based on two themes. First, they refer to a type of relatively stable pattern of firms' interactions over time; second, they imply a type of governance mechanism between market and hierarchy that allows firms to achieve a competitive stance (Jones et al., 1997; Williamson, 1991).

The present study adopts Jarillo's (1988: 32) definition for networks as the point of departure. In his definition, Jarillo emphasises interfirm relationships and outlines the strong business-orientation of interfirm networking. From a strategic perspective, networks are regarded as follows:

"complex arrays of relationships between firms. Firms establish those relationships through interactions with each other. These interactions imply investments to build the relationships, which gives consistency to the network. Competing is more a matter of positioning one's firm in the network than attacking the environment. The care of the relationships becomes a priority for management."

Scholars generally consider the concept of business networks as an effective tool to study firms' behaviours in an interconnected environment such as the market system. To begin with, the concept helps researchers obtain an overview of the subject of interest. As Stern (1979: 264) stated, "a network is a convenient construct for organising analysis of large number of actors concerned with similar activities". He continues to explain that "[T] he network approach is useful because the analysis requires continuous examination of a group of organisations interacting for a specific purpose but constantly changing in the relative number and strength of organisational units". Furthermore, the network concept assists researchers with exploring the dynamics between and among firms. Fombrun (1982: 280) states that network analysis is "a powerful means of describing and 
analysing sets of units by focusing explicitly on their interrelationships". Venkatraman and Lee (2004: 890) conclude that the network perspective is "a powerful way to holistically understand the complex resource flows and dependencies that create performance differences between firms".

The network literature overall shows the great efforts undertaken by researchers in exploring how networks may affect firms. According to Borgatti and Foster (2003), this is because one of the main themes in the early literature is to legitimise the network theory by seeking evidence of network consequences. Later, scholars become interested in firms' deliberate networking and network management issues. For example, after recognising the benefits from having relational contents in relationships with surrounding business actors, the 1980s witnessed a wide embracing of the 'network organisation' concept. In theory, it suggests firms form a type of organisational form with business actors, characterised by "repetitive exchange among semi-autonomous organisations that rely on trust and embedded social relationships to protect transactions and reduce their costs" (Borgatti and Foster, 2003: 995).

Recently, academic interest in firms' networking has continued to grow. For instance, Venkatraman and Lee (2004: 890) propose the idea of 'network orchestration' and encourage firms to develop the competency that "entails managers' simultaneously focusing on the macro-logic of network structure (how a portfolio of relationships is structured for resource access as a whole) and the micro logic of network processes (selection, cultivation, and dissolution of individual relationships) that contribute to maximal performance". From an institutional perspective, Peng and Zhou (2005) advise firms to have a clear orientation towards strong ties-based or weak ties-based network strategy for optimal organisational outcomes. The criterion, according to Peng and Zhou, is to achieve the 'appropriate' distance or closeness to partners, subject to firms' business needs and environmental conditions. 
All in all, business networks have become a popular research topic in the past two decades. Scholars acknowledge the importance of networks, and consider how firms can benefit most from their networks. Networking, or how firms develop relationships and construct a network, is a crucial strategic and managerial issue.

\subsubsection{Structural and relational level analysis}

Considering the composition of networks, Todeva (2006) concludes that network research generally puts emphasis on three aspects: the actors, the relationships, and the structure of relationships. Accordingly, Coviello (2006) suggests that a network can be portrayed by 1) who is involved, 2) how they are related, and 3) what the network looks like. In essence, this suggests that networks can be studied at two major levels: relational and structural.

Network research at a relational level and a structural level has distinct focuses. The former focuses on pair-wise relationships, and emphasises the attributes of actors and features of their dyadic relationships (Todeva, 2006). This investigates firms' interactions in more depth, and produces insights into constructs like trust, commitment, reciprocity, etc. On the other hand, structural level analysis is concerned with the structural patterns of networks and the structural positions of actors (Todeva, 2006). It underlines the whole network and strives to capture the totality of relationships as much as possible. For example, in social network analysis, researchers aim "to examine relational systems in which actors dwell and to determine how the nature of relationship structure impacts behaviours"

(Rowley, 1997: 894-5).

Given the distinctive focus of these two types of analysis, each of them has certain limitations. Scholars who advocate structural analysis point out that the relational level analysis tends to overlook the big picture by reducing the network context to direct linkages between individuals, and using nothing of the network pattern in the analysis (Fombrun, 1982; Jones et al., 1997). This leads to a reductionism by assuming dyadic relationships in isolation. Consequently, researchers may ignore 
that actors and actor-to-actor relationships can actually be influenced by the overall set of relationships - the structure. For example, early scholars like Mitchell (1969: 483) point out that, "researchers often talk of a network of relationships, but it is not the network itself that is being studied" (c.i. Provan et al., 2007).

Likewise, analysing networks only from a structural perspective is criticised for overlooking the relational aspect. First of all, structural analysis tends to simplify relationships as either present or absent, directed or symmetrical, strong or weak (Todeva, 2006). This can be inappropriate, as firms' interactions are highly dynamic. Secondly, the structural analysis often neglects the characteristics of the actors comprising the network (Zaheer and Bell, 2005). This is questionable because firms' endogenous factors can play an important role in their networking behaviours (Gulati and Gargiulo, 1999).

In different literature fields, scholars' emphasis on relational and structural levels varies. For example, marketing has a research domain of dyad-focusing relationship marketing (Dwyer et al., 1987; Ford, 1980). Despite the frequent use of the term 'networks' (e.g. Mouzas and Naude, 2007), traditionally, it was the dyadic interfirm activities and relationship characteristics that drew the attention. A network perspective that concerns the structural features of firms' networks and involves more than just pair-wise relationships, according to Healy, Hastings, Brown and Gardiner (2001) and Wilkinson (2006) is relatively a new emerging phenomenon in this field, although the number of studies moving beyond the focus on dyadic relationships has been growing.

On the contrary, network literature in sociology begins with a strong focus on network structure. In Stern's (1979: 242) early work, for example, it is noted that “...current practice in network analysis relies heavily on the use of structural measures of network characteristics and much less on examination of the historical development of a network or of the interaction processes that link 
network structure and interorganisation activity". From the late 1980s onwards, scholars become interested in both relational and structural levels of networks. Social capital theorist Coleman (1988) for instance, sheds light on the characteristics of relationships, whereas Burt (1992) draws more on the structural configuration of networks. Likewise, following Granovetter's (1985) original concept of embeddedness, researchers clearly distinguish between relational embeddedness and structural embeddedness in their studies. The former is about the strength of relationships and highlights the effects of strong relationships on network actors' behaviours and performance, while the latter is concerned about the impact of the structure of relations on actors (Gulati and Gargiulo, 1999).

In the management field, scholars have been aware of both relational and structural level analyses since the early studies in this area. However, relatively more effort has been devoted to exploring the nature of inter-organisation relationships (Galaskiewicz, 1985; Oliver, 1990). Even though some early scholars attempted to introduce a structural view of networks by drawing from the sociology literature (Fombrun, 1982; Tichy et al., 1979), empirical studies in this regard are relatively recent (Rowley, 1997).

Nowadays, scholars begin to view the relational and structural level analyses as complementary to each other, rather than exclusive (Kostova and Roth, 2003). Approaches to studying networks from a relational and a structural perspective address micro and macro level of networks respectively (Venkatraman and Lee, 2004), and the macro-level network structural properties are built up from the micro level dyadic relationships between network members (Kenis and Knoke, 2002). Nonetheless, as shown in the literature, despite a few attempts (e.g. Contractor, Wasserman and Faust, 2006; Coviello, 2006; Moran, 2005) researchers generally still tend to focus on either relational or structural level analysis only in a single study, due to the concern with the balance between research scope and scale (e.g. Dhanaraj et al., 2004; Forsgren et al., 2005; Gnyawail and Madhavan, 2001). Generally speaking, the decision in this regard is 
often subject to the primary inquiry of the research, in other words, the researchers' objectives and their major interests.

\subsubsection{Defining networks for research}

From a research point of view, some scholars consider that it would be ideal for a network study to capture the totality of relationships that are of importance (Welch, Welch, Wilkinson and Young, 1996; Stern, 1979), since a network consists of multiple actors and relationships. For example, it is suggested that a researcher planning to study a firm's network needs to identify all interorganisational relations of this firm influencing the functioning of the firm in one way or another (Schutjens and Stam, 2003).

However, this can be a very challenging task in practice, for several reasons. First, a firm's 'complete' network can be fairly comprehensive. It does not reside in a single industry, but extends to many different industries (Jones et al., 1997; Sydow, Van Well and Windeler, 1997, 1998). As Morgan and Hunt (1994) described, a firm's network in the market can include customers, competitors, suppliers, distributors, agents, non-profit organisations, government departments, and so on. Second, in a broad sense, a network contains not only first-order or direct ties, but secondary and peripheral ties (Johanston and Hausman, 2006). For example, it is reasonable to argue that 'customers' customers' should be regarded as a part of a firm's network as well (Johanson and Vahlne, 1990), even though they are not directly connected to the firm. Third, according to business network theorists, two single relationships can sometimes be connected via certain types of linkage (Andersson et al., 1994). In theory, this type of connectedness implies that a network can extend in any direction without limit (Holm, Eriksson and Johanson, 1999), which makes it technically impossible to identify its boundaries.

The last two reasons further relate to another issue network researchers have to consider -whether to limit their focus within a firm's egocentric network, or to look at the 'whole network' more broadly. A whole network, according to Provan 
et al. (2007), literally includes all parties and relationships that relate to the focal actors. In comparison, an egocentric network has the focal firm sitting at the central position of the network, and is concerned with the actors only directly connected to the firm, as well as those connecting relationships (Hite and Histerly, 2001). Importantly, the egocentric network often has direct and strong influence on the focal firm's resource flows across its boundaries, and in the meantime, the focal firm can exert control over all relationships with its partners within the network (Todeva, 2006).

To illustrate the above discussion, Figure 2-1 provides a hypothetical example for a 'broad network' containing actors connected via direct ties and peripheral ties in the Chinese context. It needs to be noted that, however, the figure only indicates a part of the 'whole network' that is identified by the authors for their specific research purpose.

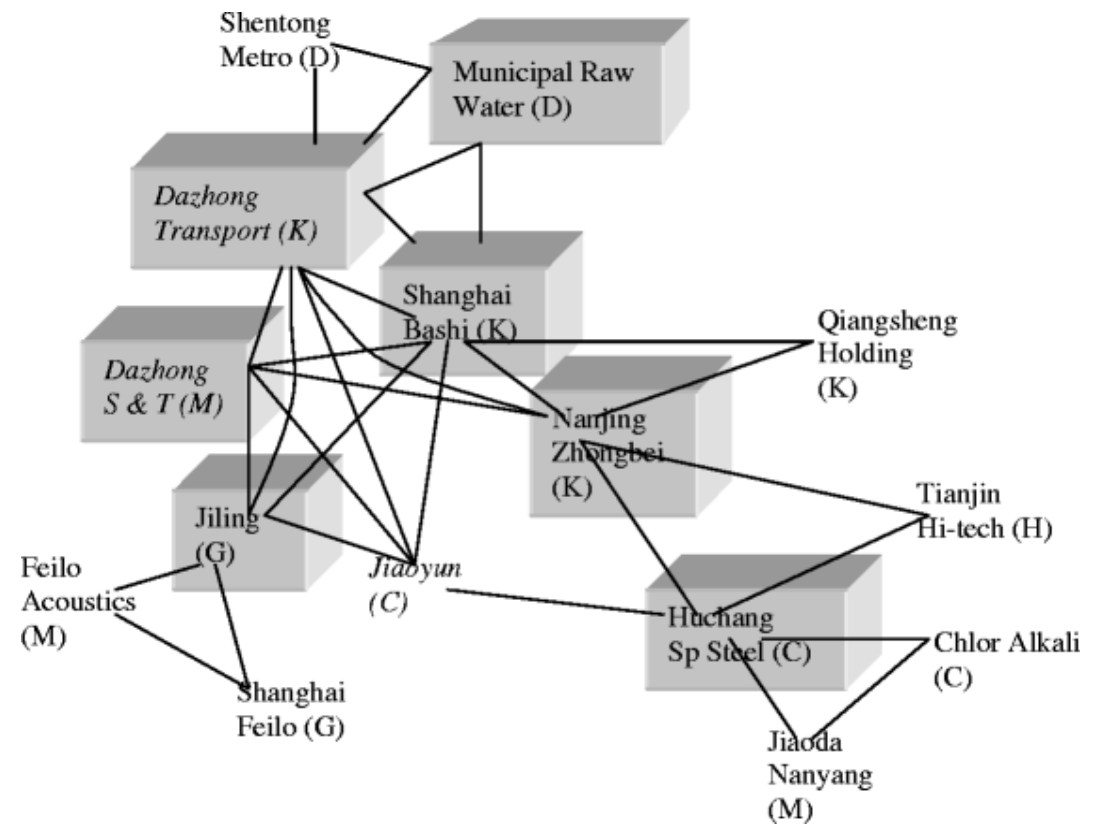

Figure 2-1 A network identified in China

Source: Ren, Au and Birtch (2009: 231)

Figure 2-1 also shows that, given the relevant complexity, in a network study researchers have to set up boundaries for their focal network by making decisions on what types of actors and relationships should be taken into account (Kenis and 
Knoke, 2002). Several methods to address this issue can be found in the literature. For example, Fomburn (1982) suggests defining networks by transactional content. Ring and Van de Ven (1994) recommend three alternatives: 1) defining a network by actor attributes, 2) defining a network by types of relationships under study, and 3) defining a network by a central issue such as an event which refers to a critical incident when parties engage in actions related to the development of their relationship.

Indeed, the approaches undertaken by researchers in their empirical studies appear to correspond to these methods. For example, Coviello and Munro (1995) and Schutjens and Stam (2003) look at networks containing a broad range of actors as well as relationships, including participants such as customers, suppliers, competitors, private actors and agencies; whereas Trimarchi and Tamaschke (2004) focus on a triad network consisting of three major actors. By looking at the network's transactional content, Peng and Zhou (2005) and Welch et al. (1996) differentiate between economic relations with business partners and noneconomic relations, such as government agencies and other institutions. Lechner, Dowling and Welpe (2006) define five types of value-added networks that go beyond exclusively economic relationships: social networks, reputational networks, marketing information networks, co-opetition networks, and cooperation technology networks. Meanwhile, some researchers study networks with a particular focus on critical events. Venkatraman and Lee (2004) look at the key players in a video game sector involved a new product development. Madhavan, Koka and Prescott (1998) investigate a strategic alliances network as being through a radical industrial change.

As for the choice between 'broad network' and egocentric networks, the literature has recently shown a growing interest in investigating networks with a large scope by employing sophisticated social network analysis (Contractor et al., 2006). 
Computer programmes such as UCINET ${ }^{3}$ are used to assist researchers with this type of structural analysis. However, as Provan et al. (2007) stated, research undertaking the 'whole network' perspective remains limited, because of not only the difficulty in identifying the network, as already discussed, but the time and effort required for conducting such a large scope analysis. Hence, relatively speaking, more attention has been given to the egocentric networks that directly influence firms' resource flows and their organisational performance.

\subsection{Economic and Social Contents of Business Networks}

The network literature has seen two seemingly distinctive perspectives to understanding the networks phenomenon and interpreting individual actors' networking activities. This body of literature is contributed by scholars in many disciplines including economics, anthropology, sociology and management. This section is not intended to review them all in detail, but rather to highlight the two perspectives (economic and social) by drawing from the most relevant and influential theories and research streams associated with the present study.

\subsubsection{Economic perspective of networks}

Firms' activities in their business networks often involve economic exchanges and are usually associated with their business objectives. At the relational level for example, business relationships are formed on the basis of economic transactions (Forsgren, 2004). Because the economic content is self-evident in business networks, early scholars undertake an economic perspective to explain the phenomenon of networks.

A major theory in this regard is transaction cost economics, originally posited by Coase (1937). The principle burden of analysis in transaction cost economics is traditionally on comparisons of transaction costs - which, broadly speaking, are the "costs of running the economic system" (Arrow, 1969: 48; c.i. Williamson,

\footnotetext{
${ }^{3}$ UCINET is a computer programme used by researchers to conduct social network analysis. It can, for example, identify structural holes, detect network brokers, and examine network density. It is created by Professor Steve Borgatti and his colleagues at the University of Kentucky, and can be downloaded for free on the Internet.
} 
1991). Prices and output, supply and demand are therefore made the focus of attention. In the interfirm environment, an initial concern of economists is whether firms should choose market or hierarchy as the organisational form to govern their activities with other market actors. Traditionally, economists view 'market' as being characterised by "faceless buyers and sellers meeting for an instant to exchange standardised goods at equilibrium prices" (Ben-Porath, 1978: 4; c.i. Williamson, 1979), with companies operating independently and pursuing their optimal benefits individually. In this situation, therefore, transactions are conducted under great opportunism by the involved parties due to the lack of control over other parties. Alternatively, hierarchy can be understood as the structure of a firm where economic activities take place with much lower transaction costs and under strict control. Although companies must invest considerable resources to internalise other independent parties, opportunismrelated risks are greatly minimised in a hierarchy situation.

Early transaction economists considered that market and hierarchy represent the entire market mechanism. This is further enriched and advanced by Williamson (1991) who adds another organisation mode: that of hybrid to the mechanism (see Table 2-1). He argues that when firms manage the trade-off between economic incentives and reduced opportunism, there exists another option - an intermediate mode between the two polar modes of market and hierarchy. Firms in this socalled hybrid mode remain autonomous, but coordinate activities efficiently. This mode contains features similar to both market and hierarchy. According to Williamson (1991: 281), the mode is "characterised by semi-strong incentives, an intermediate degree of administrative apparatus, displaying a semi-strong adaptation of both kinds, and working out of a semi-legalistic contract law regime".

The hybrid mode, essentially, is intended to deal with the phenomenon of interfirm networks, even though Williamson himself does not use this term 'network' in his work. Yet, Williamson retains his primary focus on transaction 
costs and the related outcome. Fundamentally, from the transaction cost economics point of view, firms' business decisions and behaviours in their networks are still determined by the economic incentives such as cost, price and profits.

Table 2-1 Distinguishing attributes of market, hybrid and hierarchy

\begin{tabular}{lccc}
\hline & \multicolumn{3}{c}{ Governance structure } \\
Attributes & Market & Hybrid & Hierarchy \\
\hline Instruments & ++ & + & 0 \\
Incentive intensity & 0 & + & ++ \\
Administrative controls & & + & 0 \\
Performance attributes & ++ & + & ++ \\
Adaptation (A) & 0 & + & 0 \\
Adaptation (C) & ++ & + & \\
\hline Contractual law & ++ & \\
\hline$++=$ strong; $+=$ semi-strong; $0=$ weak & & \\
\hline
\end{tabular}

Source : Williamson (1991: 281)

\subsubsection{Social perspective of networks}

In parallel to the economists, other scholars have for decades advocated a sociological view of networks. For instance, early organisational theorists regard networks to be a social action (Van de Ven, 1976). They underline the social characteristics of both dyads and the structure of relationships, to explore the phenomenon of interorganisational networks (Fombrun, 1982; Tichy et al., 1979). From the 1980s, the awareness of the social nature of business networks has continued to arise, contributed by a number of distinguished organisational sociologists, such as Macneil (1980), Granovetter (1985), Coleman (1988) and Burt (1992). As a result, the literature underlines the non-economic aspect of interfirm business networks and strongly suggests researchers focus on it as it may affect firms' business activities and performance greatly (Jarillo, 1988; Ring and Van de Ven, 1994). In strategic alliances for example, Madhok (1995) states that apart from economic transactions, an underlying social process cannot be ignored. 
These scholars also criticise the economics view of networks for its overwhelming emphasis on economic contents. For example, Maitland, Bryson and Van de Ven (1985) point out that the economics approach only cares about the transactionspecific investments involving physical or human assets, and analyses firms' activities in relationships based purely on a calculation of the expected returns to themselves. Madhok (1995) considers that the overemphasis on organisational outcome has resulted in a neglect of the social processes underlying the outcome. Jones et al. (1997) state that price and cost cannot be regarded as the key to the formation, development and function of networks. Even until recently, researchers have continued to argue that too much research focus is given to the economic content of networks (Shaw, 2006).

Below, three major literature streams are highlighted to address the social nature of business networks.

\subsubsection{Embeddedness theory}

One of the influential theories in this regard is the embeddedness theory developed by organisational sociologist Granovetter (1985, 1990). Granovetter states that, the central proposition of embeddedness theory is that all networks are social and all economic business transactions fundamentally are embedded in, and affected by, networks of social relationships. As a competing theory to the transaction cost economics, the embeddedness theory is defined as the third approach to explaining firms' market behaviours, apart from market and hierarchies. Different from Williamson's (1991) view on the hybrid mode, Granovetter sheds light on the role of social relations in networks in particular, rather than on the role of price, costs and economic benefits.

The theory is generally accepted by many scholars who are dissatisfied with classical economics in explaining firms' business activities in their networks (Dacin et al., 1999). Notably, it triggered a further historical debate between economics and sociology in the late 1980s (Swedberg, 1990). During the 1990s 
the embeddedness research became an exciting area as the theory advances the understanding of how social structure influences economic life in the network context (Uzzi, 1997).

Given its wide application, the concept of embeddedness has been unavoidably used in all sorts of situations related to the non-transaction aspect of networks. For instance, Yeung and Li (2000) study how local institutional embeddedness is formed through foreign firms' interactions with the local institutional environment. Welch and Wilkinson (2004) discuss the importance of political embeddedness in business. Andersson (2003) proposes technological embeddedness. Nielsen (2004) sheds light on knowledge embeddedness that refers to the process of effectively linking together one organisation's productive knowledge with that of another through qualitative coordination. Hagedoom (2006) differentiates between environmental embeddedness, interorganisational embeddedness, and dyadic embeddedness, and he further stresses the interactions among those micro-, mesco and macro-levels. Hite (2003) proposes five theoretical perspectives on potential sources of influence and constraint on firms in terms of embeddedness: structural, cognitive, cultural, political and institutional.

Despite these various types of embeddedness, it is the relational embeddedness and structural embeddedness that lie at the centre of network analysis. In line with Granovetter's original definition, structural embeddedness is about the configuration of an actor's network, and is considered in terms of structural characteristics; relational embeddedness refers to quality of relations, and is achieved through building up trust, reciprocity, commitment, etc. specifically strong and weak ties on the basis of shared history, norms, culture and so on (Dacin, et al., 1999; Moran, 2005). Furthermore, "relational embeddedness or cohesive perspective on networks stresses the role of direct cohesive ties as a mechanism for gaining fine-grained information... Structural embeddedness or positional perspectives on networks goes beyond the immediate ties of firms and 
emphasise the informational value of the structural position these partners occupy in the network" (Gulati, 1998: 296).

Granovetter $(1985,1990)$ particularly emphasises the fact that the core of his embeddedness theory is at the relational level - the distinction between arm'slength ties and embedded ties - because it is the composition of embedded ties that determines the degree of embeddedness in a network. These two types of embeddedness attract a great deal of attention from other scholars. Uzzi (1996, 1997) specifies that the former are market relationships involving merely economic elements. They are cool, impersonal, atomistic, and actors are motivated by instrumental profit seeking. The latter are close and special, as they embed commercial transactions in social attachments. Importantly, it is believed that the recognition of embedded ties shifts the logic of opportunism to the logic of trustful cooperative behaviour, creating behavioural expectations that are irrelevant in the atomistic view of transacting and market learning (Uzzi and Lancaster, 2003).

\subsubsection{Social capital theory}

Another literature stream underlining networks' social content is social capital theory. The concept of social capital was raised by sociologist Coleman (1988). Coleman views all actors in a network as being connected by social ties. He acknowledges the contribution of Granovetter's embeddedness theory, and further attempts to analyse the social system by introducing certain economists' principles, which explains why the term 'capital' is used. In his original work, Coleman defines social capital as a type of intangible resource existing in relations among actors, and can be used by the actors to facilitate their exchanges and achieve their interests. This viewpoint is advocated by many other scholars. For instance, Portes (1998) considers that social capital represents the ability of actors to secure benefits through their networks (c.i. Inkpen and Tsang, 2005). Adler and Kwon (2002) regard a network characterised with social relations as constituting a valuable resource for the conduct of social affairs. 
Although Coleman's original theory is developed in a purely social setting and only deals with networks involving no direct economic incentives such as individuals in a social community, it has been widely embraced by organisational scholars who apply it to the interfirm context. These scholars pay attention to the social relations between firms and show particular interest in the resulting positive effects on firms' organisational outcomes (e.g. Adler and Kwon, 2002; Bueno, Salmador and Rodriguez, 2004; Griffith and Harvey, 2004; Inkpen and Tsang, 2005; Nahapiet and Ghoshal, 1998; Tsai, 2000; Tsai and Ghoshal, 1998; WidenWulff and Ginaman, 2004; Young, 2005). Generally, it is considered that, for better organisational performance, firms must reinforce social ties with other network actors through the development of social capital. In terms of describing and measuring interfirm relationships, these scholars highlight the six key components of social capital suggested by Coleman; namely obligations, expectations, trustworthiness, information channels, norms and effective sanctions. These components are further used as the guideline for developing constructs for evaluating social capital.

Coleman also extends his theory to the structural level of networks. The rationale is, since close and relational dyadic ties are essential and all individual actors should aim to develop strong social bonds with others, the network as a whole will need to achieve high collectivity and internal cohesiveness, as well as a high level of closure that prevents actors from external danger. Such a network is considered to present the most ideal network configuration, because it facilitates exchange among actors within the focal network, and, at the same time, keeps them from imposing externalities (Coleman, 1988). Plus, the more cohesive the social capital, the more a network is stable in structure, which means less turbulence and uncertainty for the internal actors (Coleman, 1990).

Nonetheless, this viewpoint is challenged by another social network theorist Burt (1992, 1997). Burt emphasises another type of social capital resulting from 
network structural configuration other than from relational ties. He considers that even though network closure may create an environment that generates great trust among individual members, it reinforces the status quo, stabilises social structures and exaggerates distrust between groups. Actors situated in closed networks are very likely to suffer a series of negative effects of cohesiveness, like communication failure resulting from internal information redundancy, and ignorance of new emerging opportunities due to the unavoidable isolation from the outside. For instance, Burt (1997) seeks evidence from others' empirical research showing in small, dense, hierarchical networks, coordination failure is much more likely to occur for actors.

Burt (1992) further proposes his structural hole theory based on the criticism of Coleman's work. The theory suggests that network actors need to avoid a high level of internal cohesiveness, and rather, always put emphasis on connecting with other networks via the seeking and exploiting of structure holes - the gap between two separate networks. He believes that actors occupying such a brokerage position can subsequently possess the power of connecting or disconnecting these two networks, and gain advantage in terms of accessing exogenous information, knowledge and valuable resources. Thus, according to structural hole theory, the ideal network structure for individual actors should be rich in structural holes, instead of being very dense and redundant.

Burt's theory has a strong implication for relationships. As Adler and Kwon (2002) pointed out, Burt's bridging view focuses primarily on social capital as a type of resource that inheres in the social network tying a focal actor to others. The key message is that individual actors should not develop very strong and close relationships with others in their network, but maintain them at a relatively weak or moderate level. This is because weak ties would not bind actors tightly to the present network, but rather help them to reach distant actors not in the present focal network, through which structural holes can be found (Granovetter, 1973; Todeva, 2006; Uzzi and Gillespie, 2002). Surrounded by weak ties other than 
strong and close ties, firms can ensure they have more opportunities for the exchange of innovative ideas by gaining access to a more diversified pool of information and resources $(\mathrm{Wu}, 2004)$.

These two theories lead to a decade-long debate throughout the 1990s, but none of them has emerged as clearly superior to the other (Johnson, 2006). Instead, evidence of both can be found in empirical studies. For example, Podolny and Barton (1997) consider a network rich in structural holes may provide actors with timely information about new opportunities, but to exploit this opportunity requires the actors to have cohesive ties with others who have to offer help (c.i. Gargiulo and Benassi, 2000). Lee (2007) discusses that closure along with relational embeddedness acts as key mechanism in gaining high quality information, and brokerage is a mechanism for gathering information of large quantity and diversity.

Nowadays, both the theories are acknowledged by scholars involved in the network literature. Despite the distinct focus of these two theoretical approaches, they are both concerned with the non-economic aspect of networks. Specifically, the benefits yielded from strong relational ties and network cohesiveness are defined as Coleman-rent, or relational social capital; the benefits yielded from structural holes are defined as Burt-rent, or structural social capital (Duschek, 2004; Yli-Renko, Autio and Sapienza, 2001). Overall, these two types of social capital "prove[s] to be [a] powerful factor[s] in explaining actors' relative success... in an organisational setting" (Alder and Kwon, 2002: 17). This also explains why social capital has already become "the biggest growth area in organisational network research" (Borgatti and Foster, 2003: 993).

\subsubsection{Relationship marketing}

Another important literature field recognising the social aspect of business networks is relationship marketing. Relationship marketing emerged in the 1980s, and broadly refers to "all marketing activities directed towards establishing, 
developing, and maintaining successful relational exchange" (Morgan and Hunt, 1994: 22). The central argument of relationship marketing is that firms cannot play alone in the market, but have to build cooperative relationships with partners in order to succeed (Ford, 1980). Compared to the embeddedness theory and social capital theory, relationship marketing tends to have a strong relational focus and primarily deals with business-to-business relationships

Relationship marketing recognises the competition occurring increasingly between networks of firms. Despite its strong relational focus, it can be considered to be part of the developing network paradigm (Morgan and Hunt, 1994). Its major contribution is that, marketing is no longer considered as a series of independent transactions, but as a dynamic process of establishing and maintaining relationships (Dwyer et al., 1987). This body of literature builds upon a variety theories, paradigms and frameworks (Ivens and Blois, 2004). This section will look at two main theories to highlight the social content of business relationships: relational contract theory and social exchange theory.

One cornerstone of relationship marketing is Macneil's (1980) relational contract theory originally derived from contract law. In this theory, Macneil is concerned with the nature of exchanges, and differentiates between soft and hard features of business relationships. As Ivens and Bolis (2004: 240) concluded, hard features refer to "factors such as formal contracts, formalised decision structures and procedures, or economic safeguards discussed for example in contract law", whereas soft features are rooted in a sociological tradition and reflect a cooperative atmosphere and norms between business firms.

On this basis, Macneil defines discrete and relational exchange. According to him, discrete exchange is 100 percent planned, 100 percent consented to and "separated from all else between the participants at the same time and before and after" (Macneil, 1980: 60). By contrast, "relational exchange transpires over time... Relational exchange participants can be expected to derive complex, personal, 
noneconomic satisfaction and engage in social exchange" (Dwyer et al., 1987: 12). This theory has had a significant influence in marketing, and directly leads to a shift from an economics view to a relationship view.

Relationship marketing also draws heavily on social exchange theory (Bagozzi, 1975; Ferrell and Zey-Ferrell, 1977). The social exchange theory has roots in both economics and sociology. It acknowledges that actors' activities are largely based on the cost-benefit analysis, and in the meantime, it recognises that the transactional contents in relationships often involve social elements. The original intention of the theory was to include both types of contents in analysis. Applying it to the interfirm context, scholars view that dyadic business relationships involve not only exchanged goods and services, but elements that cannot be explained simply by the transaction cost analysis (Fomburn, 1982; Tichy et al., 1979).

As Whitener, Brodt, Korsgaard and Werner (1998: 515) concluded from Blau's (1964) early work, social exchange differs from economic exchange in three fundamental ways. First, "social exchanges may involve extrinsic benefits with economic values or intrinsic benefits without any direct objective economic utility"; second, "whereas benefits in economic exchanges are formal and often contracted explicitly, such benefits are rarely specified a priori or explicitly negotiated in social exchanges"; and third, "because such (social) behaviour is voluntary, there is no guarantee that benefits will be reciprocated or that reciprocation will result in receipt of future benefits".

Social exchange theory greatly enriches the traditional economics perspective of networks. One of its implications is that organisational researchers gradually shift their focus onto the social contents. For example, Shaw (2006) recently points out that the network literature has put too much emphasis on economic content. Based on his empirical findings, Shaw identifies that entrepreneurial firms' business relationships involve exchanges of information and advice, bartering-exchanges (involving the exchange of business services for a mixture of monetary and in- 
kind payment) and normative expressions. Clearly, his findings show that the interfirm transactions contain more than just economic elements.

All in all, in relationship marketing it is widely acknowledged that firms' business relationships can go beyond just economic exchanges involving buying and selling, and become characterised by social elements such as long-term orientation, reciprocity, trust and commitment, personal ties, emotional elements, etc. These social contents may facilitate economic transactions and benefit companies' business operations.

\subsubsection{Section summary}

Throughout the 1980s, the literature witnessed an ongoing debate between economists and sociologists. Although the initial starting point of this debate was mainly to explain human behaviours in the marketplace, the progress also broadened the view on analysing individuals and business firms. The outcome, as Swedberg (1990: 5) described, is that "the border line between two the major social sciences is being redrawn, thereby providing new perspectives on a whole range of very important problems both in the economy and in society at large". Even Williamson (1998) himself later acknowledges in his work that, despite certain explanatory power, the lens of transaction cost economics needs to be used alongside other partially rival and partially complementary theories, particularly social sciences, to explain and understand firms' market activities. The three literature fields outlined in Section 2.3.2 fit well in this context. Because each of them contains a large body of scholarly work, both conceptual and empirical, the purpose of this section is not to report these fields in great depth but rather convey to the readers that, although based on different theories, one common aspect is the acknowledgement and emphasis on the social aspect of business networks, which has to be explained and studied along side the economic aspect. This provides a valuable insight into the nature of firms' business relationships, which is a major concern of the study. In the following section, focus is shifted to relationships in particular. 


\subsection{Measurement of Business Relationships}

This section addresses an important issue related to the study - "describing the magnitude, degree or extent of a relationship" in the organisational context (Bove and Johnson, 2001: 189). The section conducts a brief review on the constructs and measurement of relationships that have been used in previous studies, and then discusses the three common themes for measuring relationships followed by scholars.

\subsubsection{A brief review of relationship constructs}

In the literature, relationships are examined in different forms, including relational embeddedness, social capital ${ }^{4}$, relationship quality, relationship strength, closeness, relationalism and so on. The central theme for examining relationships is to understand how network actors are linked or connected to each other. This sub-section takes a look at four different streams for a brief overview.

First, in embeddedness research, researchers attempt to identify the degree to which relationships are embedded in social mechanism. The measurements for embeddedness are often designed in line with Granovetter's (1985) original work, mentioned earlier. Uzzi (1997), for example, uses three components to examine the level of embeddedness: i.e. trust, fine-grained information transfer and joint problem-solving arrangements, which are recommended by Granovetter to regulate the expectations and behaviours of exchange partners. Other researchers may adopt different constructs, but their central focuses appear to be quite similar. For instance, Dhanaraj et al. (2004) assess embeddedness by tie strength, trust, and shared values and systems.

Second, in social capital research, it is the relational and cognitive dimensions that deal with relationship characteristics directly (Nahapiet and Ghoshal, 1998). The

\footnotetext{
${ }^{4}$ Social capital and embeddedness are sometimes examined from a structural perspective by measuring such as network size, network density, structural holes (e.g. Florin, Lubatkin and Scheulze, 2003; Fischer and Pollock, 2004). This section is not concerned with this type of approach, because of its primary focus on the nature of relationships per se.
} 
central theme is to identify the extent to which business relationships contain the "goodwill that is engendered by the fabric of social relationships and that can be mobilised to facilitate action" (Adler and Kwon, 2002: 17). Generally speaking, researchers often pay attention to those aspects of the social context indicated by Coleman, for instance, social ties, trusting relationships and value systems that facilitate individuals' actions within the context, and use them as constructs to measure relationships. Likewise, Tsai and Ghoshal (1998) look at trust and trustworthiness and shared visions. Oh et al. (2004) examine intergroup network social capital by the frequency of informal socialising activities. Inkpen and Tsang (2005) underline shared goals, shared culture and trust. Yli-Renko et al. (2001) focus on social interaction and relationship quality.

Third, another important scholarly work on examining relationships is Granovetter's (1973) early article on the strength of ties. Granovetter defines weak and strong ties by four elements: amount of time, emotional intensity, intimacy (mutual confiding) and reciprocity. Because the concept was originally developed in a purely social context, the four elements involve no economic incentives. Later organisational scholars apply this concept to the interfirm organisational setting, therefore adding economic contents to the measurement of business relationships. For example, Levin and Cross (2004) assess strength between firms by closeness of working relationships, communication frequency for business and non-business related information, and interaction frequency for economic activities and socialisation. A further example in this regard can be seen in Perry-Smith and Shalley (2003: 92-3). The authors extend Granovetter's definition to the organisational context, and describe strong and weak ties as follows. According to them, strong ties need to contain a high level of economic and social strength and vice versa for weak ties.

"The strong relationships, therefore, are those that have the highest levels of each other components, such as when the two parties truly like each other and are concerned about one another, see each other relatively frequently, 
and have similar perspectives and outlooks on the importance of their relationship. Weaker relationships are not necessarily reciprocal and involve less frequent interactions. In the work context these relationships may only involve discussions about work, with little affect or social exchange."

Fourth, marketing scholars have also made a significant contribution regarding measuring business relationships. As concluded by Blois and Ivens (2006), it is Macneil's (1980) initial work on 'exchange norms' that has had a huge influence on the way later scholars study relationships. Specifically, those norms address interfirm dyadic features, including such as role integrity, reciprocity, effectuation of consent, contractual solidarity, harmonisation with the social matrix, etc. In a similar vein, marketing scholars perceive these norms to be the "atmosphere of relationships' that determines the nature of the environment within which exchanges occur. According to the IMP group, the atmosphere can be "described in terms of the power dependence relationship which exists between the companies, the state of conflict or co-operation and overall closeness or distance of the relationship as well as by the companies' mutual expectations" (IMP Group, 2002: 28).

The method of examining relationships in the marketing literature is largely centred at operationalising the norms and the atmosphere. Measures and constructs include such aspects as information exchange, operational linkages, legal bonds, cooperation, goal congruence, relationship harmony, switching cost, relationship-specific adaptations, trust and commitment (e.g. Cannon and Perreault, 1999; Jap and Anderson, 2007; Morgan and Hunt, 1994). Additionally, the marketing literature has an impact on operational management or supply chain management in terms of measuring interfirm dyads. For example, researchers assess relationship quality by trust, adaptation, communication, interdependence, commitments, satisfaction, and co-operation (Fynes and Voss, 2002; Fynes, Voss and de Búrca, 2005a, 2005b). 


\subsubsection{Themes of relationship measurement}

From the previous section, it can be seen that the measurement for relationships appears to be similar overall in different research streams, although the constructs may be selected by researchers according to the different research settings. The literature further indicates three themes in this regard. They are discussed below for further insight of measuring relationships.

First, relationships are generally examined from behavioural and psychological perspectives. According to Schijns and Schroder (1996), the behavioural indicators refer to two firms' interactions in terms of factors such as time length, frequency, quantity of the involved exchanges, while psychological indicators are related to variables like satisfaction, trust, expectations. This perception can be noticed, for instance, in Perry-Smith and Shalley's (2003) description on tie strength noted earlier, as they talk about 'frequency of exchange', 'interaction', 'concern', and 'outlook of the relationship importance'. Other researchers demonstrate a similar approach. Donaldson and O'Toole (2000) regard action and belief as two aspects of relationships, and develop constructs on this basis.

Forsgren et al. (2005) further illustrate relationships by two layers, as shown in Figure 2-2. According to them, interfirm business relationships are featured by exchanges of products, money and information, and by mutual attitudes such as trust, commitment, and perceived dependence, which arguably pertain to the interfirm behavioural and psychological aspects respectively.

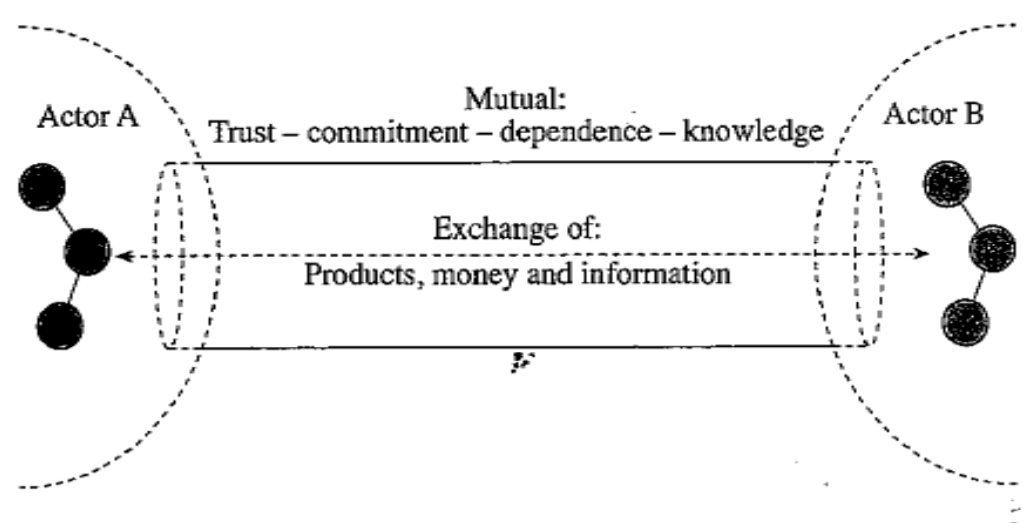

Figure 2-2 Characteristics of Business Relationships

Source: Forsgren et al. (2005: 28) 
The second theme is that economic and social contents are often included in the constructs for measuring relationships. Researchers pay specific attention to economic exchange and socialising activities, fulfilment in economic gains and harmony in cooperation. This echoes Donaldson and O'Toole's (2000) conclusion that, the essence of examining business relationships is to capture both economic linkages and the social bonds between two connected actors. Again, this view is reflected in Perry-Smith and Shalley's (2003: 93) description on strong and weak ties, as noted earlier. As they described,

"weak ties, on the one hand, as direct relationships between two actors at the low end of the tie strength continuum that involve relatively infrequent interactions, comparatively low emotional closeness, and one-way exchange....Strong ties, on the other hand, as direct relationships that involve relatively frequent interactions, high emotional closeness, and reciprocity."

Likewise, in social capital literature, researchers examine relationships by identifying the extent to which social relations exist in economic exchanges $(\mathrm{Wu}$, 2008).

The third perspective of measuring relationships is to view relationships to be situated along a continuum. This perspective is deeply rooted in a number of early scholarly works. For example, Granovetter (1985) depicts that all relationships are situated in a continuum with arm's-length ties at one end and embedded ties at the other. Macneil (1980) perceives that all exchanges lie on a spectrum ranging from discrete through to relational. He further suggests that the two extreme types of exchanges are like the mirror images of each other. Likewise, relationship 
strength is usually examined on a continuum from weak to strong, despite Granovetter's (1973) concerns regarding such an approach ${ }^{5}$.

The continuum view has a big impact on the way relationships are measured (Tangpong et al., 2008). From an operational perspective, a central task for researchers is to identify 'where' the focal relationship is situated in such a spectrum or continuum, determined by those constructs. For example, while measuring relationships for embeddedness, researchers often treat relational embeddedness as a continuous variable (Dacin et al., 1999). Ivens and Blois (2004: 254) further conclude that, the popular approach to examining relationships is for researchers to "ask respondents to indicate the point on a Likert scale which best indicates the status of a specific exchange". These indicators, as discussed earlier, are derived from the constructs and measures that involve both economic and social contents of relationships, and relate to behavioural and psychological aspects. Then, respondents' (dis)agreement with the statements suggests the position of a relationship in such a continuum.

The rating scales used to judge the relationship stimuli

\begin{tabular}{llllllllll}
\hline 1. & Compatible goals and desires & 1 & 2 & 3 & 4 & 5 & 6 & 7 & Incompatible goals and desires \\
2. & Friendly & 1 & 2 & 3 & 4 & 5 & 6 & 7 & Hostile \\
3. & Unfair & 1 & 2 & 3 & 4 & 5 & 6 & 7 & Fair \\
4. & Selfish & 1 & 2 & 3 & 4 & 5 & 6 & 7 & Altruistic \\
5. & Equal power & 1 & 2 & 3 & 4 & 5 & 6 & 7 & Unequal power \\
6. & Cooperative & 1 & 2 & 3 & 4 & 5 & 6 & 7 & Competitive \\
7. & Social-oriented & 1 & 2 & 7 & Work-oriented \\
8. & Formal & 1 & 2 & 3 & 4 & 5 & 6 & 7 \\
9. & Clashing & 1 & 2 & 3 & 4 & 5 & 6 & 7 & Informal \\
10. & Emotional & 1 & 2 & 3 & 4 & 5 & 6 & 7 & Harmonious \\
11. & Close & 1 & 2 & 3 & 4 & 5 & 6 & 7 & Intellectual \\
12. & Similar roles & 1 & 2 & 3 & 4 & 5 & 6 & 7 & Distant \\
13. & Superficial & 1 & 2 & 3 & 4 & 5 & 6 & 7 & Different roles \\
14. & Easy to leave & 1 & 2 & 3 & 4 & 5 & 6 & 7 & Intense \\
15. & Discrete transaction & 1 & 2 & 3 & 4 & 5 & 6 & 7 & Difficult to break contact \\
16. & Lot of trust & 1 & 2 & 3 & 4 & 5 & 6 & 7 & Longer term relationship \\
17. & High risk & 1 & 2 & 3 & 4 & 5 & 6 & 7 & Requires little trust \\
18. & History of relationship is important to its continuing & 1 & 2 & 3 & 4 & 5 & 6 & 7 & History not important \\
\hline
\end{tabular}

Table 2-2 An example for examining relationships in a continuum

Source: Iacobucci and Ostrom (1996: 58)

\footnotetext{
${ }^{5}$ Granovetter (1973) is aware of the multiplex nature of relationships and acknowledges that relationships can be strong in diverse ways. Although he defines relationships as weak and strong, he recommends researchers look beyond this, and pay attention to the in-depth dynamics of relationships.
} 
One example for such an approach is shown in Table 2-2. It can be seen from the table that, relationships are defined by a number of aspects, and each aspect is measured by a continuum containing two opposite statuses.

In addition to the three themes, many relationship constructs used by researchers may overlap to a certain extent and exert certain interrelationships. For instance, Granovetter (1973) acknowledges that the four components of tie strength, as per his definition, can be intra-correlated. According to Ivens and Blois (2004), marketing scholars have also paid attention to this type of internal causal structure of relationship constructs. The interaction between psychological and behavioural aspects is especially highlighted in many studies (Gruen, 1995; Morgan and Hunt, 1994).

\subsection{Effects of Business Networks on Firms}

Another main research issue in the business network literature is to discover network effects (Brass et al., 2004), which generally refer to the consequences of business networks for various indictors of organisational performance (Fomburn, 1982). Although this issue is not a major concern of the study, it may help to understand firms' rationale for network relationship development. Below, the section will review this area of research.

\subsubsection{The positive effects}

Network effects have been investigated from both relational and structural perspectives. As far as relationships are concerned, scholars traditionally perceive that strong and close relationships are preferable to business firms, because they are likely to benefit the firms' organisational outcome (Oliver, 1990). One theoretical explanation for this is provided by Dyer and Singh (1998: 662) who state that from the resource-based view, quality relationships characterised with extensive social and relational content can yield 'relational rent' which is a "supernormal profit jointly generated in an exchange relationship that cannot be 
generated by either firm in isolation and can only be created through the joint idiosyncratic contribution of the specific alliance partners".

Many studies have been conducted to seek evidence of the positive effects from well-developed relationships. For example, Morgan and Hunt (1994) propose that good relationships will facilitate market exchanges and transactions. Holm et al. (1999) find that through cooperative relationships featured by mutual commitment, firms may create greater value. In operational management scholars believe strong relationships with suppliers allow firms to ensure quality performance via obtaining superior products and services (Fynes and Voss, 2002; Fynes et al., 2005a). Generally speaking, empirical results have suggested that quality relationships may improve firms' efficiency (Oh, Chung and Labianca, 2004), help to handle external uncertainty (Madhavan et al., 1998), increase firms' survivability in the market (Baum and Oliver, 1992) particularly through transformational change (Fischer and Pollock, 2004; Uzzi, 1997) and enhance the overall performance (Florin, Lubatkin and Schulze, 2003; Luo, 1997; Shipilov, 2006). More recently, researchers have begun to investigate the effects of relationships from a knowledge and learning perspective (Dhanaraj et al., 2004; Hakansson and Johanson, 2001; Inkpen and Tsang, 2005; Levin and Cross, 2004; Yli-Renko et al., 2001).

Meanwhile, network effects are investigated from a structural perspective. It is generally believed that firms with a superior network structure are able to better exploit their internal resources and capabilities to enhance their ultimate performance (Zaheer and Bell, 2005). The rationale of this research stream is in line with the social network literature, particularly Burt's structural hole theory discussed earlier. Although relatively young, this stream has been growing rapidly in such areas as strategic management (Madhavan et al., 1998; Pollock, Porac and Wade, 2004; Shipilov, 2006), organisational studies (Burkhardt and Brass, 1990) and sociology (Finlay and Coverdill, 2000). While reporting their findings on the 
effects, a key issue researchers consider is what constitutes a superior network structure for business firms to gain maximum benefit.

Overall, from the firms' perspective, networks can help them to create competitive advantages (Duschek, 2004). The principle benefits of networking, as concluded by Pittaway, Robertson, Munir, Denyer and Neely (2004: 137), include: "risk sharing, obtaining access to new markets and technologies, speeding products to market, pooling complementary skills, safeguarding property rights when complete or contingent contracts are not possible, and acting as a key vehicle for obtaining access to external knowledge".

\subsubsection{The negative effects}

Despite these positive effects, the opposite side is concerned by many scholars, with the fundamental focus on close and strong relationships characterised with social and relational elements, and the resulting network structure featuring cohesiveness, density and closure. For instance from the social capital perspective, although Coleman values relationships rich in cognitive and relational social capital, and speculates that a network constructed on this basis can provide the ideal environment for the actors in terms of safeguard, security and resource sharing, Burt $(1992,1997)$ warns about the lock-in effect of network closure, and emphasises the benefits gained from loosely structured networks.

Burt's thought is advocated by many other scholars. Gargiulo and Benassi (1993), for example, advise firms not to be trapped in their own networks by cohesive social capital. Yli-Renko et al. (2001) point out that firms only relying on limited number of close customers may encounter problems in terms of acquiring new knowledge. Lee (2007) agrees that relational social capital as well as network closure increase the quality of information exchanged within an existing network, but repeated interactions over time can also preclude a firm from connecting with new partners beyond the network. Hitt et al. (2002) consider firms can be limited 
by their existing relational social capital, and then become less creative in network development, as well as experiencing opportunity costs.

The negative effects of networks are also discussed from an embeddedness perspective. Granovetter (1985) refers to this as the risk of over-embeddedness and suggests that network actors need to achieve a balance between being undersocialised and over-socialised, to ensure the appropriate degree to which economic behaviours need to be affected by social mechanism. Uzzi (1997: 35) further describes that " $(\mathrm{T})$ he positive effects (of social embeddedness) rise up to a threshold, after which however, embeddedness can derail economic performance by making firms vulnerable to exogenous shocks or insulating them from information existing beyond their networks".

In marketing, the negative effects are noted as well. Early scholars like Galaskiewicz (1985) point out that companies in strong relationships may experience certain constraints, because they would have invested a considerable amount of resources and become reliant on each other both economically and emotionally. This type of constraint may lead to consequences such as the lack of flexibility and loss of autonomy. More recently, Anderson and Jap (2005) have stated that sometimes the 'cosy' relationships can be the most vulnerable to decline and destruction, and then cause severe damage to firms. Their explanation is that when two parties become close over time, social relations and interpersonal ties may forge grounds for unethical activities such as corruption. Besides, the deep adaptation usually existing in strong and close relationships may cause the two parties to overlook other alternatives and then fail to be innovative in the long run. Hence, Anderson and Jap (2005: 75) call it "the dark side of close relationships", and argue that "close relationships are not always synonymous with good relationships".

In short, the negative effects of networks encourage considering two questions with regard to network development. First, at the structural level, whether network 
closeness or openness is more beneficial to firms? Second, at the relational level, whether strong relationships featured with intensive economic and social contents are favourable? Especially for the second question, scholars have advised that "the ties that bind may also turn into ties that blind" (Power and Smith-Doerr's, 1994: 39; c.i. Adler and Kwon, 2002).

\subsubsection{The mediators and contingent value of networks}

The literature underlines a number of factors which may mediate network effects. These factors basically pertain to the external market environment and firm-level characteristics such as motivation, ability, size, age, (e.g. Carlisle and Flynn, 2005; Dhanaraj et al., 2004; Gulati and Higgis, 2003; Koka et al., 2006; Madhavan et al., 1998; Peng and Luo, 2000; Pollock et al., 2004). An empirical study for example reveals that banks within a same network structure may still achieve distinctive business performance due to their different corporate strategies (Shipilov, 2006). Similarly, Acquaah (2007) found that with different strategies, the impact of social capital on firms' performance can vary greatly.

Essentially, these mediators suggest a contingent value of networks. Academic interest in this aspect has been growing in recent years. Gulati and Higgins (2003) for instance, ask the question 'which ties matter when?' The acknowledgement of a network's contingent value further enriches the network perspective by specifying the conditions under which networks may affect organisations. It also suggests that firms select appropriate network strategies depending on the situation.

\subsection{Network Development}

This section addresses the development of networks and relationships. For a comprehensive understanding in this area, the section begins with describing the interactive nature between firms and networks, and outlines the factors that may influence network development. Then, the section sheds light on the evolving nature and patterns of network structure, in order to provide the contextual 
knowledge for relationships development. Thereafter, different perspectives and models for relationship development process are highlighted. Last but not least, the section introduces an emerging research stream - network dynamics evolution - to show the evidence of the complexity of network development. A section summary is then drawn, with a particular focus on relationships.

\subsubsection{Interactive nature between firms and networks}

It is already discussed that the main research theme in the early network literature was to legitimate the network theory by seeking relevant evidence of how networks may affect firms. As a result, "the bulk of network research has been concerned with the consequences of networks" (Borgatti and Foster, 2003: 1000). However, researchers who examine network consequences often tend to view networks as a contextual independent variable, and organisational outcome as the dependent variable, which notably, leads to a network-as-given paradigm. For example, from a structural perspective, Burt (1992: 181) considers that "People and organisations are not the source of action so much as they are the vehicles for structurally induced action". This viewpoint is also partially based on the belief that a network has strong inertia of maintaining itself, due to the mechanism such as institutional environment and cognitive norms that constrain actors' behaviours and further stabilises the network's structure (Gulati and Gargiuolo, 1999). As Larson (1992: 97) depicted, "The history of interactions set down mutual obligations and expectations that are organisationally structured: individuals can come and go from particular position and roles, but their behaviours are framed and shaped by the history of exchange and the roles and identities of current participants".

In recent years, scholars begin to question this mindset and the conceptual approach to studying networks. They argue that viewing networks as a contextual variable may be useful for network analysis at one level, but risks understating the role of the very actors comprising the network, which are the firms (Parkhe et al., 2006). From a strategic point of view, since networks are stable and changing 
simultaneously (Johanson and Mattsson, 1987), researchers need to regard networks as an object to be designed and managed by firms, rather than simply a given context for firms' actions.

The literature indicates rising research interest in this area. Strategists are the pioneers recommending firms managing relationship networks proactively to pursue the individual and collective aims of network members (Koza and Lewin, 1999). They suggest firms acting as network re-engineers who foster appropriate networks for maximal performance (Venkatraman and Lee, 2004), and "potentially shape networks so as to provide a favourable context for future action" (Madhavan et al., 1998: 440). Similarly, marketing scholars acknowledge the design of interfirm relationships is "a strategic decision variable in its own right" (Heide, 1994: 71). They view firms as 'network mobilisers' who need to manage surrounding relationships with like customers, suppliers, agencies, or even competitors to achieve organisational goals (Mouzas and Naude, 2007). This, according to Hakansson and Ford (2002), implies a strong intention of developing networks deliberately. After all, as Anderson et al. (1994: 13) stated, "managers who understand the potential of business networks for their firms naturally would like to know how to build one in practice".

Furthermore, some scholars describe the interaction between firms and networks from a co-evolutionary perspective (Koza and Lewin, 1998, 1999). Co-evolution is "an action or activity initiated by someone or something set(ting) in motion activities or responses of others which then affects the original source of the activity" (Baum and Singh, 1994: 387, c.i. Hite and Hesterly, 2001). From this perspective, firms' activities are to a certain extent determined by their existing networks, and their current behaviours affect the development of the networks simultaneously (Jones et al., 1997; Gulati and Gargiulo, 1999; Koka et al., 2006). Relevant evidence is found in empirical studies. For example, researchers notice that network actors' activities shape the pattern of the network, which in turn 
impacts the actors' subsequent activities (Burkhardt and Brass, 1990; Tsai, 2000; Welch et al., 1996).

In short, the literature reveals the interactive nature between firms and their networks. Generally speaking, not only networks could affect firms, but also could firms determine their own networks to a large extent. Therefore, to achieve optimal performance, firms must first of all, understand the effects from the network, and secondly, prioritise network management practices according to their specific situations (Hakånsson and Ford, 2002).

\subsubsection{Factors influencing network development}

The literature reveals that network development may be affected by a variety of factors. These factors can be categorised in two aspects - the characteristics of firms, and the external environment of the firms. For example, Gulati and Gargiulo (1999) identify that the degree of relational embeddedness between two firms is determined by these two firms' interdependence and the current network structural properties. Especially, they describe that when the networks are not yet solidly established, like in a turbulent industry or a newly entered market, firms often have to become dedicated to developing their networks proactively, in order to achieve their network mechanism. Venkatraman and Lee (2004) also point out that structural embeddedness may affect firms' relationship development in the strategic alliance context. Meanwhile, they find that partner's technological ability could play an important role. Consistently, Doz (1996) define a set of 'initial alliance conditions' to relationship development from a learning perspective. These conditions pertain to the two aspects, containing five dimensions environment, task, process, skills and goals.

In recent years, the literature continues seeing scholarly attempts to identify the antecedents or determinants of networks. Li (2005) views firms's strategic orientations as an important factor in this regard. Luo (2003) considers that firms' network structural uncertainty, industrial regulation, and competitive pressure 
may encourage firms to network. Drawing on the institutional theory, Peng and Zhou (2005) emphasise that the macro institutional environment can influence firms' choice between strong-tie based and weak-tie based network strategies, which will shape firms' approaches to developing relationships in general.

\subsubsection{Network structure evolution}

Network studies at the structural level are concerned with such features as density, closeness, size, centrality and structural holes (Todeva, 2006). Although research directly dealing with how network structure evolves in terms of these features remains very sparse, two seemingly competing theoretical perspectives in this respect are well presented in the social capital literature, drawing from Coleman's network closure theory and Burt's structural hole theory. As emphasised in Section 2.3.2.2, these two theories recommend firms to aim at two distinctive types of networks: one is network closure with internal cohesiveness, the other one is network openness with internal flexibility based on weak ties.

From a development perspective, the closure theory and the structural hole theory indeed suggest that networks evolve towards two distinctive structural patterns. However, since neither of these two theories has emerged as clearly superior to the other (Johnson, 2006), scholars have recently tended to reconcile them. Burt (2005) for example has taken the initiative and theorised that closure is a significant contingency factor for the value of brokerage social capital; structural holes are the sources of value added, but network closure is essential to realising the value buried in the holes. Consistently, Oh et al. (2004) develop the concept of 'group social capital' offering an integral view on constructing networks.

According to them, the optimal network configuration requires a group of actors to have a moderate level of internal closure within the group, as high closure could be counterproductive; at the same time, they need to maintain a large number of bridging relationships with actors in other groups in order to keep the group effectively associated with the external networks for flexibility and fresh 
inputs. These bridging relationships, according to Granovetter (1973), often tend to be weak ties.

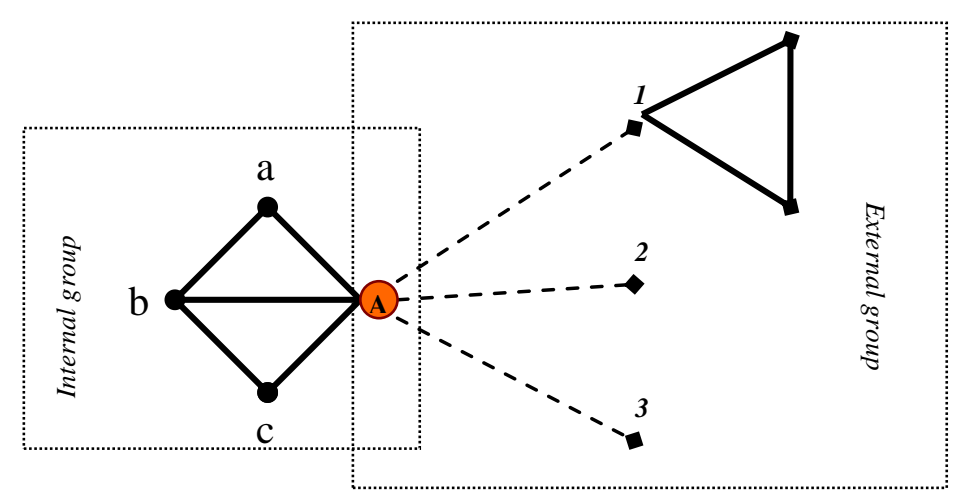

Figure 2-3 An integrated view on closure and structural hole Derived from Oh et al. (2004)

Based upon Oh et al.'s description, their viewpoint can be illustrated by Figure 23. The focal actor A has reasonably strong or semi-strong, but not always 'totally strong', relationships with a, b and c - the three internal actors in its welldeveloped 'internal group'. In the meantime, A actively tries to connect with other new actors (1,2 and 3) located in 'other groups' which allows A to occupy the brokerage position. In such a situation, A cannot only benefit from cohesiveness from its current network, but retain autonomy to link to new networks through which exotic information, additional resources and new opportunities may be obtained. This view recognises that "more of one type of social tie (cohesive and weak) is not always better" (Oh et al., 2004: 869). It acknowledges the trade-off between network closure and structural hole theory, and suggests firms benefit from both Coleman-rent and Burt-rent simultaneously (Fischer and Pollock, 2004), which further implies the ideal network structural pattern that needs to be established by firms. A similar perception is also noted by Nahapiet and Ghoshal (1998) who regard the essence of network development as the balance between associability and autonomy. Associability refers to the willingness and the ability of individual firms to behave collectively with partners (Leana and Van Buren, 
1999); autonomy means firms' capability of choosing the course of actions they desire to pursue (Van de Ven, 1976).

\subsubsection{Evolution of dyadic relationships in networks}

This section reviews the literature on the evolving process of relationships - the central concern of this study. It firstly introduces the stages model of relationship development developed by IMP scholars, which is probably the most influential in the literature. Secondly, the section examines those alternative models and perspectives that offer other complementary views to the topic.

\subsubsection{The stages model}

The most influential relationship development models are those proposed by IMP scholars in relationship marketing. As explained by Ford (1980), in this school of thought scholars undertake an interaction approach to studying the development process. The interaction approach deals with relationships that are characterised by repeated exchanges or transactions and are relatively long-term oriented. Scholars focus on the seller-buyer context and view the relationships as taking place between two active parties, rather than the buyer simply reacting to a seller's offers. Further, scholars consider that either buyer or seller may take the initiative in seeking a partner. Ford (1980: 340) describes how relationships may be developed on a mutual and reciprocal basis, as follows,

\footnotetext{
"Both companies are likely to be involved in adaptation of their own process or product technologies to accommodate each other. Neither party is likely to be able to make unilateral changes in its activities as buyer or seller without consultation, or at least consideration, of the possible reactions of their individual opposite members."
}

Specifically, two models have emerged to describe the process of relationship evolution from the interaction perspective. One contributed by Ford (1980) defines relationships as evolving gradually through five stages (Figure 2-4). The 
first stage - 'pre-relationship stage' - refers to the period where companies seek new partners yet have little knowledge or evaluation of the potential candidates. The second stage is highly experimental. One party can examine samples from the other, but the relationship may only grow very marginally. The relationship then begins to develop from stage three, involving deliveries of continuously purchasing behaviours, and, if things go as expected, the 'long-term stage' will be entered, where two parties have large scale cooperation and regard each other as important. Finally, after a long period of time, the relationship may be terminated due to a change of firms' demands and market environment.

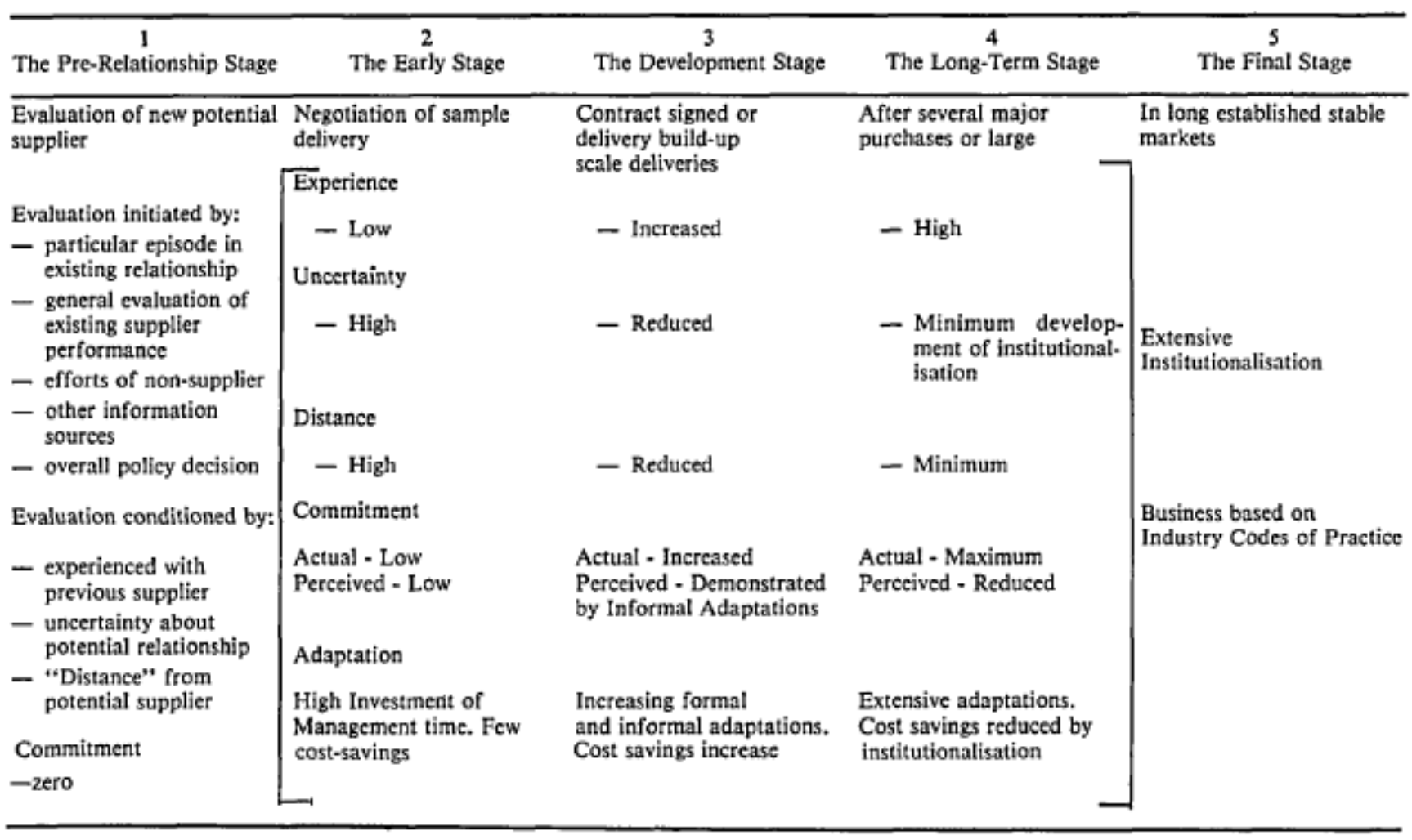

Figure 2-4 The development of buyer-seller relationships

Source: Ford (1980: 342)

The other model is presented by Dwyer et al. (1987) (Figure 2-5). The central theme of this model is that firms should develop relational ties with business partners instead of discrete ties, in order to benefit from the positive effects of social contents. On this basis, Dwyer et al. theorise the process through which relationships transform from discrete exchange to relational exchange, and define 
five general phases of this process, including awareness, exploration, expansion, commitment, and dissolution. Each phase represents a major transition in how parties regard one another. In the phase of awareness, one party recognises that the other party is a feasible partner of exchange. Then, the firm will begin the search and trial phase in relational exchange with the potential partner. Purchase for trial purposes may take place. This phase involves communication, bargaining, norm development, and so on. After those necessary and fundamental interactions, the relationship will move into phase three - expansion - which is characterised by the two parties' increasing mutual benefits and interdependence. The relationship continues growing in phase four. By this stage, the two parties have the strongest commitment to each other, and to a large extent prelude other potential partners who could actually provide similar benefits. Eventually, however, the relationship may dissolve for of various reasons - mostly economic dissatisfaction by one or both parties.

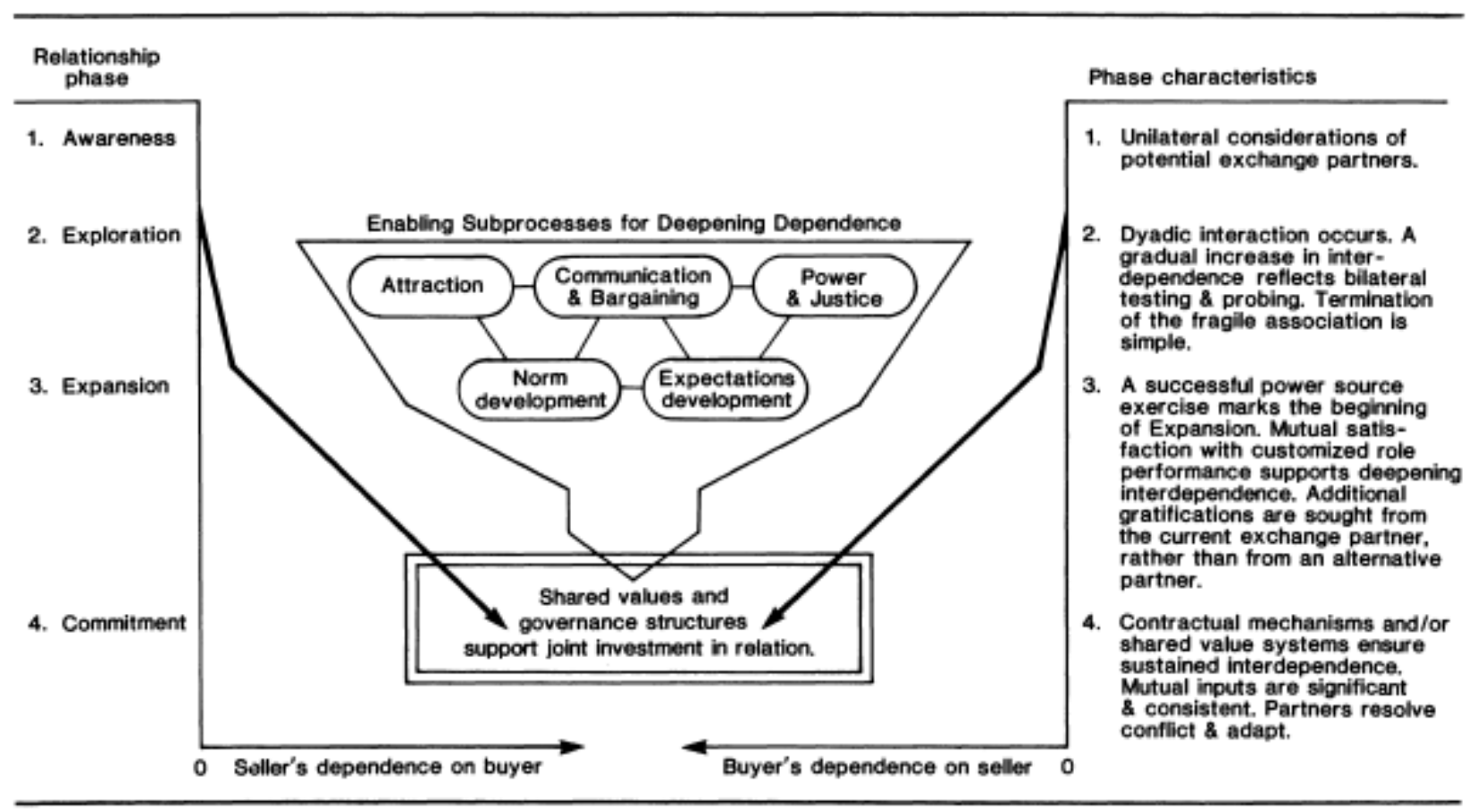

Figure 2-5 The relationship development process

Source: Dwyer et al. (1987: 21)

These two models share great commonality and are normally called stages models in the literature. This type of life-cycle model, according to Van de Ven (1992: 
177), tends to assume immanent change, that is, "the developing entity contains within it an underlying logic, program, or code that regulates the process of change and moves it from a given point of departure toward a subsequent end which is already prefigured in the present state."

One important contribution of this school of thought is its close attention to the evolving nature of relationships. In their models, Ford uses five key variables: experience, uncertainty, distance, commitment and adaptations, to indicate the evolving progress of relationships; Dwyer et al. highlight a number of constructs, including those such as communication, interaction, norms, commitment and benefits. Other studies in this research stream also highlight similar aspects of relationships. Holm et al. (1999) for example examine relationship development by trust, commitment, dependence, adaptation and norms. More recently, in their re-examination of the stages model, Jap and Anderson (2007) look at a number of 'relationship properties' comprehensively.

One way to understand the strong focus of this research stream on relationship measurement and constructs is that researchers have to use the constructs of the entity, which in this case refers to the relationships, to capture the changing attributes that reflect the evolutionary process (Van de Ven, 1992). In other words, from an operational point of view, a relationship's movement from one stage to another in the model has to be indicated and examined by increase or decrease of these constructs and variables. As Turnbull and Valla (1998) pointed out, the key theme in relationship development research is to investigate how norms and atmosphere are built up by specific episodes of exchange as well as the long-term process of interaction - which also echoes the earlier discussion about the behavioural and psychological aspects of relationships.

\subsubsection{Alternative models and perspectives}

Apart from the stages model, the literature offers a number of alternatives. One early framework (Figure 2-6) is provided by Ring and Van de Ven (1994). They 
consider two firms in a relationship are engaged in three types of activities, i.e. negotiation, commitment, and execution, through which they can make sure that cooperation reaches their expectation of efficiency and equity at all times. If both parties are satisfied, then the relationship may grow, or otherwise may decline, as reflected by an increase or decrease in firms' attitude, willingness and behaviours. Notably, the three types of interfirm activities defined by them deal with firms' behavioural and psychological aspects. They also involve formal and informal aspects, which relate to the economic and social engagement, as the two primary themes in the relationship development process. For example, 'role interactions' occur along with 'personal interactions' in executions.

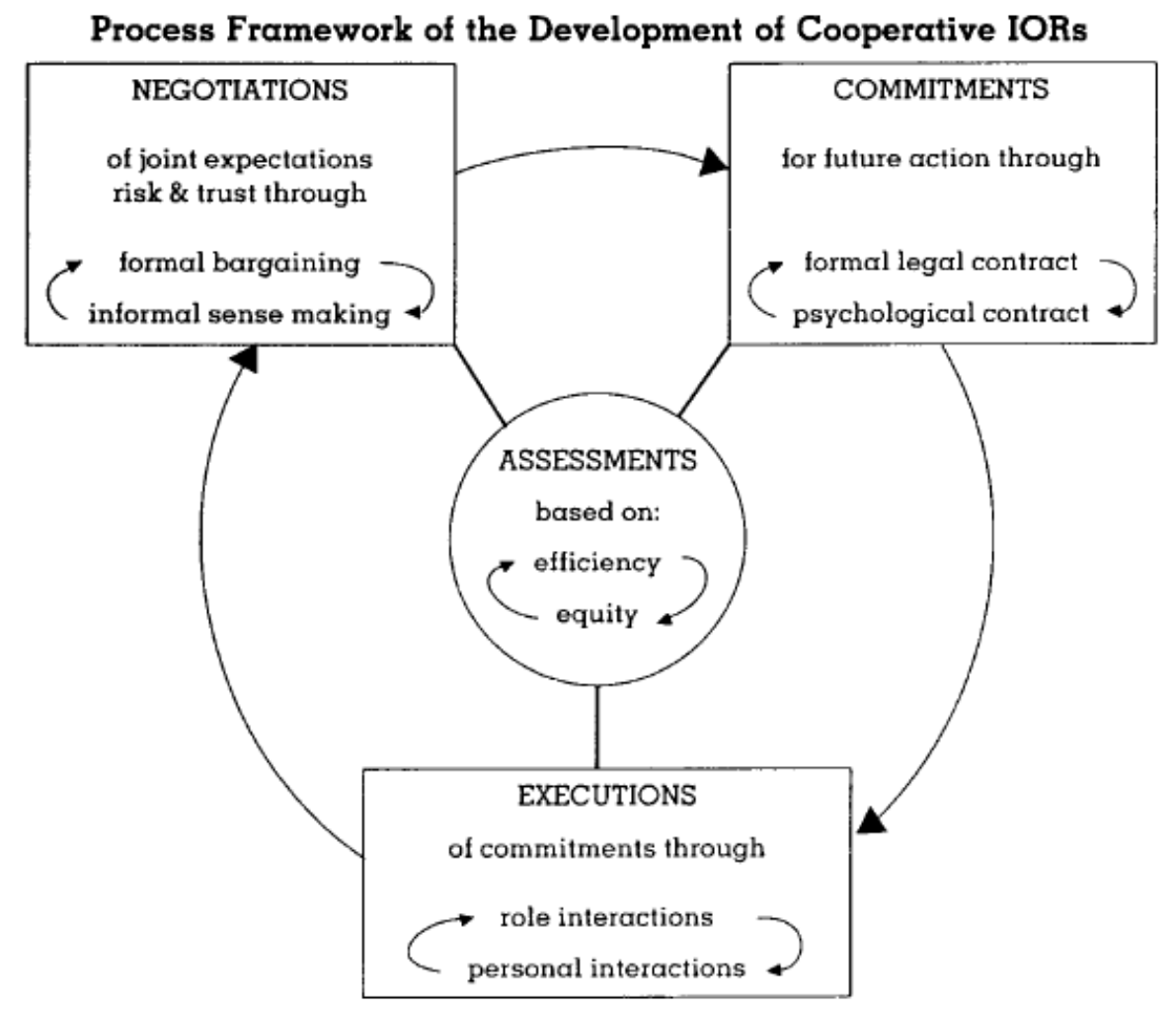

Figure 2-6 A cycle framework of relationship development Source: Ring and Van de Ven (1994: 97)

According to Jap and Anderson (2007), the main difference between the stages model and Ring and Van de Ven's cycle process framework is that the former argues that failed relationships will be abandoned, while the latter acknowledges 
the possibility of repeated cycles of negotiation, commitment and execution, even after violations of commitments. Ring and Van de Ven's framework seems to be more flexible, as it does not assume a linear life-cycle process with a clear start and finish. They emphasise firms' self-adjustments throughout the relationship development process, subject to the results of assessments. Importantly, they perceive that formal and informal activities are, to a large extent, conducted proactively by two firms, as the means of achieving their business objectives. This somewhat differs from the stages model which considers the tendency for social content to naturally emerge on the basis of repeated economic interactions and satisfactory economic outcome.

Moreover, other models or paradigms are offered by scholars who became dissatisfied with the stages model, finding that relationships do not always follow a linear growth process. One theoretical attempt is demonstrated by Beloucif, Donaldson and Waddell (2006). They suggest that relationships can end at any stage during the development process, whenever firms are dissatisfied with the ongoing relationships. In theory, they define 'relationship dissolution' as a parallel option to relationship reinforcement. This leaves the likelihood of relationship termination wide open throughout the development process, which essentially suggests that relationship development is a very vulnerable process and could fail easily.

The example of Batonda and Perry (2003a) shows how the authors advance the stages model to a states theory. Batonda and Perry firstly argue that rather than stage by stage in a linear pattern, relationships can evolve from any stage to another with reflexivity. Secondly, based on their empirical findings, they point out that, in relationship development process two actors may choose to keep their social relations alive but freeze business transactions. They further define such a situation as a dormant state in addition to these traditionally described stages. Drawing on these two arguments, a highly flexible relationship development model is presented, as shown in Figure 2-7. 


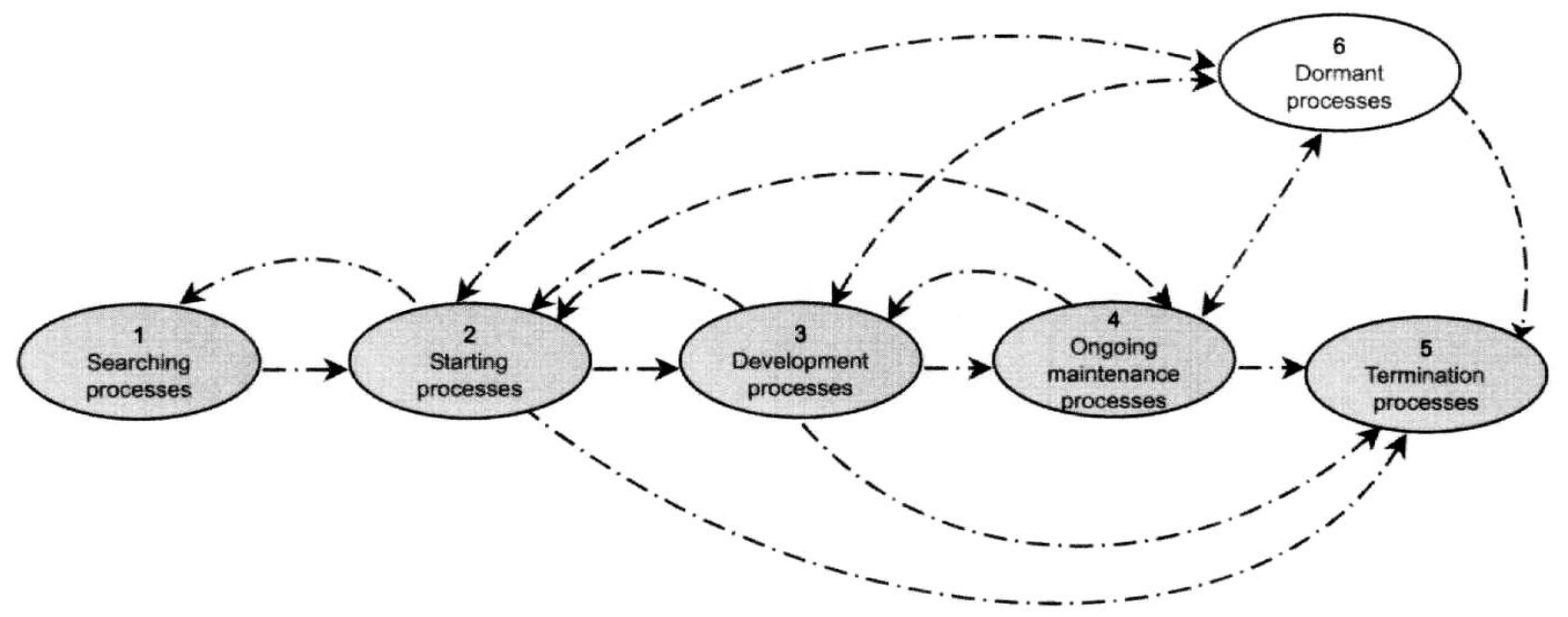

Note: $\quad \leftarrow \cdot-\rightarrow$ evolution of unpredictable states

Figure 2-7 The states model of relationship development

Source: Batonda and Perry (2003a: 1466)

Another alternative approach to explaining relationship evolution is presented by Johnston and Hausman (2006) who adopt a marriage metaphor to describe longterm relationships. Drawing from the previous literature, they define five phases in relationship evolution: single-hood, honeymoon, couple-hood, additions to the relationship, adulthood. Throughout the five phases, they consider that many variables of relationships do not homogenously increase, which means the strength of ties between two firms may fluctuate in a non-linear fashion. Their theory allows great flexibility in depicting the relationship development process. However, application of the metaphor appears to be very difficult. Johnston and Hausman (2005: 451) admitted, a study designed on this basis would "involve repeated depth interviews with multiple individuals within multiple firms within multiple networks over a long period of time...for most researchers, this is well beyond the scope that they are willing or able to accomplish".

Scholars also tend to explain relationship development from different angles. Schurr (2007) for example, considers that it may be more meaningful to pay attention to the important incidents occurring during relationship evolution because these incidents cause changes in relationships, and every change can be 
viewed as a separate episode from the previous. In other words, relationships are built upon a series of such episodes. Furthermore, Ritter (2007) analyses relationship development from the governance perspective. Illustrated in the governance triangle constructed upon the three types of governance mechanisms, his findings show no single pattern could describe the development process of relationships. For example, a relationship may evolve from position 1, to position 2, and then position 3 (Figure 2-8), whereas another relationship could evolve along a distinct path.

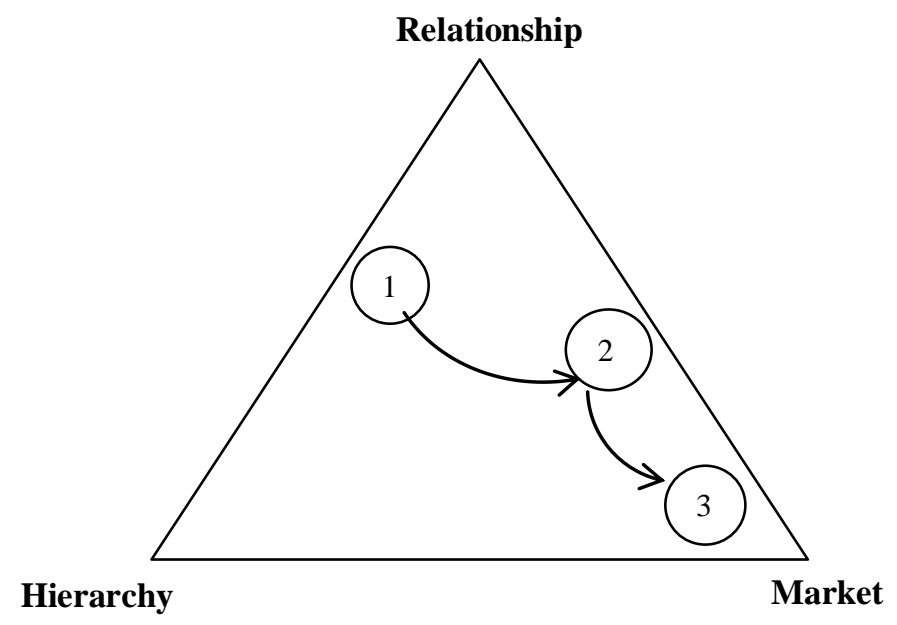

Figure 2-8 Evolutionary paths of relationship governance Adapted from Ritter (2007)

Overall, these alternative theories and models discussed in the section are quite flexible, as they are presented to accommodate the complexity of relationship development process that are observed in empirical studies and cannot be explained by the previous stages model. However, it has to be pointed out that they are also highly descriptive and seem difficult to operationalise.

\subsubsection{Network dynamics evolution of entrepreneurial firms}

The recent literature has shown another research stream on network development - network dynamics evolution (Coviello, 2006). Scholars in this field shed light on new ventures or entrepreneurial firms, and usually focus on a particular timeframe - from the early start-up or pre-founding to early growth, and investigate how network characteristics of these firms evolve through this critical 
transition period. Findings from the empirical studies have provided valuable insights in firms' business relationship development.

Generally speaking, because the entrepreneurial firms are well-known for utilising their limited but dense formal and informal networks as a vehicle for growth (Larson, 1992), scholars perceive that these firms' networks start as a social network and then become more business oriented with an increasing focus on meeting needs of new business (Schutjens and Stam, 2003), suggesting a process from social to socio-economic (Larson and Starr, 1993). Emphasising the increase of economic contents in networks, Hite and Hesterly (2001) theorise that entrepreneurial firms' egocentric networks usually develop from identity-based to calculative-based. According to them, identity-based networks contain a high proportion of personal and social ties that motivate and influence actors' economic actions; calculative networks are characterised by a greater number of weak ties which are more market-like rather than socially embedded, and are more likely to have less redundancy, be more sparse, and better able to bridge structural holes. Thus, the general evolving pattern of these firms' networks, as Hite and Hesterly described, is that, from small and cohesion based towards large and structural hole based and from socially embedded ties to a balance of embedded and arm's-length relationships.

Empirical findings however, reveal that network evolution, especially with regard to relationships, are more complicated than the theory suggests. It is found that these firms' business networks originate from a wide range such as family ties, friendship and pure economic ties, which means that the relationships can be very different at the time of initial formation, in terms of the nature and contents. These relationships may further evolve along with distinctive patterns characterised by distinctive changes of economic and social elements (Harris and Wheeler, 2005; Hite, 2003, 2005). For instance, some arm's-length ties become fully embedded, whereas some embedded ties become arm's-length (Coviello, 2006). Based on his qualitative findings, Hite (2005) concludes that there are a number of evolutionary 
paths of relationships. They are presented in Figure 2-9. From this, it can be seen that each path involves distinct development of economic and social content in relationships.

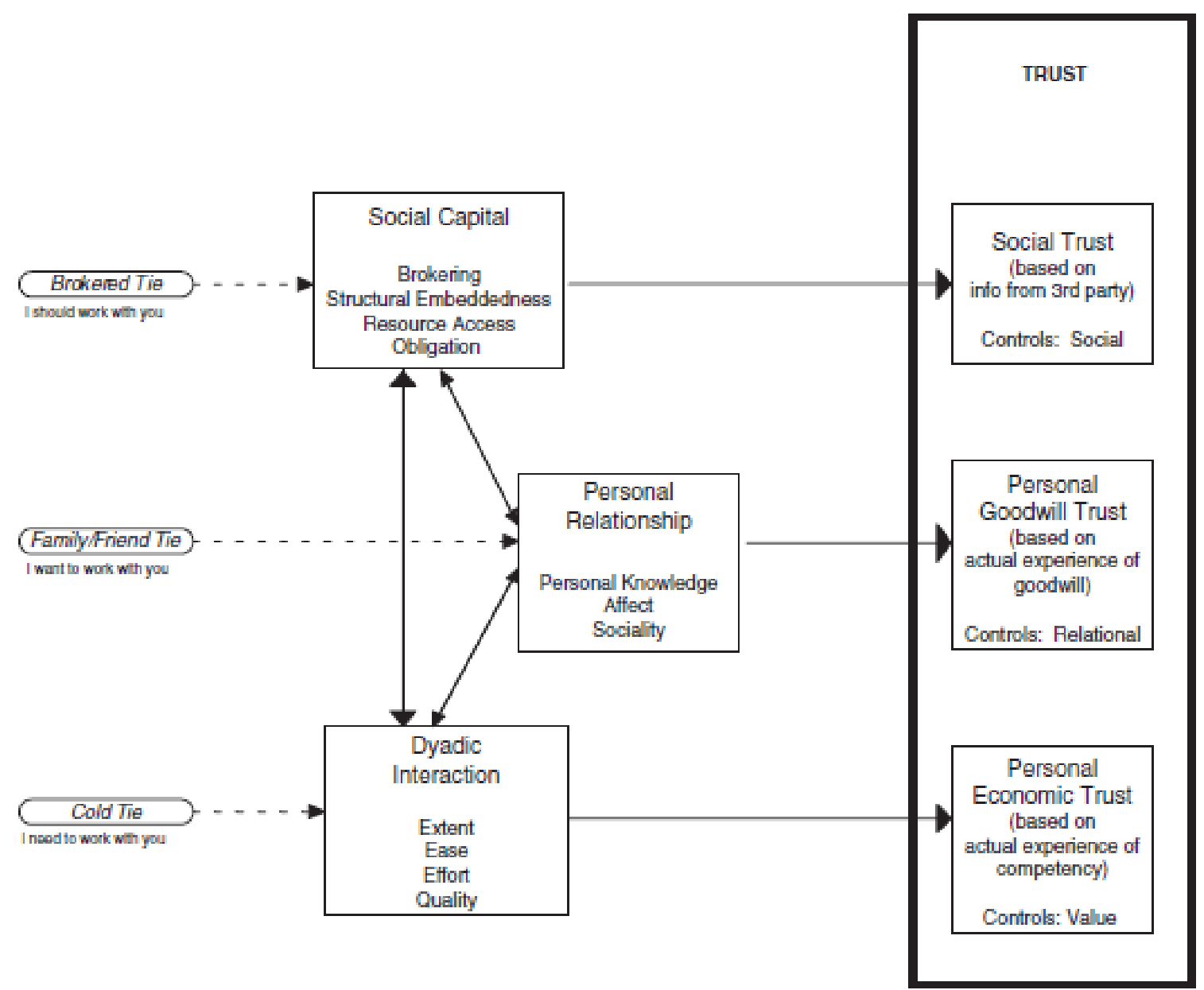

Figure 2-9 Evolutionary processes of relationships Source: Hite (2005: 124)

Overall, network dynamics evolution of entrepreneurial firms, especially international new ventures remains an under-research area (Coviello, 2006). Empirical studies in this field, however, produce insightful findings about how networks may evolve over time, and highlight the complexity and diverse paths of relationship development.

\subsubsection{Section summary}

Section 2.6 begins by introducing the interactive nature between firms and networks, followed by a brief overview of the antecedents to network 
development. Then, it sheds light on network structure evolution, before the central issue of the study - relationship development process - is addressed. This is because relationships are embedded in networks. By including these topics, the section may provide the contextual knowledge of relationship development.

The literature review shows that the stages model has been developed from a strong dyadic background. The model does not concern the network context where relationship development takes place. Rather, scholars tend to focus on the two actors only and perceive that the relationship will always go through a transition from weak to strong, discrete to relational. This, however, may need to be re-considered, because as discussed in Section 2.6.3, not every single relationship in a network will have to become very strong and highly relational.

Meanwhile, one of the main assumptions of the stages model is that, during the relationship life-cycle, "a multitude of relationship properties follow the same path, rising and falling tidily because many are related over time" (Jap and Anderson, 2007: 262); specifically, "these properties are low in the exploration phase, rise in the build-up state, climax at maturity, and then fall reaching their nadir as the relationship dissolves". A similar notion can also be identified, for example, with regard to strategic alliances. As Doz (1996: 74) noted, "partners in more successful alliances engage in (such) a series of iterative and interactive learning cycles over time, typically characterised by greater and greater trust and adaptive flexibility, as well as the willingness to make larger and larger, as well as increasingly specific and irreversible commitments". However, although some relationships may evolve in such a pattern, others may not. As shown in Section 2.6.5, in many cases relationship properties do not always evolve from a low status to a high status, but can change more dynamically. For example, Johnston and Hausman (2006: 451) point out that "no single (relationship) variable is significantly positive or negative at all times". 
In short, the stages model is challenged mostly because of the underlying assumption being questioned. Scholars argue that, rather than a linear fashion, relationships can demonstrate diverse evolutionary patterns. Models developed by these schoalrs generally appear to be much more elastic than the stages model, and are able to accommodate the divergence of relationship evolution usually encountered in reality. However, they are highly descriptive rather than analytical, and researchers have expressed difficulty in terms of their operationalisation.

\subsection{Networks and Relationships in International Business}

This section looks at the network and relationship related studies in the international business field, with a particular focus on MNCs. The section also sheds light on the research setting - China in particular.

\subsubsection{External network and internal network of MNCs}

Network related studies in the field of international business can be categorised into two different research streams. First, in the late 1980s, the IMP scholars Johanson and Mattsson (1987) demonstrated an early attempt to consider firms' internationalisation process from a business network perspective, as a competing approach to transaction cost analysis. They argue that individual firms are embedded in an industrial system involving production, distribution and the use of goods and services, therefore their business decisions and behaviours related to international market entry need to be explained by their surrounding external network relationships, rather than transaction costs.

The theory of Johanson and Mattsson has been quickly embraced by many researchers who have begun to analyse firms' internationalisation by underlining the role of business networks. Much attention is paid to specific activities related to entry mode and partner selection (e.g. Coviello and Munro, 1995; 1997; Elg, 2000; Harris and Wheeler, 2005; Li, 2004; Runch, 2001; Rustashobya and Jaensson, 2004). Foreign market entry for example, is considered to be "a matter of managing relationship development process rather than of choosing an appropriate entry mode or organisational form” (Holm et al., 1996: 1049). 
Additionally, some researchers shed light on firms' social networks in particular (Ellis, 2000; Ellis and Pecotich, 2001; Wong and Ellis, 2002). They find that those purely social ties could also affect firms' internationalising activities, although they are often beyond the traditional scope of business network studies. Importantly, findings reveal that some of these social ties may transform into business relationships later on, showing a relationship development path from social to economic-social. Overall, an important message delivered from this research stream is that MNCs should always emphasise network development with surrounding actors in their external networks. After they enter foreign markets, continuously developing local networks needs to become a crucial strategic task.

Another stream of network research in international business is built upon the well-known theory of the MNC as a network (Ghoshal and Bartlett, 1990). Ghoshal and Bartlett view an MNC as a group of geographically dispersed organisations that include the headquarters and different national subsidiaries. They adopt the network concept - "a group of organisations interacting for a specific purpose" (Stern, 1979: 264) - and define an MNC as "a network of exchange relationships among different organisational units" that are embedded in a structural context (Ghoshal and Bartlett, 1994: 604). This MNC network consists of all MNC units that usually operate in unique national environments. Ghoshal and Bartlett's theory provides a useful angle from which to view all units of a MNC at once, and highlights the importance of coordination among the units. In a similar vein, Tsai and Ghoshal (1998) and Kostova and Roth (2003) attempt to understand the internal networking mechanism of MNCs from a social capital perspective. The central research theme in this field is to probe how the headquarters may establish a control mechanism for all the subunits, so that not only can individual subsidiaries, but also the MNC as a whole, achieve great performance. 
These two research streams outlined above have distinct focuses. Research rooted in business network theory emphasises the external aspect of MNCs. As Forsgren (2004) noted, the centre of analysis of this approach is the individual relationships MNC units have with actors outside the MNC. Specifically, researchers are concerned with how firms can pursue business goals via managing relationships with external actors including those such as suppliers, buyers and distributors in the local market. In comparison, the theoretical emphasis of Ghoshal and Bartlett's (1990) work is on the internal MNC network that refers to "all the relationships and linkages that exist among the different units of the MNC" (p. 609). In this stream, according to Forsgren (2004), it is the internal structure of the MNC that forms the focus of research, while the MNC's external networks at its local subsidiary level (referring to the external part) are largely overlooked.

\subsubsection{MNC subsidiary networks in foreign markets}

In the past decade, research interest in networks at the subsidiary level has grown rapidly. One rationale for this is that from the network perspective, subsidiaries are the frontline of MNCs through which external resources can be accessed and external knowledge can be gained. In other words, subsidiaries are playing a bridging role between the internal and external networks of the MNCs (Andersson et al., 2001; Ghoshal and Bartlett, 1990).

Scholars consider subsidiary network development from two angles mainly, in line with the two theories mentioned earlier. Some pay attention to the external aspect and highlight the importance for subsidiaries to build a solid network in foreign markets and to have strong and close relationships with local actors. For example, Griffith and Harvey (2004) strongly recommend firms developing social capital in the global marketplace. London and Hart (2004) theorise local embeddedness as a critical dimension of MNCs' capabilities for global success. $\mathrm{Mu}$, Gnyawali and Hatfield (2007) examine the impact of local embeddedness on organisational learning. Their results suggest that subsidiaries need to foster social and relational elements in relationships with local actors. The other angle derived 
from Ghoshal and Bartlett's theory focuses on the internal aspect of MNC networks. Kostova and Roth (2003) for example, shed light on social capital development among the HQs and subsidiaries. They suggest that, for better coordination, there is a great need for the HQs and subsidiaries to create social capital, subject to the nature of interdependence between them.

A more balanced approach to analysing subsidiary networks is contributed by a group of Uppsala scholars (Andersson, 2003; Anderson and Forsgren, 1996, 2000; Anderssson et al., 2001, 2002; Andersson, Forsgren and Holm, 2007; Forsgren, 2004; Forsgren et al., 2005). These scholars acknowledge that first, it is the external networks that provide subsidiaries with needed knowledge and resources to become competent within the MNC and second, the subsidiaries also have to reinforce relationships with other internal actors at the same time in order to coordinate with them and transfer the competence within the MNC effectively. They also point out that once a subsidiary is too deeply embedded in one network, it is likely to become isolated from the other. The concern is that a subsidiary deeply bound with its local actors may be constrained by the local network and may not be able to coordinate effectively with other MNC units.

These Uppsala scholars further developed the concept of corporate embeddedness for the MNC internal network and local embeddedness for the external network. They argue that there is "a trade-off between embeddedness in the external network and internal network" (Forsgren, 2004: 29). Subsidiaries, therefore, must learn to manage these two types of embeddedness at an appropriate level. Andersson et al. (2001) propose the principle for subsidiaries to not only benefiting from local networks, but also avoiding the negative impact caused by overembeddedness. According to them, the optimal mode of a subsidiary's local network should be "composed of both highly embedded relationships with suppliers and customers, etc., and a number of arm's-length relationships" (p.1030). This viewpoint echoes the idea of group social capital reviewed in 
Section 2.6.3. As shown in Figure 2-3, a focal actor's network needs to be a combination of both strong and weak ties.

\subsubsection{Social networks in China}

Over the past two decades, scholars who are concerned about social networks in China have shown great interest in guanxi, the China-specific social networking (Xin and Pearce, 1996; Luo, 1997). In organisational studies, guanxi is usually studied in a business relationship setting between two exchange partners ${ }^{6}$, and perceived as the social attachment between these two partners. Recently, because of the common focus on the social aspect of relationships, scholars view guanxi as a type of relational social capital and social embeddedness, and refers to these aspects interchangeably (Bian, Breiger, Davis and Galaskiewicz, 2005; Carlisle and Flynn, 2005; Su, Yan, Zhuang, Zhou and Dou, 2009; Zhou, Wu and Luo, 2007; Zhou and Xin, 2003; Zhou, Zhao, Li and Cai, 2003). Below, the guanxi literature is reviewed because it offers valuable insight in the social content of business relationships in the Chinese context.

\subsubsection{Guanxi in business networks}

A starting point to understand guanxi is to take a brief look at China's inherent culture. As Park and Luo (2001) described, China's culture is characterised by Confucianism - a social philosophy based on the principle that human beings are fundamentally relation-oriented, and renqing - a type of social capital leveraging interpersonal exchanges of favours. In these philosophical foundations, China has formed a unique way of reaching goals through using connections / relationships. Individuals therefore, are keen on relationship building with 'useful' others for either short-term or long-term benefits, which forms the essence of guanxi. Importantly, throughout China's history guanxi is " not just as a central cultural artefact of historical dimensions, but is perhaps the key distinctive social institution defining, directly or indirectly, virtually all social interaction in China:

\footnotetext{
${ }^{6}$ The review of the literature shows that research on guanxi has been largely focusing on the relational level, even though Park and Luo (2001: 473) consider guanxi as "a mechanism for Chinese firms not only to exploit and accumulate social capital but also to broker structural gaps with key stakeholders in the environment".
} 
interpersonal; individual/group; group/group; organisation/organisation" (Parnell, 2005: 29).

Scholars usually define guanxi on this basis. For example, Chen and Chen (2004) regard guanxi as a sophisticated and elaborate system of networks and networking. Park and Luo (1997: 167) describe guanxi as "an intricate and pervasive relational network that contains implicit mutual obligations, assurances and understanding”. Importantly, they emphasise the goal of developing guanxi is to utilise guanxi eventually. In the interorganisational context, guanxi is translated as firms' networking with each other in the marketplace. Because guanxi practices are often carried out between and among managers across different firms, guanxi is sometimes discussed as managerial ties or managerial networking (Luo, 2003; Peng and Luo, 2000). The literature has shown an interest in differentiating between guanxi-like networking and Western style networking such as relational exchange. Although guanxi is not just about having emotional ties, it underlines the cultivation of long-term relationships and collectivism (Ramasamy, Goh and Yeung, 2006) and involves many more social, relational and personal elements during the networking process (Lee et al., 2001) in comparison to the Western way of business networking. Table 2-3 is a comparison of characteristics between guanxi and the Western style relational exchange.

Table 2-3 Comparison between guanxi and the Western relational exchange

\begin{tabular}{|c|c|c|}
\hline Characteristics & Guanxi & Relational exchange in the West \\
\hline $\begin{array}{l}\text { Type of involvement in the } \\
\text { relationship }\end{array}$ & Affective & Economic \\
\hline Type of commitment & Affective commitment & Calculative commitment \\
\hline $\begin{array}{l}\text { Role expectation in the } \\
\text { relationship }\end{array}$ & Implicit & Explicit \\
\hline Role boundaries & $\begin{array}{l}\text { Beyond the existing role } \\
\text { expectations }\end{array}$ & $\begin{array}{l}\text { Within the pre-determined role } \\
\text { expectations }\end{array}$ \\
\hline Relational behaviors & Care and favor & Cooperating \\
\hline $\begin{array}{l}\text { Motives for reciprocal } \\
\text { behaviors }\end{array}$ & Face saving & Mutuality \\
\hline Guiding principle & Morality and social norms & Legality and rules \\
\hline
\end{tabular}

Source: Lee et al. (2001: 55) 
A common belief about guanxi is that, at the firm-level, guanxi features social and personal characteristics and can, to a large extent, facilitate firms' business activities in the network. For example, research shows that guanxi can help firms cope with environmental uncertainty, overcome a lack of key resources, obtain critical information, safeguard their business operations, hence contribute to higher organisational performance (e.g. Park and Luo, 2001; Parnell, 2005; Wu and Choi, 2004; Wu and Leung, 2005). One explanation for the rationale is that guanxi operates in concentric circles. It leads to a social phenomenon in China whereby 'who you know' can be more important than 'what you know' (Yeung and Tung, 1996). Thus, when companies attempt to extend their business networks, guanxi can play a boundary spanning role and help firms connect with other's business networks (Carlisle and Flynn, 2005). Another popular explanation of guanxi is that, as a transitional economy, China has an underdeveloped institutional environment - therefore firms need to develop guanxi with other market actors to accommodate external uncertainty and the relatively turbulent market (Peng, 2002; Peng and Heath, 1996; Xin and Pearce, 1996). In short, as Luo (1997) considered, guanxi in China can help firms gain advantage over competitors and can be used as the most effective and efficient networkbased marketing tool for firms to achieve market growth and reduce overall costs.

However, the extent to which guanxi needs to be nurtured by firms with their exchange partners remains controversial. First, Peng and Luo (2000) consider that guanxi may be a necessary, but not a sufficient condition for firms' business success in China. Park and Luo (2001) found that guanxi has impact on sales growth, but not profit growth, because firms' financial performance can be offset by their investment in social networks. Ramasamy et al. (2006) find no evidence showing that guanxi-based strong ties are positively related to firms' learning outcome. Second, scholars point out the negative effects of guanxi. Warren, Dunfee and Li (2004) note that guanxi can distract people from doing things effectively because individuals may be forced to do things they do not want to do. Hitt et al. (2002) state that firms must overcome the constraints from guanxi and 
pursue more freedom in expanding existing business networks. Essentially, this part of literature is in line with the negative effects of strong ties and social capital, as well as overembeddedness, reviewed earlier. More recently, Gu, Hung and Tse (2008) define this dark side of guanxi as including reciprocal obligations and collective blindness. Chen and Chen (2009) summarise it as a social dilemma phenomenon about externalities. Third, Peng $(2002,2003)$ discusses the diminishing role of guanxi in China from an institutional perspective. He points out that, because China's formal institutional environment such as law and regulations are maturing rapidly, guanxi may become less necessary in business operations. In addition, research shows that because of the evolving culture in China, new generation managers become more Western-like and tend to be much more economic-oriented than those traditional Chinese managers who operate business based on guanxi (Chan, Cheng and Szeto, 2002).

Evidence of foreign firms operating in China not emphasising guanxi in their local business relationships can be found in the literature. Zhou and Xin (2003) reveal that in the Chinese IT industry, foreign MNCs manage to have hierarchical relationships with their local Chinese partners, not relational ties, despite a considerable number of economic transactions. $\mathrm{Li}$ (2001) and Trimarchi and Tamaschke (2004) find that Hong Kong companies tend to manage their mainland Chinese partners at arm's-length, because of their dominant power in the relationships. From a learning perspective, Ramasamy et al. (2006) specifically suggests that foreign firms in China could sometimes employ a short-term 'hitand-run' strategy to develop business networks, rather than a long-term oriented guanxi based approach. As they indicated, such an alternative approach may allow firms to achieve business goals more efficiently, because nurturing social ties requires a significant amount of time and resources.

\subsubsection{Guanxi and relationships development}

As far as guanxi development is concerned, Chen and Chen (2004) describe three stages of the process: initiation, building and use. Although this part of the 
literature remains limited, research shows there are some specific features of network relationship development in China, as the implications of guanxi. For instance, companies in China often develop social ties through conscious efforts via deliberating activities (Björkman and Kock, 1995). Before two parties start their formal business cooperation, a lot of social interactions are usually carried out (Xin and Pearce, 1996), because business relationships in China tend to be formed only between two parties with connection previously and trusting each other (Sikorski and Menkhoff, 2000). In other words, social ties or guanxi development can be the prerequisite to information and business exchange.

Furthermore, research shows that, in China, smaller and less competitive firms are more likely to strengthen their guanxi with business partners (Carlisle and Flynn, 2005; Peng and Luo, 2000) and firms from the Asian background are more likely to be engaged in guanxi with business partners than their Western counterparts (Hitt et al., 2002). Also interestingly, it is found that because Chinese firms having strong guanxi are likely to rely on their existing social relations and links to cope with market issues, their network evolution often appears to be pathdependent (Zhou et al., 2003). This finding is consistent with embeddedness research. According to Uzzi (1997), in an embedded network, actors prefer to go 'deep' rather than 'broad' while seeking solutions to business issues.

All in all, research shows that in China, it is relatively difficult to initialise relationships with strangers, but once this process begins, it would be easy to develop and maintain, and difficult to terminate (Batonda and Perry, 2003b). This feature, as discussed above, is largely attributed to the role of guanxi or the social elements in relationships which often take time to nurture but may transcend the economic concerns.

\subsection{Chapter Summary}

This chapter reviews the literature relating to the research problem - how do business relationships of foreign companies in China develop from a process- 
based perspective? It covers a variety of topics, including the definition of networks, network contents, relationship measurement, network development, and the particular research setting - MNC networks in China. Although the study is primarily concerned with relationships, this chapter also pays attention to the structural aspect of networks, in order to understand relationships and relationship development more fully.

Two important issues reviewed in this chapter are worth highlighting in this section as they are closely related to the following chapter. First, business networks contain economic and social contents. At the relational level, social elements are described as an important ingredient and part of the fabric of firms' relationships (Forsgren, 2004; McAllister, 1995). Together with the economic content, these elements characterise the nature of relationships. This also explains why previous research often examines relationships by incorporating economic and social contents into the constructs. In the meantime, the review shows that the constructs for relationships are derived from the behavioural and psychological aspects of firms. Second, the development process of relationships can be diverse in reality, as relationships do not always follow the linear pattern to evolve, as the stages model described, and their nature that is indicated by relationship properties, characterised by economic and social contents, could experience dynamic changes. Reasoning for this can be drawn from various aspects. For example, some relationships may never develop fully due to firms' intention of avoiding network cohesiveness. Or, some relationships could experience fast growing social content, but not the economic content.

Based on the literature review, the next chapter will propose a novel perspective to address an empirical research gap with regard to examining relationships and their development process. From this perspective, specific research questions relating to foreign firms' relationship development in China are presented. Then, three sets of hypotheses are formed in respect to these research questions. The hypotheses compare different types of firms: i.e. Asian firms as opposed to 
Western firms, small firms as opposed to large firms, and manufacturing as opposed to service firms, and explore their differences with respect to the economic and social aspects, in the process of relationship development. 


\section{Chapter Three}

\section{Conceptual Development, Research Questions and Hypotheses, and Research Design}

\subsection{Chapter Objectives}

Drawing on the literature reviewed in Chapter Two, Chapter Three aims to establish the conceptual approach to examining relationship development, and refines the research questions. It is organised as follows. First, the chapter explains the rationale for studying relationships in networks. Second, it introduces how relationship development is operationalised and investigated in this study, that is, by assessing the changing nature of relationships. Third, it discusses the distinguishable economic and social contents of relationships, and on this basis, presents a two-dimensional view to assist researcher with analysing business relationships and the development process. Fourth, the research problem is presented and further refined into two research questions; hypotheses are then, stated in response to one of the key research questions. From the two-dimensional perspective, these hypotheses compare the relationship development process of different categories of foreign firms defined by their nationality, size and industry sector. Finally, the chapter describes the two-phase research design and mixed methodology used in the study.

\subsection{The Study of Relationships in Networks}

As described in Chapter 2, network studies can be generally categorised as focusing on the structural level and relational level. In comparison to the structural level network studies that emphasise aspects like network size, density, centrality of actors and structural holes, the relational level network studies deal with the network actors and the ties connecting these actors - i.e. the relationships. Also, unlike the structural approach that tends to reduce relationships to a 'link' by describing it as either present or absent, directed or symmetrical, strong or weak, the relational approach to studying networks looks deeply into the nature of relationships in terms of, for example, strength, closeness, and quality, which may 
help researchers to reveal the subtleties occurring between two individual firms, and gain in-depth understanding of their relationship (Todeva, 2006).

The present study is concerned with interfirm relationships, in other words, the relational level of firms' networks. This is because the researcher' primary interest lies at the dynamics between foreign firms and their local Chinese network actors. The significance of studying relationships has been highlighted in the literature. According to Oliver (1990), firms often make conscious and intentional decisions in building business relationships, and their behaviours are usually driven by an explicit purpose. Hence, relationship building can be perceived to be the fundamental to firms' network development, and research in this regard may provide insight into firms' network strategy (Heide, 1994). More recently, scholars point out that the relational level analysis of networks is complementary to the structural level analysis (Kostova and Roth, 2003), because network structure can be perceived at the macro-level and must be built up from the microlevel dyadic relationships between network actors (Kenis and Knoke, 2002; Venkatraman and Lee, 2004). As Koka et al. (2006: 721) have mentioned, firms' relationship activities are "collectively necessary and sufficient to describe the basic process of network change".

In short, analysis of relationships is an essential part of network research, with its specific focus on the relationships rather than the network structure (Todeva, 2006). The study explores foreign firms' network development in China from a relational perspective, i.e. how these firms develop their relationships in the local market.

\subsection{Defining and Examining 'Process'}

Relationship development is a process-based concept. A crucial issue directing the present study is to understand what a 'process' means. According to Van de Ven (1992: 169), 'process' can be defined in three ways: 
“(1) a logic that explains a causal relationship between independent and dependent variables, (2) a category of concepts or variables that refers to the actions of individuals or organisations, and (3) a sequence of events that describes how things change over time”.

Van de Ven further states that these three definitions suggest distinct angles for considering a process, and, therefore, guide researchers to employ different approaches to investigating a process-related phenomenon. The way this study examines the relationship development process echoes the second definition. This means that the researcher will operationalise the concepts and variables of the entity - which, in this case, refers to the relationship - as constructs, and use them to measure how the entity has changed. More specifically, these constructs are to be examined along numerical scales from low to high, and from one time point to another, in order to find out the degree of change that has occurred within the focal timeframe. According to Van de Ven, in this approach, the central research focus is on the evolving characteristics of the entity, whereas antecedents to the change of constructs are not of concern.

By undertaking the approach in response to the second definition, the study may add to the existing relationship development literature in two ways. First, with a particular focus on the relationship constructs, the study essentially deals with the nature of contents of relationships. According to Brass et al. (2004), the nature of relationships draws increasing research interest from scholars. It is key to comprehending the dynamics between the two parties (Todeva, 2006), and serves as an effective angle to allow the researcher to unfold the relationship development process (Turnbull et al., 1996). Second, research examining the relationship development process by assessing the evolving nature of relationships over time is still limited (Coviello, 2006). For instance, the stages model described in Chapter 2 emphasises episodes and the described sequential logic for a relationship to grow, which means it relates to the third definition. Other studies 
tend to shed light on the antecedents and determinants of relationships, which follows the first definition.

Overall, the relationship development process is investigated in this study by assessing the evolving nature of relationships, indicated by the changes of specific relationship constructs. This approach is intended to enrich the extant literature on relationships and relationship development by producing valuable findings from a unique angle.

\subsection{The Nature of Relationships and Their Development}

This section highlights the nature of relationships and their development. It argues for the distinguishable nature of the economic and social contents of relationships, especially in the context of relationship development.

As described in Chapter 2, the literature has provided some useful insights into the nature of business networks. Generally speaking, firms' business networks can be perceived as comprising an integration of economic and social networks (Lechner et al., 2006). The economic network is constructed based upon interfirm business exchanges that involve economic transactions and are directly associated with firms' anticipated economic outcomes; the social network is formed via social exchanges containing informal characteristics and are not necessarily related to firms' business operations in a direct way. In the past decades, social networks have attracted a great deal of academic interest, witnessing the emergence of a number of theories including, for example, embeddedness, social capital and social exchange, and related research exploring the social content of business networks (Duschek, 2004; Granovetter, 1985; Peng and Luo, 2000; Tsai and Ghoshal, 1998; Uzzi, 1997; Walker, Kogut and Shan, 2005; Wu, 2004; Yli-Renko et al., 2001).

With regard to business relationships, the literature also suggests that they contain both economic and social contents. As mentioned earlier, social exchange theory 
suggests that, apart from economic transactions, relationships can involve bartering-exchanges that are a mixture of monetary and in-kind payment, and normative expressions, among others (Shaw, 2006). Relationship marketing underlines the 'soft' features rooted in a sociological tradition, as opposed to 'hard' features associated with an economic view, which refers to features such as formal contracts, formalised decision structures and procedures, and economic safeguards (Ivens and Blois, 2004). Social capital studies show that social elements are often embedded in dyadic business relationships and influence firms' activities (Yli-Renko et al., 2001; Zhou et al., 2007).

Such a social and economic perspective of the nature of business relationships helps to shape the way relationships are defined and measured. For example, Donaldson and O'Toole (2000) state it is the economic and social elements that jointly determine the overall strength and quality of business relationships. The definition on strong and weak ties from Perry-Smith and Shalley (2003: 93) provides an example in this respect.

"Weak ties, on the one hand, as direct relationships between two actors at the low end of the tie strength continuum involve relatively infrequent interactions, comparatively low emotional closeness, and one-way exchange...Strong ties, on the other hand, direct relationships involve relatively frequent interactions, high emotional closeness, and reciprocity."

Their definition implies a continuum view of defining relationships, as described in Section 2.4.2. The continuum consists of economic and social contents, and may be illustrated in Figure 3-1. 


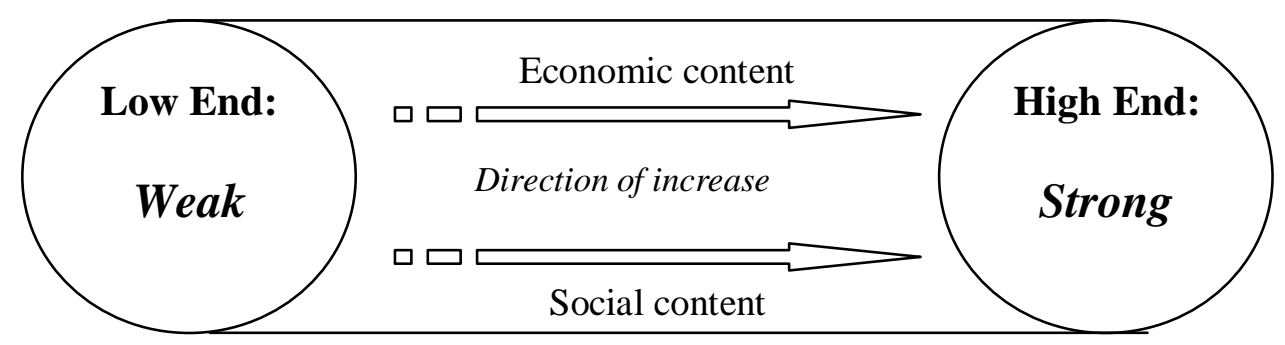

Figure 3-1 A continuum view to analysing business relationships

In a similar vein, scholars consider that the evolution of the economic and social contents represents the two main themes of relationship development (Larson and Starr, 1993). For example, Holm et al. (1999) draws on the stages model, and describes the generic process of how a relationship may grow. Generally speaking, two firms usually start from simple and minimal economic transactions, and then evolve along with social exchanges between them, finally forming a long-term cooperative business relationship. During this transformation, the degree of the firms' economic exchange increases, together with the growing informal and social content. Similarly, as reviewed in Section 2.6.4.2, Ring and Van de Ven (1994) demonstrate the relationship development logic that relationship evolution occurs based upon the rising or declining economic and social elements, such as formal business activities and personal interactions.

Although researchers acknowledge the co-existence of economic and social contents, they do not always distinguish between them when analysing relationships. Such an approach appears to be questionable in terms of allowing researchers the opportunity to gain deep understanding about relationships and the relationship development process. This concern has not yet been presented explicitly in the literature, but some relevant insights can be seen from three aspects. First, the definition of strong and weak ties quoted above from PerrySmith and Shalley (2003), for example, holds an implicit message that the economic and social contents tend to be high or low simultaneously. However, a number of qualitative studies have reported the 'irregular' or 'atypical' 
relationships that seemingly contain uneven economic and social contents. For example, Mudambi and Mudambi (1995) mention that many Western buyersupplier relationships are 'close and adversarial', characterised by strong formal but not informal commitment. In this type of relationship, both parties are deeply engaged in transactions, but there remains a high likelihood of opportunism. Likewise, Donaldson and O'Toole (2000: 494) note that, "a relationship may be very co-operative and open but not have strong economic ties, or a relationship may have strong economic ties through dependency but be very uncooperative and forced". These empirical findings are largely descriptive. They underline the diversity of relationships by nature, and invite scholars to consider whether it is sufficient to define relationships as two polar-types along a single continuum based upon the combination of economic and social contents (Tangpong et al., 2008), as illustrated in Figure 3-1.

Second, previous research on relationship development does not usually separate the social contents from economic contents (Björkman and Kock, 1995). However, some recent qualitative exploratory studies have shown that these two types of contents do not necessarily demonstrate an identical evolutionary pattern in the development process of a relationship. Taking entrepreneurial firms as an example, their business relationships may have distinct economic and social status even from the early formation stage, because the firms seek relationships from sources such as family ties, friendship and pure market ties (Coviello, 2006; Hite, 2003; Schutjens and Stam, 2003). Further, the economic and social contents in these relationships may not evolve concurrently afterwards, driving the relationships necessarily towards the high end of the relationship continuum. For instance, some initially socially embedded ties could become arm's-length and more business oriented, suggesting, perhaps, increasing economic content and declining social content. As Golicic et al. (2003) argued, not all relationships of firms will need to be strong and close, or truly collaborative or reflecting great intimacy. This may explain why the stages model sometimes fails to predict relationship development in reality. It also corresponds to alternative models 
highlighted in Chapter 2, which address the diverse development patterns of relationships.

Third, it has been pointed out that many constructs for relationships actually consist of economic and social aspects. For example, Madhok (1995) and McAlister (1995) describe trust as multidimensional other than unidimensional, because it contains an economic component that pertains to the firms' business outcome, and a social component that is not calculative, and is labelled as social glue. Likewise, scholars note that commitment comprises calculative commitment and affective commitment (Geyskens, Steenkamp, Scheer and Kumar, 1996). The former is based upon rational and objective calculation of the costs and benefits that are associated with the relationship, whereas the latter is based upon emotional elements and represents the social relations between two actors. However, these constructs are always treated as being unidimensional (Clarke, 2006). This may hinder in-depth understanding of the constructs, and consequently, the relationship. Recently in the field of international business, Styles, Patterson and Ahmed (2008) and Chua, Morris and Ingram (2009) have paid attention to this issue. Particularly, Chua et al. (2009) have found that the affect-based trust and cognition-based trust are more distinguishable in China than in the West. Their findings suggest the importance of differentiating between the economic and social components of relationship constructs, for deep understanding of the relationships.

The reasoning for the uneven development of economic and social contents in relationships may be extended as follows, by drawing on the literature reviewed in Chapter 2. To begin with, despite the positive impact, the typically strong and close relationships which are featured by substantial economic and social contents could possibly affect firms in negative ways. Hence, firms may only develop their relationships to an appropriate extent, based on the perception of "how close is too close" with respect to each exchange partner (Peng, 2002: 264). Specifically, they may be cautious of nurturing the social content in their relationships. As Anderson 
and Jap (2005) pointed out, close relationships do not always mean good relationships for firms, mainly because of the potential destructive effects of the social and interpersonal ties in the business setting. This also relates to the theoretical argument of overembeddedness (Uzzi, 1997) and the dark-side of social capital (Gargiulo and Benassi, 2000). Further, from a managerial perspective, firms may not always regard the development of the social content as necessary. For instance, as long as arm's-length ties can fulfil firms' business goals, there may be little need to foster strong social bonds (Larson, 1992). In a competitive and fast changing market such as China, despite the emphasis on social networks, Ramasamy et al. (2006) recommend that firms should sometimes undertake strategies to develop relationships based on arm's-length ties, so that economic goals can be achieved more effectively, given the higher costs and time needed for nurturing social content (Westlund and Nilson, 2005).

Explanation may be also drawn from an overall network perspective. As discussed in Chapter 2, firms have to deal with the trade-off between network closure and openness, in order to benefit from, but not be trapped by, their network (Gargiulo and Benassi, 2000). Such a balance between relational and structural social capital implies that firms should only develop strong and close relationships selectively (Oh et al., 2004). This further means that the economic and social contents of each relationship need to be nurtured carefully by firms for the purpose of achieving an optimal network structural pattern. Similar concern is noted in the MNC literature with regard to network development of subsidiaries. Andersson et al. (2001) suggest that, theoretically, a subsidiary's business network in a foreign market should not be completely locally embedded; rather, it needs to be established on the basis of a combination of both arm's-length ties and embedded ties. In other words, not all relationships of a subsidiary should become fully developed. This points toward the complexity of the subsidiary's relationship development in the local market. 
It would be meaningful to consider why the early relationship development literature failed to take into account the possible explanations discussed above. Perhaps, this is because the recognition of the negative impact of strong and close relationships is relatively recent, whereas the early network literature, overall, sheds light predominantly on the positive effects. Also, the early literature on business relationships generally has an excessive focus on the dyads (Wilkinson, 2006), and less, if any, focus on the network context. Additionally, the early relationship development literature is largely developed in a Western context. One underlying perception is that social elements in relationships tend to emerge naturally from firms' repeated business activities, which emphasises the closely intertwined nature between economic and social contents, and is, arguably, incomplete in addressing the subtleties of social development in business relationships. For instance, Westlund and Nilson (2005) found that a notable proportion of social elements in relationships actually originate from firms' noneconomic activities, such as socialisation. Their finding is particularly applicable to an Asian cultural background, because unlike in the West, social relations in China are often developed by firms much more proactively through deliberate approaches (Björkman and Kock, 1995; Chen and Chen, 2004).

Overall, this section sheds light on the nature of business relationships - an important issue for investigating the relationship development process in the study. It is noted that the literature reports a business relationship as containing two primary types of contents, economic and social. However, differentiation between these two does not seem to be emphasised enough, in the context of analysing relationships as well as relationship development, especially with regard to research on MNCs operating in a non-Western context, such as China.

\subsection{A Two-dimensional View for Analysing Relationships and Relationship Development}

In response to the issue identified in the previous section, the researcher proposes to analyse the economic and social contents separately for an in-depth 
understanding of relationships, which is essential to the investigation of relationship development in this study. The literature often refers to the economic and social contents of relationships as economic and social aspects, respectively. In this study, these two aspects are explored at a detailed level, and so terminology is used to better enable the distinction between them, as well as their separate components. Specifically, the study conceptualises two primary dimensions of business relationships, the economic dimension, defined broadly as the economic ties, and the social dimension, defined broadly as the social bonds, in a relationship.

A firm's focus on the economic dimension of a relationship reflects its strong business focus and concern with the associated anticipated economic outcomes. This dimension is based on two firms' profit-oriented economic exchanges, such as buying and selling of materials and services (Bagozzi, 1975), resource combinations (Morgan and Ghoshal, 1999) such as production and R\&D adaptation, transaction specific investments and other types of business activities, like business-related communications. This type of relationship content is sometimes discussed as economic integration (Luo, 2008a) and transaction linkages (Liu, Wang and Wei, 2009) between firms. The economic dimension defined in this study also contains the psychological factors required for, and closely related to, business operations and necessary for interfirm relationships to perform. For example, to be engaged in a relationship, two firms have to trust each other's capability and professionalism in fulfilling demands and completing tasks; they also need to be committed to accomplishing the task specified in their agreement, and probably willing to cooperate on similar or other tasks in the near future (Blois, 1999). Overall, the strength of the economic dimension or the economic ties indicates the extent to which two firms are engaged in the relationship to pursue business objectives.

Social bonds are defined as representing the social ingredient (Forsgren, 2004) and social fabric (McAllister, 1995) in business relationships, and may not be 
directly associated with firms' economic goals (Whitener et al., 1998). This dimension relates to relational and cognitive social capital (Alder and Kwon, 2002; Kostova and Roth, 2003; Nahapiet and Ghoshal, 1998), and can be indicated by the level of socialisation and concerns with the soft factors like norms, reciprocity, social obligations, benevolence trust, and affective commitment between two firms. The strength of social bonds suggests two firms' associability in their relationship that implies their willingness and ability to behave collectively with each other (Leana and Van Buren, 1999). In other words, strong social bonds suggest that firms sacrifice, to some extent, their individualism, freedom and autonomy. Hence, two firms bonded by strong social bonds are less likely to behave opportunistically, and more likely to interact with their partner beyond the scope of normal economic indicators, such as a formal written contract.

The two dimensions defined above reflect the economic and social aspects or 'contents' of relationships. A relationship with a strong economic dimension can be viewed as containing substantial economic content; one with a strong social dimension would have of substantial social content. Each of these dimensions comprises a number of constructs that define them; for example, economic interaction and social interaction, economic trust and social trust, as indicated above and further explained in Chapter 5. Following the literature, these two dimensions are presumed to co-exist and jointly determine the overall nature of relationships.

This two-dimensional view could assist the researcher in obtaining insight into the nature of relationships, which may not be otherwise identified. As far as relationship development is concerned, this view suggests that economic ties and social bonds are likely to demonstrate distinctive evolutionary patterns over time. For example, the degree to which one dimension increases may not be the same as for the other. To address the potential 'unequal' development of these two dimensions, researchers who intend to comprehend fully the development process of a relationship may have to scrutinise its changes along the economic ties and 
social bonds separately. This forms the conceptual approach of the study. Note that the economic and social contents can be interrelated, as the literature suggests, but it does not contradict the two-dimensional view and the resulting conceptual approach explained above; that is, the economic ties and social bonds may be developed differently by firms, and are, therefore, distinguishable.

\subsection{Research Problem and Research Questions}

The international business literature recognises that local network development is an important strategic task for MNCs operating in international markets in order to achieve business success (Forsgren et al., 2005; Griffith and Harvey, 2004; Kostova and Roth, 2003; London and Hart, 2004; Mu et al., 2007; Yli-Renko et al., 2002). This study is an attempt to explore this issue by focusing on foreign firms' relationships in China. The Chinese market provides an interesting context for examining relationship development, not only because of the large number of foreign MNCs operating in the market, but also because it has a unique institutional environment that may encourages firms to become engaged in local networking. Thus, as noted earlier, the overarching research problem underpinning the study is:

\section{How do foreign firms operating in China develop business relationships with local actors?}

Relationships and relationship development in this study are analysed from a twodimensional view, by differentiating between the economic and social dimensions of the relationships. The research problem is therefore, refined, and presented as two key related research questions. First,

\section{Research Question 1: Do foreign firms operating in China emphasise their economic ties and social bonds differently in developing business relationships?}


Moreover, the researcher intends to explore how foreign firms operating in China may differ from each other in terms of their relationship development process. Given the variety of foreign firms operating in China, foreign firms in this study are categorised by their nationality, size and industry sector, because the literature has suggested that firms defined by these three factors are likely to develop networks and relationships differently. The second research question, therefore, is:

\author{
Research Question 2: Are there any differences in the relationship \\ development process of different types of foreign firms, with respect to \\ the economic ties and social bonds? If yes, then what are these \\ differences?
}

With regard to the comparisons noted above, three sub-questions are formed to address the second research question. They are as follows:

2a ) In China, how do Asian foreign firms and Western foreign firms differ in their relationship development process, with respect to the economic and social dimensions?

2b ) In China, how do large foreign firms and small foreign firms differ in their relationship development process, with respect to the economic and social dimensions?

2c) In China, how do foreign manufacturing firms and foreign service firms differ in their relationship development process, with respect to the economic and social dimensions?

The literature concerning comparisons between these different types of firms is highlighted in the following section, along with the development of the hypotheses regarding the three sub-questions. As noted in Chapter 1, the two key research questions are closely related, serving the overall objective of 
understanding the overarching research problem. By addressing research question 1 , the conceptual basis of the study, that is, the two-dimensional view of relationships and relationship development, can be examined and justified in the Chinese setting. Research question 2 extends the use of the two-dimensional view, by examining differences between different types of foreign firms in their relationship development processes in China along the economic and social dimensions.

\subsection{Hypotheses Development}

In this section, hypotheses are developed in response to the second research question, specifically questions $2 \mathrm{a}, 2 \mathrm{~b}$ and $2 \mathrm{c}$. The three organisation-level factors (foreign firms' nationality, size and industry sector) are explained in the context of relationship development. Notably, the relationship development process in this study is analysed from the time of formation onwards, and a relationship is considered to be formed when two firms conduct their initial economic exchanges. This is because, from an operational perspective, the formation of relationships serves as a clear starting point for an empirical investigation of relationship development (Dyer and Chu, 2000).

\subsubsection{Comparison between Asian and Western foreign firms}

Luo (1997) suggests that the foreign firms operating in China can be characterised as two general groups by their cultural origin: those from the West and those from other Asian countries. The former refers to, for example, the US and European countries; the latter mainly includes countries like Japan and Korea which were largely influenced by the Chinese culture in their history, and other countries and regions, the so-called 'Chinese commonwealth origin', where overseas Chinese or Chinese descendents play an important role in the economy, such as Singapore, Malaysia, Taiwan and Hong Kong. The differences between Western and Asian cultures, including China, have been highlighted by many scholars. For example, one difference is long-term versus short-term orientation and another is individualism versus collectivism (Hofstede, 1994). Long-term orientation 
emphasises values like perseverance and fulfilment of social obligations and reflects a dynamic and future-oriented mentality (Hofstede and Bond, 1998); a collective culture values group harmony, cohesiveness and social objectives (Tse, Lee, Vertinsky and Wehrung, 1988). Generally speaking, as Hofstede (1994) pointed out, Western cultures tend to be more short-term oriented and individualistic, whereas Asian cultures are usually long-term oriented and collectivistic.

Firms' original national culture impacts their management styles (Hofstede, 1980; Peng, 2002). It is argued that Western and Asian firms may advocate distinctive approaches to building relationships. Particularly, research shows that MNCs from other Asian countries tend to behave similarly to Chinese firms in this respect. For instance, these MNCs emphasise networking much more strongly, undertake a long-term network strategy, have a high propensity for relying on strong ties to conduct business, and are keen on building social relations with business partners (Hitt et al., 2002; Peng and Zhou, 2005; Sikorski and Menkhoff, 2000). Chen and Chen (1998), for example, find that Asian firms sometimes utilise their relational linkages to enter China.

To further understand the difference in relationship building between Asian and Western firms, it is helpful to consider the Chinese culture as the starting point. As a typical example of Asian culture, Chinese culture has been widely documented for its strong social network orientation and its emphasis on guanxi in the business context. For instance, Chinese firms tend to foster social ties in business networks, because this can provide them with access to resources and safeguard their business operations (Wu and Choi, 2004). Further, the philosophy of guanxi highlights the cultivation of long-term personal relationships and collectivism, based on social ties between actors (Parnell, 2005). In many cases, therefore, having social bonds becomes a prerequisite to starting a business relationship (Sikorski and Menkhoff, 2000). Although this may make it relatively difficult for firms to initiate new relationships in the market, once social ties or 
guanxi are established, the business relationships become easy to develop and maintain, and hard to terminate (Batonda and Perry, 2003b). Also, Chinese firms tend to rely on their existing guanxi, or social relations and links to cope with market issues (Zhou et al., 2003).

Given the cultural similarity between China and other Asian countries, the features of networking and relationship building of the Chinese firms noted above may be likely to be seen in the foreign firms from an Asian background. In comparison, Western firms are likely to behave quite distinctively from the Chinese, as well as other Asian firms. Despite a notable change in the last decade, whereby Western firms are seen to develop social and cultural proximity to local firms for localised learning and long-term success (Maskell and Malmberg, 1999), their inherent cultural characteristics may not easily change. For example, even though Western firms might be willing to learn about the culture they are exposed to and attempt to create a culture-blend (Batonda and Perry, 2003b), scholars consider that Asian firms can better understand China's informal business rules and are superior in forming and maintaining relationships, reflecting special managerial skills that they have developed over a long period (Hitt et al., 2002; Lee et al., 2001; Nes, Solberg and Silkoset, 2007). As Luo (1999) discussed, this disadvantage could make Western firms less competitive than Asian firms in terms of China-specific knowledge and environmental familiarity. This type of location-specific knowledge can however, be as crucial as technological expertise for firms operating in China (Yeung and Tung, 1996).

Nonetheless, Western firms' preference for applying their own business practices, and low motivation for, and competence in, fostering social bonds in relationships, may not necessarily mean that their network approach would hinder their business success in China. As a matter of fact, Western firms are generally viewed as advanced in technology, managerial skills and organisational capabilities (Luo, 1999). They are, therefore, fairly attractive to local Chinese firms because the latter usually perceive cooperation with foreign firms as an opportunity for 
improvement and are willing to adapt to Western practices (Duanmu and Fai, 2007; Zhou and Xin, 2003). Also, it has to be noted that, despite endowing positive effects, social networks or guanxi alone are insufficient for business success in China (Yeung and Tung, 1996). This is not only because firms' technology and other tangible resources play a crucial role in this respect, but also because guanxi may cause negative impacts on firms as well (Chen and Chen, 2009). As noted earlier, some researchers recommend that in certain circumstances a short-term transactional strategy may help firms to achieve business objectives more efficiently in China (Ramaramay et al., 2006).

Relatively, Western firms are more likely to adopt this type of network approach, because they are inherently less constrained by strong social ties in business (Chen and Chen, 2004).

The above discussion suggests that Asian and Western foreign firms in China may have different relationship development processes. It leads to the following hypotheses in respect to the differences in their economic and social dimensions.

H1a: Western foreign firms form stronger economic ties than Asian foreign firms in their new local business relationships in China.

H1b: Western foreign firms form weaker social bonds than Asian foreign firms in their new local business relationships in China.

H1c: After relationship formation, Western foreign firms have greater growth in their economic ties than Asian foreign firms in China.

H1d: After relationship formation, Western foreign firms have less growth in their social bonds than Asian foreign firms in China.

These hypotheses do not imply that Asian firms do not have to pay attention to issues such as technology, organisational capabilities, and quality that are related to the economic aspect of relationships; nor do that Western firms not emphasise the social content in their relationships. The hypotheses proposed here, and those following, are presented in a relative, not absolute sense. 


\subsubsection{Comparison between small and large foreign firms}

This study considers firms at the subsidiary level. It is the size of subsidiary, rather than the entire $\mathrm{MNC}$, that is investigated. The role of subsidiary size in the MNCs' activities in the local market has begun to draw attention from researchers recently (Chiao, Yu, Li and Chen, 2008; Johnson and Menguc, 2007). A fundamental theoretical perspective in this respect is that larger subsidiaries tend to be more resourceful and capable (Johnston and Menguc, 2007; Prahalad and Doz, 1981). Compared to their smaller counterparts, they usually possess greater competitive advantages, and are more likely to gain competitive positions in local marks (Isobe, Makino and Montgomery, 2000). Thus, it can be argued that the differences between small and large firms may apply to small and large subsidiaries in a MNC context. For the purpose of this research, the China-based subsidiaries are viewed as stand-alone entities ${ }^{7}$. They are established in China by the foreign headquarters and it is assumed that, over time these subsidiaries may develop their own capabilities which allow them to compete in the local market individually (Chiao et al., 2008). These capabilities, according to Chiao et al., may not be necessarily determined by the parent MNCs. The following paragraphs provide insights into the comparisons between small and large subsidiaries, by drawing particularly on the literature relating to small firms.

The literature has outlined comparisons between large and small firms in networking. Even though small firms are not necessarily inferior to large firms, size as a variable has certain explanatory power in terms of competence (Rowden, 2001). Because of a fundamental concern that the less competitive a firm is, the more reliant it needs to be on networks (Peng and Luo, 2000), scholars clearly point out that small firms need to utilise networks to complement their inherent limitations relating to resources and capabilities. Particular recommendations have, therefore, been made for small firms to develop the social elements in their relationships (Klang, Ihlström and Olsson, 2002; Larson, 1992). A similar concern also exists in the social capital literature (Rundh, 2001). Research conducted in

\footnotetext{
${ }^{7}$ The focal firms' MNC background in this study is further discussed in Chapter 7, with respect to the findings.
} 
China further provides evidence that small firms are more likely to be dependent on their surrounding business networks to achieve business success than their large counterparts (Peng and Luo, 2000).

In the international business literature, many studies have reported how small firms utilise network relationships to internationalise (e.g. Coviello and Munro, 1995, 1997; Keeble, Lawson, Smith, Moore and Wilkinson, 1998). To begin with, compared to large firms, small firms are more likely to rely on their social ties in business operations. For instance, research shows that small firms' business decisions related to internationalisation can be influenced by social ties rather than economic factors such as market-seeking and efficiency-seeking, which explains why, sometimes, their behaviours seem to be 'irrational' or not well-planned (Ellis, 2000; Harris and Wheeler, 2005; Wong and Ellis, 2002).

After initial foreign market entry, small firms often continue to encounter challenges such as having less credibility than large firms in foreign markets. To overcome this liability of foreignness, scholars suggest that an effective solution for them is to further develop relationships and nurture social capital to make themselves known and gain access to local resources (Lu and Beamish, 2001; Luo, 1998; Prashantham and Berry, 2004; Rundh, 2001). As Rusashobya and Jaensson (2004) stated, social elements in relation to trust, for example, would help small firms to minimise transaction costs and overcome psychic distance. With regard to the Chinese market, such an approach could be more crucial and practical given the guanxi-oriented culture.

Further, small firms generally have greater vulnerability to business failure than large firms, because of their limited resources (Chen et al., 2004). This may affect their approach to establishing new relationships. Arguably, small firms may be cautious of dealing with the unfamiliar new exchange partners, and tend to foster social bonds which can be leveraged to facilitate business activities and secure business operations (Alder and Kwon, 2002). At the same time, because new 
relationships often involve high uncertainties and risks, small firms may be reluctant to engage in economic exchanges too fast. Chen et al. (2004) for instance, found that, compared to large MNCs in China, small MNCs appear to be less active in developing economic linkages with their local business partners. They further attribute this to the lower level of capability of small firms in absorbing risks associated with developing networks.

On the other hand, even though large firms may adopt a less social and relational network strategy, their economic ties are still likely to evolve rapidly. First, they could be motivated to save time and resources associated with developing social elements to focus on enhancing economic ties with partners. Second, their relatively superior resources and advanced capabilities, plus the large capacity for risk absorption, could assist them to control their relationships and support economic operations through a transactional approach (Koka et al., 2006). This could be viewed as an efficient way of developing business because it allows firms to connect with more actors in the marketplace within a short period of time (Uzzi and Lancaster, 2003).

Overall, the above discussion suggests different approaches for small and large foreign firms in developing their business relationships in China. The resulting hypotheses are stated as follows.

H2a: Larger foreign firms form stronger economic ties than smaller foreign firms in their new local business relationships in China.

$\mathrm{H} 2 \mathrm{~b}$ : Larger foreign firms form weaker social bonds than smaller foreign firms in their new local business relationships in China.

H2c: After relationship formation, larger foreign firms have greater growth in their economic ties than smaller foreign firms in China. 


\subsubsection{Comparison between manufacturing firms and service firms}

Services differ from manufactured goods in that they are often intangible, perishable, and require simultaneous production and consumption (Song, Di Benedetto and Zhao, 1999). Even though these differences may become less apparent for the 'hard' services which share certain common features with manufactured goods (Erramilli, 1990), the literature has strongly suggested that service firms should, in general, undertake a more proactive and relational approach to developing networks and relationships, compared to manufacturing firms. Below, this section sheds light on the distinction of service providers as opposed to manufacturers, and hypotheses relating to their differences in relationships and relationship development are presented.

Scholars acknowledge that a key factor relating to service firms' success is the tailoring of their offerings to meet customer needs and expectations (Lovelock and Yip, 1996; Lovelock, 1999). In practice, this is often addressed through intensive customer contact and extensive customisation (Knight, 1999). This implies that one of the essential characteristics of service firms is their frequent interactions with business partners, especially customers, to seek relevant knowledge (Gordon, Kaminski, Calantone and di Benedetto, 1993), as an important and effective means of enhancing their service quality (Eriksson, Majkgård and Sharma, 1999; O'Farrell and Wood, 1999). From a managerial perspective, these features underline the relative significance of networking and relationship building for service firms, compared to manufacturing firms, because networks would allow them to gather information, acquire customer-related specific knowledge and further seek new partners effectively (O'Farrell, Wood and Zheng, 1998).

Scholars therefore, recommend that service firms should aim to build strong and quality relationships with business partners based on key elements like trust, effective communication, satisfaction and loyalty, for competitive advantage and optimal organisational performance (Eisingerich and Bell, 2008; Eriksson et al., 
1999; Shamdasani and Balakrishnan, 2000). They explicitly emphasise the social content in business relationships (Alon and Mekee, 1999). As Doz (1996) stated, strong business relationships characterised by social bonds are often preferred by service firms during networking because effective interaction with local partners and fast adaptation require cooperative relations, rather than arm's-length transactions. Recent research also produces evidence supporting this statement; Freeman and Sandwell (2008), for example, underline the strategic implications of service firms' social networks.

Scholarly attention to service firms in the field of international business is a relatively recent phenomenon (Grönroos, 1999), although earlier strategists recognised that dealing directly with local customers is crucial for service firms in international markets (Carman and Langeard, 1980). For instance, even until the 1990s, Erramilli and Rao (1993) pointed out that little was known about service firms' internationalisation activities, such as market entry strategies. Over the past two decades, research has however, been devoted to addressing this issue. One major consideration is that networks and relationships need to be emphasised for their role in service firms' international operations. For instance, Erramilli (1990) found that a distinctive feature of these firms is that their existing relationships with customers may be a main driver of the market entry choice. More recently, Freeman and Sandwell (2008) found that service firms' social networks with business actors in a foreign country could act as a basis for the firms' strategic choice of entering the market. O'Farrell et al. (1999) further point out that, after market entry, service firms often face a critical transition from early arrival to subsequent local market development, and struggle between a high requirement for local adaptation and their inability to understand local customers' needs (Reardon, Erramilli, and Dsouza, 1996). These firms should, therefore, emphasise interactions with the local actors, and continue establishing local networks, which might help them to overcome these obstacles, as well as another major the challenge of cultural adaptation (Knight, 1999). In particular, Nicoulaud (1988) has suggested that service firms must build their knowledge about local social 
networks, social acceptance, roles and group identification, as these may assist them in addressing problems and securing their local market performance.

Further, the literature suggests that service firms operating in international markets should perform in a more locally responsive manner than manufacturers (Li and Guisinger, 1992). The nature of services could provide insights into this issue. For example, Lovelock and Yip (1996) note that, although all products, both goods and services, consist of a core element that is surrounded by a variety of supplementary elements, the degree to which the core and supplementary elements may be customised differs greatly between service firms and manufacturing firms. Relatively, the supplementary elements of services are more likely to be adjusted and modified, which provides service firms with greater flexibility in customising their offerings to accommodate different clients. Hence, Lovelock and Yip argue that it is easier for service firms operating in international markets to provide a globally standardised core service augmented by nationally customised supplementary service elements, compared to manufacturers with their respective core product and product element.

One implication of service firms' higher local adaptation and customisation is that they may be capable of developing their economic ties with local actors more efficiently and effectively. In addition, as discussed earlier, service firms' business relationships may be formed with stronger social bonds, which could also facilitate their economic activities with local actors, suggesting greater development in the economic dimension for service firms compared with manufacturing firms. Further, Liu, Leach and Bernhardt (2005) found that service firms are generally more concerned about the possibility of relationship failure with their existing customers, and therefore, keen to continue reinforcing their business relationships after the initial formation. With respect to international markets, Cheung and Leung (2007) report a similar finding; that is that service firms which have been internationalised via a client-following strategy are usually 
highly committed to continually reinforcing their relationships with their clients, by constantly modifying their business operations to suit the clients' needs.

Additionally, as far as the research context for this study - China - is concerned, early research reports that foreign service providers often have a long-term orientation in this host-country (Lo and Yund, 1988). Lately, Ling, Ibbs and Cuervo (2005) identified that foreign service firms tend to regard local network development as an important part of their business strategy in the Chinese market. This also echoes Peng and Luo's (2000) hypothesis that business relationships are more likely to play an important role for foreign service firms than for manufacturing firms. In comparison, Chen et al. (2004) noted that foreign manufacturing firms appear to be quite rational and business outcome oriented in their local networking approach, and have a low risk-taking attitude when building relationships. This may imply that they are less tolerant toward underperforming local actors and more willing to terminate the business relationships with those who cannot meet their business expectations.

Overall, the above discussion outlines the prominent characteristics of service firms in networking and relationship building, compared to manufacturing firms. It may be argued that manufacturing firms tend to pay more attention to developing strengths in technological and organisational capabilities such as quality, pricing and advertising (Barney, 1991; Scherer, 1980), independent of their business relationships; whereas service firms are more relationship-intensive and rely more on external resources and information. The comparison between manufacturing and service firms draws attention in the field of international business (Buckley, Pass and Prescott, 1992). Recently, scholars have suggested further investigating the difference between these two types of firms in terms of network development, especially in the international business context. For example, Mu et al. (2007) consider that it would be meaningful to compare their levels of local embeddedness, given the assumption that service MNCs generally need to be more locally responsive than manufacturing MNCs. Specific attention 
is paid to foreign service firms in China, because both the internal characteristics (the service firms) and external characteristics (the Chinese market) imply the strategic importance of local network development (Wu and Choi, 2004). In line with this emerging research trend, two hypotheses are developed, as follows.

H3a: Foreign service firms form stronger social bonds than foreign manufacturing firms in their new local business relationships in China.

$\mathrm{H} 3 \mathrm{~b}$ : After relationship formation, foreign service firms have greater growth in their economic ties than foreign manufacturing firms in China.

\subsection{The Two-phase Design and Mixed Methodology}

Research questions 1 and 2 are addressed in two sequential phases, respectively. The study, therefore, is in response to the model of two-phase design described by Creswell (1994) and Creswell and Clark (2007). Particularly, the main objective of Phase 1 is to explore how foreign firms operating in China develop their business relationships with respect to the economic and social dimensions. In Phase 2, the objective is to examine the differences between different types of foreign firms in relationship development, from the two-dimensional view.

A qualitative approach is adopted in Phase 1. First, this is because a qualitative approach can yield rich and descriptive data allowing researchers to understand the details and context related to the central research issue (Gall, Gall and Borg, 1999; Gay and Airasian, 2000; Mason, 2002). Second, as discussed in this chapter, the two-dimensional view is somewhat implicit in the literature, despite the acknowledgement of the economic and social nature of relationships. In other words, how firms deal with their economic and social dimensions in the relationship development setting remains under-researched. To gain familiarity or insight into such a phenomenon that is not fully investigated and described, a qualitative approach is appropriate (Eisenhardt, 1989; Schmitt and Klimoski, 1991). Likewise, Edmondson and McManus (2007: 1177) indicate that, from a 'methodological fit' perspective, "the less is known about a phenomenon in the organisational literature, the more likely exploratory qualitative research will be a 
fruitful strategy". In Phase 2, a quantitative approach is adopted, and specifically, multiple regression analysis is undertaken to test the hypotheses stated previously.

According to Creswell (1994), researchers who use a two-phase design need to establish a linkage between the two phases. In this study, the two phases are closely linked. Relationship development is explored in Phase 1 qualitatively, and the findings are expected to provide rich insights into the uneven development of firms' economic ties and social bonds in their relationships, enabling the researcher to examine and justify the two-dimensional view. Phase 1 thus contributes to the conceptual base on which the hypotheses tested in Phase 2 are formed, that is, examining relationships by the economic and social dimension is an effective approach; the testing of the hypotheses also extends of the application of the two-dimensional view to specific situations.

The study, as described above, undertakes a mixed methodology approach to address the overarching research problem. A number of different names have also been given to such a research strategy. As Denscombe (2007) summarised, 'mixed methods', 'multi-strategy research', 'integrated methods' and 'combined methods' are just some of the alternatives. Central to this approach is to use qualitative and quantitative approaches within a single research project. In recent two decades, scholars have shown increasing interest in mixed methodology. They discuss the merits of combining qualitative and quantitative approaches in a single study with a particular focus on the distinctive features of the data. It is argued that the "soft, flexible and subjective" qualitative data and "hard, fixed and objective" quantitative data (Halfpenny, 1979: 799) can often supplement each other, so that the weakness associated with one type of approach may be compensated by the strength of the other (Marshall and Rossman, 1989). Eisenhardt (1989: 538) for instance, discusses that, "the qualitative data are useful for understanding the rationale or theory underlying relationships revealed in the quantitative data", while "quantitative evidence can indicate relationships which may not be salient to the researcher". This further suggests that the use of more 
than one method can enhance the research findings by providing a more complete picture of the object that is being studied (Denscombe, 2007). As far as the present study is concerned, the qualitative data will contribute to the interpretation of the quantitative findings, which is discussed in Chapter 7. In addition, since qualitative data are generally in-depth and contextual, scholars consider they can help a researcher to identify variables and instruments that underpin the following quantitative analysis (Creswell and Clark, 2007). This is also described by Miles and Huberman (1994) as the linkage between qualitative and quantitative data. Likewise, Edmondson and McManus (2007: 1177) also state that, "a mix of qualitative and quantitative data leverages both approaches to develop new constructs". Hence, although the qualitative phase in this study is primarily intended to examine the two-dimensional view, valuable findings on the constructs and measurement of relationships are expected to result.

Overall, the research questions are addressed in two sequential phases in this study. Such a two-phase type design helps the researcher to better understand the phenomenon being tested or explored (Creswell, 1994), which, in this study, concerns the overarching research problem: foreign firms' business relationship development in China. Meanwhile, the mixed methodological approach provides the researcher with comprehensive findings about the research problem, and permits the researcher greater understanding of these foreign firms' business relationships in China, with regard to the economic and social aspects. With regard to the qualitative-quantitative sequence, it is consistent to Punch's (2005) statement that how the two approaches are combined should be determined by the reasons for doing so, which is described in this section.

\subsection{Chapter Summary}

Based on a review of the literature, a two-dimensional approach is introduced in this chapter as a way view and analyse business relationships. This approach allows for the investigation of the relationship development process by separately examining changes in the economic and social dimensions. In line with this 
conceptual approach, the research questions are presented to address the overarching research problem - relationship development of foreign firms operating in China. The questions are intended to generate insights into the development of the economic and social dimensions of firms' relationships. Three groups of hypotheses are developed and presented in this chapter, in order to address differences in relationships and relationship development of different types of foreign firms in China. Also, the two-phase design and mixed methodology adopted in this study are discussed in the context of the research questions to be addressed.

The next chapter sheds light on the qualitative phase of the study in particular. The qualitative field work, data analysis procedure, and the main qualitative findings relating to the overarching research problem are reported. 


\section{Chapter Four The Qualitative Phase of the Study}

\subsection{Chapter Objectives}

This chapter focuses on Phase 1, the qualitative component of the study. It describes the qualitative methodology used in this phase, reports the data collection process and the sample characteristics, and explains the techniques used for the data analysis. Thereafter, the key findings are presented, followed by a discussion of the business relationships involved in this part of the study, which are characterised by distinctive combination of economic and social nature.

\subsection{Qualitative Methodology}

This section addresses the methodological aspects in Phase 1. It highlights the objectives and introduces the research design. Then, it describes the procedure for recruiting participant firms, and reports the sample profiles. The interview process along with the interview protocol is introduced, followed by a presentation of the various types of relationships covered during the interviews.

\subsubsection{Objective and design in Phase One}

A researcher who uses the two-phase design model addresses specific issues in each phase (Creswell, 1994). In this study, Phase 1 is intended to address the first research question, by obtaining a broad understanding of foreign firms' relationship development in China, with respect to the economic and social dimensions. In the meantime, Phase 1 is expected to contribute to the conceptual basis of the study, i.e. the two-dimensional view, by producing evidence of the uneven development of economic and social dimensions in firms' relationships.

As discussed earlier, firms' relationship development in China can be complex, as it often involves not only economic exchanges, but also deliberate social networking. In such a background, a multiple-case design is adopted, to allow the researcher to use replication rather than sample logic to overcome the limitations of generalisation from a single case study, and permit replication and extension of 
individual cases (Eisenhardt, 1989, 1991; Yin, 1994). Also, multiple cases can enable a broader exploration of the research questions and theoretical elaboration (Eisenhardt and Graebner, 2007). Compared to a single case, they add confidence to findings, and are more compelling, as they can strengthen the validity and stability of the findings (Miles and Huberman, 1994).

\subsubsection{Sampling and firm recruitment}

Between March and April 2008, fieldwork was conducted in China in Phase 1 of the study. The researcher sought participant firms mainly in Shanghai, the most economically developed metropolis in China. Three criteria were complied with to identify candidates from subsidiaries of foreign MNCs in China: different cultural background, different in their size, and operating in different industry sectors. They correspond to the hypotheses formed in Chapter 3, as well as the three explanatory variables that are used in the quantitative analysis in Phase 2. The rationale for choosing such a deliberate sampling plan was twofold mainly. First, the researcher aimed to select diverse firms that were closely related to the central research question of the study (Eisenhardt, 1989). Second, the researcher aimed to select cases that could accommodate the variables of interest to the study (Ghauri, 2004). In addition, firms were expected to have entered the Chinese market from year 2000 onwards, in order to make sure they had experienced a similar period of time to develop their local networks.

Two methods were undertaken to gain access to firms. First, from a range of public sources including local yellow pages, industry associations, Chamber and Commerce, and professional recruiting websites, approximately 35 potential participants that met the criteria were identified in the Shanghai region. These firms were contacted by the researcher by phone. The initial contact person was generally the firm's administrator and sometimes personal assistant of the CEO or General Manager. The researcher explained to them the objective of the study, and then provided them the research documents - Research Introduction and Consent Form (see Appendix 1 and 2) - by fax soon after the phone conversation. 
The documents were sent to the senior managers, such as the General Manager and CEO, or someone who was advised specifically by the initial contact person. Follow-up calls were made a week later to find out if the managers were willing to accept the invitation to participate in the research. Second, being aware of the difficulty in accessing firms in China for academic research, as noted by others (e.g. Peng and Luo, 2000; Zhou et al., 2007), a referral-based approach was undertaken to seek access to companies through a third-party. The researcher approached people known to him who were able to introduce the researcher to senior managers in foreign firms through their connections. These people acted as intermediaries between the researcher and potential interviewees. They recommended twelve firms and passed on the information about the research to the managers. These twelve firms were located not only in Shanghai, but also in Suzhou and Nanjing ${ }^{8}$, all complying with the same criteria mentioned earlier. Then, the researcher initiated the contact with the managers via phones and emails, to further introduce the research project and invite them for an interview.

Eventually, eight firms agreed to participate in the research, and the referral-based approach contributed five of them. Among these eight firms, seven of them were located in Shanghai, and one was located in Nanjing. The information of these firms and the interviewees is shown in Table 4-1. As a result of the deliberate selection method, the sample contains firms with a different background in terms of nationality, size, and industry sector. Such diversity can facilitate a relatively comprehensive understanding about foreign firms' relationship development in China. Also, despite the similar length of operations in China of these firms, the interview data reveal that they were in very different business situations. Some had been growing rapidly and had already become the market leader. Some had recently been through radical organisational changes, such as redesigning of the corporate strategy, and mergers and acquisitions, whereas some were still at a very early stage of business development, facing a range of different challenges. For more detailed background of these firms, please refer to Appendix 3.

\footnotetext{
${ }^{8}$ Suzhou and Nanjing are both economically developed cities and located approximately 100 and 200 kilometres away from Shanghai, respectively.
} 
Table 4-1 Characteristics of the interviewed firms

\begin{tabular}{|c|c|c|c|c|c|c|c|}
\hline Firm name ${ }^{1}$ & Year est. & Major business / Industry sector & Nationality $^{2}$ & Ownership & FTEs & Interviewee & $\begin{array}{c}\text { Cultural background of } \\
\text { interviewee }\end{array}$ \\
\hline WATERHEAT & 2000 & $\begin{array}{r}\text { Water heaters and boilers } \\
\text { manufacturing }\end{array}$ & US & WOS & 3000 & $\begin{array}{r}\text { Vice President-China, } \\
\text { CEO }\end{array}$ & $\begin{array}{l}\text { Chinese living in the US } \\
\text { for more than } 15 \text { years }\end{array}$ \\
\hline DATABASE & 2005 & Commercial database & US & $\mathrm{JV}$ & 170 & Sales Director & Local Chinese \\
\hline VIDEOCON & 2001 & Online video conferencing & US & WOS & 120 & $\begin{array}{r}\text { Sales Director in Asia } \\
\text { Pacific }\end{array}$ & Singaporean Chinese \\
\hline HRCONSULT & 2003 & $\begin{array}{l}\text { HR management consulting, } \\
\text { executive recruitment }\end{array}$ & Belgium & WOS & 18 & CEO, General Manager & Belgian \\
\hline HOTEL & 2002 & Hotel management group & US & $\mathrm{JV}$ & 350 & $\begin{array}{r}\text { Regional Director of } \\
\text { Great China }\end{array}$ & British \\
\hline EVENT & 2006 & $\begin{array}{r}\text { Event management, corporate } \\
\text { image consulting }\end{array}$ & Germany & $\begin{array}{l}\text { Rep. } \\
\text { office }\end{array}$ & 28 & $\begin{array}{l}\text { Managing Director, } \\
\text { Chief Representative }\end{array}$ & $\begin{array}{r}\text { Chinese living in } \\
\text { Germany for more than } 5 \\
\text { years }\end{array}$ \\
\hline ANIMATION & 2006 & Online game programme developer & US & WOS & 45 & $\begin{array}{r}\text { Business Development } \\
\text { Director }\end{array}$ & Local Chinese \\
\hline SOFTWARE & 2005 & Management supportive software & HK & WOS & 10 & Marketing Director & Hong Kong Chinese \\
\hline
\end{tabular}

${ }^{\mathrm{T}}$ Names of the interviewed firms were modified to ensure the confidentiality of the research.

${ }^{2}$ Despite the diversity in nationality of the sample, the researcher acknowledges that1) the sample was to some extent US-dominant and 2) there is imbalance between Western and Asian firms. 


\subsubsection{Research instrument and the interview process}

Semi-structured interviews were conducted in Phase 1 to collect rich, empirical data from the eight firms, to help develop an understanding of the complex phenomenon (Yin, 1981), which, in this case, concerns interfirm business relationships. An interview protocol was initially developed in English, and then translated into a Chinese version. The Chinese version was further back-translated into English, according to Brislin (1980) and Douglas and Craig (2007), by two colleagues of the researcher to ensure consistency of meaning. A similar approach has been undertaken by other scholars who have conducted research in China (e.g. Wu, 2008; Xin and Pearce, 1996). Following advice from Park and Luo (2001) that consultation with local practitioners via informal testing can be very helpful to develop interview questionnaires for research in China, two pilot interviews were conducted with local business people in Shanghai using the Chinese version questionnaire, before interviewing the managers from the eight firms. Some minor changes and modifications were made to the original interview protocol, to make the questions more precise and logical for the interviewee.

The finalised version of the interview protocol contained three main sections (see Appendix 4). The first section included a brief introduction of the research and questions about the firm's overall business operations in the Chinese market. This provided background information on the firm's growth, performance, problems, and so on, that also helped to identify valuable topics for further inquiry. The second section shifted focus onto business relationships and explored the interviewee's understanding of their relationships with local business actors. In the third section, the researcher paid close attention to the firm's relationship practices with its exchange partners, mainly customers and suppliers, in terms of aspects such as selection, maintenance and development. The economic and social contents of relationships were of primary interest. Specific aspects included: How the firm usually sought potential exchange partners and then initiated the relationships; if and how economic exchanges changed over time; how the firm described its trust in and commitment to other business actors; to what extent the 
firm considered that social relations played a role in its current relationships; what were the main sources of the social elements of its relationships; and what was the firm's attitude toward developing the social elements.

During the interview process, the meaning and content in respect to the economic and social aspects of relationships were carefully interpreted, as this could contribute insight into the constructs and measurement of the two dimensions. Additionally, extreme cases of firms' relationships were probed, in line with Eisenhardt's (1989) suggestion. Managers were invited to recall examples of successful business relationships and relationship failures. Follow-up questions were raised where appropriate, in keeping with qualitative research practice.

All the interviews were completed by the researcher in person in a face-to-face setting with the interviewee. Interviewees were the CEOs, the General Managers and senior directors of the firms, who were considered to have the best knowledge in terms of overseeing the firms' networks and business operations in the local market. Both languages - English and Chinese - were used across these interviews, depending on the interviewees' preference. Three were in English and five in Chinese ${ }^{9}$. The length of time taken for the interviews varied from one to two and half hours. All were tape recorded with the interviewees' permission. Notes were taken during the process to assist data analysis later on.

\subsubsection{Business relationships of the firms}

Although the primary focus during the interviews was on firms' business relationships with their local exchange partners including mainly customers and suppliers, the interviewees occasionally extended their conversation to other relevant network actors, such as the government departments, their firms' headquarters, and other types of alliances. Data for these additional types of relationships provide contextual information about the networks in which these

\footnotetext{
${ }^{9}$ Transcription from the interview tapes was completed soon after the interviews. Following the approach adopted by other researchers (Park and Luo, 2001; Peng and Luo, 2000; Zhou et al., 2007), the Chinese transcripts were translated into English for data analysis.
} 
firms were operating, even though they are not analysed in this study. A general representation of such an egocentric network of the firms is illustrated as follows (see Figure 4-1), based on the summary of the relationship types referred by the firms during the interviews. As described in Chapter 2, an egocentric network has the focal firm sitting at the central position of the network, and is concerned with the actors only directly connected to the firm, as well as those connecting relationships (Hite and Histerly, 2001). Egocentric networks are often the strategic focus of the firms (Todeva, 2006).

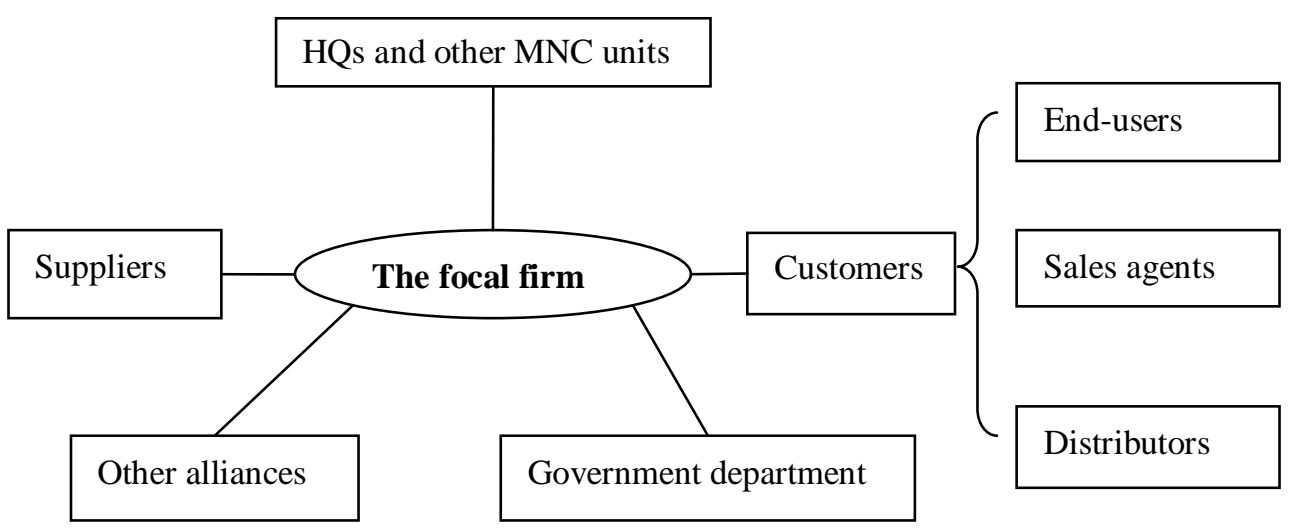

Figure 4-1 A generic representation of firms' egocentric business network

The figure is intended to provide a comprehensive picture on the focal firms' networks. However, the actual pattern of each firm's business network could vary, subject to its business operation modes. In other words, some actors described in the figure may not necessarily exist in some firms' networks. For example, firms dealt with the end-users directly did not necessarily have relationships with the sales agents and distributors. Also, firms could have distinct emphases on these relationships. Some, like the manufacturer, interacted with suppliers frequently, while the service providers tended to pay much less attention to suppliers, and more to customers. As a result, the interviewees also tended to emphasise different types of relationships during the interviews. Table 4-2 summarises the relationships that were discussed by the managers in regard to each firm. 
Table 4.2 Relationships discussed in interviews

\begin{tabular}{rccccccc}
\hline & SPL* $^{*}$ & DTT* $^{*}$ & SLA* $^{*}$ & EUS* $^{*}$ & GVT* $^{*}$ & ALC* $^{*}$ & HQS* \\
\hline WATERHEAT & $\bullet$ & $\bullet$ & $\bullet$ & & $\bullet$ & & $\bullet$ \\
DATABASE & $\bullet$ & & $\bullet$ & $\bullet$ & $\bullet$ & & $\bullet$ \\
VIDEOCON & & & & $\bullet$ & & $\bullet$ & $\bullet$ \\
HRCONSULT & & & & $\bullet$ & & & $\bullet$ \\
HOTEL & $\bullet$ & & $\bullet$ & $\bullet$ & & & $\bullet$ \\
EVENT & $\bullet$ & & & $\bullet$ & & & $\bullet$ \\
ANIMATION & & $\bullet$ & & & & $\bullet$ & $\bullet$ \\
SOFTWARE & & & $\bullet$ & $\bullet$ & $\bullet$ & $\bullet$ & \\
\hline
\end{tabular}

*SPL: supplier; DTT: distributor; SLA: sales agent; EUS: end-user; GVT: government department; ALC: alliance; HQS: foreign headquarters

\subsection{Coding and Data Interpretation}

Qualitative data analysis, unlike quantitative data analysis, does not happen only after the data are collected, but begins from the time of data collection to the end of writing of the results (Miles and Huberman, 1994). As Creswell (1994) described, it is a multi-functioning process involving collecting the information from the field, sorting the information into categories, formatting the information into a story, and writing the qualitative text. This section focuses on data reduction, i.e. coding, and data interpretation, as data collection has been addressed in the previous section; the written text is presented in the following results section.

\subsubsection{Data reduction $\left(\right.$ coding $\left.^{10}\right)$}

In qualitative data analysis, codes are used to organise the data and information. The main process of coding is to reduce the data and sort them into categories for subsequent analysis (Miles and Huberman, 1994). It can therefore, be regarded as a de-contextualisation process (Creswell, 1994). However, scholars warn that

\footnotetext{
${ }^{10}$ The Computer programme, NVivo 8.0, was used to assist the coding process. NVivo allows the researcher to not only categorise the data subject to the established nodes efficiently, but also deal with the emerging themes of the data flexibly by creating new nodes. Also, by using this computer programme, the researcher was able to address the multiple coded data efficiently - data that are coded into multiple codes (Miles and Huberman, 1994).
} 
researchers must not summarise the data too tightly for risk of losing rich contextual detail (Eisenhardt and Graebner, 2007). To deal with the voluminous data yielded from the eight interviews, Eisenhardt's (1989) and Creswell's (1994) recommendations were followed in Phase 1. According to these two scholars, the key to coding is to select the main categories and themes of the data relevant to the central research problems and inquiries, and then segment the data on this basis, so that the main findings can be captured and important contextual data are kept.

Hence, the data for firms' local business relationships were coded in the way that the central two-dimension proposition could be derived and supported. The overall coding process involved three steps. First, a preliminary coding structure was established prior to the coding process, in response to the primary objective of Phase 1. It included a number of descriptive codes such as 'relationship with strong economic ties', 'relationship with weak economic ties', 'relationship with strong social bonds', and 'relationship with weak social bonds'. It also included other descriptive codes like 'firms' actions associated with relationships', 'firms' perceptions of relationships', and 'motivations' that explained firms' specific behaviours with regard to relationships. Then, as the next step, the data were coded into these existing codes.

Second, as coding was undertaken for each case, variations for the codes were made to accommodate the new emerging issues, reflecting the learning process of the researcher associated with the qualitative data analysis procedure (Miles and Huberman, 1994). For example, some codes were separated for further differentiation, and new pattern codes were created to provide more valuable information relevant to the central research questions. Examples of these new codes included such as 'external business environment' of firms, 'causal link' indicating the linkage between factors and firms' preference to different types of relationships. Additionally, the data for the prominent relationship components for instance, interfirm trust and interfirm communication, were coded to allow the 
researcher to understand the meaning of relationships in the specific research setting. Third, after these two steps of coding, all the codes were revisited. Some codes that did not contain particularly relevant information were discarded, and some codes were converged with others because of their relevance and similarity of the data.

The coding process described above allowed the researcher to highlight the crucial data that were the most relevant to the central inquiries of the qualitative study, and also to retain the rich and contextual data about the background of the relationships and the interviewed firms, which was critical in terms of understanding firms' rationale for the relationships. Overall, this phase provided rich contextual data and a platform for understanding the two dimensional view of relationships in the context of foreign firms operating in China; these outcomes contributed directly to the subsequent quantitative component of the study in phase 2 , and assisted in the interpretation of some quantitative findings.

\subsubsection{Data interpretation}

Data interpretation in Phase 1 was conducted based upon multiple cases, also called cross-case analysis (Miles and Huberman, 1994). The aim of using crosscase analysis is often to understand how a phenomenon is qualified by local conditions, and then to develop more sophisticated descriptions and powerful explanations across multiple cases. In this study, cross-case analysis allows the researcher to deepen the understanding of relationships by examining the data in divergent ways, and to seek the explanations for emerging issues and findings from varying perspectives of firms. In the meantime, drawing on a group of firms, cross-case analysis can help the researcher to avoid the 'danger' that "investigators reach premature and even false conclusions as a result of [these] information-processing biases" (Eisenhardt, 1989: 540).

The study follows Miles and Huberman's (1994) recommendations for conducting data interpretation. Essentially, the researcher attempted to understand in general 
terms the extent to which the economic and social nature of firms' business relationships exist in an even or uneven manner. The data, after their reduction to the topics and categories indicated earlier, were examined in-depth to identify relationships featured by distinct economic and social contents, and the firms' motivation and rationale for their approaches to these relationships, for the purpose of describing and explaining. In addition, the descriptive data for relationships, such as 'interfirm actions' and 'firm's perceptions', were analysed in order to provide a detailed understanding of the nature of relationships, as this might relate to the measurement of economic ties and social bonds, which is a key task in the following quantitative phase.

\subsection{Qualitative Findings}

Eisenhardt and Graebner (2007) point out that key to reporting the qualitative findings in a written form is to avoid readers' confusion by showing that the overall approach is clear and the objective is straightforward. They offer two pieces of advice on this aspect: first, researchers can divide their writing into sections to support the distinct propositions by empirical evidence; second, researchers can make use of the qualitative data strategically by categorising them to support specific arguments and propositions, rather than organising the data into cases and using replication logic to build the theory. The second piece of advice is related to the cross-case analysis, because it is infeasible to present a complete and unbroken narrative of every case in multiple-case study analysis. Based on these two sets of advice, the main qualitative findings of Phase 1 in relation to the two-dimensional view are reported. These findings suggest the separation between the economic and social dimensions, and further, four categories of relationships defined by economic ties and social bonds.

\subsubsection{Distinctive emphasises on the economic and social dimensions}

The data show that developing the economic and social components are the two primary themes in firms' relationship management. This is consistent with Li's (2005) description that interfirm business relationships in China are an integration 
of traditional social based managerial ties and the modern management philosophies. What is worth noting however, is that the firms carefully distinguished the social bonds from economic ties, and deliberately controlled the degree to which these two dimensions were developed. The Director at WATERHEAT described managing some of their relationships in the following way:

"Our company chooses a scientific and professional approach to manage the suppliers. We have been trying to prevent guanxi with them (suppliers) in relationships, because we do not want personal and emotional elements to affect our business operations."

Likewise, HOTEL had large projects with its contractors, mainly designers and builders. The Director described their relationships as follows:

"We do have a lot of businesses with them (contractors) and sometimes a single project could be valued at several million RMB (1RMB=0.15USD), and take up to three years to complete. We enjoy working with them and like to maintain the relationships in a long-term, particularly with those capable and competitive ones. However, we usually don't socialize with these contractors, and prefer everything sorted in working hours and in office. In fact, we don't want them to view us as their 'friends'. Instead, they should understand we are their customers who give them jobs. If they appreciate the opportunities and deliver us the best result, that's the best relationship for us. Frankly, I would not regard them as our 'partners', although we have very cooperative working relationships."

On the contrary, firms may emphasize the social bonds in order to maintain some relationships. The manager at DATABASE discussed the importance of building interpersonal ties. He said that, 
"We required our sales representatives and managers to visit our clients on a regular basis, even though there is not 'much' going on. When we visit them, we don't have to talk about business, but something more private. In China, we must know how to sell ourselves first, in order to sell the products."

Similarly, despite the intentional control of interpersonal and emotional elements in relationships with contractors, HOTEL strived to enhance the social bonds in relationships with its investors. As the informant described:

"We certainly interact with them (the investor owners) a lot. To me, they are our real partners. Relationships with them are like marriage, and can last forever."

From the above, it can be seen that the development of the social dimension is largely a managerial issue and subject to the firms' objectives with their exchange partners and their perceptions on the 'need' for having social relations. With some suppliers, for example, firms may not be willing to invest, or be engaged, in nurturing social bonds, because, first, this may not create any extra value for them, and second, this could lead to unexpected outcomes.

\subsubsection{Four categories of relationships}

In line with the previous section, four categories of relationships are identified, reflecting firms' distinctive emphases on the economic and social dimensions.

\subsubsection{Relationships with weak economic ties and social bonds}

Some of the interviewees discussed relationships that were weak in both the social and economic dimensions. Such relationships involved low volumes of economic transaction and resource exchange, and exchanged information that allowed both parties to understand each other's expectations, but little else. Mutual trust existed, but was limited, and based merely on both parties' market capabilities that pertained to the completion of business tasks. Similarly, only short-term 
commitment that was strictly related to the specific business project could be noticed. In this type of relationship, firms did not view the other party as 'one of us'; neither did they rely greatly on the other party for market success.

The interview data suggest that, not surprisingly, firms tend to manage newlyformed relationships by the above approach. Concerns about potential risks and limited knowledge about the partner makes it a rational choice to start cooperation on a trial basis and in the context of a relatively prescribed business task. For example, when HOTEL came into contact with potential new suppliers, it examined their portfolios and investigated their background. According to the manager, the firm would only offer small contracts to new suppliers, while large contracts were normally allocated to familiar and trusted partners, who were already on the firm's supplier list.

Although this approach to managing relationships at an early stage of development seems to be typical, as described by previous scholars (Dwyer et al., 1987), the study enriches the literature by providing the China-specific insight. Mainly, the data suggest that an underlying reason for foreign firms to engage in this type of relationship is their limited local network resources and knowledge about China. As a result, they must extend their networks actively, and explore new opportunities for sourcing quality services and materials, along with selling their own products and services, despite the high risk associated with new relationships. Thus, as a standard procedure, such firms often start relationships cautiously, and large investments are made only after the initial cooperation generated a positive outcome and partners proved themselves to be capable and trustworthy. For example, EVENT's first contract with a local state-ownedenterprise (SOE) was priced at only RMB 20,000 (approximately USD 3,000), which was undoubtedly a very small project, compared to the norm for the firm, and the profit was negligible. According to the CEO, 
"This is the first time we have worked with a large SOE. I don't mind how big the business is right now and how much profit we can make. I would just like to find out if our services and expertise would suit them and create benefit for them."

On the other hand, the client was expressing interest in the firm's services, but was not totally convinced, in terms of the potential benefits. Thus, both parties felt comfortable about starting their relationship on a small scale, as an experiment and involving little failure risk.

Firms sometimes may maintain relationships at this status for a long time, meaning that there is little or no growth in the economic aspect, and the social bond is retained at a low level to just keep the connection 'alive'. The Marketing Director of DATABASE described a type of customer that only purchases partial services from the firm approximately every two years, noting that these customers did not have full demand for DATABASE's services, due to their operational models. Nonetheless, the firm did not ignore these customers, calling them "repeated customers without a long-term contract", and noting that "you never know when they might have similar demands again, or they could have other new demands that our company can satisfy". The Director further noted that "followup phone calls or maybe a visit once a year can be helpful to make sure they would come back to us". This is an example of how firms retain their small customers in the competitive Chinese market. They do not give up on the small customers; neither do they manage them through purely discrete ties. Rather, they attempt to at least maintain the current level of economic cooperation, and ensure there is a minimal level of social bonds between them.

\subsubsection{Relationships with strong economic ties and weak social bonds}

Despite the Chinese context which would be expected to encourage the development of social bonds, interviews with foreign firms operating in China revealed evidence of relationships that were characterised by high economic and 
low social content. Participating firms carried out high volume and frequent transactions, or cooperated on a large project. They trusted each other's capabilities with respect to offering quality products or services, and had strong commitments to continuing the relationship under the current conditions. However, they clearly held the view that 'business is business' and their social bonds were maintained at a very low level. For example, managers of the businesses did not socialise, and rarely formed strong personals ties with people in the other firms, keeping each other at a distance.

For example, as indicated earlier, WATERHEAT described developing this type of relationship as a "scientific and professional" approach to managing its suppliers. The firm explicitly aimed to prevent guanxi in relationships with suppliers, and did not allow personal and emotional elements to affect business operations. To this end, all of WATERHEAT's suppliers were managed by a special team consisting of members from different departments who were rotated off the team every three months. In addition, the firm only signed year-long contracts with its suppliers, and required them to engage in an annual re-bidding process. According to the CEO, this method not only pushed the existing suppliers to continuous improvement, but also ensured that the firm acquired the best products and services in the market, helping it to remain competitive.

Likewise, despite the high financial value of projects and deep trust in suppliers' competence and capabilities, in the relationships between HOTEL and its suppliers, the development of social bonds did not appear to be symmetric with the strong economic ties. In other words, the relationships were managed in a strictly contractual way.

Some firms also managed their relationships with customers via such an approach. VIDEOCON for example which was working to establish a 'technology-driven' corporate image in the market did not prioritise building personal and social relations with its customers. According to the Director, although the firm did not 
discourage its sales people from socialising with customers, "the worst case would just be having some dinners and entertain them a little bit". As he further explained, this was mainly because the firm aimed to establish an efficient corporate image and promote a belief that "things can be done efficiently on the web", whereas too many social activities and personal-level contacts with customers would not be helpful in this regard, and even be detrimental to what the firm was working to portray in the market.

ANIMATION provided another example of how this type of relationship could result from a firms' strategy for cooperation. The firm built an alliance with an online gaming company, for internet distribution. The contract was valued at RMB 15 million (approximately USD 2.2 million), and had a two-year duration. However, the Director did not regard this alliance be built on a strong relationship, and saw little probability for long-term cooperation. This was mainly because, in the longer term, ANIMATION's headquarters was primarily interested the B2C market in China, so the subsidiary's cooperation with this partner was only for the short term, and highly unlikely to be extended past the current contract. In this project, the two parties were driven purely by economic motivations, and had only a temporary loyalty to each other. The relationship was not embedded, and involved a minimal social dimension.

In short, the data provide evidence that some relationships are very cooperative and generate substantial economic outcome for both parties, but they demonstrate little social involvement, and are dominated by contractual governance. Firms may deliberately choose to engage with business partners through this type of relationship in some circumstances.

\subsubsection{Relationships with weak economic ties and strong social bonds}

Relationships may have strong social and weak economic aspects, although this appears to be the least-represented category. HRCONSULT described the 'soft' marketing approach it employed to seek out new customers. Its relationship 
development approach for clients seemed to be largely based on building strong social ties. For example, the CEO attended social occasions organised by groups such as the Chamber of Commerce, to meet other foreign expatriates in Shanghai. The CEO reported that this was an effective approach to identifying potential clients, and that some of the connections created in this manner even resulted in the taking of holidays together. The CEO revealed the rationale for undertaking such an approach:

\footnotetext{
"As consultant, we often have to create clients' demands for our services, by identifying their underlying problems that they do not yet realise. This requires us to obtain critical information about them (the clients). We don't get this information through formal channels such as meetings. So, we have to stay close to them, listen to them carefully and then analyse... We always bring a private ear and a business ear, and this is how to do business in this industry."
}

Fierce market competition may provide a motivation for companies to enhance their social bonds with clients, especially in the service sector. As the CEO of HRCONSULT continued to note, there were approximately 6,000 recruiting agents in Shanghai. Even though the firm made great efforts to differentiate itself from its competitors, customers still had strong bargaining power and a great deal of choice. In this scenario, having a social tie with the senior managers of potential customers' could be extremely valuable, and serve as a competitive advantage for the firm.

HRCONSULT's intention to develop social relations with potential and existing clients was clear. However, strong social bonds did not always guarantee the winning of a big contract for the firm, for various reasons. For example, clients may have already been using another service provider, they may currently have limited budgets allocated for the professional service that the firm provides, or they may not entirely trust the firm's capability and competence, despite the 
existence of social trust. Therefore, HRCONSULT often had to start with small projects, such as psychological assessments or niche consulting work. The CEO indicated that this was a normal part of the process of developing business. Usually, the firm continued to maintain its social bonds with current and potential customers, and waited patiently for opportunities. In the meantime, through small projects, the firm had the chance to demonstrate its capabilities and competences to its clients. As the CEO noted, this could be perceived as the early stage of the relationships, and it was critical not to let customers down.

\subsubsection{Relationships with strong economic ties and strong social bonds}

Evidence of relationships that are strong with respect to both economic and social dimensions was found in several of the case firms. These relationships were welldeveloped and replete with social capital. As already described, WATERHEAT's relationships with its two chain-store distributors provides a good example. According to the CEO, these two distributors contributed nearly 50 per cent of the firm's sales revenue. To achieve efficiency in the cooperation, the firm adapted its organisational structure and management procedures to suit the needs of these two partners. Social bonds can also be observed in the CEO's statement:

\footnotetext{
"In terms of the sales volume in their (the distributors) stores, our company is certainly incomparable to those home appliances manufacturers of refrigerators, televisions, and washing machines. However, they invite me to give a speech at their New Year party every year as the representative of all suppliers. In China, this means huge face and great honour. Many other suppliers cannot understand, and wonder why and how I have such a good relationship with them."
}

In another example, DATABASE had a number of clients that accounted for approximately 60 per cent of its revenue. The firm aimed to not only maintain the current economic relationship, but further develop it by exploiting these customers' underlying demands for other products and services. Substantial 
amounts of time and resources were invested in these key accounts and the firm formed a special team dedicated exclusively to these accounts. This indicates adaptation in terms of human resources, organisational structure and managerial procedure. Frequent interactions, including on-site visits, were regarded as very important. The Director was clear about the fact that these interactions were not only for business issues, but also to build personal ties: "when you visit them, you don't always have to talk about business, but something more private”. Creating friendships was viewed as crucial: "to sell products, you must know how to sell yourself first".

Another example of this type of business relationship, having strong economic ties and strong social bonds was seen between HOTEL and its investors, who undertook substantial investments on building hotels under the firm's brands. According to the Director, such a large-scale project involves extensive and numerous interactions, and requires strong mutual trust and commitment. For successful cooperation, the parties had to reach agreement on many critical issues, such as the location, size, style and operations of hotels. All of these issues had to be discussed openly and clarified from the beginning of each project. The Director perceived strong social bonds as important, because they would enable both parties to know each other better, which, in turn, would facilitate economic cooperation. As described by the Director: "They (the investors) are our real partners. Relationships with them are like marriage, and can last forever".

\subsubsection{Additional findings on economic ties and social bonds}

As indicated earlier, Phase 1 also aimed to build contextual meaning of the economic and social aspects of relationships from the firms' perspective, within the particular Chinese context. During the data interpretation process, the rich and contextual qualitative data offered further insights in the elements of the economic and social dimensions, as summarised briefly in Table 4-3. These elements relate to a number of aspects of business relationships, including, for example, firms' economic exchanges, socialisation, communication, trust and commitment. They 
provide an important input into a key aspect of Phase 2 of the study - clarifying the constructs and measurement of the economic and social dimensions.

Table 4-3 A summary of qualitative findings on economic and social elements

\begin{tabular}{|c|c|}
\hline Economic ties & Social bonds \\
\hline $\begin{array}{l}\text { - Transaction-related issues (volume, } \\
\text { frequency, percentage counted) } \\
\text { - Multiple projects on sales, R\&D etc. } \\
\text { - After-sales maintenance } \\
\text { - Knowledge transfer in technology and } \\
\text { management know-how } \\
\text { - Regular business meetings } \\
\text { - Understand each other's expectations on } \\
\text { - price, due date, performance, etc. } \\
\text { - Fast response on urgent issues } \\
\text { - Share essential information about the } \\
\text { - Kooperation } \\
\text { structure and important personnel } \\
\text { - Trust in financial situation, management } \\
\text { capability, technology, market influence, } \\
\text { growth potential, etc. } \\
\text { - Belief in partner's willingness and } \\
\text { integrity in the cooperation } \\
\text { - Devotion to the current task(s) } \\
\text { - Interest in increasing the scale and scope } \\
\text { of the cooperation } \\
\text { - Intention of long-term cooperation } \\
\text { - Willing to 'grow up' together in } \\
\text { business }\end{array}$ & $\begin{array}{l}\text { - Meet in social events } \\
\text { - Catch-up after work } \\
\text { - Gift-giving and visiting in holidays } \\
\text { - Take vocation together } \\
\text { - Discuss business informally } \\
\text { - Exchange information un-related or not } \\
\text { - directly related to business } \\
\text { - Discuss future strategy and seeking } \\
\text { advice from partners } \\
\text { - Acceptance of informal agreement } \\
\text { - Partner's goodwill and concern about } \\
\text { its wellbeing } \\
\text { - Build personal tie with people in } \\
\text { - } \text { Interest in retaining the personal ties } \\
\text { even after relationship termination } \\
\text { - Forgiveness and forbearance in the } \\
\text { relationship } \\
\text { - Similar business philosophy } \\
\text { - Compatible business goals and strategic } \\
\text { visions } \\
\text { - Similar attitude towards the product } \\
\text { and service } \\
\text { - Group identification like 'one of us' }\end{array}$ \\
\hline
\end{tabular}

\subsection{Discussion of the Four Relationship Categories}

The findings in Phase 1 provide support for the two-dimensional view.

Particularly, the four categories of business relationships reported in the previous section can be comprehended as a $2 \times 2$ matrix, as shown in Figure 4-2. The matrix is constructed on the basis of the two defined dimensions - economic ties and social bonds. Its four quadrants represent four distinctive types of business relationships with substantially different economic and social content, labelled as 
Relationship Type I, II, III and IV in this study. These correspond to the groups identified from the qualitative findings presented in the previous section. Below, the four types of relationships are further discussed in relation to the literature.

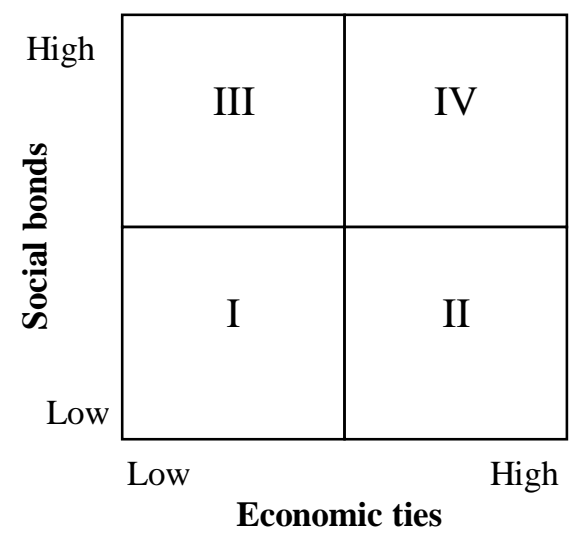

Figure 4-2 Defining relationships by the economic and social dimensions

Relationship Type I represents a relationship between two firms that are neither socially nor economically close to each other, suggesting typical weak ties, overall. The literature has described that many newly formed relationships are likely to fall into this category (Dwyer et al., 1987), particularly if the relationship is a 'virgin tie' between two 'stranger' firms with no endorsement from a common third-party referral (Kenis and Knoke, 2002). The rationale is that at the early stage, two parties do not know each other well, and are cautious of risks associated with the relationship. For example, previous research shows that foreign firms in China tend to select local suppliers by first evaluating their production facilities, then experimentally allocating these candidates a small number of orders to see if they can meet expectations (Duanmu and Fai, 2007).

Moreover, the qualitative data suggest that Type I relationship can also exist in the long-term. As already mentioned, WATERHEAT purchased a small volume of standard components from some local suppliers for years. The relationships were not strong in the economic sense from the focal firm's point of view, given the low level of transactions and perceived dependence on the suppliers. In the 
meantime, the firm saw little need to nurture social elements with those suppliers because, first this would not create any additional benefit and economic value, and, second the social bonds could constrain them from shifting to new competitive alternatives in the market.

Relationship Type II contains strong economic ties, but weak social bonds. As found in Phase 1, although two firms may have a high level of economic interaction and adaptation in production, and so on, and probably have some social contact and mutual trust with respect to aspects such as integrity, they clearly hold the view that 'business is business' and rarely form strong social bonds. Under such circumstances, cooperation needs to be secured largely by a written contract and other types of necessary activities, such as frequent sitevisiting and monitoring. Even though China is generally considered to emphasise social networks, this type of socially weak and economic strong relationship has been reported in some recent China-related research. For example, Trimarchi and Tamaschke (2004) found that Hong Kong traders maintain relationships with their mainland Chinese suppliers only at arm's-length and with very limited social interactions, despite a high level of economic exchanges. Zhou and Xin (2003) identified that in the Chinese IT industry, the relationships between foreign Western MNCs and their local partners are hierarchical and lack social attachment, in spite of their high level of economic cooperation.

Relationship Type III contains weak economic ties but strong social bonds. Like mentioned earlier, this type of relationship may reflect firms' social approach to networking. In the literature, similar findings can be seen in the field of entrepreneurial firms (Hite, 2005), because entrepreneurial firms are also likely to derive their business networks from social networks. Also, this type of relationship has been reported in several China-based studies. Wu and Choi (2004), and Batonda and Perry (2003a) found that, in a well-established relationship when party A can no longer meet party B's expectations, B may have to reduce the level of business exchanges or even terminate the economic ties 
completely. However, B might choose to retain strong social bonds with A, to keep the chance for revitalising the relationship once A improves.

Relationship Type IV represents another type of relationship, being high in both economic and social dimensions. The literature has highlighted this type of relationship, usually regarding it as typical strong and fully embedded ties (Ford, 1980; Hite, 2003, 2005; Larson, 1992; Uzzi, 1997). Two firms connected by such a relationship have considerable economic activities and strong social bonds. They are deeply adapted or accommodating towards each other in terms of aspects such as production, R\&D, administration, and strategy; at the same time, their strong social bonds suggests high level of relational and cognitive social capital, which means that both parties are concerned with each other's wellbeing, and would not harm their relationship lightly. The traditional literature tends to perceive this type of relationship to be a successful marriage (Johnston and Hausman, 2006), and believes it as the most ideal and ultimate objective for relationship development. However, the qualitative data also suggest that, even though this type of relationship often plays an important role in firms' business networks, it is not seen very commonly. One explanation is that this relationship can be very difficult to achieve, and usually takes time to evolve. The other reason, arguably, is that, due to the concern with the negative effects of strong social relations or guanxi, firms may not necessarily seek this type relationship with all the exchange partners.

Overall, the Type I and II relationships seem to be associated with transactional ties and arm's-length ties noted for their weak social bonds. These indicate a high contractual or economic emphasis in the governance mechanism (Vandaele, Rangarajan, Gemmel and Lievens, 2007), whereas the other two types of relationships appear to be more embedded, given the higher level of social bonds. Compared with the continuum paradigm for defining relationships (see Figure 31), the matrix provides a more comprehensive description for the nature of relationships. For example, it accommodates Type II and III relationships, which 
are usually considered to be 'outliers' from the continuum-based point of view, due to their substantially distinctive economic and social contents (Tangpong et al., 2008).

\subsection{Chapter Summary}

This chapter begins by explaining the rationale for combining both the qualitative and quantitative approaches, and outlines the two-phase research design used in this study. Then, it sheds light on the qualitative Phase 1 component, describing its specific research objective and question that are associated with the fundamental research problem of the study. The methodological aspect of Phase 1, including sampling, data collection, the interview process, data coding and interpretation are also reported. The qualitative findings highlight four categories of business relationships featuring distinctive economic and social contents, which further suggest a $2 \times 2$ matrix describing relationships by their economic and social dimensions, lending support for the two-dimensional view presented in the previous chapter. Also, findings related to the measurement of the economic and social dimensions are summarised in this chapter, which may provide input into the following quantitative phase of the study. Additionally, note that Phase 1 also produced insights into the changes in the economic and social dimensions during the relationship development process. These findings are addressed in Chapter 7.

After examining the two-dimensional view, the study moves into Phase 2 address the second research question, by exploring how different categories of foreign firms develop their relationships along the economic and social dimensions. The next chapter, Chapter 5, addresses the methodological aspects of Phase 2. Specifically, it explains the objective for Phase 2, describes the survey design, outlines the constructs and measurement for the economic and social dimensions, introduces the variables and strategies for the quantitative analysis, reports the data collection procedure, and provides a brief overview of the sample portfolio. 


\section{Chapter Five Quantitative Methodology}

\subsection{Chapter Objectives}

This chapter states the objective and explains the research design for the quantitative Phase 2 of the study, and then highlights the constructs and measurement for the economic and social dimensions. Next, the chapter introduces the variables used in the multiple regressing modelling, along with the strategy for data analysis. Last, the data collection procedure is reported, followed by a brief overview of the quantitative sample.

\subsection{Objective and Research Design}

As discussed in Chapter 4, the qualitative findings in Phase 1 support the twodimensional view of analysing business relationships along the economic and social dimensions. This further underpins the conceptual approach to unfolding the development process of a relationship by assessing its changes in these two dimensions. On this basis, the study moves into Phase 2 to initially seek further empirical support for the two-dimensional view, and then address the second research question primarily, through testing the hypotheses outlined in Chapter 3. A quantitative approach is chosen because it emphasises the measurement and analysis of relationships between variables (Denzin and Lincoln, 2000). Specifically, multiple regression analysis is undertaken to test the hypotheses. In the regression modelling, categorical dummy variables can be employed as the predictors for the dependent variable, and the results may inform the differences between the two groups represented by the predictor, in respect to the dependent variable (Field, 2005). This is appropriate for the hypotheses in the study. Meanwhile, control variables can be incorporated in multiple regression analysis, allowing a comprehensive investigation of firms' relationship development process.

Unlike the qualitative Phase 1 that explores firms' business relationships with a range of local business actors, Phase 2 sheds light on firms' important local customers only. This is because customers play a crucial role in firms' network 
and market success, and firms' relationships with customers have attracted a great deal of attention from researchers (Holm et al., 1996). Also, given the comparative nature of these hypotheses, it would be appropriate to conduct the analysis based on the data about a similar category of business relationships of firms. Drawing on the qualitative data in Phase 1, 'customers' in Phase 2 are defined as the parties that directly purchase, distribute or utilise firms' products or services, and can be sales agents, distributors and end-users. These parties are generally called kehu (i.e. 'customers') in Chinese, and have a similar meaning to the 'buyers' defined in relationship marketing (Morgan and Hunt, 1994).

To collect the data for analysis, a cross-sectional survey was conducted in this study, because a survey design provides quantitative or numeric description of a sample (Creswell, 1994). The survey process is described later in this chapter. In the survey instrument - a questionnaire - the definition for 'customers' was provided. Each respondent was asked to identify one of the firm's 'important' and 'active' customers, and then provide the data for this customer relationship which has been 'developing' over time. In order to capture the dynamics of the relationship development process, the data for the economic and social dimensions of firms' customer relationships were collected with respect to two time points: the relationship formation stage ${ }^{11}$ (defined as Time 1) and the time of the survey completion (defined as Time 2). The Time 1 data inform the nature of relationships at the early formation stage, and the Time 2 data show the nature of relationships at the time of the survey. Based on these two datasets, the degree of change in the strength of economic ties and social bonds from Time 1 to Time 2 can be calculated, reflecting the 'growth' of the relationships since the formation.

In the survey, the data for customer relationships were collected from the focal firms' perspective. Some scholars recommend taking both parties into consideration when studying dyadic relationships, as they might have different stories to tell (Mohr and Spekman, 1994). However, this can be a very difficult

${ }^{11}$ As explained in Chapter 3, a relationship is considered to be formed when the two firms conduct the initial business exchanges for their products and services (Dyer and Chu, 2000). 
task for the researcher, because he or she has to locate and gain access to both parties in a relationship (Cannon and Prereault, 1999), which also explains why only a few studies have undertaken such an approach (e.g. Styles et al., 2008; Su et al., 2009; Wong, Tjosvold and Zhang, 2005).

Further, the survey addressed one relationship of each respondent firm. Studying a single relationship of a firm is, in fact, a common approach adopted by many researchers using surveys (e.g. Andersson and Forsgren, 1996; Cannon and Prerreault, 1999; Holm et al., 1996; Wong et al., 2005). According to Andersson and Forsgren (1996: 493), this approach can be justified because "research has confirmed that a company's important relationships often tend to be rather few". They further argue that, although a firm may often have multiple 'important' customers, the representative relationship should be a good indicator of the firm's overall customer relationships.

\subsection{Measures for Economic Ties and Social Bonds}

The constructs and measures for the economic ties and social bonds of relationships were developed in the study via three steps. First, a number of key relationship constructs that were commonly used in the literature were highlighted. Second, these constructs were further refined with respect to the economic and social aspects, suggesting the economic and social constructs specifically. Third, the scale for each of these economic and social constructs was developed by seeking the relevant items used in the literature. These multiple-item scales were used in the survey to obtain the empirical data for the relationships.

Moreover, by using the empirical quantitative data, exploratory factor analysis was performed for each construct to explore the underlying structure of the multiple items in the scale (Hair et al., 1998). All factor analyses were conducted by using the computer programme SPSS 17.0. In SPSS, principle component extraction and varimax rotation were selected, and factors with eigenvalue greater than 1 were considered. Factor analyses were conducted by using both the Time 1 
and Time 2 data, to assess the construct equivalence (Hult, Ketchen, Griffith and Finnegan 2008) in the two different time points. Based on the results, some items were removed and not used in the subsequent multiple regression analysis.

Reliability analysis was also performed for these constructs, by checking the Cronbach alpha score, to test their consistency (Cohen, Cohen, West and Aiken, 2003).

The following sub-sections report the constructs and items that are used in the subsequent quantitative data analysis.

\subsubsection{Refine relationship constructs by the economic and social aspects}

Relationships are measured in previous studies in various ways and by diverse attributes (for reviews see Bove and Johnson, 2001; Golicic et al., 2003). As outlined in Chapter 2, however, it is the behavioural and psychological aspects that draw the most attention from researchers. According to Schijins and Schroder (1996), the behavioural aspect may be represented by two firms' interactions in terms of factors such as length of time, frequency, quantity of the involved exchange; the psychological aspect may be represented by variables such as attractiveness, trust, and the perceived switching costs. Scholars have attempted to define relationships based on these two aspects. For example, Donaldson and O'Toole (2000) focus on action and belief as the two primary components of relationships. These two components are in correspondence with the behavioural and psychological aspects. Forsgren et al. (2005) describe relationships as involving two types of elements, the exchanges of products, money and information, and mutual emotional elements like trust and commitment. PerrySmith and Shalley (2003) construct relationship strength based upon two aspects: the frequency of exchange and emotional closeness, which reflect the behavioural and psychological aspects as well. In a similar vein, Turnbull et al. (1996) point out that the behavioural and psychological aspects are of interest to the IMP scholars when studying the relationship development. 
Drawing on the above, four general relationship constructs that relate to the behavioural and psychological aspects are identified in this study: firms' interaction, communication, trust and commitment. These constructs have been used widely in the previous literature. The first two constructs pertain to the behavioural aspect of relationships. Interaction is often adopted as a basic measure for relationships, by taking the frequency and intimacy of contact as the reference (Tsai and Ghoshal, 1998). Communication, as the other behavioural construct, is also regarded as an important type of interfirm behaviour, and used as a key indicator for relationship vitality (Mohr and Spekman, 1994) and relationship strength (Gargiulo and Benassi, 2000). The other two constructs - trust and commitment - pertain to the psychological aspect. They are often treated as a pair of sister-constructs to represent relationships in many forms. Morgan and Hunt (1994) view them as the principle factors resulting in cooperative behaviours in business relationships. Bove and Johnson (2001) discuss them as the central measurement of the magnitude of relationships. Hausman (2001) use them to assess relationship strength. Kwon (2008) consider them as the key elements of social capital. As Ruyter, Moorman and Lemmink (2001) described, trust and commitment are the most popular 'relationship building blocks'.

The extant literature has suggested these four constructs comprise both the economic and social contents, which provides the foundation for developing the further constructs for the economic and social dimensions. This is discussed in great detail in the following sub-sections. Additionally, drawing on the social capital literature, norms and values are included as another social construct in this study, relating to the psychological aspect (Nahapiet and Ghoshal, 1998).

\subsubsection{Economic constructs and the items}

The constructs and items for the economic ties are presented in this section, along with the results of the factor analysis. 


\subsubsection{Economic interaction}

Based on interfirm interaction, two constructs, economic and social interaction, are extracted. Economic interaction reflects two actors' resource exchange and resource combination to create value (Larson, 1992; Tsai and Ghoshal, 1998). At a basic level, researchers have examined economic interaction by two parties' transactions that are often assessed by volume and frequency (Fynes and Voss, 2002; Gundlach and Achrol, 1993; Jones et al., 1997; McAllister, 1995; Mhor and Spekman, 1994; Yli-Renko et al., 2001). A deeper level of economic interaction may be indicated by two firms' joint programmes and multiple projects (Cannon and Perreault, 1999), and this type of resource synthesis can further relate to various aspects including production, personnel and distribution channels (Tang and Xi, 2006). In a similar vein, technical bonds (Johanson and Mattson, 1987) are also considered as an indicator of firms' economic interaction with partners. Drawing from the above, the items adopted from the literature to represent economic interaction are as follows:

Table 5-1 Items for economic interaction

1 We have a large volume of transactions with this customer.

2 We have frequent transactions with this customer.

3 We work on multiple projects with this customer.

4 This customer contributes a large percent of our business revenue.

5 We share resources related to production, distribution and personnel with this customer.

6 We transfer our product-related technology to this customer.

7 We transfer our management know-how to this customer.

The factor analysis ${ }^{12}$ results show that these seven items were loaded onto two factors, with $74.8 \%$ of the variance explained. The first factor included items 1,2 , 3 and 4 that were related to transactions and mutual projects between firms, and the business revenue, while the second factor (items 5, 6 and 7) pertained to resource sharing in production, distribution and personnel, as well as technology

\footnotetext{
${ }^{12}$ Factor analysis was conducted by using both the Time 1 and Time 2 datasets. For the consistency of writing in this chapter, the results of factor analysis are discussed based on the Time 1 dataset. More information about the factor analysis and reliability test for the two datasets can be found in Appendixes 5 and 6.
} 
and managerial knowledge transfer. Given the different nature of these two factors, two sub-constructs were formed accordingly: tangible economic interaction and intangible economic interaction. The four items of tangible economic interaction have $63.58 \%$ of the variance explained, and the Cronbach alpha score at 0.80 . The three items of intangible economic interaction have $60.46 \%$ of the variance explained, with Cronbach alpha score at 0.67 , which was acceptable given the explanatory nature of the study.

\subsubsection{Economic communication}

Communication is often used by scholars to assess relationships in terms of such aspects as strength (Gargiulo and Benassi, 2000; Van de Ven, 1976). The core of communication is information exchanges which involve open sharing of information useful to both parties (Cannon and Perreault, 1999). From this viewpoint, communication can involve information that is not only work-related, necessary and essential to accomplish two actors' contractual business tasks (Westlund and Nilsson, 2005), but is confidential to focal firms, as well as unnecessary and irrelevant to the ongoing tasks. It is generally considered that the former suggests strong economic ties, while the latter implies strong social bonds between partners (MacNeil, 1980; Mohr and Spekman, 1994). Hence, the study differentiates between economic and social communication by the content of information. Specifically, economic communication concerns work-related issues. It is about sharing information to fulfil the requirement of accomplishing the firms' ongoing business tasks.

Communication is usually assessed by its quantity, quality, and efficiency or timeliness of information exchange (Larson, 1992; Mohr and Spekman, 1994; Ramasamy et al., 2006; Wu and Choi, 2004). In line with this, the study examines two firms' economic communication by assessing the frequency of their business meetings and visits during work time (Ring and Van de Ven, 1992), understanding each other's expectations with regard to the business cooperation (Morgan and Hunt, 1994), and information sharing and discussion on emerging 
issues related to the core business tasks (Ford, 1980; Morgan and Hunt, 1994). In addition, previous research suggests that firms' familiarity with the other party's important personnel may indicate the effectiveness of communication. For instance, Lee et al. (2001) suggest that a firm's knowledge of whom to talk to in another firm while dealing with particular business issues may reflect the level of 'decision making uncertainty' in the focal relationship. This is also echoed by the qualitative data in Phase 1. Overall, seven items were adopted to represent economic communication.

Table 5-2 Items for economic communication

1 This customer and our company have frequent business meetings and visits.

2 We understand this customer's demands and expectations of us, in terms of price.

3 We understand this customer's demands and expectations of us, in terms of quality.

4 We understand this customer's demands and expectations of us, in terms of due dates for delivery.

5 We inform this customer about new developments regarding our joint project(s).

6 We inform this customer about business-related emergencies in a timely manner and we discuss them together.

7 When there is a problem, we know with whom to discuss this issue in this customer's company.

Results of factor analysis show that these items were clearly extracted to one factor, explaining $62.47 \%$ of the variance. The Cronbach alpha score for the construct based on these times was 0.90 , which was highly acceptable. Hence, all the items were kept in the scale for economic communication.

\subsubsection{Economic trust}

Trust, as probably the most well-known relationship construct, has been studied by many scholars (Blois, 1999). Despite various definitions, trust in general can be considered as one party's confidence in a partner's reliability and integrity (Morgan and Hunt, 1994; Thorelli, 1986). Scholars acknowledge the multidimensional nature of trust, and further explore it by considering issues including such as what a firm trusts in and why a firm trusts (Nguyen et al., 2005), as well as the psychological processes in which trust is based (Chua et al., 2009). For example, McAllister (1995) examines affect- and cognition-based trust. Doney 
and Cannon (1997) pay attention trust in credibility and benevolence trust. Another influential work in this respect is contributed by Madhok (1995) who distinguishes between the structural and social component of trust. As Svejenova (2005: 13) revisited,

"The structural component captures the synergic complementarities of the partners' resources and capabilities and hence, their potential to create more value together than separately. The social component of trust, which is labelled as social glue, keeps the parties together, allowing the valuecreating potential of their collaboration to be realised."

Notably, research shows that economic-related trust, like the structural trust, cognition-based trust and credibility trust, can exist in a business relationship in spite of little social element (Dyer and Chu, 2000). In the presence of this type of economic trust, firms are likely to increase economic interactions and undertake increased levels of business with the trusted partners (Ford, 1980; Liu et al., 2005; Mohr and Spekman, 1994). However, research also shows that relationships purely based on economic trust can be relatively fragile, and are often governed strictly by formal and contractual means (Leana and Van Buren, 1999).

Hence, the study defines the economic aspect of trust, i.e. economic trust, by drawing on Madhok's (1995) structural trust and McAllister's (1995) cognitionbased trust. Scholars also differentiate between two components of economic trust: competence trust and contractual trust (Styles et al., 2008). Competence trust is based on firms' beliefs in the other party's competence in or capability of accomplishing a business task (Levin and Cross, 2004; Ring and Van de Ven, 1992). It can be assessed by firms' perceptions of their partners' market capabilities (Ford, 1980), financial strength (Larson, 1992; Morgan and Hunt, 1994), and knowledge of cooperation with like companies (Doney and Cannon, 1997). Contractual trust is based on a belief that partners will fulfil their obligations without taking any advantage unethically during the exchange process 
(Dhanaraj et al., 2004). It can be reflected by a firm's perception of whether to receive timely payment from its business partners (Wu and Choi, 2004), whether these partners are honest in explaining business-related issues (Jap and Anderson, 2007), and whether partners would adhere to the agreed contract (Styles et al., 2008). Thus, based on the literature, the items for trust were developed based upon both competence trust and contractual trust, as shown in Table 5-3.

Table 5-3 Items for economic trust

1 This customer is well-known in its market(s).

2 This customer has strong influence in its market(s).

3 This customer has strong growth potential.

4 This customer is knowledgeable about our products and how to work effectively with us.

$5^{*}$ This customer understands that we are offering them a reasonable price.

6 This customer is financially healthy and strong.

7 This customer makes their payments to us on time.

8 This customer is honest in explaining business-related issues to us.

9 This customer behaves as agreed in the contract.

* This item was derived from the qualitative data (see Table 4-3). It is consistent to the meaning of the construct discussed in the section.

The first six items (1-6) are for competence trust, and the last three items (7-9) are for contractual trust. Previous scholars have pointed out that competence trust and contractual trust may not be always equally developed. For instance, Wu and Choi (2004) find that trust on a partner's anti-opportunistic behaviours does not mean trust on this partner's capability of offering compatible and suitable resources. For complete economic trust, i.e. firms' willingness to rely on others (Morgan and Hunt, 1994), both these two types of trust are needed. As Bolis (1999: 200) described, "I know that you have the capability of delivering this item as ordered and therefore can rely on you to do so".

Factor analysis was first run with all the items for competence trust and contractual trust. The results show that items of these two types of trust were loaded separately from each other, suggesting the possibility for two sub- 
constructs. A second round of factor analysis was then conducted for competence trust and contractual trust, respectively. The six items of competence trust loaded into one factor with $62.05 \%$ variance explained, Cronbach alpha score at 0.87 . The three items of contractual trust loaded into one factor with $78.87 \%$ variance explained, Cronbach alpha score at 0.87 . Hence, all the items were kept, and competence trust and contractual trust are treated as two separate constructs for economic trust in this study.

\subsubsection{Economic commitment}

Commitment has been defined as the tendency to resist change and intention to pursue continuity of the relationship (Dwyer et al., 1987; Morgan and Hunt, 1994). When commitment is high, two firms behave less opportunistically, and intend to achieve individual business goals jointly (Mohr and Spekman, 1994). Scholars have argued for not treating commitment as a 'global' construct (Geyskens, 1996), but differentiating between the distinguishable components for a comprehensive understanding of the construct and their role in relationships (Mathieu and Zajac, 1990). However, this remains as a limitation until recently (Clarke, 2006).

One of the most common approaches to addressing the multifaceted nature of commitment is to define the calculative commitment and affective commitment (Mathieu and Zajac, 1990). The former refers to partners' perceptions of the need to maintain a relationship given the benefits of sustaining it and the estimated switching cost. This is based upon rational and objective calculation of the costs and benefits associated with continuing or terminating a relationship. In comparison, the latter exists when a partner's motivation for maintaining or strengthening the relationship is based on a general positive feeling towards and the sense of emotional attachment to the other party, reflecting a type of informal and social bonds. These two types of commitment indicate different motivations for maintaining a relationship and play distinguishable role in the relationship setting (Geyskens et al., 1996). For instance, with calculative commitment, two firms may have a strong intention to maintain their current economic cooperation 
and undertake further investment in the relationship (Robson and Katsikeas, 2005), but they may or may not be willing to maintain strong social connections with each other, regardless the status of economic interactions, which requires affective commitment.

This study therefore, proposes economic commitment and social commitment, based on the essence of calculative commitment and affective commitment, respectively. In line with the meaning of economic ties defined in Chapter 3, economic commitment deals with the firms' intention of maintaining and further enhancing economic interaction, in order to pursue economic outcome and benefits. Strong economic commitment suggests that firms would not only continue the current business interactions, but also tend to increase investment in the relationship (Robson and Katsikeas, 2005).

Table 5-4 Items for economic commitment

1 We devote a great deal of effort and resources to accomplish tasks with this customer.

2 We are willing to increase the level of cooperation with this customer as soon as possible.

3 We are willing to maintain our ongoing business relationship with this customer on a long-term basis.

4 We are willing to grow our business together with this customer.

5 We are continually on the lookout for another customer to replace this customer (reverse coding). (removed).

As shown in Table 5-4, economic commitment in this study is assessed by firms' devotion of resources and efforts to complete current business tasks (Morgan and Hunt, 1994), firms' propensity to reinforcing cooperation for more benefits through such as increasing transaction volume (Doney and Cannon, 1997) and other bilateral investments, as well as long-term orientation of the ongoing business relationships (Jap and Anderson, 2007; Holm et al., 1999), and firms' intention for replace existing partners with competitive alternatives (Holden and O'Toole, 2004; Styles et al., 2008). All these items are derived from the previous studies. 
Results of the factor analysis show that the first four items loaded into one factor, with one item "...continually on the lookout for another customer to replace this customer' being isolated. Given the exploratory nature of the factor analysis, this single item was removed ${ }^{13}$, and the four items were kept to represent the economic commitment. These four remaining items contribute $68.29 \%$ of the variance explained and the Cronbach alpha score is 0.84 .

\subsubsection{Social constructs and items}

This section explains the five social constructs, and presents the associated items that are derived from the literature. The factor analysis results are reported.

\subsubsection{Social interaction}

In response to economic interaction defined earlier, social interaction refers to the interfirm socialising activities taking place in the setting of social occasions and usually involving no business contents. It attracts increasing attention from scholars. For example, Tsai and Ghoshal (1998), and Yli-Renko et al. (2001) use social interaction to measure the degree of two actors' social connection. MolinaMorales and Martinez-Fernandez (2009) use it as an indicator of relational social capital in firms' relationships. In particular to the Chinese market, research has shown that deliberating social exchange behaviours are an important means of developing social relations (Björkman and Kock, 1995).

In this study, items for social interaction are drawn from the literature. They are concerned with whether managers of firms socialise with each other by attending social events and having lunch, dinner or drinks together (Doney and Cannon, 1997; Yli-Renko et al., 2002), whether they get together primarily for fun rather than any direct business objective (Doney and Cannon, 1997), and whether there exists a strong social connection between two parties at the personal level (Turnbull et al., 1996; Westlund and Nilsson, 2005; Yli-Renko et al., 2002). Furthermore, two types of social activities relating to China are documented in the

${ }^{13}$ The researcher did not retain this item as its own variable for economic commitment, also for the purpose of controlling the number of economic constructs used in the regression analysis. 
literature. First, gift-giving in China plays an important role in maintaining and developing business relationships, even though it tends to happen in a one-way direction, such as from supplier to a powerful buyer and from firms to the government officials (Xin and Pearce, 1996). Second, Chinese people have the tradition of visiting members of their social networks during traditional holidays, like the Chinese New Year. Sociologists use 'visiting during traditional holidays' to assess the strength of social ties and gauge the social distance between actors in China (Bian et al., 2005). These two activities were also identified during the interviews in Phase 1, as shown in Table 4-3. As a result of the above discussion, the following items are adopted to represent firms' social interactions.

Table 5-5 Items for social interaction

1 We invite this customer to our company's social events.

2 We and this customer sometimes get together primarily for fun, not necessarily for business.

3 We and this customer socialise, for example, having dinner and drinks together.

4 We have personal contacts with people in this customer company.(removed)

5 We visit this customer during traditional holidays.

6 We give this customer gifts during traditional holidays.

The results of the factor analysis show that only one factor was extracted from these six items of social interaction. However, it was noticed that by removing the item '...personal contacts with people in customer company', Cronbach alpha score for the scale increased from 0.62 to 0.88 . Therefore, only the other five items were kept for the subsequent regression analysis, and they contributed $68.45 \%$ of the variance explained.

\subsubsection{Social communication}

As explained earlier, economic communication and social communication are distinguished by the content of the exchanged information. Social communication, in comparison to economic communication discussed earlier, is considered to involve information sharing that is 'unnecessary' or 'un-related' for these firms to accomplish their on-going business tasks such as economic exchange or a joint programme. Social communication allows firms to exchange information with a 
greater breadth, and helps them to become more knowledgeable about each other's business, suggesting a high quality of communication, overall.

Scholars have paid attention to this type of communication while analysing relationships. For example, researchers examine the extent to which firms exchange information beyond the 'need-to-know' basis (Donadlson and O'Toole, 2000 ) that is not noted in a pre-specified agreement (Fynes et al., 2002; Mohr and Spekman, 1994). It may include information not merely limited to basic issues like price and volume (Gundlach and Achrol, 1993), but related to inventory, supply and demand forecasts, business strategy, etc. (Cannon and Perreault, 1999). Also, it is generally regarded that firms in strong and close relationships would inform each other about emergencies or events that are unrelated to their business cooperation project but which might affect partners (Jap and Anderson, 2007), discuss their future business plans and seek advice and guidance on business (Styles et al., 2008; Yli-Renko et al., 2001), and even share confidential and proprietary information (Mohr and Spekman, 1994). Based on the above, items used in the study to represent social communication are as follows.

Table 5-6 Items for social communication

1 We and this customer share information beyond a 'need-to-know' basis.

2 Our discussions with this customer are not limited to price and volume issues.

3 We and this customer share information regarding future strategy and supply and demand forecasts.

4 We and this customer share a lot of confidential business information. (removed)

5 We inform this customer of events and changes that are not related to our cooperation, but that might affect their firm. (removed)

6 We seek this customer's advice and guidance concerning our market operations.

The results of factor analysis show that five items loaded into one factor, whereas one item '...share confidential information' was clearly in a separate dimension. Given the exploratory nature of the factor analysis, this item was removed, and not used as single variable. The second round of factor analysis was conducted for the remaining five items. '...inform customers of un-related information' appeared to have much lower factor loading (0.52) than the others. The reliability analysis further suggested by removing this item, the Cronbach alpha score for the 
remaining five would increase from 0.63 to 0.77 . It was then also removed from the subsequent regression analysis. The four remaining items contributed $59.93 \%$ of the variance explained.

\subsubsection{Social trust}

Following the earlier discussion, social trust is different from economic trust (i.e. competence trust and contractual trust) that is closely related to two parties' business agreement and projects. The social aspect of trust has been conceptualised by many scholars, even though it is not always separated from the economic counterpart in the operationalisation. For example, it has been addressed in various forms including the social component of trust (Madhok, 1995), affect-based trust (McAllister, 1995), benevolence trust (Doney and Cannon, 1997; Levin and Cross, 2004), resilient trust (Leana and Van Buren, 1999; Ring and Van de Ven, 1992), and goodwill trust (Ring and Van de Ven, 1992; Styles et al., 2008).

Social trust may suggest a strong emotional and psychological bond between two parties (Morgan and Hunt, 1994). In its presence, two firms' cooperation can extend beyond the boundaries of the core business that they are currently dealing with. For example, they may feel psychologically comfortable in asking each other for resources and using them, although it is not written in any formal contract (Kostova and Roth, 2003). They will also "behave in a way that is beneficial to both partners beyond that which is expected of them according to the contractual agreements" (Styles et al., 2008: 886). Their relationships can survive transactions where benefits and costs are not equilibrated (Leana and Van Buren, 1999). Particularly, this type of emotion-oriented trust may play an important role in the Chinese environment because of the social network oriented culture (Chua et al., 2009).

The present study examines social trust using firms' perceptions on whether partners would be concerned about their well-being, while making important 
decisions and making sure not to make demands that can seriously damage the other party (Dhanaraj et al., 2004; Jap and Anderson, 2007; Levin and Cross, 2004; Yli-Renko et al., 2002), whether partners would take advantage of their weakness (Cannon and Perreault, 1999; Dhanaraj et al., 2004), and whether partners would align with new competitive alternatives when there is an opportunity to do so (Styles et al., 2008). In addition, social trust may be also assessed by the degree to which firms feel comfortable and secure about verbal and informal agreement with their partners (Dhanaraj et al., 2004; Donaldson and O'Toole, 2000; Holden and O'Toole, 2004; Wu and Choi, 2004). In summary, the items representing social trust in this study are as follows.

\section{Table 5-7 Items for social trust}

1 This customer is concerned about our company's welfare, and cares about what might happen to our company when making important decisions.

2 This customer does not take advantage of any of our weaknesses in business negotiations, for their own gain.

3 This customer will not replace our company with a competitor, in order to achieve small benefits.

4 This customer and our company count on each other's verbal or informal agreement.

Results of factor analysis show that all these four items were loaded to one factor. Although the total explained variance $(55.56 \%)$ seemed to be relatively low compared to other constructs, the KMO measure (0.74) and Cronbach alpha (0.73) were acceptable. They were therefore, all kept for the regression analysis.

\subsubsection{Social commitment}

As already explained, the term social commitment is largely derived from the meaning of affective commitment that has been defined by previous scholars. Affective commitment exists when a partner's underlying motivation for maintaining a relationship is a generalised sense of positive regard for, and attachment to, the other partner (Geyskens et al., 1996). It is not determined by rational business decisions, but driven by firms' goodwill on the other party and the enjoyment of being in a relationship (Styles et al., 2008). On this basis, social commitment refers to firms' intention not to harm the other party, and to retain 
business interaction for psychological reasons, not necessarily for economic costs and benefits on which economic commitment is based.

Social commitment represents a type of emotional attachment between two parties. The implication of social commitment on business relationships can be further understood in two ways. First, even though a firm is aware of the potential for increased economic benefit by aligning with a new alternative, its propensity to leave the present partner could be mediated by its social commitment to their relationship. Second, if the economic benefit from a relationship has become unaffordable to a firm, the firm may have to reduce or terminate its business interaction with the other, but it is very likely to retain strong social bonds. In other words, the social dimension of the relationship retains. This is in fact identified as China-specific approach to managing declining business relationships (Batonda and Perry, 2003b).

The study investigates social commitment from two angles. First, whether firms are willing to make sacrifices for keeping relationships intact, specifically, by firms' patience and forgiveness in dealing with partners' mistakes (Gundlach and Achrol, 1993; Styles et al., 2008; Turnbull et al., 1996), and by firms' tendency to changing and modifying original terms of cooperation if necessary, which is sometimes considered to be an item of 'relationship flexibility' (Gundlach and Achrol, 1993). Second, social commitment is indicated by the extent to which firms would resist stopping their business cooperation and shifting to new alternatives, when a relationship suffers poor economic outcome.

Table 5-8 Items for social commitment

\footnotetext{
1 If this customer makes mistakes, we are willing to forgive them and then continue the relationship.

2 We are willing to make sacrifices for this customer, to keep the relationship intact.

3 We are willing to modify terms for this customer, in response to changes in the market.

4 If the relationship with this customer has to be terminated, we tend to maintain a social bond with them.
} 
Overall, four items are developed to represent social commitment in the study. They are listed in Table 5-8. The factor analysis shows the four items are loaded to one factor, having $61.59 \%$ variance explained, and Cronbach alpha score at 0.79. They were all kept and used for the regression analysis.

\subsubsection{Norms and values}

Norms and values are sometimes used to measure the cognitive aspect of social capital. They provide the foundation for shared representations, interpretations, and systems of meaning among parties, because common norms and values may create group identification which means that individuals perceive themselves belonging to the same group as the others (Nahapiet and Ghoshal, 1998), for example, in terms of membership (Widen-Wulff and Ginman, 2004). As a result of group identification, individual firms might even feel reluctant to terminate business cooperation with others due to peer pressure from other network members (Turnbull et al., 1996). Coleman (1988) for example, considers that individuals with shared norms and values could forgo self-interest and act in the interest of collectivism, and then behave in a more collective manner.

Previous researchers examine norms and values by 'soft elements' including such as shared language and codes, norms (Tsai and Ghoshal, 1998), shared goals and culture (Inkpen and Tsang, 2005), and shared visions (Forsgren et al., 2005). In this study, this social construct is measured by firms' perception of partners as 'one of us' (Nahapiet and Ghsohal, 1998; Kostova and Roth, 2003), and their willingness to 'sink or swim' together (Wong et al., 2005). It is also assessed by two firms' similarity in business philosophy (Dhanaraj et al., 2004) and approaches to dealing with business issues (Doney and Cannon, 1997), and their commonality on market economic goals (Turnbull et al., 1996). The six items are summarised in Table 5-9.

The factor analysis results show that these six items were loaded into one factor, suggesting a very strong internal consistency for the scale. All the items were 
therefore, kept for the regression analysis. The construct has $57.78 \%$ variance explained and Cronbach alpha score at 0.85 .

Table 5-9 Items for norms and values

1 We are willing to 'sink or swim' together with this customer.

2 We consider this customer to be 'one of us'.

3 We and this customer have similar business philosophies.

4 We and this customer have similar views of the Chinese market.

5 We and this customer have compatible economic goals.

6 We and this customer have similar approaches to dealing with many business issues.

\subsubsection{Section remark}

In Table 5-10, the constructs and the number of the remaining items for each construct used in the regression analysis are summarised. The researcher also conducted reliability analysis for all the items in each dimension, and presents the results in the table. A complete list of the descriptions for all these remaining items and the factor analysis results can be found in Appendixes 5 and 6 .

As demonstrated in this section, all the constructs and the associated items are derived from the extant literature, based on the conceptualisation of the economic ties and social bonds. These constructs fundamentally represent distinct facets of business relationships, and operationalising them separately may enable detailed understanding of the complex nature of business relationships. The literature has shown a similar attempt in this regard. For example, Clarke (2006) and Geyskens et al. $(1996,1998)$ point out that researchers who study trust and commitment do not always follow the conceptual differentiation between the economic and social aspects in their operational measurement, which remains as a limitation in the literature. Their concern is seen being addressed by scholars recently in the field of international business (e.g. Styles et al., 2008; Su et al., 2009). In addition, the items derived from the literature for these constructs appear to be in correspondence to the economic and social elements of relationships identified in Phase 1 (summarised in Table 4-3). The qualitative findings of the uneven economic and social dimensions suggest that those elements could be emphasised 
by firms differently, which might imply the unequal development of these items and further constructs in practice.

Table 5-10 Summary of the economic and social constructs used in regressions

\begin{tabular}{lccc}
\hline & $\begin{array}{c}\text { Total number } \\
\text { of items }\end{array}$ & $\begin{array}{c}\text { Time1 } \\
\text { Cronbach } \\
\text { alpha }\end{array}$ & $\begin{array}{c}\text { Time2 } \\
\text { Cronbach } \\
\text { alpha }\end{array}$ \\
Economic ties & $27^{*}$ & 0.93 & 0.92 \\
Tangible economic interaction & 4 & 0.80 & 0.75 \\
Intangible economic interaction & 3 & 0.67 & 0.65 \\
Economic communication & 7 & 0.90 & 0.87 \\
Competence trust & 6 & 0.87 & 0.82 \\
Contractual trust & 3 & 0.87 & 0.79 \\
Economic commitment & 4 & 0.84 & 0.83 \\
\hline Social bonds & $23 *$ & 0.92 & 0.90 \\
Social interaction & 5 & 0.88 & 0.86 \\
Social communication & 4 & 0.77 & 0.74 \\
Social trust & 4 & 0.73 & 0.71 \\
Social commitment & 4 & 0.79 & 0.70 \\
Norms and values & 6 & 0.85 & 0.83 \\
\hline
\end{tabular}

*Analysis also shows that the removal of any economic item would not lower the Cronbach alpha score below 0.93 at Time 1 and below 0.91 at Time 2. Likewise, the lowest Cronbach alpha value after removing any social item is 0.91 at Time 1 , and 0.90 at Time 2.

In the survey instrument, all the items for these economic and social constructs were assessed with respect to Time 1 (relationship formation) and Time 2 (the time of survey completion), using a 9-point Likert scale ${ }^{14}$ ( $0=$ "Strongly disagree", $5=$ "Neutral", 9= "Strongly agree"), in order to examine the economic and social nature of relationships and their change from Time 1 to Time 2 in great detail. As Cooper and Schindler (2002) mentioned, the Likert scale is frequently used by researchers to allow the respondents to express either a favourable or unfavourable attitude toward the object of interest. Meanwhile, in case respondents were not sure about the answer, or some items might be inapplicable,

\footnotetext{
${ }^{14}$ In the survey, all the continuous variables concerned with the growth or change from Time 1 to Time 2 were assessed by using a 9-point Likert scale, for more detailed data. Others only concerned with the present were measured by using a 7-point Likert scale.
} 
another two options, "Don't know" and "Not applicable", were provided in the instrument.

\subsection{Variables and Analysis Strategy for Multiple Regressions}

Multiple regression analysis is used in Phase 2 to test the hypotheses stated in Chapter 3. This section addresses two main issues regarding the regression modelling. First, it introduces the dependent variables, explanatory variables and control variables. Second, it describes the strategy for the regression analysis. Note that multiple regression analysis in the study is conducted at multiple levels, with the dependent variables pertaining to the development process of the economic ties and social bonds, and of each economic and social construct.

\subsubsection{Dependent variables for the economic ties and social bonds}

To begin with, the study is concerned with the development process of the economic ties and social bonds, directly addressing the hypotheses. Four dependent variables are defined in particular, with respect to the formation and subsequent growth of relationships. Namely, they are: economic ties at relationship formation (Time 1), social bonds at relationship formation (Time 1), the degree of change in economic ties to the time of survey completion (from Time 1 to Time 2), and the degree of change in social bonds to the time of survey completion (from Time 1 to Time 2). By employing these four dependent variables, the regression modelling is intended to explore how the economic and social dimensions of relationships evolve from Time 1 to Time 2.

The value of a dimension is acquired by summing all the constructs in the dimension, using the factor scores. So, the first two dependent variables are: Economic Ties at Relationship Formation $=\sum$ (economic constructs) at Time 1; Social Bonds at Relationship Formation $=\sum$ (social constructs) at Time 1. Following the same logic, the factor scores of each construct at Time 2 are summed, to obtain the value of economic and social dimensions: Economic Ties at the Survey Completion $=\sum$ (economic constructs $)$ at Time $2 ;$ Social Bonds at 
the Survey Completion $=\sum$ (social constructs) at Time 2. On this basis, the other two dependent variables are calculated: the Degree of Change in Economic Ties = Economic Ties at the Survey Completion - Economic Ties at Relationship Formation; the Degree of Change in Social Bonds = Social Bonds at the Survey Completion (Time 2) - Social Bonds at Relationship Formation (Time 1).

Throughout the study, the term 'degree of change' is used to address the growth of relationships. It is represented by the change in the item scores of each respective relationship construct along the 9-point Likert scale, from Time 1 to Time 2. Collectively, these changes reflect an overall degree of change in the construct. It cannot be strictly claimed that these changes equate to a measure of relationship 'strength', since the items do not all use 'strength-related' measures. However, for the purposes of this study, the aggregate change at construct-, and also dimension-level is interpreted to reflect change in the strength of the construct or dimension respectively. This could be a positive, negative, or neutral change, reflecting an increase, decrease, or maintained of economic and social constructs or dimensions, respectively. In Phase 2, the study is concerned with the development of firms' important local customer relationships which remained active at the time of the survey, from the initial formation onwards. Since these relationships are involved in development, the degree of change is, therefore, expected to be positive, meaning an increase or growth from Time 1 to Time 2 . This is further discussed in Chapter 6, based on the empirical data for the focal relationships in the sample.

\subsubsection{Dependent variables for the economic and social constructs}

The study is further concerned with the changing status of each economic and social construct within the timeframe (from Time 1 to Time 2). As noted earlier, these constructs represent particular aspects of relationships relating to the economic and social dimensions. Regression analysis at such a construct level can produce additional findings on how the foreign firms in China may differ during the relationship development process, in regard to the respective aspects 
associated with the constructs. These findings facilitate the testing of the hypotheses outlined in Chapter 3. Meanwhile, they may not be identified in the analysis for the economic ties and social bonds at the aggregate level through summations of the constructs, as described in the previous section.

Two dependent variables relating to each construct are used in the multiple regression analysis. The first dependent variable pertains to the 'initial status' of the construct at relationship formation, using the construct's Time 1 factor score in the regression modelling; the second dependent variable pertains to the 'degree of change' of the construct, and the value is computed using the construct's Time 2 factor score minus the Time 1 score. Table 5-11 shows all the dependent variables used in the construct-level analysis.

Table 5-11 Summary of dependent variables in the construct-level analysis

\begin{tabular}{|c|c|c|}
\hline & Initial status (Time 1) & Degree of change (Time 2 - Time 1 ) \\
\hline \multirow{6}{*}{$\begin{array}{l}\text { Economic } \\
\text { constructs } \\
\text { related } \\
\text { dependent } \\
\text { variables }\end{array}$} & $\begin{array}{r}\text { Economic tangible interaction at } \\
\text { formation }\end{array}$ & $\begin{array}{r}\text { Degree of change in economic tangible } \\
\text { interaction }\end{array}$ \\
\hline & $\begin{array}{r}\text { Economic intangible interaction } \\
\text { at formation }\end{array}$ & $\begin{array}{r}\text { Degree of change in economic } \\
\text { intangible interaction }\end{array}$ \\
\hline & $\begin{array}{r}\text { Economic communication at } \\
\text { formation }\end{array}$ & $\begin{array}{r}\text { Degree of change in economic } \\
\text { communication }\end{array}$ \\
\hline & Competence trust at formation & Degree of change in competence trust \\
\hline & Contractual trust at formation & Degree of change in contractual trust \\
\hline & $\begin{array}{r}\text { Economic commitment at } \\
\text { formation } \\
\end{array}$ & $\begin{array}{r}\text { Degree of change in economic } \\
\text { commitment }\end{array}$ \\
\hline \multirow{5}{*}{$\begin{array}{l}\text { Social } \\
\text { constructs } \\
\text { related } \\
\text { dependent } \\
\text { variables }\end{array}$} & Social interaction at formation & Degree of change in social interaction \\
\hline & $\begin{array}{r}\text { Social communication at } \\
\text { formation }\end{array}$ & $\begin{array}{r}\text { Degree of change in social } \\
\text { communication }\end{array}$ \\
\hline & Social trust at formation & Degree of change in social trust \\
\hline & Social commitment at formation & $\begin{array}{r}\text { Degree of change in social } \\
\text { commitment }\end{array}$ \\
\hline & Norms and values at formation & Degree of change in norms and values \\
\hline
\end{tabular}

\subsubsection{Explanatory variables}

The explanatory variables used in the regression modelling pertain to firm size, nationality and industry. These variables are introduced in this section, along with 
the approaches taken to obtain the data. For the purpose of quantitative analysis, the data for these variables are recoded before they are used in the regression modelling. The recoding process is described in detail in Chapter 6.

\subsubsection{Firm size}

As explained in Chapter 3, the hypotheses with regard to the comparison between larger and smaller firms are concerned with the subsidiary level, rather than the entire MNC. Hence, firm size is measured by a single item ${ }^{15}$ : the total number of full-time employees (FTEs) of the respondent firms, as used by other researchers (Chiao et al., 2008; Johnston and Menguc, 2007). To collect the data, eight categories by FTEs were provided in the survey instrument: namely 1-19, 20-49, 50-99, 100-199, 200-399, 400-599, 600-999, and $\geq 1$,000. Respondents were requested to select the category appropriate to their firms' situation. For the regression modelling, the original data for firm size are transformed to create two variables: SIZE1 represents three categories of firms: (1=small firms; $2=$ medium firms; and 3=large firms); SIZE2 contains two categories: ( $0=$ smaller firms; $1=$ larger firms). These two variables are used in the full-sample analysis and splitsample analysis, respectively. More descriptions and utilisation of these two variables are explained in the following chapter (Section 6.1.1).

\subsubsection{Nationality}

This variable aims to reflect the foreign cultural background of the focal firms, indicated by the nationality of a firm's foreign parent. Survey respondents were requested to indicate the location of their firms' foreign headquarters from among 16 given options, including such as the US, Europe, the UK, Japan, South Korea, Australia, Hong Kong, Taiwan, and Singapore ${ }^{16}$. These options were derived from the China's official record on sources of inward foreign direct investment

\footnotetext{
${ }^{15}$ A financial indicator for firm size - i.e. firm's total financial asset - was initially considered, but finally removed from the survey instrument, due to the concern that it might affect the response rate of the survey, as recommended by the practitioners who previewed the questionnaire.

${ }^{16}$ The assumption is made that the location of the headquarters represents the country-of-origin of the MNC. However, the researcher acknowledges that this may not always be the case.
} 
(www.stats.govt.cn). For the purpose of hypothesis testing, the data are recoded to create a categorical variable of nationality $(0=$ Asian firms; $1=$ Western firms $)$.

\subsubsection{Industry sector}

Identifications of firms' industry sectors were derived from the classification of Chinese Statistical Yearbook 2007, a method adopted by other researchers (Luo, 2003). To collect the data in the survey instrument, respondents were requested to indicate the industry sectors of their firms from 16 categories. For those firms operating in multiple industries, the study only considers the primary sector. In the regression modelling, industry sector is used as a categorical variable ( $0=$ Manufacturing; $1=$ Services). The original data for industry collected from the survey are recoded, accordingly.

\subsubsection{Control variables}

A number of control variables are included in the regression modelling. They pertain to two aspects: the organisation, including both the focal firm and the MNC (i.e. ownership structure, influence from the foreign headquarters, and presence of other subsidiary/ies in China), and the relationship addressed in the survey (i.e. relationship benefit, relationship dependence, relationship duration, and relationship satisfaction).

\subsubsection{Ownership structure}

Early studies suggest that international joint ventures and other non-equity forms such as wholly owned subsidiaries in China may differ in their capability for developing and utilising local network relationships, given the presence of local actors in the top management team (Luo, 1997). Ownership structure of the focal subsidiary in the study is controlled for in the study, and is included as a dummy variable ( 1 for international equity joint ventures; 0 for others including wholly owned subsidiaries, and wholly owned and operated representative offices) in the regression modelling. 


\subsubsection{Influence from the foreign headquarters}

Firms investigated in this study are subsidiaries of foreign MNCs. In theory, the headquarters could exert influence on its overseas subsidiaries, in terms of local networking (Andersson et al., 2002). This influence is treated as a control variable, and measured by combining two items adapted from Andersson and Forsgren's $(1996,2000)$ 'parental control' perceived by subsidiaries. Both items were assessed by a 7-point Likert Scale in the survey (1 = "Strongly disagree", 4 = "Neutral", 7 = "Strongly agree").

Table 5-12 Items for HQs' managerial influence on subsidiaries

1 Our company's business operations in China are influenced by the foreign parent / partner company's headquarters.

2 Our company follows the foreign parent / partner company's guidelines with 2 respect to developing the Chinese market.

\subsubsection{Presence of other subsidiary/ries in China}

Given the enormous size of the Chinese market, it is likely that foreign firms set up more than one subsidiary in China. According to the network theory of the MNC (Ghoshal and Bartlett, 1990), one subsidiary's experience and knowledge about the Chinese market can be transferred to another within the MNC internal network. Based on this learning effect, a focal firm with other sister subsidiary/ries in China might perform differently in networking and relationship building, compared to others having no sister subsidiary/ries. Hence, the absence or presence of other subsidiary/ries of the focal firm in China is represented as a control variable, coded as 0 and 1 , respectively.

\subsubsection{Relationship benefit and relationship dependence}

A relationship is established and developed when both parties perceive it as beneficial (Morgan and Hunt, 1994). The benefit associated with the relationship is therefore, treated as a control variable. Relationship benefit can be understood as a firm's perceived economic gain that encourages it to continue with the business relationships with its partner, in terms of aspects such as cost saving and 
value creation (Ford, 1980; Liu et al., 2005). Drawing on the previous research, this variable is measured by combining four items.

\section{Table 5-13 Items for Relationship Benefit}

1 We derive satisfactory profitability from our relationship with this customer.

2 This customer helps us to improve our products / services.

3 This customer helps us to gain advantages over our competitors.

4 This customer offers us long-term benefits, in terms of developing the Chinese market.

Moreover, relationship dependence is used as a control variable in the regression analysis. It refers to a firms' reliance on partners to achieve business success (Dwyer et al., 1987), and is often measured by firms' perceptions on the extent to which they are able to find replacements in the market (Heide, 1994), and the extent to which they need to count on the other for satisfactory market performance (Fynes et al., 2005; Jap and Anderson, 2007). Relationship dependence is also associated with the switching costs of the relationship, and can be examined by such means as the perceived consequence of relationship termination (Heide, 1994; Jap and Anderson, 2007). Styles et al. (2008) for example, look at the difficulty firms might face once a relationship is terminated. Drawing on these previous studies, four items are developed to assess relationship dependence, as shown in Table 5-14.

\section{Table 5-14 Items for Relationship Dependence}

1 It is difficult for us to find other new customers in China.

2 This customer has a big impact on our market performance in the Chinese market.

3 We have to rely on this customer to achieve business success in China.

4 Failure of the relationship with this customer would cause substantial damage to us.

Note that in the survey, the data for relationship benefit and dependence were collected not only based on the respondents' overall perception about the relationships, but also their perception with respect to the early formation stage (Time 1). This is because, compared to other control variables, such as ownership structure and the presence of other subsidiary/ries in China, relationship benefit 
and dependence are closely related to the characteristics of the focal relationships and more likely to be subject to change. Since the study is concerned with the dynamic relationship development process, it is meaningful to take the changes of these variables into consideration.

Hence, the 'initial relationship benefit' and 'initial relationship dependence' perceived by firms at Time 1 are used for the regression analysis for the formation of relationships; the 'overall relationship benefit' and 'overall relationship dependence' are used in the regression analysis for the growth of relationships. As explained earlier (see Footnote 15 in Section 5.3.4), because these two variables are concerned with different time points, a 9-point Likert scale was used in the survey to measure the items $(1=$ "Strongly disagree", $5=$ "Neutral", $9=$ "Strongly agree"). Based on the empirical data collected in the survey, reliability test was performed for these two variables. The Cronbach alpha scores for relationship benefit appeared to be acceptable ( $\alpha=0.76$ for initial relationship benefit, $\alpha=0.71$ for overall relationship benefit), so were relationship dependence ( $\alpha=0.75$ for initial relationship dependence, $\alpha=0.72$ for overall relationship dependence).

\subsubsection{Relationship duration}

The duration of a relationship is defined as the length of time from its initial formation (Time 1) toward the time of survey completion (Time 2). It is used as a control variable, because of an underlying assumption that the longer the relationship has been in existence, the more likely the relationship contains social elements, through repeated interfirm and possibly inter-personal activities (Dyer and $\mathrm{Chu}, 2000)$. In the survey, each respondent was asked to indicate the duration of the relationship, from 1 to more than 10 years, and the data are used in the regression modelling directly. Note that this variable is used only in the regressions for the growth of relationships, because the value of this variable at Time 1 is technically zero. 


\subsubsection{Relationship satisfaction}

Another control variable included in the study pertains to firms' satisfaction with the relationships. In theory, two firms tend to evaluate each other constantly during the relationship development process, and they will continue to develop the relationship if they feel satisfied with the outcome (Ring and Van de Van, 1994). Previous research also shows that the growth of trust and commitment are influenced by whether two parties meet each other's expectations in the relationship (Morgan and Hunt, 1994). In the survey, relationship satisfaction was measured by combining two items that were adopted from Styles et al. (2008), assessed by a 7-point Likert scale ( 1 = "Strongly disagree", 4 = "Neutral", 7 = "Strongly agree").

Table 5-15 Items of relationship satisfaction

1 Our decision to work with this customer was a wise one.

2 Overall, our company has been satisfied with this customer since the start of the relationship.

This control variable is used only in the regression modelling for the growth of relationships after formation, because satisfaction has to be based on the prior experience in cooperation between two parties, whereas the formation stage is only the start of a relationship, involving some, but very limited experience.

\subsubsection{Analysis strategy for regression modelling}

The analysis strategy employed in Phase 2 has three aspects. First, in order to understand the dataset, a preliminary exploration of the data for each of the variables is carried out. This includes an examination of the frequency distributions, means, medians of the data, and also other basic analysis techniques such as t-tests and scatterplots, to help identify some of the characteristics of the focal relationships. For instance, relationship constructs at the two different time points (Time 1 and Time 2) are compared, as the results might indicate whether and how the relationships changed within the focal timeframe. Also, the economic ties are compared with the social bonds, to explore if these two dimensions were 
developed evenly or unevenly in the relationships.

Second, after the preliminary analysis of the data, the study draws on multiple regression analysis to test the hypotheses. Specifically, the regression modelling addresses the relationship development process with respect to the formation and the subsequent growth, or the degree of change, within the focal timeframe (i.e. between Time 1 and Time 2). As noted earlier, the regressions are conducted at multiple levels, with respect to the economic ties and social bonds, and to the individual constructs for these two dimensions. The regression modelling structures for these two levels of analyses are shown in Tables 5-16 and 5-17, respectively. Factor scores for the economic and social constructs are used in the regression modelling for the dependent variables, as described earlier.

Third, using each of the three categorical explanatory variables introduced earlier, the full-sample is stratified into two split-samples of firms: nationality (Western firms vs. Asian firms), size (small firms vs. large firms) and industry (manufacturing firms vs. service firms). On this basis, a split-sample analysis is conducted for all the models described in Tables 5-16 and 5-17. The split-sample analysis is expected to facilitate a detailed investigation of the hypotheses, by exploring the relationships between the explanatory variables and dependent variables in more depth. For example, the estimated coefficient associated with an explanatory variable may not be significant for a dependent variable in the fullsample analysis, but it could be significant in the split-sample analysis based on (a) particular group(s) of firms. Also, if the coefficient associated with an explanatory variable is significant, then the results from the split-sample analysis could further inform whether this result is driven by particular group(s) of firms. 
Table 5-16 Regression modelling for the economic ties and social bonds

\begin{tabular}{|c|c|c|c|}
\hline Hypothesis & Dependent variable & Explanatory variables & Control variables \\
\hline $\begin{array}{l}\text { Regression modelling about relationship formation } \\
\text { (1a) Western foreign firms form stronger economic ties } \\
\text { than Asian foreign firms in their new local business } \\
\text { relationships in China. }\end{array}$ & $\begin{array}{r}\text { Economic ties at } \\
\text { relationship formation } \\
(\text { Time 1) }\end{array}$ & $\begin{array}{r}\text { Firm size, nationality, } \\
\text { industry sector }\end{array}$ & $\begin{array}{r}\text { Ownership, headquarters' } \\
\text { influence, presence of other } \\
\text { subsidiary, relationship benefit at } \\
\text { Time1, relationship dependence at } \\
\text { Time } 1\end{array}$ \\
\hline $\begin{array}{l}\text { (2a) Larger foreign firms form stronger economic ties than } \\
\text { smaller foreign firms in their new local business } \\
\text { relationships in China. }\end{array}$ & As above & As above & As above \\
\hline $\begin{array}{l}\text { (1b) Western foreign firms form weaker social bonds than } \\
\text { Asian foreign firms in their new local business } \\
\text { relationships in China. }\end{array}$ & $\begin{array}{r}\text { Social bonds at } \\
\text { relationship formation } \\
\text { (Time 1) }\end{array}$ & As above & As above \\
\hline $\begin{array}{l}\text { (2b) Larger foreign firms form weaker social bonds than } \\
\text { smaller foreign firms in their new local business } \\
\text { relationships in China. }\end{array}$ & As above & As above & As above \\
\hline $\begin{array}{l}\text { (3a) Foreign service firms form stronger social bonds than } \\
\text { foreign manufacturing firms in their new local } \\
\text { business relationships in China. }\end{array}$ & As above & As above & As above \\
\hline \multicolumn{4}{|c|}{ Regression modelling about the subsequent development of relationships } \\
\hline $\begin{array}{l}\text { (1c) After relationship formation, Western foreign firms } \\
\text { have greater growth in the economic ties than Asian } \\
\text { foreign firms in China. }\end{array}$ & $\begin{array}{l}\text { The degree of change in } \\
\text { economic ties (from } \\
\text { Time } 1 \text { to Time } 2\end{array}$ & $\begin{array}{r}\text { Firm size, nationality, } \\
\text { industry sector }\end{array}$ & $\begin{array}{r}\text { Ownership, headquarters' } \\
\text { influence, presence of other } \\
\text { subsidiary, overall relationship } \\
\text { benefit, overall relationship } \\
\text { dependence, relationship duration, } \\
\text { relationship satisfaction }\end{array}$ \\
\hline
\end{tabular}




\begin{tabular}{|c|c|c|c|}
\hline Hypothesis & Dependent variable & Explanatory variables & Control variables \\
\hline $\begin{array}{l}\text { (2c) After relationship formation, larger foreign firms have } \\
\text { greater growth in the economic ties than smaller } \\
\text { foreign firms in China. }\end{array}$ & As above & As above & As above \\
\hline $\begin{array}{l}\text { (1d) After relationship formation, Western foreign firms } \\
\text { have less growth in the social bonds than Asian } \\
\text { foreign firms in China. }\end{array}$ & $\begin{array}{r}\text { The degree of change in } \\
\text { social bonds (from Time } \\
1 \text { to Time } 2\end{array}$ & As above & As above \\
\hline $\begin{array}{l}\text { (3b) After relationship formation, foreign service firms } \\
\text { have greater growth in the economic ties than foreign } \\
\text { manufacturing firms in China. }\end{array}$ & As above & As above & As above \\
\hline
\end{tabular}


Table 5-17 Regression modelling for the economic and social constructs

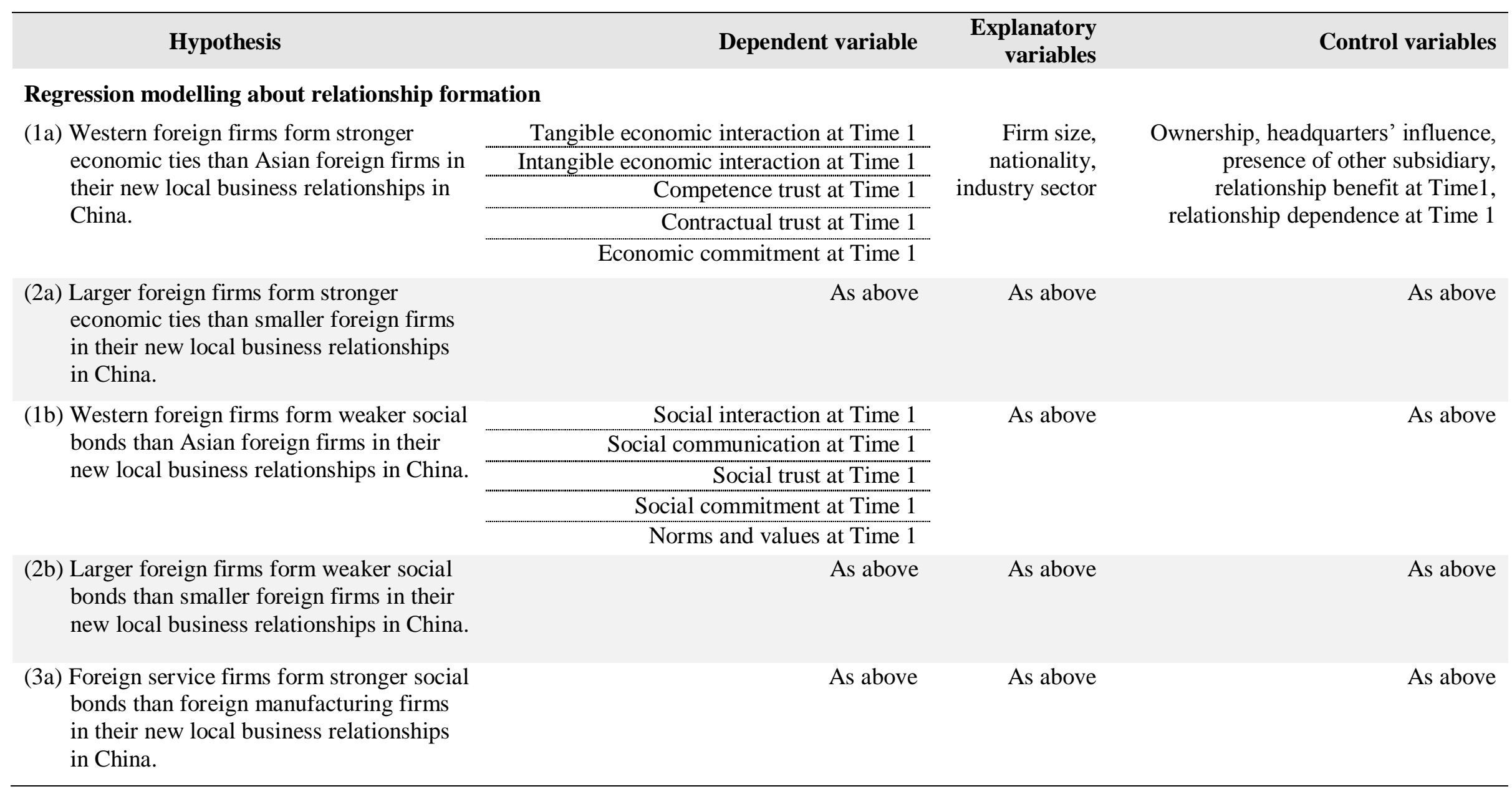




\begin{tabular}{|c|c|c|c|}
\hline Hypothesis & Dependent variable & $\begin{array}{r}\text { Explanatory } \\
\text { variables }\end{array}$ & Control variables \\
\hline \multicolumn{4}{|c|}{ Regression modelling about the subsequent development of relationships } \\
\hline $\begin{array}{l}\text { (1c) After relationship formation, } \\
\text { Western foreign firms have } \\
\text { greater growth in the economic } \\
\text { ties than Asian foreign firms in } \\
\text { China. }\end{array}$ & $\begin{array}{r}\text { Degree of change in tangible economic interaction } \\
\text { Degree of change in intangible economic interaction } \\
\text { Degree of change in competence trust } \\
\text { Degree of change in contractual trust } \\
\text { Degree of change of economic commitment }\end{array}$ & $\begin{array}{r}\text { Firm size, } \\
\text { nationality, } \\
\text { industry sector }\end{array}$ & $\begin{array}{r}\text { Ownership, headquarters' influence, } \\
\text { presence of other subsidiary, overall } \\
\text { relationship benefit, overall } \\
\text { relationship dependence, relationship } \\
\text { duration, relationship satisfaction }\end{array}$ \\
\hline $\begin{array}{l}\text { (2c) After relationship formation, } \\
\text { larger foreign firms have greater } \\
\text { growth in the economic ties } \\
\text { than smaller foreign firms in } \\
\text { China. }\end{array}$ & As above & As above & As above \\
\hline $\begin{array}{l}\text { (1d) After relationship formation, } \\
\text { Western foreign firms have less } \\
\text { growth in the social bonds than } \\
\text { Asian foreign firms in China. }\end{array}$ & $\begin{array}{r}\text { Degree of change in social interaction } \\
\text { Degree of change in social communication } \\
\text { Degree in change of social trust } \\
\text { Degree of change in social commitment } \\
\text { Degree of change in norms and values }\end{array}$ & As above & As above \\
\hline $\begin{array}{l}\text { (3b) After relationship formation, } \\
\text { foreign service firms have } \\
\text { greater growth in the economic } \\
\text { ties than foreign manufacturing } \\
\text { firms in China. }\end{array}$ & As above & As above & As above \\
\hline
\end{tabular}


Results of all the regression analyses are reported in the next chapter. During the data analysis process, before interpreting the results of regression models, the applicability of a number of assumptions necessary to undertake inference using the results was assessed. These assumptions - homoscedasticity, independence and normality of the error terms - were assessed for each model using residual analysis (Field, 2005). The residual analysis was conducted by studying the histogram of the residuals and the plot of the residuals versus the predicted values of the dependent variable. Multicollinearity, which is the result of strong linear relationships between two or more explanatory and/or control variables in the regression model, was also considered. Pairwise correlations and variance inflation factors (VIFs) were examined, to assess the potential for multicollinearity among the explanatory variables (Hair et al., 1998). This study adopts the rule that VIF score must be lower than 2.0, to ensure that multicollinearity is not creating problems with model estimation and interpretation. Then, model interpretation, including $\mathrm{F}$ values for the model and $\mathrm{t}$ values for coefficient estimates were considered. In addition, with respect to the split-sample analysis, confidence intervals for the estimated coefficients were compared for each pair of split-samples. The results show no differences in the estimated coefficients between the stratified split-samples.

\subsection{The Survey Instrument and Data Collection}

This section introduces the survey instrument, and reports the data collection process in China. In Phase 2, the study achieved a final sample of 96 foreign firms, each producing one useable response to the survey. The sample is also described briefly in this section.

\subsubsection{The survey instrument}

The survey instrument was a questionnaire containing three sections. Section 1 referred to the demographic information about the respondent's background, including gender, nationality, and position in his or her firm. Section 2 was concerned with the three explanatory variables and four control variables 
(ownership, headquarters' influence, presence of other subsidiary/ries). In Section 3 , the respondent was requested to identify one important local Chinese customer of the firm that remained active at the time of the survey. Also, the respondent had to be familiar with the history about the relationship with the chosen customer. Then, questions about this particular customer relationship were raised, to collect the data for the four control variables (relationship benefit, relationship dependence, relationship duration, and relationship satisfaction) and the dependent variables in respect to the economic and social dimensions. The order of all these questions was randomised by the researcher, in response to Chang, van Witteloostuijn and Eden's (2010) recommendation with regard to the common method variance.

A draft of the survey questionnaire was initially developed in English. According to Brislin (1980) and Douglas and Craig (2007), the draft was then translated into Chinese, and the Chinese version was back-translated into English to ensure accuracy, as well as the validity. This is also an approach adopted by other researchers conducting surveys in China (e.g. Wu, 2008; Xin and Pearce, 1996). The two language versions of questionnaire were first proofread by Chinese and English native speakers respectively, and then further reviewed by both academic experts and industry practitioners (including two managers who participated in the interviews in Phase One), to make sure that, 1) the items were consistent with the theoretical domain of the construct, 2) the items were representative of the constructs that were proposed to be measured, and 3) the items were not difficult, ambiguous or had multiple meaning. According to Creswell (1994), this procedure is crucial for a survey instrument, as it may improve the face validity, reliability, and test stability of the instrument. In addition, this procedure also allowed the researcher to estimate the time taken for completion of the questionnaire. The draft was revised based upon the feedback from these reviewers, mostly about the clarification of the questions in terms of wording and relevance, and the overall flow of the questions. 
The final English version of the questionnaire is included in Appendix 7, along with the Research Information Sheet attached to the questionnaire in Appendix 8. On the cover page of the questionnaire, it was emphasised that, there was no right or wrong answers, and the respondents were expected to provide the appropriate answer as honestly as possible. Meanwhile, respondents were allowed to indicate their interest in requesting a copy of the final report of the research.

\subsubsection{Data collection methods and the sample}

The survey was conducted between October 2008 and December 2008. The target respondent firms were the subsidiaries of foreign MNCs operating in China. Multiple methods were undertaken to collect the data in the Shanghai region. These are described as follows.

First, from the latest edition 'Foreign Companies and Representative Offices in Shanghai $2008^{17}$, the researcher selected 350 firms that were diverse in nationality, size and industry. In October 2008, a letter enclosing a copy of the questionnaire and Research Information Sheet, both the English and Chinese versions, was posted to these 350 firms. Three weeks after the mail-out (international airmail from New Zealand to China takes up to two weeks), a reminder email instead of a follow-up postal reminder was sent to these firms, due to the constraint of the financial budget.

The researcher also attempted to gain access to firms through other sources. As the second method, assistance was sought from a well-respected local university in Shanghai, a method used by other researchers especially in emerging economies like China (Zhou et al., 2007). Two lecturers at the university helped in the recruitment of a group of business students to act as research assistants. These students were instructed to approach local firms, and invite them to participate in the research. A name list of the 350 firms mentioned above was also provided to the students, to make sure they would not be approached twice. This data

\footnotetext{
17 This catalogue was published by the local government authorities, containing information on more than 3,000 foreign firms registered in Shanghai.
} 
collection process took up to three weeks, and produced 70 returned questionnaires. To ensure the validity of the questionnaire, the two lecturers monitored the entire data collection process. The researcher also checked approximately 30 questionnaires by calling the respondents, according to the name and telephone number voluntarily provided by them in the questionnaire. They were all proved to be genuine.

The third method follows Cycyota and Harrison's (2006) suggestion that, in survey research, sponsorship by an organisation or person in the informants' social networks can significantly increase response rate. It may be argued that, because the Chinese social network based culture emphasises personal ties, the referral-based approach may be even more effective. Hence, the researcher contacted people he knew in Shanghai who were capable of accessing foreign firms for the survey.

By December 2008, 118 questionnaires were collected from all these three methods, and 22 were discarded as they either were incomplete or contained too much unusable information. The final sample, therefore, contains 96 useable questionnaire responses from firms located in the Shanghai region. Table 5-18 provides an overview of the number of the questionnaire returns generated from each method. Compared to postal survey, the other two were much more effective. As the sample was achieved via three different methods, the overall response rate cannot be calculated for the study.

Table 5-18 Survey responses in Phase 2

\begin{tabular}{llcrc}
\hline No. & \multicolumn{1}{c}{ Method } & $\begin{array}{c}\text { Total } \\
\text { response }\end{array}$ & $\begin{array}{c}\text { Response } \\
\text { rate }\end{array}$ & $\begin{array}{c}\text { Valid } \\
\text { questionnaires }\end{array}$ \\
1 & Random postal survey & 6 & $1.7 \%$ & 5 \\
2 & Collaboration with local university & 70 & $23.4 \%$ & 59 \\
3 & Access through a third-party & 42 & $55.7 \%$ & 32 \\
& Total & 118 & n.a & 96 \\
\hline
\end{tabular}


The sample firms and focal relationships generated from methods 2 and 3 were compared by the researcher. The results show that among the 59 firms from method 2, 59 per cent were from Asian countries and 41 per cent were from the West; and among the 32 firms from method 3, those from Asian countries accounted for 54 per cent. On average, firms from method 2 had been operating in China for 10 years, compared to 12 years for the firms from method 3 . Also, the average size for firms produced by both methods 2 and 3 both fell into the 400599 category specified in the survey. In terms of the duration for the focal customer relationships, the mean was 4.7 years for method 2, and 5.1 years for method 3. Based on these results, it may be argued that there is no apparent difference between the split-samples generated from these two methods.

To further compare the survey to previous studies, Table 5-19 shows the data collection methods of, and the response rates for, surveys previously undertaken by other researchers in China.

Table 5-19 Examples of previous surveys in China

\begin{tabular}{lllll}
\hline No. & Data Collection Method & $\begin{array}{l}\text { Total } \\
\text { response }\end{array}$ & $\begin{array}{l}\text { Response } \\
\text { rate }\end{array}$ & Source \\
1 & Random postal survey & 127 & $31.8 \%$ & Peng and Luo (2000) \\
2 & Random postal survey & 364 & $36.4 \%$ & Luo (2003) \\
3 & Random postal survey & 108 & $11 \%$ & $\mathrm{Wu}(2008)$ \\
4 & $\begin{array}{l}\text { Survey conducted by local } \\
\text { research assistants }\end{array}$ & 201 & $93 \%$ & $\mathrm{Wu}(2004)$ \\
5 & $\begin{array}{l}\text { Hiring local business students } \\
\text { as independent contractors }\end{array}$ & 129 & $\mathrm{n} / \mathrm{a}$ & Zhou, Wu and Luo (2007) \\
6 & $\begin{array}{l}\text { Survey conducted by a local } \\
\text { research company }\end{array}$ & 145 & $73 \%$ & $\begin{array}{l}\text { Zhao, Yeung and Lee } \\
\text { (2004) }\end{array}$ \\
7 & $\begin{array}{l}\text { Survey conducted by a local } \\
\text { research company }\end{array}$ & 181 & $30.2 \%$ & Li (2005) \\
8 & $\begin{array}{l}\text { Survey conducted by a local } \\
\text { research company }\end{array}$ & 128 & $32 \%$ & Park and Luo (2001) \\
9 & $\begin{array}{l}\text { Cooperation with the State } \\
\text { Statistics Bureau }\end{array}$ & 274 & $45.7 \%$ & Yiu, Lau and Bruton (2007) \\
\hline
\end{tabular}


Table 5-20 presents the specific types of customer relationships the respondents defined in the questionnaires. It can be seen that the 'end-users' account for the largest portion in the sample, followed by 'sales agents' and 'distributors'.

Table 5-20 Types of relationships in the survey

\begin{tabular}{cll}
\hline Relationship type & $\mathrm{N}^{*}$ & Percentage \\
End-users & 45 & 46.9 \\
Sales agents & 24 & 25 \\
Distributors & 16 & 16.7 \\
Other & 11 & 11.5
\end{tabular}

* As explained to the respondents in the questionnaire, the defined 'customer' can play multiple roles such as both the sales agent and distributor. Therefore, the total number of this column is more than 96.

Table 5-21 shows the background of the respondents. Most respondents were top managers in the participating firms. 40 were marketing directors, which was appropriate for the study that was concerned with firms' customer relationships. 56 respondents were male, and 39 were female. The majority of the respondents were Chinese.

Table 5-21 Demographic information of the respondents

\begin{tabular}{cllr}
\hline Respondents background & & & \\
Gender & N & Position in company & N \\
Male & 56 & CEO / GM & 15 \\
Female & 39 & Chief Representative & 13 \\
Missing & 1 & Marketing manager / director & 40 \\
Nationality & N & Production manager / & 18 \\
Chinese & 89 & director & 9 \\
Non-Chinese & 6 & Other & 1 \\
Missing & 1 & & \\
\hline
\end{tabular}

\subsection{Chapter Summary}

This chapter addresses several key methodological aspects of the quantitative Phase 2 in the study. It highlights the research objective and describes the research design for Phase 2. Then, it outlines the constructs and measurement for the economic and social dimensions of business relationships. These constructs are 
largely derived from the extant literature, and their associated items are further examined by factor analysis using the empirical quantitative data obtained from the survey administered in Phase 2. Based on these constructs, the dependent variables used for data analysis are explained, followed by the introduction of the explanatory variables and control variables. Next, the analysis strategy for using multiple regression modelling to test the hypotheses stated in Chapter 3 is highlighted. Last, the chapter reports the empirical data collection process, and provides a brief overview of the sample profile.

The next chapter presents the analyses of the quantitative data from the 96 respondent firms. Results from the multiple regression analysis, including the hypothesis testing are highlighted. 


\section{Chapter Six Quantitative Data Analysis and Results}

\subsection{Chapter Objectives}

In this chapter, the quantitative data from the 96 survey responses obtained in Phase 2 are analysed. First, the data are explored to provide an understanding of the sample firms and the focal customer relationships. Empirical support for the two-dimensional view developed in Phase 1 is also highlighted. Second, the analysis and results for the main focus of Phase 2, which is the second research question, are presented. Following the analysis strategy described in Chapter 5, multiple regression analysis is conducted to test the hypotheses. The regression modelling is run at different levels with respect to the economic ties and social bonds, and the individual constructs for these two dimensions. In the meantime, the regression modelling is run based not only the full-sample, but also on the split-samples stratified by firms' nationality, size and industry sector, as the splitsample analysis assists with detailed investigation of the hypotheses. Results from the multiple regression analysis are reported along with the findings in relation to the hypotheses. The statistical programme SPSS 17.0 is used for the quantitative analysis.

\subsection{Data for the Variables}

An important step prior to statistical analysis is for researchers to gain familiarity with the data (Field, 2005). To address this, the data for the variables used in the multiple regression analysis are explored. In this section, the data for the explanatory variables are first presented and recoded for the regression modelling. Then, the data for the dependent variables are analysed to identify the different economic and social nature of the focal relationships, and to assess the changes of these relationships from Time 1 (the relationship formation) to Time 2 (the time of survey completion). Last, the data for the control variables are described. 


\subsubsection{Data for the explanatory variables}

The explanatory variables employed in Phase 2 pertain to firms' nationality, size and industry sector. Firm nationality is indicated by the location of the foreign firm's headquarters; firm size is measured by the number of full-time employees (FTEs) at the time of the survey completion; and firm industry refers to the primary industry sector for the firm's business. Frequencies of the data for these variables are displayed in Table 6-1, in order to show the sample firms' characteristics with regard to the three aspects.

As shown in the table, the sample contains a range of firms with different characteristics. For the purpose of testing the hypotheses, the original data for the explanatory variables were recoded. As described in Chapter 5, first, to compare Western and Asian foreign firms operating in China, the categorical explanatory variable NATIONALITY was created $(0=$ Asian firms; $1=$ Western firms). Specifically, firms with foreign headquarters located in East Asian and South East Asian countries such as Japan, South Korea, Malaysia and Thailand were categorised to be Asian firms, and those with headquarters located in North America and Europe, including the UK, were regarded as Western firms. Second, SIZE1 was created, defining firms in three categories: small, medium and large ${ }^{18}$. The other size related categorical variable SIZE2 ( $0=$ Small firms; $1=$ Large firms) was also created to divide firms into two sub-groups, adopting the median (400 employees approximately) as the cut-off point, for the purpose of split-sample analysis. Third, INDUSTRY was created to reflect two categories $(0=$ Manufacturing; $1=$ Services). The services category includes all the industries except for the manufacturing industry shown in Table 6-3. In the regression modelling, NATIONALITY and INDUSTRY were used for both the full-sample and split-sample analyses; SIZE1 and SIZE2 were used for the full-sample and split-sample analyses, respectively.

\footnotetext{
${ }^{18}$ The definition of small- and medium-sized firms in China is complex and varies greatly across industries (www.stats.govt.cn). For the purpose of the study, in the full-sample analysis, firms with less than 200 employees are regarded to be 'small', more than 600 employees are regarded to be 'large', and those in between are considered to be 'medium', as shown in Table 6-4.
} 
Table 6-1: Nationality, size and industry of the sample firms

\begin{tabular}{lrr}
\hline Location of the headquarters & $\mathrm{N}$ & Percent \\
US & 31 & 31.3 \\
Canada & 1 & 1.0 \\
UK & 3 & 3.1 \\
Europe & 17 & 17.7 \\
New Zealand & 1 & 1.0 \\
Japan & 13 & 13.5 \\
Korea & 6 & 6.3 \\
Hong Kong & 17 & 17.7 \\
Taiwan & 1 & 1.0 \\
Singapore & 4 & 5.2 \\
Other & 2 & 2.1 \\
Total & 96 & 100 \\
Number of full-time employees & & \\
1-19 & 7 & 7.3 \\
20-49 & 9 & 9.4 \\
50-99 & 6 & 6.3 \\
100-199 & 17 & 17.7 \\
200-399 & 10 & 10.4 \\
400-599 & 13 & 13.5 \\
600-999 & 10 & 10.4 \\
ב 1,000 & 24 & 25.0 \\
Total & 96 & 100 \\
Primary industry & & \\
Manufacturing & 42 & 43.7 \\
Construction & 4.2 \\
Transportation and storage & 5 & 5.2 \\
Communication, ITS & 10 & 10.4 \\
Wholesale and retail & 7 & 7.3 \\
Hotel and restaurants & 3 & 3.1 \\
Finance \& intermediation & 4 & 4.2 \\
Real estate & 3 & 3.1 \\
Renting \& business services & 6 & 6.3 \\
Education & 2 & 2.1 \\
Health \& community services & 1 & 1.0 \\
Cultural \& recreational services & 4 & 4.2 \\
Other & 5 & 5.2 \\
Total & 96 & 100 \\
\hline
\end{tabular}

Frequency distributions of the four recoded variables are presented in Table 6-2. Each of the three dichotomous explanatory variables - NATIONALITY, SIZE2 and INDUSTRY - divides the full sample into two split-samples, which allows for conducting the split-sample analysis in the regression modelling. Namely, the 
six defined split-samples underpinning the split-sample analysis are Asian firms ( $\mathrm{N}=41)$ as opposed to Western firms $(\mathrm{N}=55)$, small firms $(\mathrm{N}=49)$ as opposed to large firms $(\mathrm{N}=47)$, and manufacturing firms $(\mathrm{N}=42)$ as opposed to service firms $(\mathrm{N}=54)$.

Table 6-2 Explanatory variables used in regression modelling

\begin{tabular}{|c|c|c|c|}
\hline Recoded variable & Description & $\mathrm{N}$ & Percent \\
\hline \multicolumn{4}{|l|}{ NATIONALITY } \\
\hline Asian (0) & $\begin{array}{l}\text { Japan, S. Korea, Taiwan, HK, } \\
\text { Singapore }\end{array}$ & 41 & $43 \%$ \\
\hline Western (1) & US, Canada, UK, Europe, NZ, other & 55 & $57 \%$ \\
\hline Total & & 96 & $100 \%$ \\
\hline \multicolumn{4}{|c|}{ SIZE1 (used in full-sample analysis only) } \\
\hline Small & $0<$ FTEs $\leq 199$ & 39 & $41 \%$ \\
\hline Medium & $200 \leq$ FTEs $\leq 599$ & 23 & $24 \%$ \\
\hline Large & FTEs $\geq 600$ & 34 & $35 \%$ \\
\hline Total & & 96 & $100 \%$ \\
\hline \multicolumn{4}{|c|}{ SIZE2 (used in split-sample analysis only) } \\
\hline Small (0) & $0<$ FTEs $\leq 399$ & 49 & $51 \%$ \\
\hline Large (1) & FTEs $\geq 400$ & 47 & $49 \%$ \\
\hline Total & & 96 & $100 \%$ \\
\hline \multicolumn{4}{|l|}{ INDUSTRY } \\
\hline Manufacturing (0) & Manufacturing & 42 & $44 \%$ \\
\hline \multirow[t]{14}{*}{ Services (1) } & Construction & 54 & $56 \%$ \\
\hline & Manufacturing & & \\
\hline & Electricity, gas and water & & \\
\hline & Transportation and storage & & \\
\hline & Communication, ITS & & \\
\hline & Wholesale and retail & & \\
\hline & Hotel and restaurants & & \\
\hline & Finance \& intermediation & & \\
\hline & Real estate & & \\
\hline & Renting \& business services & & \\
\hline & Education & & \\
\hline & Health \& community services & & \\
\hline & Cultural \& recreational services & & \\
\hline & Other & & \\
\hline Total & & 96 & $100 \%$ \\
\hline
\end{tabular}

\subsubsection{Data for the dependent variables}

The dependent variables in Phase 2 pertain to the economic and social nature of business relationships at Time 1 (relationship formation), and their subsequent changes noted by Time 2 (the time of the survey completion). In the survey, data 
for the economic and social constructs were collected from a 9-point Likert scale, with respect to both Time 1 and Time 2. The data in respect to these two times allow the researcher to compute the degree of change of the focal relationships over time. Descriptive statistics for the data for economic ties are reported in Table 6-3, and the data for social bonds are reported in Table 6-4.

Tables 6-3 and 6-4 show that there were missing data for the items. Missing data in this study may be caused by respondents accidently missing out questions, not knowing the answers, or considering the questions as being inapplicable ${ }^{19}$. Given the small percentage of these missing data, they were replaced by the sample mean, a common method used by other researchers to address this issue (Hair et al., 1998). The two tables also reveal that the sample mean of each item at Time 2 seems to be higher than at Time 1, suggesting the possibility of a degree of increase in the economic and social dimensions of these relationships over this time period.

${ }^{19}$ The 'don't know' and 'not applicable' options in the questionnaire were treated as missing values in the data analysis. 
Table 6-3: Descriptive statistics of economic constructs and items

\begin{tabular}{|c|c|c|c|c|c|c|c|c|c|c|c|c|}
\hline \multirow{2}{*}{$\begin{array}{c}\text { Economic dimension } \\
\text { Surveyed by a 9-point Likert scale }\end{array}$} & \multicolumn{6}{|c|}{ Time 1: Initial formation } & \multicolumn{6}{|c|}{ Time 2: Survey completion } \\
\hline & $\mathrm{N}$ & Min & Max & Mean & Std. Dev & Median & $\mathrm{N}$ & Min & Max & Mean & Std. Dev & Median \\
\hline \multicolumn{13}{|l|}{ Tangible economic interaction about } \\
\hline - volume of transactions & 92 & 1 & 9 & 4.97 & 2.57 & 5.0 & 95 & 1 & 9 & 6.77 & 1.89 & 7.0 \\
\hline - frequency of transactions & 91 & 1 & 9 & 5.33 & 2.43 & 5.0 & 92 & 1 & 9 & 6.67 & 1.90 & 7.0 \\
\hline - working on multiple projects & 92 & 1 & 9 & 4.98 & 2.70 & 5.0 & 92 & 1 & 9 & 6.17 & 2.48 & 7.0 \\
\hline - revenue derived from the customer & 92 & 1 & 9 & 5.43 & 2.41 & 5.5 & 93 & 1 & 9 & 6.41 & 2.10 & 7.0 \\
\hline \multicolumn{13}{|l|}{ Intangible economic interaction about } \\
\hline - resource sharing & 89 & 1 & 9 & 3.48 & 2.44 & 3.0 & 90 & 1 & 9 & 4.33 & 2.46 & 5.0 \\
\hline - technology transfer & 88 & 1 & 9 & 5.18 & 2.85 & 5.0 & 89 & 1 & 9 & 5.70 & 2.57 & 6.0 \\
\hline - managerial knowledge transfer & 87 & 1 & 9 & 4.80 & 2.61 & 5.0 & 88 & 1 & 9 & 5.84 & 2.27 & 6.0 \\
\hline \multicolumn{13}{|l|}{ Economic communication about } \\
\hline - business meetings and visits & 94 & 1 & 9 & 5.87 & 2.46 & 7.0 & 94 & 1 & 9 & 6.61 & 2.11 & 7.0 \\
\hline - understanding on price & 94 & 1 & 9 & 6.50 & 2.13 & 7.0 & 94 & 1 & 9 & 7.28 & 1.90 & 8.0 \\
\hline - understanding on quality & 93 & 1 & 9 & 6.80 & 1.97 & 7.0 & 93 & 1 & 9 & 7.71 & 1.54 & 8.0 \\
\hline - understanding on delivery & 89 & 1 & 9 & 6.99 & 2.00 & 7.0 & 90 & 3 & 9 & 7.80 & 1.42 & 8.0 \\
\hline - updating project progress & 90 & 1 & 9 & 6.26 & 2.28 & 7.0 & 90 & 1 & 9 & 7.14 & 1.94 & 7.0 \\
\hline - informing customers timely & 92 & 1 & 9 & 6.80 & 2.24 & 7.0 & 92 & 1 & 9 & 7.41 & 1.92 & 8.0 \\
\hline - knowing whom to discuss & 92 & 1 & 9 & 7.20 & 1.88 & 8.0 & 92 & 3 & 9 & 7.82 & 1.48 & 8.0 \\
\hline \multicolumn{13}{|l|}{ Competence trust about customer's } \\
\hline - market reputation & 90 & 1 & 9 & 6.46 & 2.43 & 7.0 & 91 & 2 & 9 & 7.19 & 1.87 & 8.0 \\
\hline - market influence & 92 & 1 & 9 & 6.24 & 2.52 & 7.0 & 93 & 1 & 9 & 6.84 & 2.08 & 7.0 \\
\hline - growth potential & 95 & 1 & 9 & 6.55 & 2.08 & 7.0 & 95 & 3 & 9 & 7.20 & 1.61 & 7.0 \\
\hline - knowledge about us & 91 & 1 & 9 & 6.46 & 2.07 & 7.0 & 92 & 4 & 9 & 7.48 & 1.51 & 8.0 \\
\hline - understanding on our price & 90 & 1 & 9 & 5.99 & 2.26 & 6.0 & 89 & 1 & 9 & 6.63 & 1.92 & 7.0 \\
\hline - financial situation & 89 & 2 & 9 & 6.83 & 1.93 & 7.0 & 89 & 1 & 9 & 7.12 & 1.76 & 7.0 \\
\hline \multicolumn{13}{|l|}{ Contractual trust about } \\
\hline - customer making their payment on time & 90 & 1 & 9 & 6.99 & 1.9 & 7.0 & 92 & 4 & 9 & 7.31 & 1.65 & 8.0 \\
\hline - customer behaving as agreed & 93 & 2 & 9 & 6.95 & 1.76 & 7.0 & 93 & 3 & 9 & 7.51 & 1.48 & 8.0 \\
\hline - customer's honesty & 89 & 1 & 9 & 6.63 & 1.90 & 7.0 & 90 & 1 & 9 & 7.04 & 1.66 & 7.0 \\
\hline \multicolumn{13}{|l|}{ Economic commitment about } \\
\hline - accomplishing business tasks & 95 & 2 & 9 & 7.33 & 1.79 & 8.0 & 95 & 1 & 9 & 7.93 & 1.39 & 8.0 \\
\hline - increasing the level of cooperation & 95 & 2 & 9 & 7.18 & 1.91 & 8.0 & 95 & 4 & 9 & 7.62 & 1.35 & 8.0 \\
\hline - maintaining a long-term relationship & 94 & 2 & 9 & 7.17 & 1.82 & 8.0 & 94 & 3 & 9 & 7.78 & 1.45 & 8.0 \\
\hline - growing business with the customer & 96 & 1 & 9 & 6.74 & 2.28 & 7.5 & 96 & 1 & 9 & 7.13 & 1.97 & 8.0 \\
\hline
\end{tabular}


Table 6-4: Descriptive statics of social constructs and items

\begin{tabular}{|c|c|c|c|c|c|c|c|c|c|c|c|c|}
\hline \multirow{2}{*}{$\begin{array}{l}\text { Social dimension } \\
\text { Surveyed by a 9-point Likert scale }\end{array}$} & \multicolumn{6}{|c|}{ Time 1: Initial formation } & \multicolumn{6}{|c|}{ Time 2: Survey completion } \\
\hline & $\mathrm{N}$ & Min & Max & Mean & Std. Dev & Median & $\mathrm{N}$ & Min & $\operatorname{Max}$ & Mean & Std. Dev & Median \\
\hline \multicolumn{13}{|l|}{ Social interaction about } \\
\hline - inviting customer to social events & 90 & 1 & 9 & 5.74 & 2.64 & 6.0 & 89 & 1 & 9 & 6.35 & 2.33 & 6.5 \\
\hline - getting together primarily for fun & 91 & 1 & 9 & 5.66 & 2.53 & 6.0 & 90 & 1 & 9 & 6.22 & 2.33 & 6.5 \\
\hline - socialising activities (e.g. dinner and drinks) & 92 & 1 & 9 & 5.83 & 2.56 & 6.0 & 92 & 1 & 9 & 6.42 & 2.35 & 7.0 \\
\hline - visiting customer during holidays & 90 & 1 & 9 & 5.69 & 2.90 & 6.0 & 90 & 1 & 9 & 6.18 & 2.78 & 7.0 \\
\hline - gifting during holidays & 90 & 1 & 9 & 5.86 & 2.80 & 6.0 & 90 & 1 & 9 & 6.45 & 2.60 & 7.0 \\
\hline \multicolumn{13}{|l|}{ Social communication about } \\
\hline - sharing additional information & 89 & 1 & 9 & 5.57 & 2.55 & 6.0 & 88 & 1 & 9 & 6.44 & 2.40 & 7.0 \\
\hline - discussing rather than price and volume & 88 & 1 & 9 & 6.36 & 2.44 & 7.0 & 92 & 1 & 9 & 7.30 & 1.82 & 8.0 \\
\hline - sharing information on future strategy & 88 & 1 & 9 & 6.03 & 2.26 & 6.0 & 89 & 1 & 9 & 6.84 & 2.12 & 7.0 \\
\hline - seeking customer's advice and guidance & 89 & 1 & 9 & 5.21 & 2.51 & 6.0 & 89 & 1 & 9 & 5.81 & 2.46 & 6.0 \\
\hline \multicolumn{13}{|l|}{ Social trust about customer's } \\
\hline - concern on company's welfare & 88 & 1 & 9 & 5.50 & 2.37 & 6.0 & 89 & 1 & 9 & 5.94 & 2.25 & 7.0 \\
\hline - verbal and informal agreement & 89 & 1 & 9 & 4.95 & 2.54 & 5.0 & 90 & 1 & 9 & 5.72 & 2.33 & 6.0 \\
\hline - taking no advantage of company & 90 & 1 & 9 & 5.20 & 2.25 & 5.0 & 91 & 1 & 9 & 5.69 & 2.16 & 6.0 \\
\hline - willingness to maintain relationship & 86 & 1 & 9 & 5.84 & 2.24 & 6.0 & 90 & 1 & 9 & 6.58 & 2.15 & 7.0 \\
\hline \multicolumn{13}{|l|}{ Social commitment about } \\
\hline - forgiving customer's mistake & 90 & 1 & 9 & 6.53 & 2.10 & 7.0 & 92 & 2 & 9 & 6.85 & 1.77 & 7.0 \\
\hline - making sacrifice for customer & 90 & 1 & 9 & 6.23 & 2.10 & 6.5 & 91 & 1 & 9 & 6.82 & 1.70 & 7.0 \\
\hline - being flexible on customer & 89 & 1 & 9 & 6.48 & 2.13 & 7.0 & 92 & 2 & 9 & 7.13 & 1.69 & 7.0 \\
\hline - maintaining social bonds with customer & 89 & 1 & 9 & 6.51 & 2.35 & 7.0 & 91 & 1 & 9 & 6.91 & 2.24 & 7.0 \\
\hline \multicolumn{13}{|l|}{ Norms and values about } \\
\hline - 'sink or swim' together with customer & 89 & 1 & 9 & 5.40 & 2.80 & 6.0 & 89 & 1 & 9 & 5.81 & 2.54 & 6.0 \\
\hline - considering customer as 'one of us' & 92 & 1 & 9 & 6.00 & 2.55 & 7.0 & 94 & 1 & 9 & 6.44 & 2.28 & 7.0 \\
\hline - similar business philosophies with customer & 89 & 1 & 9 & 6.03 & 1.98 & 6.0 & 91 & 1 & 9 & 6.41 & 1.89 & 7.0 \\
\hline - similar views of the Chinese market & 90 & 1 & 9 & 6.06 & 2.07 & 6.0 & 92 & 1 & 9 & 6.35 & 2.00 & 7.0 \\
\hline - compatible economic goals & 89 & 1 & 9 & 6.73 & 1.97 & 7.0 & 89 & 1 & 9 & 7.11 & 1.78 & 8.0 \\
\hline - similar business approaches & 87 & 1 & 9 & 5.27 & 2.14 & 5.0 & 89 & 1 & 9 & 5.90 & 2.09 & 6.0 \\
\hline
\end{tabular}


Further, t-tests were conducted to examine the differences in the means of each construct between Time 1 and Time 2. These constructs consist of the items shown in Tables 6-3 and 6-4. For the purpose of conducting t-tests, the value for each construct was obtained by aggregating the original data from the respective items from the 9-point Likert scale, and dividing by the number of items. Results of the t-tests are presented in Table 6-5.

Table 6-5 T-tests for means of relationship constructs between Time 1 and Time 2

\begin{tabular}{lcccccc}
\hline & \multicolumn{2}{c}{ Time1 } & \multicolumn{2}{c}{ Time2 } & & $\mathrm{t}^{*}$ \\
& Mean & SE & Mean & SE & df & (Time 1 - Time 2) \\
Economic constructs & & & & & & \\
$\quad$ Tangible economic interaction & 5.18 & 0.20 & 6.51 & 1.54 & 95 & $-7.68 * * *$ \\
$\quad$ Intangible economic interaction & 4.48 & 1.88 & 5.29 & 1.73 & 95 & $-6.25 * * *$ \\
Economic communication & 6.64 & 1.55 & 7.40 & 1.23 & 95 & $-7.53 * * *$ \\
Competence trust & 6.43 & 1.64 & 7.08 & 1.22 & 95 & $-5.82 * * *$ \\
Contractual trust & 6.86 & 1.53 & 7.29 & 1.26 & 95 & $-4.03 * * *$ \\
Economic commitment & 7.11 & 1.61 & 7.61 & 1.26 & 95 & $-4.30 * * *$ \\
Social constructs & & & & & & \\
$\quad$ Social interaction & 5.76 & 2.10 & 6.33 & 1.88 & 95 & $-4.82 * * *$ \\
$\quad$ Social communication & 5.80 & 1.74 & 6.60 & 1.53 & 95 & $-5.77 * * *$ \\
$\quad$ Social trust & 5.37 & 1.59 & 5.98 & 1.51 & 95 & $-4.49 * * *$ \\
$\quad$ Social commitment & 6.44 & 1.59 & 6.93 & 1.27 & 95 & $-4.48 * * *$ \\
$\quad$ Norms and values & 5.91 & 1.54 & 6.34 & 1.40 & 95 & $-3.90 * * *$ \\
\hline$\quad * \mathrm{p}<0.10, * * \mathrm{p}<0.05, * * * \mathrm{p}<0.01$ & & & & & \\
\hline
\end{tabular}

The results suggest that the means for these economic and social constructs at the time of survey completion were significantly higher than the means at the time of relationship formation. This shows an increase in the constructs relating to the economic and social dimensions, and provides evidence that the relationships investigated in Phase 2 have generally experienced growth from the initial formation stage to the time of survey, meaning that the degree of change of these relationships was positive.

Moreover, $\mathrm{t}$-tests were conducted to compare the means for the economic ties and social bonds at both Time 1 and Time 2, rather than their component constructs. For the purpose of the t-test procedure, the values for the economic ties and social 
bonds of each focal relationship were calculated, by summing the original data for all the items in each dimension and dividing by the total number of the items ${ }^{20}$. The results show that at Time 1 , the means of the economic ties (Mean $=6.23, \mathrm{SE}$ $=0.13)$ were significantly higher than the means of the social bonds (Mean $=5.81$, $\mathrm{SE}=1.33, \mathrm{p}<0.01)$. Similar results can be seen for Time 2 , as the means of the economic ties $($ Mean $=6.98, \mathrm{SE}=0.10)$ were also significantly higher than the means of the social bonds (Mean $=6.42, \mathrm{SE}=0.12, \mathrm{p}<0.01$ ). These results suggest the degree to which economic and social dimensions of the relationships in the sample were developed was not even, at the formation stage, and at the time of survey completion.

Moreover, for an overview of the relationships investigated in the survey, two scatterplots of the focal relationships are produced with respect to Time 1 and Time 2, using the values for the economic ties and social bonds explained above. As shown in Figures 6-1a and 6-1b, the horizontal axes for the scatterplots are represented by the economic ties, and the vertical axes are represented by the social bonds.

\footnotetext{
${ }^{20}$ In the later regression analysis, however, the values for the overall economic ties and social bonds were obtained using the factor scores of the constructs.
} 


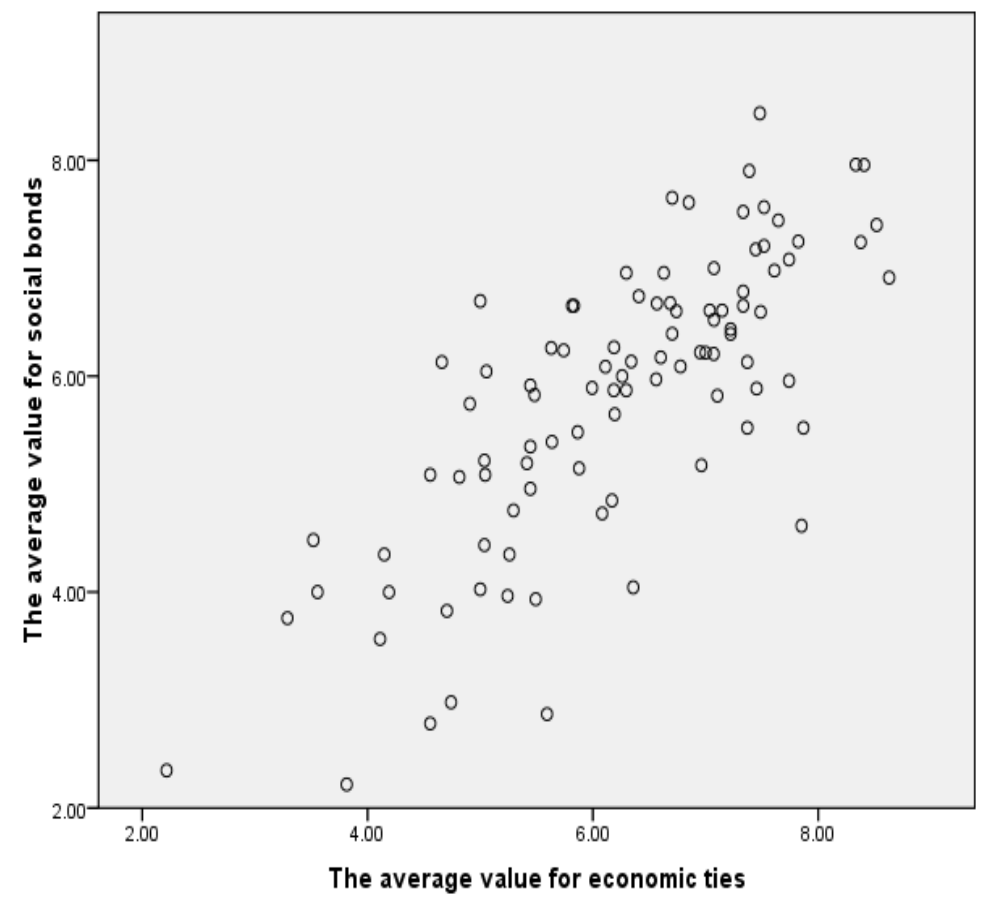

Figure 6-1a Scatterplots for the relationships in the survey at Time 1 (relationship formation)

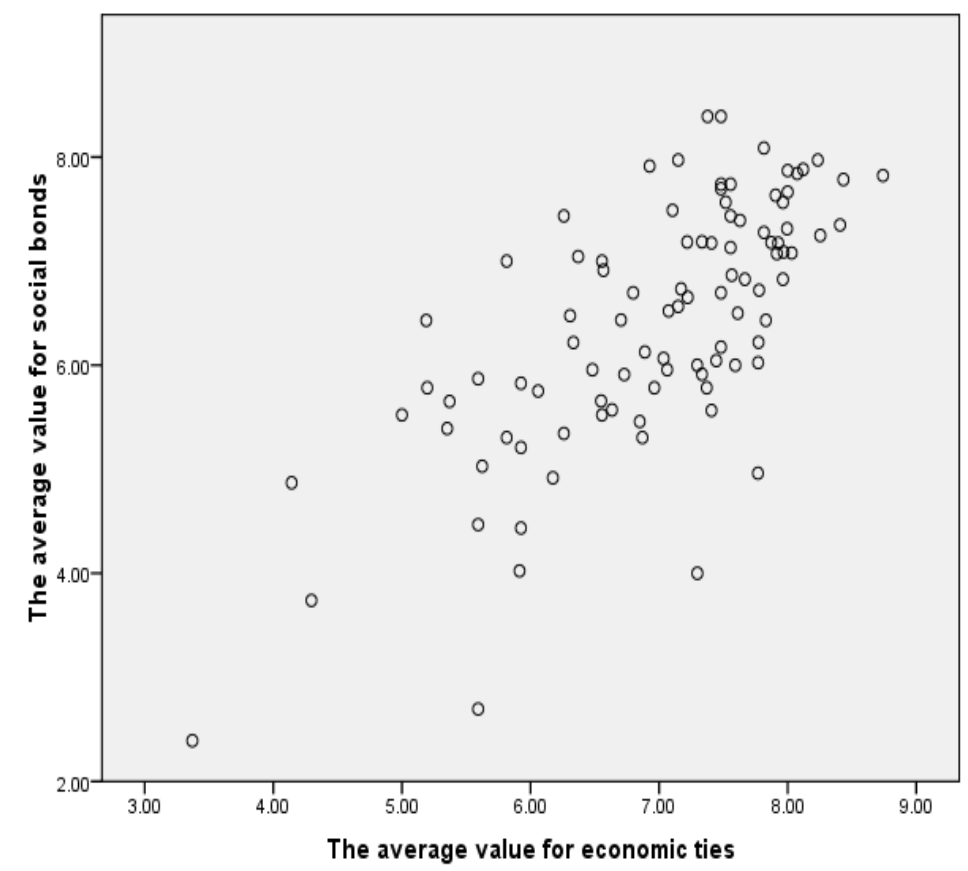

Figure 6-1b Scatterplots for the relationships in the survey at Time 2 (the time of survey completion) 
These two scatterplots illustrate the focal relationships by their economic and social nature. Three initial observations can be drawn from these visual representations. First, there appears to be a general trend in the data, such that higher levels of economic ties are associated with higher levels of social bonds. This is not surprising because these two dimensions, i.e. the economic ties and social bonds, are interrelated to some extent, as described in the literature. Second, however, the relative levels of economic and social dimension differ amongst the different relationships, reflecting seemingly unequal combinations of social and economic dimensions amongst the firms. This relates to the two-dimensional view forming the focus of this study, indicating that examining relationships by their separate economic and social dimensions may be a more appropriate approach than examining them as entirely interwoven. The data comprising these two scatterplots therefore, support the conceptual views developed in Chapter 3 and illustrated by the matrix in Chapter 4, based on the qualitative findings (see Figure 4-2). Third, from a visual perspective, the patterns of relationships at Time 1 and Time 2 do not appear to be identical. This may be in response to the results obtained in the t-tests that suggest a positive degree of change occurring between the two time points, along the economic and social dimensions. This changing nature of these relationships is of key interest in Phase 2, and is examined through multiple regression analysis later in this chapter.

\subsubsection{Data for the control variables}

The control variables employed in this study are related to two aspects: the respondent firms and the focal dyads. They pertain to firms' ownership, presence of the MNC's other subsidiaries in China, influence from the headquarters, relationship duration, relationship benefit, relationship dependence, and relationship satisfaction.

As explained in Chapter 5, the data for 'relationship benefit' and 'relationship dependence' were collected not only based on the respondents' overall perception about the relationships, but also in respect to the time of relationship formation. 
This contributes four variables - the 'initial relationship benefit', 'initial relationship dependence', 'overall relationship benefit' and 'overall relationship dependence'. The former two were used in the regression modelling for relationship formation, whereas the latter two were adopted for the regression analysis relating to the overall growth, or the degree of change, in the relationships.

As explained earlier, the items for both relationship benefit and relationship dependence were assessed by using a 9-point Likert scale in the survey instrument, in order to capture the changes in greater depth. Descriptive statistics for these two variables are presented in Table 6-6a. After replacing the small percentage of missing data by the sample mean, t-tests were conducted to compare the means of 'initial relationship benefits' with 'overall relationship benefits', and 'initial relationship dependence' with 'overall relationship dependence', based on the original data obtained from the multiple items. The results suggest that on average, the means of 'overall relationship benefit' $(\mathrm{Mean}=6.71, \mathrm{SE}=1.26)$ are significantly higher than the means of 'initial relationship benefit' at Time 1 $(\mathrm{Mean}=5.76, \mathrm{SE}=1.59, \mathrm{p}<0.01)$. Likewise, the means of 'overall relationship dependence' $($ Mean $=5.61, \mathrm{SE}=1.67)$ are significantly higher than the means of 'initial relationship dependence' at Time $1($ Mean $=5.01, \mathrm{SE}=1.78, \mathrm{p}<0.01)$. The results indicate that on average, from the firms' perspective, the benefit from, and dependence on, the relationships have increased since the initial formation stage.

Additionally, another two continuous control variables, headquarters' influence and relationship satisfaction are included in the table. Items for these two variables were assessed by using a 7-point Likert scale in the survey instrument. It can be seen that firms' satisfaction with the relationships was relatively high, with sample means at 5.07 and 5.61 for each item. Also, the level of influence that firms received from their foreign headquarters was slightly above the average, with sample means at 4.55 and 4.90 out of 7 for the two items. 
Table 6-6a: Descriptions of the control variables (1)

\begin{tabular}{|c|c|c|c|c|c|c|c|c|c|c|c|c|}
\hline \multirow{2}{*}{ Control variables } & \multicolumn{6}{|c|}{ Time 1: Initial formation } & \multicolumn{6}{|c|}{ The overall perception } \\
\hline & $\mathrm{N}$ & Min & $\operatorname{Max}$ & Mean & Std. Dev & Median & $\mathrm{N}$ & Min & Max & Mean & Std. Dev & Median \\
\hline \multicolumn{13}{|l|}{ Relationship benefit about (9-point Likert scale) } \\
\hline - profitability & 95 & 1 & 9 & 5.36 & 2.24 & 5.0 & 95 & 1 & 9 & 6.43 & 1.79 & 6.5 \\
\hline - products/services improvement & 90 & 1 & 9 & 6.03 & 2.12 & 6.0 & 90 & 2 & 9 & 6.99 & 1.83 & 7.0 \\
\hline - obtaining market advantages & 89 & 1 & 9 & 5.48 & 2.23 & 5.0 & 91 & 1 & 9 & 6.50 & 1.91 & 7.0 \\
\hline - long-term market development & 93 & 1 & 9 & 6.17 & 2.23 & 6.0 & 94 & 1 & 9 & 6.90 & 1.68 & 7.0 \\
\hline \multicolumn{13}{|l|}{ Relationship dependence about (9-point Likert scale) } \\
\hline - finding other customers & 90 & 1 & 9 & 5.54 & 2.15 & 5.0 & 91 & 1 & 9 & 6.29 & 2.13 & 7.0 \\
\hline - customer's impact on performance & 91 & 1 & 9 & 4.54 & 2.42 & 5.0 & 92 & 1 & 9 & 5.33 & 2.34 & 6.0 \\
\hline - reliance on customer in China & 94 & 1 & 9 & 5.78 & 2.69 & 6.0 & 94 & 1 & 9 & 6.43 & 2.32 & 7.0 \\
\hline - consequence of relationship failure & 92 & 1 & 9 & 4.20 & 2.50 & 4.0 & 92 & 1 & 9 & 4.39 & 2.62 & 5.0 \\
\hline HQ's influence on (7-point Likert scale) & $\mathrm{n} / \mathrm{a}$ & & & & & & & & & & & \\
\hline - business operations in China & & & & & & & 96 & 1 & 7 & 4.55 & 1.98 & 5.0 \\
\hline - the guideline for market development & & & & & & & 96 & 1 & 7 & 4.90 & 1.90 & 5.0 \\
\hline Relationship satisfaction (7-point Likert scale) & $\mathrm{n} / \mathrm{a}$ & & & & & & & & & & & \\
\hline - work with the customer is a wise decision & & & & & & & 96 & 1 & 7 & 5.07 & 1.42 & 6.0 \\
\hline - company's overall satisfaction & & & & & & & 96 & 1 & 7 & 5.61 & 1.24 & 5.0 \\
\hline
\end{tabular}


Frequency distributions for the remaining three control variables are reported in Table 6-6b. Relationship duration is indicated by the number of years that a relationship has been actively operating since the initial buying-selling transaction between two parties. As shown in the table, the majority of the relationships examined in the survey were less than five years old, and 19 per cent of the relationships were active for more than 10 years at the time of the survey. The data for relationship duration were used in regressions directly. With regard to firms' ownership, the international joint ventures between the foreign $\mathrm{MNC}$ and a Chinese partner accounted for about 22 per cent of the sample, whereas the rest of the firms were in the non-joint venture ownership form. Also, for approximately 81 per cent of the firms in the sample, the MNC as a whole operated in China with more than one subsidiary. For the purpose of the regression modelling, non-joint venture ownership was coded as 0 , as opposed to joint venture, which was coded as 1 . The absence of other subsidiary/ies was coded as 0 , and the presence of other subsidiary/ies as 1 .

Table 6-6b Descriptions of the control variables (2)

\begin{tabular}{|c|c|c|c|}
\hline Variables & Description & $\mathrm{N}$ & Percent \\
\hline \multicolumn{4}{|c|}{ Relationship duration } \\
\hline & 1 year & 12 & $12.5 \%$ \\
\hline & 2 years & 15 & $15.6 \%$ \\
\hline & 3 years & 20 & $20.8 \%$ \\
\hline & 4 years & 8 & $8.3 \%$ \\
\hline & 5 years & 10 & $10.4 \%$ \\
\hline & 6 years & 6 & $6.2 \%$ \\
\hline & 7 years & 3 & $3.1 \%$ \\
\hline & 8 years & 2 & $2.1 \%$ \\
\hline & 9 years & 1 & $1.0 \%$ \\
\hline & 10 years & 1 & $1.0 \%$ \\
\hline & More than 10 years & 18 & $18.8 \%$ \\
\hline & Valid N & 96 & $100 \%$ \\
\hline \multicolumn{4}{|c|}{ Firms' ownership structure } \\
\hline Nol & wned subsidiary and Rep. office) (0) & 75 & $78.1 \%$ \\
\hline & Joint ventures (1) & 21 & $21.9 \%$ \\
\hline & Valid N & 96 & $100 \%$ \\
\hline \multicolumn{4}{|c|}{ Existence of other subsidiary } \\
\hline & No presence of other subsidiary (0) & 15 & $15.6 \%$ \\
\hline & Presence of other subsidiary (1) & 81 & $84.4 \%$ \\
\hline & Valid N & 96 & $100 \%$ \\
\hline
\end{tabular}




\subsubsection{Section summary}

Section 6.2 provides an overview of the data from the quantitative sample which includes 96 foreign firms operating in China. It first describes the data for the explanatory variables and explains how they were recoded for the purpose of multiple regression analysis. Second, it explores the data for the dependent variables, using t-tests. The results show that for the focal relationships, the degree to which their economic ties and social bonds were developed was different at Time 1 and Time 2. This relates to the two-dimensional view presented in the study. The results also show that these relationships experienced an increase from their initial formation to the time of the survey completion, suggesting the degree of change was positive. Last, the descriptive data for the control variables provide additional insights into the sample firms and their relationships. The table in Appendix 9 presents the summary statistics and correlation matrix for the variables used in the multiple regression analysis at the level of the economic ties and social bonds.

\subsection{Multiple Regression Analysis for Hypothesis Testing}

The results from the multiple regression analysis are reported and interpreted in a marginal sense in this section, with particular attention given to the significant results $^{21}$ that are related to the hypotheses. This section contains five sub-sections. The first four sub-sections deal with the development process of the economic ties and social bonds, and the evolving status of each economic and social construct, and the last sub-section summarises the key findings from all these analyses.

As mentioned earlier, as part of the hypotheses testing process, all the regression analyses were conducted on both the full-sample and the split-samples stratified by firms' nationality, size and industry sector. Specifically, the full-sample was stratified into two split-samples by every categorical explanatory variable: Western firms vs. Asian firms, small firms vs. large firms, and manufacturing firms vs. service firms. The analysis based on these split-samples, i.e. the split-

\footnotetext{
${ }^{21}$ Significance is assessed at three levels, $\mathrm{p}<0.01, \mathrm{p}<0.05$ and $\mathrm{p}<0.10$.
} 
sample analysis, is expected to produce detailed insights in firms' relationship development processes as they relate to the hypotheses. In the analysis, factors scores were used for the measures representing the dependent variables.

\subsubsection{Development of the economic ties and social bonds}

In this sub-section, the regression results with regard to the initial formation of the economic ties and social bonds, and the subsequent changes of these two dimensions to the survey completion are reported. A summary of the findings is provided at the end of this sub-section.

\subsubsection{Economic ties at relationship formation}

The degree of economic ties at relationship formation was used as the dependent variable to test the related hypotheses. In Table 6-7, the results from the fullsample regression modelling are reported first, followed by the results from the split-sample analysis based on the six split-samples. Other tables reporting the regression results in this chapter follow the same format.

The models in Table 6-7 show the estimated coefficients for the economic ties at relationship formation. In Model 1-1, the coefficient associated with NATIONALITY is positively significant $(\mathrm{p}<0.05)$, meaning that this variable has explanatory power for the dependent variable, marginal to other variables in the model. This provides support for Hypothesis 1a based on the full-sample analysis, by indicating that Western-based foreign firms in China are likely to build stronger economic ties than Asian foreign firms, when forming new business relationships with local customers. The results from the split-sample analysis further show that this finding is driven by large firms and manufacturing firms in the sample. As shown in Model 1-5 and 1-6, in these two respective split-samples, the coefficients associated with firms' nationality are significant and positive ( $p<0.10$ for large firms and $p<0.05$ for manufacturing firms). 
Table 6-7 Regression results for economic ties at relationship formation

\begin{tabular}{|c|c|c|c|c|c|c|c|}
\hline & $\begin{array}{l}\text { Full-sample } \\
\text { Model 1-1 }\end{array}$ & $\begin{array}{l}\text { Asian firms } \\
\text { Model 1-2 }\end{array}$ & $\begin{array}{l}\text { Western firms } \\
\text { Model 1-3 }\end{array}$ & $\begin{array}{l}\text { Small firms } \\
\text { Model 1-4 }\end{array}$ & $\begin{array}{l}\text { Large firms } \\
\text { Model 1-5 }\end{array}$ & $\begin{array}{l}\text { Mfg firms } \\
\text { Model 1-6 }\end{array}$ & $\begin{array}{l}\text { Service firms } \\
\text { Model 1-7 }\end{array}$ \\
\hline Constant & $-2.252(1.564)$ & $0.472(1.944)$ & $0.492(1.301)$ & $-1.169(2.141)$ & $-2.701(2.798)$ & $-4.809(2.955)$ & $-0.724(1.828)$ \\
\hline \multicolumn{8}{|l|}{ Explanatory variables } \\
\hline $\begin{array}{l}\text { NATIONALITY } \\
(0=\text { Asian; } 1=\text { Western })\end{array}$ & $1.762 * *(0.751)$ & & & $1.148(1.008)$ & $2.169 *(1.218)$ & $3.019 * *(1.253)$ & $0.541(0.982)$ \\
\hline SIZE1 (Full-sample) & $-0.326(0.492)$ & & & & & & \\
\hline $\begin{array}{l}\text { SIZE2 (Split-samples) } \\
(0=\text { Small; 1=Large })\end{array}$ & & $-0.444(1.344)$ & $0.050(0.966)$ & & & $-0.332(1.321)$ & $0.362(1.006)$ \\
\hline $\begin{array}{l}\text { INDUSTRY } \\
\text { (0=Manu; } 1=\text { Service })\end{array}$ & $-0.206(0.746)$ & $0.524(1.307)$ & $-1.179(0.928)$ & $-0.457(1.104)$ & $-0.626(1.112)$ & & \\
\hline \multicolumn{8}{|l|}{ Control variables } \\
\hline $\begin{array}{l}\text { Ownership } \\
(0=\text { Others; } 1=\mathrm{IJV})\end{array}$ & $0.376(0.893)$ & $-0.297(1.529)$ & $0.509(1.208)$ & $-0.069(1.341)$ & $0.200(1.320)$ & $0.942(1.513)$ & $-0.398(1.217)$ \\
\hline HQs' influence & $0.185(0.389)$ & $1.124 *(0.655)$ & $-0.432(0.532)$ & $0.628(0.555)$ & $-0.460(0.616)$ & $-0.148(0.655)$ & $0.477(0.501)$ \\
\hline $\begin{array}{l}\text { Other subsidiary } \\
(0=\text { Not exist, } 1=\text { Exist })\end{array}$ & $0.136(1.147)$ & $-1.527(1.826)$ & $0.978(1.459)$ & $-0.358(1.306)$ & $-0.463(2.411)$ & $0.300(2.428)$ & $-0.329(1.296)$ \\
\hline Initial benefit & $2.700 * * *(0.389)$ & $2.930 * * *(0.670)$ & $2.903 * * *(0.546)$ & $2.133 * * *(0.528)$ & $3.613 * * *(0.621)$ & $2.858 * * *(0.715)$ & $2.712 * * *(0.504)$ \\
\hline Initial dependence & $0.101(0.405)$ & $0.212(0.649)$ & $-0.012(0.592)$ & $0.229(0.647)$ & $-0.289(0.558)$ & $-0.193(0.789)$ & $0.261(0.484)$ \\
\hline \multicolumn{8}{|l|}{ Model characteristics } \\
\hline $\mathrm{R}^{2}$ & 0.45 & 0.40 & 0.50 & 0.37 & 0.58 & 0.49 & 0.46 \\
\hline Adjusted $\mathrm{R}^{2}$ & 0.40 & 0.28 & 0.43 & 0.26 & 0.48 & 0.38 & 0.37 \\
\hline F ratio & $8.89 * * *$ & $3.20 * *$ & $6.71 * * *$ & $3.44 * *$ & $7.00 * * *$ & $4.62 * * *$ & $5.51 * * *$ \\
\hline $\mathrm{N}$ & 96 & 41 & 55 & 49 & 47 & 42 & 54 \\
\hline Maximum VIF & 1.38 & 1.30 & 1.89 & 1.50 & 1.41 & 1.68 & 1.31 \\
\hline
\end{tabular}


In Table 6-7, neither the full-sample analysis nor the split-sample analysis reports a significant coefficient associated with SIZE1 or SIZE2 ( $>0.10)$. This suggests that firm size does not have marginal explanatory power for the dependent variable. In other words, holding other variables in the model constant, larger firms do not appear to have stronger economic ties than smaller firms in the newly formed customer relationships. Hence, no support for Hypothesis $2 \mathrm{a}$ is found. Likewise, none of the models in the table reports a significant estimated coefficient associated with INDUSTRY, indicating on average, manufacturing firms and service firms are not significantly different in their economic ties at the early stage of relationship development, marginal to the other variables in the models.

Significant coefficients are found to be associated with two control variables. First, the relationship benefit initially perceived by firms is positively related to the dependent variable in all the models $(\mathrm{p}<0.01)$, marginal to other variables. This suggests that at the formation stage, the beneficial business relationships are more likely to consist of strong economic ties. In the split-sample of Asian firms, the coefficient associated with headquarters' influence is significant $(p<0.10)$, with other variables being held constant in the model. This indicates a positive relationship between the degree to which Asian firms receive managerial intervention from their foreign headquarters, and the degree to which economic ties are established by the firms in their new local customer relationships.

\subsubsection{Social bonds at relationship formation}

The degree of social bonds at relationship formation was used as the dependent variable to test the related hypotheses. The results based on the full-sample and split-sample analysis are reported in Table 6-8. 
Table 6-8 Regression results for social bonds at relationship formation

\begin{tabular}{|c|c|c|c|c|c|c|c|}
\hline & $\begin{array}{l}\text { Full-sample } \\
\text { Model 2-1 }\end{array}$ & $\begin{array}{l}\text { Asian firms } \\
\text { Model 2-2 }\end{array}$ & $\begin{array}{l}\text { Western firms } \\
\text { Model 2-3 }\end{array}$ & $\begin{array}{l}\text { Small firms } \\
\text { Model 2-4 }\end{array}$ & $\begin{array}{l}\text { Large firms } \\
\text { Model 2-5 }\end{array}$ & $\begin{array}{l}\text { Mfg firms } \\
\text { Model 2-6 }\end{array}$ & $\begin{array}{l}\text { Service firms } \\
\text { Model 2-7 }\end{array}$ \\
\hline Constant & $-3.049 * * *(1.476)$ & $-0.508(1.684)$ & $2.311 *(1.297)$ & $-1.113(2.077)$ & $-5.119 *(2.544)$ & $-2.243(2.792)$ & $-2.573(1.609)$ \\
\hline \multicolumn{8}{|l|}{ Explanatory variables } \\
\hline $\begin{array}{l}\text { NATIONALITY } \\
(0=\text { Asian; } 1=\text { Western })\end{array}$ & $2.732 * * *(0.708)$ & & & $1.840 *(0.977)$ & $3.134 * * *(1.108)$ & $3.162 * *(1.184)$ & $1.892 * *(0.865)$ \\
\hline SIZE1 (Full-sample) & $-0.362(0.464)$ & & & & & & \\
\hline $\begin{array}{l}\text { SIZE2 (Split-samples) } \\
(0=\text { Small; } 1=\text { Large })\end{array}$ & & $-0.643(1.165)$ & $0.366(0.964)$ & & & $-0.969(1.248)$ & $0.496(0.886)$ \\
\hline $\begin{array}{l}\text { INDUSTRY } \\
\text { (0=Manu; } 1=\text { Service })\end{array}$ & $0.385(0.703)$ & $0.920(1.132)$ & $-0.132(0.926)$ & $-0.263(1.071)$ & $0.815(1.020)$ & & \\
\hline \multicolumn{8}{|l|}{ Control variables } \\
\hline $\begin{array}{l}\text { Ownership } \\
(0=\text { Others; } 1=\mathrm{IJV})\end{array}$ & $1.034(0.843)$ & $1.512(1.325)$ & $0.655(1.204)$ & $1.858(1.301)$ & $-0.217(1.200)$ & $2.207(1.429)$ & $-0.004(1.072)$ \\
\hline HQs' influence & $0.098(0.367)$ & $0.482(0.568)$ & $0.018(0.530)$ & $0.421(0.539)$ & $-0.514(0.560)$ & $-0.383(0.619)$ & $0.747 *(0.441)$ \\
\hline $\begin{array}{l}\text { Other subsidiary } \\
(0=\text { Not exist, } 1=\text { Exist })\end{array}$ & $-1.214(1.082)$ & $-1.606(1.582)$ & $-1.622(1.455)$ & $-2.370 *(1.267)$ & $-0.470(2.192)$ & $-3.410(2.294)$ & $-0.607(1.140)$ \\
\hline Initial benefit & $1.410 * * *(0.367)$ & $2.229 * * *(0.580)$ & $1.272 * *(0.545)$ & $1.254 * *(0.513)$ & $1.780 * * *(0.565)$ & $1.595 * *(0.676)$ & $1.639 * * *(0.444)$ \\
\hline Initial dependence & $0.863 * *(0.382)$ & $1.786 * * *(0.563)$ & $0.378(0.590)$ & $1.237 *(0.628)$ & $0.425(0.507)$ & $0.828(0.745)$ & $0.727 *(0.426)$ \\
\hline \multicolumn{8}{|l|}{ Model characteristics } \\
\hline $\mathrm{R}^{2}$ & 0.37 & 0.46 & 0.19 & 0.36 & 0.46 & 0.41 & 0.46 \\
\hline Adjusted $\mathrm{R}^{2}$ & 0.31 & 0.35 & 0.07 & 0.25 & 0.37 & 0.29 & 0.38 \\
\hline F ratio & $6.44 * * *$ & $4.00 * * *$ & 1.563 & $3.31 * * *$ & $4.81 * * *$ & $3.33 * *$ & $5.63 * * *$ \\
\hline $\mathrm{N}$ & 96 & 41 & 55 & 49 & 47 & 42 & 54 \\
\hline Maximum VIF & 1.38 & 1.30 & 1.89 & 1.50 & 1.41 & 1.68 & 1.31 \\
\hline
\end{tabular}

Estimated coefficients are reported in the table. Standard errors are in parentheses. Missing values are replaced with sample means. $* \mathrm{p}<0.10 ; * * \mathrm{p}<0.05 ; * * * \mathrm{p}<0.01$.

No difference in the confidence intervals $(95 \%)$ of the control variables was found between each pair of split-samples (Asian vs. Western; Small vs. Large;

Manufacturing vs. Services) 
The models in Table 6-8 show the estimated coefficients for social bonds at the formation stage of relationships. The coefficients associated with NATIONALITY are significantly positive in the full-sample Model 2-1 ( $<<0.01)$, suggesting that, in a marginal sense, Western firms, on average, form stronger social bonds than their Asian counterparts at the beginning of relationships. Similar significant and positive coefficients associated with nationality also exist in the split-sample analysis (at least $\mathrm{p}<0.10$ ). Hypothesis $1 \mathrm{~b}$, which predicates that Asian firms would emphasise the social dimension more than Western firms at this stage of relationship development, is then contradicted. Moreover, no significant coefficients are found to be associated with the explanatory variables pertaining to firm size and industry in all the models ( $p>0.10)$. Hypothesis $2 b$ and Hypothesis $3 \mathrm{a}$ are therefore, not supported in the modelling.

With regard to the control variables, initial relationship benefit is positively related to the dependent variables in all the models (at least $\mathrm{p}<0.05$ ), indicating that the beneficial relationships may contain stronger social bonds at the early development stage. Initial relationship dependence is found to be positively related to the degree of social bonds in the full-sample analysis $(\mathrm{p}<0.05)$, and the result, as shown in the split-sample analysis, is driven by Asian firms $(\mathrm{p}<0.01)$, small firms $(p<0.10)$, and service firms $(p<0.10)$. In Model 2-7, the coefficient associated with firms' headquarters' influence is positive $(\mathrm{p}<0.10)$, suggesting that in a marginal sense, within a group of service firms, those that receive greater managerial influence from the foreign headquarters form stronger social bonds with local customers at the beginning. Additionally, in Model 2-4, the negative coefficient associated with the presence of other subsidiary/ies $(\mathrm{p}<0.10)$ implies that, for small foreign firms, with other variables being held constant, those having at least one subsidiary in China tend to form weaker social bonds in relationships. 


\subsubsection{Change in economic ties after relationship formation}

To test the hypotheses related to the growth of economic ties, the degree of change in economic ties was used as the dependent variable in regression modelling. As explained earlier, the 'overall relationship benefit' and 'overall relationship dependence' replaced the 'initial relationship benefit' and 'initial relationship dependence', respectively. Another two control variables relationship duration and relationship satisfaction - were also added to the modelling. The results are reported in Table 6-9.

The coefficients associated with firms' nationality are not significantly different to zero in any of the models ( $p>0.10)$, indicating that this variable has no marginal explanatory power for the dependent variable. In other words, foreign firms from a Western background are not significantly different from those from an Asian background, in terms of the degree to which economic ties are reinforced after the formation of relationships, holding the other variables in the model constant. Hypothesis 1c therefore, is not supported. Moreover, the results show that firm size (SIZE1) is significantly and positively related to the dependent variable in the full-sample analysis $(\mathrm{p}<0.05)$. It indicates that with other variables being controlled for, larger firms tend to experience greater growth in economic ties than smaller firms. This lends support for Hypothesis 2c. Further split-sample analysis shows that this result is driven by the groups of Western firms and manufacturing firms where the coefficients associated with firm size are significant (both at $\mathrm{p}<0.05$ ). As for the third explanatory variable, INDUSTRY, none of the associated coefficients is significant ( $p>0.10)$, suggesting that it has no explanatory power for the dependent variable. Because no marginal difference can be found between manufacturing firms and service firms in the degree of change in their economic ties, Hypothesis $3 b$ is not supported. 
Table 6-9 Regression results for the degree of change in economic ties

\begin{tabular}{|c|c|c|c|c|c|c|c|}
\hline & $\begin{array}{c}\text { Full-sample } \\
\text { Model 3-1 }\end{array}$ & $\begin{array}{l}\text { Asian firms } \\
\text { Model 3-2 }\end{array}$ & $\begin{array}{c}\text { Western firms } \\
\text { Model 3-3 }\end{array}$ & $\begin{array}{c}\text { Small firms } \\
\text { Model 3-4 }\end{array}$ & $\begin{array}{c}\text { Large firms } \\
\text { Model 3-5 }\end{array}$ & $\begin{array}{l}\text { Mfg firms } \\
\text { Model 3-6 }\end{array}$ & $\begin{array}{c}\text { Service firms } \\
\text { Model 3-7 }\end{array}$ \\
\hline Constant & $-0.789(1.288)$ & 0.927 & $-1.421(1.128)$ & $0.911(1.757)$ & $0.621(2.415)$ & $3.851 *(2.184)$ & $-2.035(1.671)$ \\
\hline \multicolumn{8}{|l|}{ Explanatory variables } \\
\hline $\begin{array}{l}\text { NATIONALITY } \\
(0=\text { Asian; } 1=\text { Western })\end{array}$ & $-0.608(0.632)$ & & & $-1.040(0.851)$ & $0.696(1.090)$ & $-1.455(0.952)$ & $-0.217(0.895)$ \\
\hline SIZE1 (Full-sample) & $1.103 * *(0.395)$ & & & & & & \\
\hline $\begin{array}{l}\text { SIZE2 (Split-samples) } \\
(0=\text { Small; } 1=\text { Large })\end{array}$ & & $0.746(1.184)$ & $1.884 * *(0.811)$ & & & $2.090 * *(0.938)$ & $0.906(0.908)$ \\
\hline $\begin{array}{l}\text { INDUSTRY } \\
(0=\text { Manu; } 1=\text { Service })\end{array}$ & $-0.575(0.579)$ & $-1.379(1.097)$ & $-0.111(0.742)$ & $-0.639(0.848)$ & $-0.446(0.917)$ & & \\
\hline \multicolumn{8}{|l|}{ Control variables } \\
\hline $\begin{array}{l}\text { Ownership } \\
\text { (0=Others; } 1=\mathrm{IJV})\end{array}$ & $0.043(0.695)$ & $-0.633(1.291)$ & $0.247(0.951)$ & $-1.038(1.034)$ & $1.670(1.141)$ & $0.723(1.092)$ & $-0.254(1.048)$ \\
\hline HQs' influence & $-0.146(0.315)$ & $0.360(0.592)$ & $0.114(0.428)$ & $-0.026(0.424)$ & $0.622(0.546)$ & $0.217(0.469)$ & $-0.106(0.451)$ \\
\hline $\begin{array}{l}\text { Other subsidiary } \\
(0=\text { Not exist, } 1=\text { Exist })\end{array}$ & $-0.021(0.914)$ & $0.031(1.689)$ & $-0.004(1.162)$ & $0.736(1.093)$ & $-1.802(1.959)$ & $-1.919(1.716)$ & $1.090(1.137)$ \\
\hline Overall benefit & $1.207 * * *(0.323)$ & $1.675 * *(0.684)$ & $0.855 * *(0.415)$ & $1.229 * *(1.093)$ & $0.816(0.521)$ & $1.664 * * *(0.488)$ & $0.700(0.473)$ \\
\hline Overall dependence & $-1.558 * * *(0.307)$ & $-1.903 * * *(0.569)$ & $-1.350 * * *(0.425)$ & $-1.387 * * *(0.004)$ & $-1.699 * * *(0.494)$ & $-1.435 * *(0.560)$ & $-1.456 * * *(0.419)$ \\
\hline Duration & $0.005(0.092)$ & $-0.073(0.224)$ & $0.035(0.109)$ & $-0.015(0.155)$ & $0.052(0.129)$ & $-0.227(0.158)$ & $0.155(0.118)$ \\
\hline Satisfaction & $0.507 *(0.309)$ & $0.297(0.543)$ & $0.510(0.422)$ & $0.415(0.386)$ & $0.524(0.456)$ & $1.114 * *(0.494)$ & $0.159(0.432)$ \\
\hline \multicolumn{8}{|l|}{ Model characteristics } \\
\hline $\mathrm{R}^{2}$ & 0.36 & 0.43 & 0.29 & 0.38 & 0.37 & 0.52 & 0.29 \\
\hline Adjusted $\mathrm{R}^{2}$ & 0.28 & 0.26 & 0.15 & 0.24 & 0.22 & 0.39 & 0.15 \\
\hline F ratio & $4.66 * * *$ & $2.51 * *$ & $2.02 *$ & $2.61 * *$ & $2.40 * *$ & $3.92 * * *$ & $1.98 *$ \\
\hline $\mathrm{N}$ & 96 & 41 & 55 & 49 & 47 & 42 & 54 \\
\hline Maximum VIF & 1.357 & 1.62 & 1.53 & 1.48 & 1.54 & 1.76 & 1.44 \\
\hline
\end{tabular}


With regard to the control variables, a positive coefficient associated with relationship benefit is found in the full-sample $(\mathrm{p}<0.01)$, marginal to other variables included in the model. Further split-sample analysis shows that this result can be seen in the groups of small firms $(\mathrm{p}<0.05)$ and manufacturing firms $(\mathrm{p}<0.01)$, and both Asian firms $(\mathrm{p}<0.05)$ and Western firms $(\mathrm{p}<0.05)$. Another finding is the negative coefficients associated with relationship dependence in all the models in the table (at least $\mathrm{p}<0.05$ ), which suggests that holding other variables constant, the more dependent a firm is on its partner, the stronger the decrease its economic ties experience during the development process. Further, in the full-sample model, relationship satisfaction is found to be significantly and positively related to the change of economic ties $(\mathrm{p}<0.10)$, marginal to other variables in the model. This result, according to the split-sample analysis, mainly comes from the manufacturing firms group $(\mathrm{p}<0.05)$.

\subsubsection{Change in social bonds after relationship formation}

The degree of change in social bonds was used as the dependent variable in regression modelling to test the hypotheses related to the growth of social bonds. Table 6-10 shows the results from the full-sample and split-sample analyses.

The full-sample Model 4-1 does not report significant coefficient associated with NATIONALITY $(\mathrm{p}>0.10)$, but this variable has a negative and significant coefficient in Model 4-4 ( $<<0.10)$, estimated using the smaller firms in the sample. This means that, within this particular split-sample, holding other variables in the model constant, social bonds of Asian firms have, on average, a greater degree of increase than Western firms during the development process. This result lends support for Hypothesis 1d. 
Table 6-10 Regression results for the degree of change in social bonds

\begin{tabular}{|c|c|c|c|c|c|c|c|}
\hline & $\begin{array}{l}\text { Full-sample } \\
\text { Model 4-1 }\end{array}$ & $\begin{array}{l}\text { Asian firms } \\
\text { Model 4-2 }\end{array}$ & $\begin{array}{c}\text { Western firms } \\
\text { Model 4-3 }\end{array}$ & $\begin{array}{l}\text { Small firms } \\
\text { Model 4-4 }\end{array}$ & $\begin{array}{l}\text { Large firms } \\
\text { Model 4-5 }\end{array}$ & $\begin{array}{l}\text { Mfg firms } \\
\text { Model 4-6 }\end{array}$ & $\begin{array}{c}\text { Service firms } \\
\text { Model 4-7 }\end{array}$ \\
\hline Constant & $-0.563(1.217)$ & $2.489(1.646)$ & $-0.717(1.068)$ & $2.179(1.530)$ & $-0.749(2.358)$ & $4.334 *(2.344)$ & $-2.412 *(1.361)$ \\
\hline \multicolumn{8}{|l|}{ Explanatory variables } \\
\hline $\begin{array}{l}\text { NATIONALITY } \\
(0=\text { Asian; } 1=\text { Western })\end{array}$ & $-0.589(0.597)$ & & & $-1.365 *(0.741)$ & $0.527(1.064)$ & $-1.631(1.022)$ & $0.301(0.719)$ \\
\hline SIZE1 (Full-sample) & $0.668 * *(0.373)$ & & & & & & \\
\hline $\begin{array}{l}\text { SIZE2 (Split-samples) } \\
(0=\text { Small; 1=Large) }\end{array}$ & & $0.036(1.063)$ & $1.252(0.768)$ & & & $2.031 *(1.007)$ & $-0.594(0.740)$ \\
\hline $\begin{array}{l}\text { INDUSTRY } \\
(0=\text { Manu; } 1=\text { Service })\end{array}$ & $-1.398 * *(0.546)$ & $-2.514 * *(0.985)$ & $-0.751(0.702)$ & $-0.971(0.739)$ & $-2.119 * *(1.064)$ & & \\
\hline \multicolumn{8}{|l|}{ Control variables } \\
\hline $\begin{array}{l}\text { Ownership } \\
(0=\text { Others; } 1=\mathrm{IJV})\end{array}$ & $0.561(0.656)$ & $-0.065(1.159)$ & $0.693(0.900)$ & $-0.503(0.901)$ & $1.788(1.115)$ & $0.398(1.173)$ & $1.138(0.854)$ \\
\hline HQs' influence & $0.560 *(0.298)$ & $1.013 *(0.531)$ & $0.421(0.405)$ & $0.404(0.369)$ & $1.016 * * 0.533)$ & $0.642(0.504)$ & $0.292(0.367)$ \\
\hline $\begin{array}{l}\text { Other subsidiary } \\
(0=\text { Not exist, } 1=\text { Exist })\end{array}$ & $0.251(0.863)$ & $0.340(1.516)$ & $0.160(1.100)$ & $0.271(0.952)$ & $1.605(1.913)$ & $-1.141(1.843)$ & $1.389(0.927)$ \\
\hline Overall benefit & $1.308 * * *(0.305)$ & $1.283 * *(0.614)$ & $1.287 * * *(0.393)$ & $1.012 * *(0.415)$ & $1.259 * *(0.509)$ & $1.494 * * *(0.524)$ & $1.110 * * *(0.385)$ \\
\hline Overall dependence & $-1.584 * * *(0.290)$ & $-1.965 * * *(0.511)$ & $-1.607 * * *(0.402)$ & $-1.481 * * *(0.396)$ & $-1.574 * * *(0.482)$ & $-1.689 * * *(0.601)$ & $-1.399 * * *(0.341)$ \\
\hline Duration & $-0.093(0.087)$ & $-0.341 *(0.201)$ & $-0.038(0.103)$ & $-0.008(0.135)$ & $-0.117(0.126)$ & $-0.270(0.170)$ & $0.026(0.096)$ \\
\hline Satisfaction & $0.123(0.292)$ & $-0.206(0.487)$ & $0.328(0.416)$ & $0.279(0.412)$ & $-0.125(0.445)$ & $0.714(0.531)$ & $-0.221(0.352)$ \\
\hline \multicolumn{8}{|l|}{ Model characteristics } \\
\hline $\mathrm{R}^{2}$ & 0.40 & 0.50 & 0.35 & 0.43 & 0.46 & 0.49 & 0.37 \\
\hline Adjusted $\mathrm{R}^{2}$ & 0.33 & 0.35 & 0.22 & 0.29 & 0.33 & 0.35 & 0.24 \\
\hline F ratio & $5.69 * * *$ & $3.35 * * *$ & $2.68 * *$ & $3.16 * * *$ & $3.53 * * *$ & $3.40 * * *$ & $2.81 * *$ \\
\hline $\mathrm{N}$ & 96 & 41 & 55 & 49 & 47 & 42 & 54 \\
\hline Maximum VIF & 1.357 & 1.62 & 1.51 & 1.48 & 1.54 & 1.76 & 1.44 \\
\hline
\end{tabular}

Estimated coefficients are reported in the table. Standard errors are in parentheses. Missing values are replaced with sample means. $* \mathrm{p}<0.10 ; * * \mathrm{p}<0.05 ; * * * \mathrm{p}<0.01$.

No difference in the confidence intervals $(95 \%)$ of the control variables was found between each pair of split-samples (Asian vs. Western; Small vs. Large;

Manufacturing vs. Services) 
Moreover, SIZE1 is associated with a positive and significant coefficient in the full-sample Model 4-1 ( $\mathrm{p}<0.01)$, marginal to other variables, indicating that larger firms are likely to experience a greater degree of increase in their social bonds with local customers after relationships are formed. Results from the split-sample analysis further show that this result is driven by the group of manufacturing firms $(\mathrm{p}<0.10)$. The third explanatory variable, INDUSTRY, is associated with a significant and negative coefficient in the full-sample Model 4-1 ( $\mathrm{p}<0.05)$, suggesting that, holding other variables in the model constant, the relationships of manufacturing firms have, on average, a higher degree of increase in the social dimension than service firms. Split-sample analysis further suggests that this result comes from the groups of Asian firms $(\mathrm{p}<0.05)$ and larger firms $(\mathrm{p}<0.05)$.

With regard to the control variables, relationship benefit is positively related to the dependent variable (at least $\mathrm{p}<0.05$ ) in all the models, with other variables being held constant, indicating that a more beneficial perceived relationship is likely to be associated with a greater increase in the social dimension. The coefficients associated with relationship dependence in all the models suggest a significant and negative relationship between this variable and the dependent variable (at least $\mathrm{p}<0.05$ ), marginal to the contributions from other variables in the model. In the full-sample model, headquarters' influence is positively related to the dependent variable $(\mathrm{p}<0.10)$. This implies that in a marginal sense, relationships of firms which receive stronger intervention from the foreign headquarters are likely to experience a higher degree of increase in the social dimension. This result is driven by the split-samples of Asian firms $(\mathrm{p}<0.10)$ and larger firms ( $\mathrm{p}<0.05)$. In addition, for Asian firms in particular (Model 4-2), a significant and negative relationship between relationship duration and the dependent variable is observed $(p<0.10)$, marginal to other variables in the model.

\subsubsection{Summary of findings in the analysis of economic ties and social bonds}

All the results from the regression modelling addressed in the previous four subsections are summarised in Table 6-11. 
Table 6-11 Summary of the regression results at the level of economic ties and social bonds

\begin{tabular}{|c|c|c|c|c|c|c|c|c|}
\hline \multirow{2}{*}{\multicolumn{2}{|c|}{ Hypothesis }} & \multirow{2}{*}{$\begin{array}{c}\text { Full- } \\
\text { sample }\end{array}$} & \multicolumn{6}{|c|}{ Split-samples } \\
\hline & & & Asian & Western & Small & Large & $\mathrm{Mfg}$ & Service \\
\hline $\mathrm{H} 1 \mathrm{a}$ & $\begin{array}{l}\text { Western foreign firms form stronger economic ties than Asian foreign } \\
\text { firms in their new local business relationships in China }\end{array}$ & S & n.a. & n.a. & $\mathrm{N}$ & $S$ & S & $\mathrm{N}$ \\
\hline $\mathrm{H} 1 \mathrm{~b}$ & $\begin{array}{l}\text { Western foreign firms form weaker social bonds than Asian foreign } \\
\text { firms in their new local business relationships in China. }\end{array}$ & $\mathrm{C}$ & n.a. & n.a. & $\mathrm{C}$ & $\mathrm{C}$ & $\mathrm{C}$ & $\mathrm{C}$ \\
\hline $\mathrm{H} 1 \mathrm{c}$ & $\begin{array}{l}\text { After formation, Western foreign firms have greater growth in their } \\
\text { economic ties than Asian firms in China. }\end{array}$ & $\mathrm{N}$ & n.a. & n.a. & $\mathrm{N}$ & $\mathrm{N}$ & $\mathrm{N}$ & $\mathrm{N}$ \\
\hline H1d & $\begin{array}{l}\text { After formation, Western foreign firms have less growth in their social } \\
\text { bonds than Asian firms in China }\end{array}$ & $\mathrm{N}$ & n.a. & n.a. & $S$ & $\mathrm{~N}$ & $\mathrm{~N}$ & $\mathrm{~N}$ \\
\hline $\mathrm{H} 2 \mathrm{a}$ & $\begin{array}{l}\text { Larger foreign firms form stronger economic ties than smaller foreign } \\
\text { firms in their new local business relationships in China. }\end{array}$ & $\mathrm{N}$ & $\mathrm{N}$ & $\mathrm{N}$ & n.a. & n.a. & $\mathrm{N}$ & $\mathrm{N}$ \\
\hline $\mathrm{H} 2 \mathrm{~b}$ & $\begin{array}{l}\text { Larger foreign firms form weaker social bonds than smaller foreign } \\
\text { firms in their new local business relationships in China. }\end{array}$ & $\mathrm{N}$ & $\mathrm{N}$ & $\mathrm{N}$ & n.a. & n.a. & $\mathrm{N}$ & $\mathrm{N}$ \\
\hline $\mathrm{H} 2 \mathrm{c}$ & $\begin{array}{l}\text { After relationship formation, larger foreign firms have greater growth } \\
\text { in their economic ties than smaller foreign firms in China. }\end{array}$ & S & $\mathrm{N}$ & $S$ & n.a. & n.a. & S & $\mathrm{N}$ \\
\hline $\mathrm{H} 3 \mathrm{a}$ & $\begin{array}{l}\text { Foreign service firms form stronger social bonds than foreign } \\
\text { manufacturing firms in their new local business relationships in China. }\end{array}$ & $\mathrm{N}$ & $\mathrm{N}$ & $\mathrm{N}$ & $\mathrm{N}$ & $\mathrm{N}$ & n.a. & n.a. \\
\hline $\mathrm{H} 3 \mathrm{~b}$ & $\begin{array}{l}\text { After relationship formation, foreign service firms have greater growth } \\
\text { in their economic ties than foreign manufacturing firms in China. }\end{array}$ & $\mathrm{N}$ & $\mathrm{N}$ & $\mathrm{N}$ & $\mathrm{N}$ & $\mathrm{N}$ & n.a. & n.a. \\
\hline
\end{tabular}

'S' means the hypothesis is supported in the model; ' $\mathbf{C}$ ' means the hypothesis is contradicted by the results in the model; ' $\mathbf{N}$ ' means neither support nor contradiction is found, i.e. non-significant result in the analysis; 'n.a.' means the specific split-sample is not applicable for the regression modelling for the hypothesis. 
From this table, it can be seen that Hypothesis 1a is supported by the results from the full-sample analysis and the split-sample analysis based on large firms and manufacturing firms. Hypothesis $1 \mathrm{~b}$ is contradicted by the results from the fullsample analysis and the split-sample analysis of all the four groups of firms. Hypothesis 1d is supported by the results from the split-sample analysis based on small firms. Hypothesis $2 \mathrm{c}$ is supported by the results from the full-sample analysis, and the split-sample analysis based on Western firms and manufacturing firms. No support for Hypotheses 1c, 2a, 2b, 3a and 3b can be found from either the full-sample or the split-sample analysis.

Apart from these, the results shown in Table 6-10 reveal that, with other variables being held constant in the full-sample model (Model 4-1), larger firms are likely to have a greater increase in the social bonds, and the result is driven by the splitsample of manufacturing firms (Model 4-6). Likewise, manufacturing firms, on average, achieve a higher degree of increase in social bonds (Model 4-1), and the result is driven by the split-samples of Asian firms (Model 4-2) and large firms (Model 4-5). These contribute two additional findings to the hypotheses:

1. After relationship formation, larger foreign firms have greater growth in their social bonds than smaller foreign firms in China.

2. After relationship formation, foreign manufacturing firms have greater growth in their social bonds than foreign service firms in China.

The reason for this study not to form hypotheses on the comparison between larger and smaller firms, and between manufacturing firms and service firms, in respect to the growth of social bonds, is mainly due to the lack of relevant literature to support them. These two additional findings, therefore, supplement the testing of the hypotheses, and contribute to understanding of the relationship development process more comprehensively. 


\subsubsection{Changing status of economic and social constructs}

As described in Chapter 5, in order to test the hypotheses in more detail, multiple regression analysis was further conducted to examine the changing status of the economic and social constructs (see Section 5.4.2), because each of these constructs represents a distinctive facet of relationships, reflecting the nature of the economic and social dimensions. In the regression modelling, the status of a construct at the formation stage (Time 1) and its subsequent degree of change (from Time 1 to Time 2) were used as the dependent variables, based on the factor scores. Results are reported in the following four sub-sections, with regard to economic constructs at formation, social constructs at formation, the degree of change in economic constructs, and the degree of change in social constructs, respectively. A summary of all the results is provided at the end of this section.

\subsubsection{Economic constructs at relationship formation}

The initial status of each economic construct at Time 1 was used as the dependent variable in regression modelling. Control variables remained the same as those used in the modelling for the overall economic ties and social bonds at relationship formation. The results are reported in Tables 6-12a, b, c, d, e and f.

First, tangible economic interaction at relationship formation was used as the dependent variable. In Table 6-12a, the estimated coefficient associated with NATIONALITY in Model 5-1 is significant and positive $(\mathrm{p}<0.10)$, marginal to other variables in the model, suggesting that Western firms operating in China, on average, are engaged in a higher degree of tangible economic interaction with their new customers than Asian foreign firms. For instance, this may relate to the volume and frequency of transactions and the probability of working on multiple projects. Split-sample analysis further reveals that the result mainly is driven by the group of large firms $(\mathrm{p}<0.05)$. Moreover, the table shows that, based on the full-sample, firms' ownership is positively associated with the dependent variable $(\mathrm{p}<0.10)$. This indicates that, with other variables controlled for, the international joint ventures, on average, achieve a higher degree of tangible economic 
interaction at the beginning of relationships than firms in other ownership forms. Headquarters' influence is positively related to the degree of tangible interaction $(\mathrm{p}<0.05)$ in the split-sample model of Asian firms, marginal to other variables, suggesting that within the group of Asian firms, those receiving stronger influence from their foreign headquarters are likely to be engaged in deeper tangible interaction with new customers. Last, the coefficients associated with relationship benefit are positive across all the models $(\mathrm{p}<0.01)$, showing that, holding other variables in the models constant, the relationships that are perceived as being more beneficial are likely to involve a higher degree of economic transactions and other types of resource exchanges between the two parties at the formation stage.

Second, intangible economic interaction at relationship formation was used as the dependent variable for regression modelling. In Table 6-12b, the coefficient associated with INDUSTRY in the full-sample model is positive $(p<0.05)$, indicating that with other variables in the model being constant, service firms, on average, involve a higher degree of intangible economic interaction in their relationships than manufacturing firms. The split-sample analysis shows that this result is driven particularly by the group of large firms $(\mathrm{p}<0.05)$. As for the control variables, the initial relationship benefit is positively related to the dependent variable in all the models (at least $p<0.05$ ), marginal to other variables, which suggests that at the formation stage, the relationships perceived as being more beneficial by firms are likely to contain a higher level of intangible economic interaction.

Third, economic communication at relationship formation was used as the dependent variable. In Table 6-12c, the coefficient associated with NATIONALITY in the full-sample model is positive $(\mathrm{p}<0.05)$, meaning that on average, Western firms are engaged in more economic communication with their new customers than Asian firms. With regard to the control variables, the coefficient associated with headquarters' influence is positive $(p<0.10)$ in the model based on service firms. This suggests that for service firms in particular, in 
a marginal sense, the stronger managerial intervention they receive from their foreign headquarters, the more economic communication they have with local customers in newly formed relationships. The positive coefficients associated with the initial relationship benefit in all the models (at least $\mathrm{p}<0.05$ ) also demonstrate the marginal explanatory power of this variable for the degree of economic communication. Further, split-sample analysis shows that for Asian firms $(p<0.05)$ and small firms $(\mathrm{p}<0.10)$, the initial relationship dependence is significantly and positively related to the economic communication, marginal to other variables in the model.

Fourth, competence trust at relationship formation was used as the dependent variable in regression modelling. As shown in Table 6-12d, the coefficient associated with NATIONALITY is positive in the full-sample model $(\mathrm{p}<0.05)$, suggesting that in a marginal sense, Western firms, on average, have stronger trust in new customers' market competence than Asian firms. Further split-sample analysis shows that the result is driven by the group of large firms $(\mathrm{p}<0.10)$ and manufacturing firms $(\mathrm{p}<0.01)$, implying that for these two types of firms, the distinction in competence trust in relationships due to nationality may exist, with other variables being held constant. Also, in the full-sample model, the coefficient associated with SIZE1 is negative $(\mathrm{p}<0.10)$, suggesting that smaller firms are likely to have stronger trust in their new local customers' market competence, than larger firms. For the control variables, relationship benefit is positively related to the dependent variable in all the models (at least $\mathrm{p}<0.05$ ), holding other variables constant. Relationship dependence also has marginal explanatory power for the dependent variable in the full-sample model $(\mathrm{p}<0.10)$.

Fifth, contractual trust at relationship formation was used as the dependent variable in regression modelling, and the results are presented in Table 6-12e. In the model estimated using the manufacturing firms, NATIONALITY is associated with a positive coefficient $(\mathrm{p}<0.10)$, marginal to other variables in the model. It implies that, holding other variables constant, Western manufacturing firms, on 
average, have stronger contractual trust in their new customers than Asian manufacturing firms. Relationship benefit is positively related to the dependent variable in the full-sample model $(\mathrm{p}<0.05)$, and according to the split-sample analysis, the result is driven by the groups of Western firms $(\mathrm{p}<0.01)$, large firms $(\mathrm{p}<0.05)$ and manufacturing firms $(\mathrm{p}<0.05)$. Relationship dependence is negatively related to the dependent variable in the model estimated using the manufacturing firms $(\mathrm{p}<0.05)$, which implies that, in a marginal sense, among this group of firms, the more they are dependent on new customers, the lower contractual trust they have in the customers.

Sixth, economic commitment at relationship formation was used as the dependent variable in regression modelling. The results are displayed in Table 6-12f. In the models based on the Western firms and small firms, the coefficients associated with industry are negative $(\mathrm{p}<0.10)$, marginal to other variables, which suggests that in these two particular groups of firms, manufacturing firms, on average, have stronger economic commitment to their new customers. With regard to the control variables, the table shows that the initial relationship benefit is positively related to the dependent variable in all the models (at least $\mathrm{p}<0.05$ ), marginal to the contributions of other variables. 
Table 6-12a Regression results for tangible economic interaction at relationship formation

\begin{tabular}{|c|c|c|c|c|c|c|c|}
\hline & $\begin{array}{c}\text { Full-sample } \\
\text { Model 5-1 }\end{array}$ & $\begin{array}{l}\text { Asian firms } \\
\text { Model 5-2 }\end{array}$ & $\begin{array}{c}\text { Western firms } \\
\text { Model 5-3 }\end{array}$ & $\begin{array}{c}\text { Small firms } \\
\text { Model 5-4 }\end{array}$ & $\begin{array}{l}\text { Large firms } \\
\text { Model 5-5 }\end{array}$ & $\begin{array}{l}\text { Mfg firms } \\
\text { Model 5-6 }\end{array}$ & $\begin{array}{c}\text { Service firms } \\
\text { Model 5-7 }\end{array}$ \\
\hline Constant & $-0.527(0.385)$ & $0.409(0.398)$ & $-0.015(0.361)$ & $0.051(0.569)$ & $-0.912(0.629)$ & $-0.631(0.712)$ & $-0.456(0.467)$ \\
\hline \multicolumn{8}{|l|}{ Explanatory variables } \\
\hline $\begin{array}{l}\text { NATIONALITY } \\
(0=\text { Asian; } 1=\text { Western })\end{array}$ & $0.355 *(0.185)$ & & & $0.046(-.268)$ & $0.680 * *(0.274)$ & $0.447(0.302)$ & $0.271(0.251)$ \\
\hline SIZE1 (Full-sample) & $0.020(0.121)$ & & & & & & \\
\hline $\begin{array}{l}\text { SIZE2 (Split-samples) } \\
(0=\text { Small; } 1=\text { Large })\end{array}$ & & $-0.408(0.275)$ & $0.314(0.269)$ & & & $-0.055(0.318)$ & $0.205(0.257)$ \\
\hline $\begin{array}{l}\text { INDUSTRY } \\
(0=\text { Manu; } 1=\text { Service })\end{array}$ & $-0.157(0.183)$ & $-0.290(0.267)$ & $-0.176(0.258)$ & $-0.167(0.293)$ & $-0.209(0.252)$ & & \\
\hline \multicolumn{8}{|l|}{ Control variables } \\
\hline $\begin{array}{l}\text { Ownership } \\
(0=\text { Others; } 1=\mathrm{IJV})\end{array}$ & $0.422 *(0.220)$ & $0.447(0.313)$ & $0.291(0.336)$ & $0.517(0.356)$ & $0.349(0.297)$ & $0.513(0.365)$ & $0.223(0.311)$ \\
\hline HQs' influence & $0.106(0.096)$ & $0.288 * *(0.134)$ & $-0.072(0.148)$ & $0.094(0.148)$ & $0.072(0.138)$ & $0.061(0.158)$ & $0.138(0.128)$ \\
\hline $\begin{array}{l}\text { Other subsidiary } \\
(0=\text { Not exist, } 1=\text { Exist })\end{array}$ & $-0.086(0.282)$ & $-0.492(0.373)$ & $0.030(0.406)$ & $-0.250(0.347)$ & $-0.129(0.542)$ & $-0.050(0.585)$ & $-0.213(0.331)$ \\
\hline Initial benefit & $0.522 * * *(0.096)$ & $0.425 * * *(0.137)$ & $0.582 * * *(0.152)$ & $0.435 * * *(0.140)$ & $0.644 * * *(0.140)$ & $0.581 * * *(0.172)$ & $0.485 * * *(0.129)$ \\
\hline Initial dependence & $-0.058(0.100)$ & $-0.131(0.133)$ & $0.002(0.165)$ & $0.081(0.172)$ & $-0.178(0.125)$ & $-0.188(0.190)$ & $0.019(0.124)$ \\
\hline \multicolumn{8}{|l|}{ Model characteristics } \\
\hline $\mathrm{R}^{2}$ & 0.33 & 0.40 & 0.34 & 0.26 & 0.48 & 0.36 & 0.33 \\
\hline Adjusted $\mathrm{R}^{2}$ & 0.27 & 0.27 & 0.24 & 0.13 & 0.39 & 0.23 & 0.23 \\
\hline F ratio & $5.36 * * *$ & $3.10 * *$ & $3.43 * * *$ & $2.02 *$ & $5.13 * * *$ & $2.75^{* *}$ & $3.28 * * *$ \\
\hline $\mathrm{N}$ & 96 & 41 & 55 & 49 & 47 & 42 & 54 \\
\hline Maximum VIF & 1.38 & 1.30 & 1.89 & 1.50 & 1.41 & 1.68 & 1.31 \\
\hline
\end{tabular}


Table 6-12b Regression results for intangible economic interaction at relationship formation

\begin{tabular}{|c|c|c|c|c|c|c|c|}
\hline & $\begin{array}{c}\text { Full-sample } \\
\text { Model 6-1 }\end{array}$ & $\begin{array}{l}\text { Asian firms } \\
\text { Model 6-2 }\end{array}$ & $\begin{array}{c}\text { Western firms } \\
\text { Model 6-3 }\end{array}$ & $\begin{array}{c}\text { Small firms } \\
\text { Model 6-4 }\end{array}$ & $\begin{array}{l}\text { Large firms } \\
\text { Model 6-5 }\end{array}$ & $\begin{array}{l}\text { Mfg firms } \\
\text { Model 6-6 }\end{array}$ & $\begin{array}{c}\text { Service firms } \\
\text { Model 6-7 }\end{array}$ \\
\hline Constant & $-0.455(0.390)$ & $-0.070(0.440)$ & $-0.517(0.350)$ & $-0.422(0.594)$ & $0.251(0.599)$ & $-0.340(0.671)$ & $0.285(0.494)$ \\
\hline \multicolumn{8}{|l|}{ Explanatory variables } \\
\hline $\begin{array}{l}\text { NATIONALITY } \\
(0=\text { Asian; } 1=\text { Western })\end{array}$ & $0.042(0.187)$ & & & $0.132(0.280)$ & $-0.197(0.261)$ & $0.132(0.285)$ & $-0.076(0.266)$ \\
\hline SIZE1 (Full-sample) & $0.108(0.123)$ & & & & & & \\
\hline $\begin{array}{l}\text { SIZE2 (Split-samples) } \\
(0=\text { Small; } 1=\text { Large })\end{array}$ & & $0.210(0.305)$ & $0.035(0.260)$ & & & $0.056(0.300)$ & $0.400(0.272)$ \\
\hline $\begin{array}{l}\text { INDUSTRY } \\
(0=\text { Manu; } 1=\text { Service })\end{array}$ & $0.427 * *(0.186)$ & $0.476(0.296)$ & $0.413(0.250)$ & $0.301(0.306)$ & $0.532 * *(0.240)$ & & \\
\hline \multicolumn{8}{|l|}{ Control variables } \\
\hline $\begin{array}{l}\text { Ownership } \\
(0=\text { Others; } 1=\mathrm{IJV})\end{array}$ & $-0.081(0.223)$ & $0.270(0.347)$ & $-0.378(0.325)$ & $0.031(0.372)$ & $-0.361(0.283)$ & $0.190(0.344)$ & $-0.460(0.329)$ \\
\hline HQs' influence & $-0.036(0.097)$ & $-0.048(0.149)$ & $-0.123(0.143)$ & $0.003(0.154)$ & $-0.172(0.132)$ & $-0.022(0.149)$ & $-0.047(0.135)$ \\
\hline $\begin{array}{l}\text { Other subsidiary } \\
(0=\text { Not exist, } 1=\text { Exist })\end{array}$ & $-0.038(0.286)$ & $-0.494(0.414)$ & $0.441(0.393)$ & $-0.028(0.362)$ & $0.007(0.516)$ & $-0.196(0.552)$ & $-0.075(0.350)$ \\
\hline Initial benefit & $0.483 * * *(0.097)$ & $0.334 * *(0.152)$ & $0.511 * * *(0.147)$ & $0.304 * *(0.147)$ & $0.718 * * *(0.133)$ & $0.513 * * *(0.163)$ & $0.492 * * *(0.136)$ \\
\hline Initial dependence & $0.054(0.101)$ & $-0.015(0.147)$ & $0.100(0.159)$ & $0.029(0.180)$ & $-0.010(0.120)$ & $-0.056(0.179)$ & $0.134(0.131)$ \\
\hline \multicolumn{8}{|l|}{ Model characteristics } \\
\hline $\mathrm{R}^{2}$ & 0.31 & 0.24 & 0.42 & 0.13 & 0.56 & 0.28 & 0.32 \\
\hline Adjusted $\mathrm{R}^{2}$ & 0.25 & 0.08 & 0.34 & -0.02 & 0.48 & 0.13 & 0.22 \\
\hline F ratio & $4.89 * * *$ & 1.49 & $4.94 * * *$ & 0.85 & $6.99 * * *$ & $1.90 *$ & $3.09 * * *$ \\
\hline $\mathrm{N}$ & 96 & 41 & 55 & 49 & 47 & 42 & 54 \\
\hline Maximum VIF & 1.377 & 1.30 & 1.89 & 1.50 & 1.41 & 1.68 & 1.31 \\
\hline
\end{tabular}


Table 6-12c Regression results for economic communication at relationship formation

\begin{tabular}{|c|c|c|c|c|c|c|c|}
\hline & $\begin{array}{l}\text { Full-sample } \\
\text { Model 7-1 }\end{array}$ & $\begin{array}{l}\text { Asian firms } \\
\text { Model 7-2 }\end{array}$ & $\begin{array}{c}\text { Western firms } \\
\text { Model 7-3 }\end{array}$ & $\begin{array}{l}\text { Small firms } \\
\text { Model 7-4 }\end{array}$ & $\begin{array}{l}\text { Large firms } \\
\text { Model 7-5 }\end{array}$ & $\begin{array}{l}\text { Mfg firms } \\
\text { Model 7-6 }\end{array}$ & $\begin{array}{c}\text { Service firms } \\
\text { Model 7-7 }\end{array}$ \\
\hline Constant & $0.399(0.386)$ & $0.290(0.456)$ & $0.156(0.320)$ & $0.016(0.438)$ & $-0.906(0.769)$ & $-0.729(0.801)$ & $-0.527(0.3834)$ \\
\hline \multicolumn{8}{|l|}{ Explanatory variables } \\
\hline $\begin{array}{l}\text { NATIONALITY } \\
(0=\text { Asian; } 1=\text { Western })\end{array}$ & $0.412 * *(0.185)$ & & & $0.218(0.206)$ & $0.549(0.335)$ & $0.501(0.340)$ & $0.273(0.206)$ \\
\hline SIZE1 (Full-sample) & $-0.132(0.121)$ & & & & & & \\
\hline $\begin{array}{l}\text { SIZE2 (Split-samples) } \\
(0=\text { Small; } 1=\text { Large })\end{array}$ & & $-0.185(0.315)$ & $-0.127(0.237)$ & & & $-0.222(0.358)$ & $-0.014(0.211)$ \\
\hline $\begin{array}{l}\text { INDUSTRY } \\
(0=\text { Manu; } 1=\text { Service })\end{array}$ & $-0.161(0.184)$ & $-0.112(0.306)$ & $-0.329(0.228)$ & $-0.265(0.226)$ & $-0.163(0.309)$ & & \\
\hline \multicolumn{8}{|l|}{ Control variables } \\
\hline $\begin{array}{l}\text { Ownership } \\
(0=\text { Others; } 1=\mathrm{IJV})\end{array}$ & $-0.069(0.221)$ & $-0.161(0.359)$ & $0.032(0.297)$ & $-0.192(0.274)$ & $-0.110(0.363)$ & $0.154(0.410)$ & $-0.242(0.255)$ \\
\hline HQs' influence & $0.022(0.096)$ & $0.235(0.154)$ & $-0.034(0.131)$ & $0.135(0.114)$ & $-0.158(0.169)$ & $-0.156(0.177)$ & $0.204 *(0.105)$ \\
\hline $\begin{array}{l}\text { Other subsidiary } \\
(0=\text { Not exist, } 1=\text { Exist })\end{array}$ & $0.118(0.283)$ & $-0.313(0.428)$ & $0.325(0.358)$ & $-0.144(0.267)$ & $0.090(0.663)$ & $0.086(0.658)$ & $0.071(0.272)$ \\
\hline Initial benefit & $0.462 * * *(0.096)$ & $0.657 * * *(0.157)$ & $0.512 * * *(0.134)$ & $0.399 * * *(0.108)$ & $0.612 * * *(0.171)$ & $0.461 * *(0.194)$ & $0.467 * * *(0.106)$ \\
\hline Initial dependence & $0.049(0.100)$ & $0.323 * *(0.152)$ & $-0.186(0.145)$ & $0.230 *(0.132)$ & $-0.138(0.153)$ & $0.216(0.214)$ & $-0.056(0.101)$ \\
\hline \multicolumn{8}{|l|}{ Model characteristics } \\
\hline $\mathrm{R}^{2}$ & 0.33 & 0.44 & 0.30 & 0.45 & 0.34 & 0.35 & 0.41 \\
\hline Adjusted $\mathrm{R}^{2}$ & 0.26 & 0.32 & 0.20 & 0.35 & 0.22 & 0.21 & 0.32 \\
\hline F ratio & $5.25 * * *$ & $3.70 * * *$ & $2.88 * *$ & $4.69 * * *$ & $2.86^{* *}$ & $2.26 * *$ & $4.56 * * *$ \\
\hline $\mathrm{N}$ & 96 & 41 & 55 & 49 & 47 & 42 & 54 \\
\hline Maximum VIF & 1.38 & 1.30 & 1.89 & 1.50 & 1.41 & 1.68 & 1.31 \\
\hline
\end{tabular}


Table 6-12d Regression results for competence trust at relationship formation

\begin{tabular}{|c|c|c|c|c|c|c|c|}
\hline & $\begin{array}{l}\text { Full-sample } \\
\text { Model 8-1 }\end{array}$ & $\begin{array}{l}\text { Asian firms } \\
\text { Model 8-2 }\end{array}$ & $\begin{array}{l}\text { Western firms } \\
\text { Model 8-3 }\end{array}$ & $\begin{array}{l}\text { Small firms } \\
\text { Model 8-4 }\end{array}$ & $\begin{array}{l}\text { Large firms } \\
\text { Model 8-5 }\end{array}$ & $\begin{array}{l}\text { Mfg firms } \\
\text { Model 8-6 }\end{array}$ & $\begin{array}{l}\text { Service firms } \\
\text { Model 8-7 }\end{array}$ \\
\hline Constant & $0.344(0.371)$ & $-0.015(0.449)$ & $0.250(0.311)$ & $-0.541(0.511)$ & $-0.185(0.680)$ & $-1.664 * * *(0.582)$ & $0.242(0.488)$ \\
\hline \multicolumn{8}{|l|}{ Explanatory variables } \\
\hline $\begin{array}{l}\text { NATIONALITY } \\
(0=\text { Asian; } 1=\text { Western })\end{array}$ & $0.371 * *(0.178)$ & & & $0.307(0.240)$ & $0.499 *(0.296)$ & $0.817 * * *(0.247)$ & $-0.016(0.262)$ \\
\hline SIZE1 (Full-sample) & $-0.127 *(0.117)$ & & & & & & \\
\hline $\begin{array}{l}\text { SIZE2 (Split-samples) } \\
(0=\text { Small; } 1=\text { Large })\end{array}$ & & $-0.015(0.311)$ & $-0.101(0.231)$ & & & $-0.079(0.260)$ & $-0.079(0.269)$ \\
\hline $\begin{array}{l}\text { INDUSTRY } \\
(0=\text { Manu; } 1=\text { Service })\end{array}$ & $0.005(0.177)$ & $0.325(0.302)$ & $-0.314(0.222)$ & $0.096(0.263)$ & $-0.196(0.273)$ & & \\
\hline \multicolumn{8}{|l|}{ Control variables } \\
\hline $\begin{array}{l}\text { Ownership } \\
(0=\text { Others; } 1=\mathrm{IJV})\end{array}$ & $0.207(0.212)$ & $-0.155(0.353)$ & $0.432(0.288)$ & $0.147(0.320)$ & $0.283(0.321)$ & $0.139(0.298)$ & $0.197(0.325)$ \\
\hline HQs' influence & $0.042(0.092)$ & $0.213(0.151)$ & $-0.009(0.127)$ & $0.085(0.132)$ & $-0.004(0.150)$ & $-0.072(0.129)$ & $0.116(0.134)$ \\
\hline $\begin{array}{l}\text { Other subsidiary } \\
(0=\text { Not exist, } 1=\text { Exist })\end{array}$ & $-0.063(0.272)$ & $-0.295(0.422)$ & $0.070(0.348)$ & $0.045(0.312)$ & $-0.665(0.586)$ & $0.475(0.478)$ & $-0.254(0.346)$ \\
\hline Initial benefit & $0.475 * * *(0.092)$ & $0.616 * * *(0.155)$ & $0.451 * * *(0.130)$ & $0.407 * * *(0.126)$ & $0.612 * * *(0.151)$ & $0.378^{* *}(0.141)$ & $0.551 * * *(0.135)$ \\
\hline Initial dependence & $0.168 *(0.096)$ & $0.158(0.150)$ & $0.175(0.141)$ & $0.125(0.154)$ & $0.176(0.136)$ & $0.159(0.155)$ & $0.174(0.129)$ \\
\hline \multicolumn{8}{|l|}{ Model characteristics } \\
\hline $\mathrm{R}^{2}$ & 0.38 & 0.38 & 0.43 & 0.30 & 0.46 & 0.51 & 0.36 \\
\hline Adjusted $\mathrm{R}^{2}$ & 0.32 & 0.25 & 0.34 & 0.18 & 0.36 & 0.40 & 0.27 \\
\hline F ratio & $6.60 * * *$ & $2.87 * *$ & $5.01 * * *$ & $2.55 * *$ & $4.68 * * *$ & $4.95 * * *$ & $6.74 * * *$ \\
\hline $\mathrm{N}$ & 96 & 41 & 55 & 49 & 47 & 42 & 54 \\
\hline Maximum VIF & 1.38 & 1.30 & 1.89 & 1.50 & 1.41 & 1.68 & 1.31 \\
\hline
\end{tabular}


Table 6-12e Regression results for contractual trust at relationship formation

\begin{tabular}{|c|c|c|c|c|c|c|c|}
\hline & $\begin{array}{l}\text { Full-sample } \\
\text { Model 9-1 }\end{array}$ & $\begin{array}{l}\text { Asian firms } \\
\text { Model 9-2 }\end{array}$ & $\begin{array}{c}\text { Western firms } \\
\text { Model 9-3 }\end{array}$ & $\begin{array}{c}\text { Small firms } \\
\text { Model 9-4 }\end{array}$ & $\begin{array}{c}\text { Large firms } \\
\text { Model 9-5 }\end{array}$ & $\begin{array}{l}\text { Mfg firms } \\
\text { Model 9-6 }\end{array}$ & $\begin{array}{c}\text { Service firms } \\
\text { Model 9-7 }\end{array}$ \\
\hline Constant & $-0.423(0.441)$ & $-0.174(0.612)$ & $0.094(0.313)$ & $-0.215(0.547)$ & $-1.197(0.820)$ & $-1.125(0.784)$ & $-0.104(0.511)$ \\
\hline \multicolumn{8}{|l|}{ Explanatory variables } \\
\hline $\begin{array}{l}\text { NATIONALITY } \\
(0=\text { Asian; } 1=\text { Western })\end{array}$ & $0.281(0.211)$ & & & $0.145(0.258)$ & $0.428(0.357)$ & $0.619 *(0.333)$ & $0.068(0.275)$ \\
\hline SIZE1 (Full-sample) & $-0.099(0.139)$ & & & & & & \\
\hline $\begin{array}{l}\text { SIZE2 (Split-samples) } \\
(0=\text { Small; } 1=\text { Large })\end{array}$ & & $-0.182(0.423)$ & $0.041(0.233)$ & & & $0.181(0.351)$ & $-0.314(0.281)$ \\
\hline $\begin{array}{l}\text { INDUSTRY } \\
\text { (0=Manu; } 1=\text { Service })\end{array}$ & $-0.048(0.210)$ & $0.163(0.412)$ & $-0.316(0.233)$ & $0.070(0.282)$ & $-0.484(0.329)$ & & \\
\hline \multicolumn{8}{|l|}{ Control variables } \\
\hline $\begin{array}{l}\text { Ownership } \\
(0=\text { Others; } 1=\mathrm{IJV})\end{array}$ & $0.038(0.252)$ & $-0.361(0.482)$ & $0.244(0.291)$ & $-0.334(0.343)$ & $0.292(0.387)$ & $-0.209(0.401)$ & $0.278(0.340)$ \\
\hline HQs' influence & $0.053(0.109)$ & $0.243(0.206)$ & $-0.084(0.128)$ & $0.148(0.142)$ & $0.013(0.180)$ & $0.132(0.174)$ & $-0.049(0.140)$ \\
\hline $\begin{array}{l}\text { Other subsidiary } \\
(0=\text { Not exist, } 1=\text { Exist })\end{array}$ & $0.217(0.323)$ & $0.137(0.575)$ & $0.156(0.351)$ & $0.051(0.334)$ & $0.733(0.706)$ & $0.284(0.644)$ & $0.130(0.362)$ \\
\hline Initial benefit & $0.297 * *(0.110)$ & $0.248(0.211)$ & $0.385 * * *(0.131)$ & $0.161(0.135)$ & $0.442 * *(0.182)$ & $0.443 * *(0.190)$ & $0.234(0.141)$ \\
\hline Initial dependence & $-0.165(0.114)$ & $-0.309(0.205)$ & $-0.091(0.142)$ & $-0.276(0.166)$ & $-0.129(0.163)$ & $-0.471 * *(0.209)$ & $0.001(0.135)$ \\
\hline \multicolumn{8}{|l|}{ Model characteristics } \\
\hline $\mathrm{R}^{2}$ & 0.12 & 0.15 & 0.21 & 0.13 & 0.26 & 0.31 & 0.09 \\
\hline Adjusted $\mathrm{R}^{2}$ & 0.04 & -0.03 & 0.10 & -0.01 & 0.12 & 0.16 & -0.04 \\
\hline F ratio & 1.51 & 0.833 & 1.82 & 0.909 & $1.92 *$ & $2.14 *$ & 0.68 \\
\hline $\mathrm{N}$ & 96 & 41 & 55 & 49 & 47 & 42 & 54 \\
\hline Maximum VIF & 1.38 & 1.30 & 1.89 & 1.50 & 1.41 & 1.68 & 1.31 \\
\hline
\end{tabular}


Table 6-12f Regression results for economic commitment at relationship formation

\begin{tabular}{|c|c|c|c|c|c|c|c|}
\hline & $\begin{array}{l}\text { Full-sample } \\
\text { Model 10-1 }\end{array}$ & $\begin{array}{l}\text { Asian firms } \\
\text { Model 10-2 }\end{array}$ & $\begin{array}{l}\text { Western firms } \\
\text { Model 10-3 }\end{array}$ & $\begin{array}{l}\text { Small firms } \\
\text { Model 10-4 }\end{array}$ & $\begin{array}{l}\text { Large firms } \\
\text { Model 10-5 }\end{array}$ & $\begin{array}{c}\text { Mfg firms } \\
\text { Model 10-6 }\end{array}$ & $\begin{array}{c}\text { Service firms } \\
\text { Model 10-7 }\end{array}$ \\
\hline Constant & $-0.104(0.394)$ & $0.032(0.494)$ & $0.524(0.326)$ & $-0.057(0.513)$ & $0.247(0.732)$ & $-0.320(0.752)$ & $-0.164(0.447)$ \\
\hline \multicolumn{8}{|l|}{ Explanatory variables } \\
\hline $\begin{array}{l}\text { NATIONALITY } \\
(0=\text { Asian; } 1=\text { Western })\end{array}$ & $0.301(0.189)$ & & & $0.300(0.242)$ & $0.210(0.319)$ & $0.503(0.319)$ & $0.021(0.931)$ \\
\hline SIZE1 (Full-sample) & $-0.095(0.124)$ & & & & & & \\
\hline $\begin{array}{l}\text { SIZE2 (Split-samples) } \\
(0=\text { Small; 1=Large })\end{array}$ & & $0.135(0.342)$ & $-0.114(0.242)$ & & & $-0.213(0.336)$ & $0.164(0.246)$ \\
\hline $\begin{array}{l}\text { INDUSTRY } \\
\text { (0=Manu; } 1=\text { Service })\end{array}$ & $-0.272(0.188)$ & $-0.039(0.332)$ & $-0.456 *(0.233)$ & $-0.493 *(0.265)$ & $-0.107(0.293)$ & & \\
\hline \multicolumn{8}{|l|}{ Control variables } \\
\hline $\begin{array}{l}\text { Ownership } \\
(0=\text { Others; } 1=\mathrm{IJV})\end{array}$ & $-0.142(0.225)$ & $-0.337(0.389)$ & $-0.112(0.303)$ & $-0.239(0.321)$ & $-0.253(0.345)$ & $0.155(0.385)$ & $-0.395(0.297)$ \\
\hline HQs' influence & $-0.003(0.098)$ & $0.193(0.167)$ & $-0.110(0.133)$ & $0.163(0.133)$ & $-0.211(0.161)$ & $-0.092(0.167)$ & $0.114(0.122)$ \\
\hline $\begin{array}{l}\text { Other subsidiary } \\
(0=\text { Not exist, } 1=\text { Exist })\end{array}$ & $-0.012(0.289)$ & $-0.071(0.464)$ & $-0.044(0.366)$ & $-0.033(0.313)$ & $-0.498(0.630)$ & $-0.298(0.618)$ & $0.012(0.317)$ \\
\hline Initial benefit & $0.460 * * *(0.098)$ & $0.651 * * *(0.170)$ & $0.461 * * *(0.137)$ & $0.428 * * *(0.127)$ & $0.585 * * *(0.162)$ & $0.482 * *(0.182)$ & $0.483 * * *(0.123)$ \\
\hline Initial dependence & $0.054(0.102)$ & $0.186(0.165)$ & $-0.012(0.148)$ & $0.041(0.155)$ & $-0.010(0.146)$ & $0.147(0.201)$ & $-0.011(0.118)$ \\
\hline \multicolumn{8}{|l|}{ Model characteristics } \\
\hline $\mathrm{R}^{2}$ & 0.30 & 0.34 & 0.31 & 0.37 & 0.31 & 0.34 & 0.32 \\
\hline Adjusted $\mathrm{R}^{2}$ & 0.23 & 0.20 & 0.21 & 0.27 & 0.19 & 0.21 & 0.22 \\
\hline F ratio & $4.60 * * *$ & $2.45^{* *}$ & $3.00 * *$ & $3.50 * * *$ & $2.55^{* *}$ & $2.54 * *$ & $3.10 * * *$ \\
\hline $\mathrm{N}$ & 96 & 41 & 55 & 49 & 47 & 42 & 54 \\
\hline Maximum VIF & 1.38 & 1.30 & 1.89 & 1.50 & 1.41 & 1.68 & 1.31 \\
\hline
\end{tabular}




\subsubsection{Social constructs at relationship formation}

The initial status of each social construct at relationship formation was used as the dependent variable in the regression modelling, employing the same control variables as those outlined in the previous section. The results are reported in Tables 6-13a, b, c, d, e and f.

First, social interaction at relationship formation was used as the dependent variable. As presented in Table 6-13a, the coefficient associated with NATIONALITY in the full-sample model is positive $(\mathrm{p}<0.05)$, marginal to other variables in the model. It suggests that, holding other variables constant, Western firms, on average, carry out more social interaction with new customers than Asian firms. This result, according to the split-sample analysis, is driven by the manufacturing firms $(\mathrm{p}<0.10)$, which means that the above distinction due to nationality may exist in a group of manufacturing firms.

As for the control variables, the coefficient associated with firms' ownership is significantly positive in the model based on manufacturing firms $(\mathrm{p}<0.10)$, implying that holding other variables constant, among the manufacturing firms, the international joint ventures, on average, carry out more social interactions than other non-equity based subsidiaries with their new customers. The initial relationship benefit is positively related to the dependent variable in all the models (at least $\mathrm{p}<0.10$ ), suggesting that the more relationships are perceived as being beneficial, the more socialising activities may be seen between the two parties at the early relationship formation stage. Also, the initial relationship dependence is found positively related to the dependent variable in the models estimated using Asian firms $(\mathrm{p}<0.01)$, small firms $(\mathrm{p}<0.10)$ and manufacturing firms $(\mathrm{p}<0.10)$, meaning that in a marginal sense, within these groups of firms, the more firms are dependent on the new customers, the more social interactions are carried out in the relationships. However, in the split-sample of Western firms, relationship dependence appears to be negatively related to the dependent variable $(\mathrm{p}<0.10)$. 
Second, social communication at relationship formation was used as the dependent variable in regression modelling. Table 6-13b shows that the coefficients associated with NATIONALITY are significantly positive in all the models $(\mathrm{p}<0.05)$. It implies that holding other variables constant, Western firms, on average, have more social communication than Asian firms with their new customers. The full-sample model shows that SIZE1 is negatively related to the dependent variable $(\mathrm{p}<0.10)$, suggesting that, in a marginal sense, larger firms conduct less social communication in newly formed customer relationships, than smaller firms.

In the model based on service firms, headquarters' influence is positively related to the dependent variable $(\mathrm{p}<0.01)$, marginal to other variables in the model. This indicates that within a group of service firms, those that receive greater managerial intervention from their foreign headquarters are likely to be engaged in more social communication with local customers. Relationship benefit is positively related to the dependent variable in Model 12-1 ( $\mathrm{p}<0.05)$. Split-sample analysis shows that similar result can be seen in the models estimated using Asian firms $(\mathrm{p}<0.01)$, service firms $(\mathrm{p}<0.01)$, and both small firms $(\mathrm{p}<0.05)$ and large firms $(\mathrm{p}<0.10)$. Additionally, in the model based on Asian firms, the results show that, relationship dependence is positively related to the dependent variable $(\mathrm{p}<0.05)$, marginal to other variables in the model.

Third, social trust at relationship formation was used as the dependent variable. Table 6-13c presents all the results from regression modelling. It can be seen that the coefficient associated with NATOINALITY is positive in the full-sample model $(\mathrm{p}<0.05)$, marginal to other variables. Split-sample analysis shows that this result comes from the large firms $(\mathrm{p}<0.05)$ and service firms $(\mathrm{p}<0.10)$, suggesting that within these two groups of firms, those from a Western-based background, on average, have more social trust in their new customers. Regarding the control variables, the coefficients associated with the presence of other subsidiaries are negative in the split-sample models for Asian firms $(\mathrm{p}<0.05)$, small firms $(\mathrm{p}<0.05)$, 
and manufacturing firms $(\mathrm{p}<0.05)$, marginal to other variables in the models. It implies that within these respective groups of firms, firms having at least one other sister-subsidiary in China, on average, have stronger social trust in their new local customers, than firms having no other subsidiary/ries. In addition, for the split-sample of service firms, relationship dependence is significantly positively related to social trust at formation $(\mathrm{p}<0.10)$, marginal to other variables in the model.

Fourth, social commitment at relationship formation was used as the dependent variable. As presented in Table 6-13d, the coefficient associated with NATIONALITY is significantly positive in the full-sample model $(\mathrm{p}<0.05)$, marginal to other variables in the model. Further split-sample analysis reveals that the result is driven by the groups of small firms $(\mathrm{p}<0.10)$ and manufacturing firms $(\mathrm{p}<0.10)$. This implies that in these two groups, with other variables being constant, firms from a Western background, on average, are more socially committed to their new customers than those from an Asian background. Also, SIZE1 is negatively related to the dependent variable in the full-sample model $(p<0.05)$, indicating that in a marginal sense, larger firms are likely to have less social commitment to their new customers. As for the control variables, relationship benefit is positively related to the dependent variable in the fullsample model $(\mathrm{p}<0.05)$, and similar results can be further seen in the split-sample models estimated using Asian firms $(\mathrm{p}<0.05)$, large firms $(\mathrm{p}<0.05)$, and service firms $(\mathrm{p}<0.05)$. This implies that the variable has marginal explanatory power for firms' social commitment in relationships. Likewise, in nearly all the models except for Western firms, relationship dependence is significantly and positively related to firms' social commitment to their local customers in newly formed relationships (at least $\mathrm{p}<0.05$ ).

Fifth, norms and values at relationship formation was used as the dependent variable in regression modelling, and the results are presented in Table 5-13e. The positive coefficient associated with NATIONALITY in the full-sample model 
$(\mathrm{p}<0.01)$ suggests that, with other variables being held constant, Western firms tend to have more common norms and values than Asian firms with their new local customers. The split-sample analysis reveals that similar results can be observed in the models based on large firms $(\mathrm{p}<0.01)$, and both manufacturing firms $(\mathrm{p}<0.01)$ and service firms $(\mathrm{p}<0.10)$. Another explanatory variable INDUSTRY - has a negative coefficient in the model based on smaller firms $(p<0.10)$. In a marginal sense, this implies that among the smaller firms, service firms, on average, have less common norms and values with new customers, than manufacturing firms. As for the control variables, relationship benefit is significant and positively related to the dependent variable in all the models (at least $\mathrm{p}<0.10$ ), indicating its marginal explanatory power. 
Table 6-13a Regression results for social interaction at relationship formation

\begin{tabular}{|c|c|c|c|c|c|c|c|}
\hline & $\begin{array}{l}\text { Full-sample } \\
\text { Model 11-1 }\end{array}$ & $\begin{array}{l}\text { Asian firms } \\
\text { Model 11-2 }\end{array}$ & $\begin{array}{l}\text { Western firms } \\
\text { Model 11-3 }\end{array}$ & $\begin{array}{l}\text { Small firms } \\
\text { Model 11-4 }\end{array}$ & $\begin{array}{l}\text { Large firms } \\
\text { Model 11-5 }\end{array}$ & $\begin{array}{l}\text { Mfg firms } \\
\text { Model 11-6 }\end{array}$ & $\begin{array}{c}\text { Service firms } \\
\text { Model 11-7 }\end{array}$ \\
\hline Constant & $-0.739 *(0.412)$ & $-0.614(0.491)$ & $0.241(0.327)$ & $-0.301(0.547)$ & $-1.009(0.710)$ & $-0.362(0.682)$ & $-0.677(0.483)$ \\
\hline \multicolumn{8}{|l|}{ Explanatory variables } \\
\hline $\begin{array}{l}\text { NATIONALITY } \\
(0=\text { Asian; } 1=\text { Western })\end{array}$ & $0.446 * *(0.198)$ & & & $0.412(0.258)$ & $0.230(0.309)$ & $0.550 *(0.289)$ & $0.154(0.260)$ \\
\hline SIZE1 (Full-sample) & $-0.040(0.130)$ & & & & & & \\
\hline $\begin{array}{l}\text { SIZE2 (Split-samples) } \\
(0=\text { Small; } 1=\text { Large })\end{array}$ & & $0.240(0.340)$ & $-0.067(0.243)$ & & & $-0.253(0.305)$ & $0.301(0.266)$ \\
\hline $\begin{array}{l}\text { INDUSTRY } \\
\text { (0=Manu; } 1=\text { Service })\end{array}$ & $0.047(0.196)$ & $0.351(0.330)$ & $-0.217(0.233)$ & $-0.226(0.282)$ & $0.342(0.285)$ & & \\
\hline \multicolumn{8}{|l|}{ Control variables } \\
\hline $\begin{array}{l}\text { Ownership } \\
\text { (0=Others; } 1=\mathrm{IJV})\end{array}$ & $0.238(0.235)$ & $0.279(0.386)$ & $0.497(0.303)$ & $0.267(0.343)$ & $-0.047(0.335)$ & $0.638 *(0.349)$ & $0.002(0.322)$ \\
\hline HQs' influence & $0.000(0.102)$ & $-0.043(0.166)$ & $0.160(0.133)$ & $0.075(0.142)$ & $-0.191(0.156)$ & $-0.112(0.151)$ & $0.186(0.132)$ \\
\hline $\begin{array}{l}\text { Other subsidiary } \\
(0=\text { Not exist, } 1=\text { Exist })\end{array}$ & $0.038(0.302)$ & $0.101(0.461)$ & $0.011(0.366)$ & $-0.353(0.334)$ & $0.553(0.612)$ & $-0.686(0.561)$ & $0.344(0.343)$ \\
\hline Initial benefit & $0.351 * *(0.013)$ & $0.509 * * *(0.169)$ & $0.470 * * *(0.137)$ & $0.288 * *(0.135)$ & $0.471 * * *(0.158)$ & $0.326 *(0.165)$ & $0.448 * * *(0.133)$ \\
\hline Initial dependence & $0.104(0.107)$ & $0.476 * * *(0.164)$ & $-0.286 *(0.149)$ & $0.332 *(0.166)$ & $-0.116(0.142)$ & $0.350 *(0.182)$ & $-0.084(0.128)$ \\
\hline \multicolumn{8}{|l|}{ Model characteristics } \\
\hline $\mathrm{R}^{2}$ & 0.23 & 0.36 & 0.23 & 0.33 & 0.33 & 0.39 & 0.31 \\
\hline Adjusted $\mathrm{R}^{2}$ & 0.16 & 0.22 & 0.19 & 0.21 & 0.20 & 0.27 & 0.21 \\
\hline F ratio & $3.28 * *$ & $2.65 * *$ & $2.03 *$ & $2.82 * *$ & $2.69 * *$ & $3.11 * *$ & $2.98 * *$ \\
\hline $\mathrm{N}$ & 96 & 41 & 55 & 49 & 47 & 42 & 54 \\
\hline Maximum VIF & 1.38 & 1.30 & 1.89 & 1.50 & 1.41 & 1.68 & 1.31 \\
\hline
\end{tabular}


Table 6-13b Regression results for social communication at relationship formation

\begin{tabular}{|c|c|c|c|c|c|c|c|}
\hline & $\begin{array}{l}\text { Full-sample } \\
\text { Model 12-1 }\end{array}$ & $\begin{array}{l}\text { Asian firms } \\
\text { Model 12-2 }\end{array}$ & $\begin{array}{l}\text { Western firms } \\
\text { Model 12-3 }\end{array}$ & $\begin{array}{l}\text { Small firms } \\
\text { Model 12-4 }\end{array}$ & $\begin{array}{l}\text { Large firms } \\
\text { Model 12-5 }\end{array}$ & $\begin{array}{c}\text { Mfg firms } \\
\text { Model 12-6 }\end{array}$ & $\begin{array}{c}\text { Service firms } \\
\text { Model 12-7 }\end{array}$ \\
\hline Constant & $-0.602(0.398)$ & $-0.108(0.455)$ & $0.720 *(0.375)$ & $-0.497(0.533)$ & $-1.020(0.752)$ & $-0.733(0.818)$ & $-0.509(0.376)$ \\
\hline \multicolumn{8}{|l|}{ Explanatory variables } \\
\hline $\begin{array}{l}\text { NATIONALITY } \\
(0=\text { Asian; } 1=\text { Western })\end{array}$ & $0.655 * *(0.191)$ & & & $0.556 * *(0.251)$ & $0.698 * *(0.327)$ & $0.796 * *(0.347)$ & $0.477 * *(0.202)$ \\
\hline SIZE1 (Full-sample) & $-0.111 *(0.125)$ & & & & & & \\
\hline $\begin{array}{l}\text { SIZE2 (Split-samples) } \\
(0=\text { Small; } 1=\text { Large })\end{array}$ & & $-0.081(0.314)$ & $-0.095(0.266)$ & & & $-0.174(0.366)$ & $-0.132(0.207)$ \\
\hline $\begin{array}{l}\text { INDUSTRY } \\
\text { (0=Manu; } 1=\text { Service })\end{array}$ & $0.076(0.190)$ & $0.220(0.306)$ & $-0.022(0.255)$ & $0.080(0.275)$ & $0.051(0.301)$ & & \\
\hline \multicolumn{8}{|l|}{ Control variables } \\
\hline $\begin{array}{l}\text { Ownership } \\
\text { (0=Others; } 1=\mathrm{IJV})\end{array}$ & $0.176(0.227)$ & $0.168(0.358)$ & $0.100(0.332)$ & $0.402(0.334)$ & $-0.091(0.355)$ & $0.449(0.419)$ & $-0.071(0.250)$ \\
\hline HQs' influence & $0.099(0.099)$ & $0.210(0.153)$ & $0.066(0.146)$ & $0.169(0.138)$ & $-0.031(0.165)$ & $-0.095(0.181)$ & $0.313 * * *(0.103)$ \\
\hline $\begin{array}{l}\text { Other subsidiary } \\
(0=\text { Not exist, } 1=\text { Exist })\end{array}$ & $-0.362(0.292)$ & $-0.362(0.427)$ & $-0.461(0.401)$ & $-0.530(0.325)$ & $-0.205(0.648)$ & $-0.678(0.672)$ & $-0.177(0.267)$ \\
\hline Initial benefit & $0.278 * *(0.099)$ & $0.528 * * *(0.157)$ & $0.180(0.150)$ & $0.292 * *(0.132)$ & $0.311 *(0.167)$ & $0.250(0.198)$ & $0.401 * * *(0.104)$ \\
\hline Initial dependence & $0.158(0.103)$ & $0.331 * *(0.152)$ & $0.112(0.163)$ & $0.206(0.161)$ & $0.103(0.150)$ & $0.160(0.218)$ & $0.116(0.099)$ \\
\hline \multicolumn{8}{|l|}{ Model characteristics } \\
\hline $\mathrm{R}^{2}$ & 0.28 & 0.36 & 0.11 & 0.33 & 0.27 & 0.25 & 0.50 \\
\hline Adjusted $\mathrm{R}^{2}$ & 0.22 & 0.23 & -0.018 & 0.22 & 0.14 & 0.10 & 0.42 \\
\hline F ratio & $4.29 * * *$ & $2.64 * *$ & 0.864 & $2.881 * *$ & $2.05 *$ & 1.64 & $6.54 * * *$ \\
\hline $\mathrm{N}$ & 96 & 41 & 55 & 49 & 47 & 42 & 54 \\
\hline Maximum VIF & 1.38 & 1.30 & 1.89 & 1.50 & 1.41 & 1.68 & 1.31 \\
\hline
\end{tabular}


Table 6-13c Regression results for social trust at relationship formation

\begin{tabular}{|c|c|c|c|c|c|c|c|}
\hline & $\begin{array}{l}\text { Full-sample } \\
\text { Model 13-1 }\end{array}$ & $\begin{array}{l}\text { Asian firms } \\
\text { Model 13-2 }\end{array}$ & $\begin{array}{l}\text { Western firms } \\
\text { Model 13-3 }\end{array}$ & $\begin{array}{l}\text { Small firms } \\
\text { Model 13-4 }\end{array}$ & $\begin{array}{l}\text { Large firms } \\
\text { Model 13-5 }\end{array}$ & $\begin{array}{c}\text { Mfg firms } \\
\text { Model 13-6 }\end{array}$ & $\begin{array}{c}\text { Service firms } \\
\text { Model 13-7 }\end{array}$ \\
\hline Constant & $-0.440(0.426)$ & $0.569(0.423)$ & $0.205(0.413)$ & $0.346(0.632)$ & $-0.981(0.701)$ & $0.507(0.706)$ & $-0.564(0.530)$ \\
\hline \multicolumn{8}{|l|}{ Explanatory variables } \\
\hline $\begin{array}{l}\text { NATIONALITY } \\
(0=\text { Asian; } 1=\text { Western })\end{array}$ & $0.453 * *(0.204)$ & & & $0.063(0.297)$ & $0.768 * *(0.305)$ & $0.267(0.299)$ & $0.529 *(0.285)$ \\
\hline SIZE1 (Full-sample) & $-0.007(0.134)$ & & & & & & \\
\hline $\begin{array}{l}\text { SIZE2 (Split-samples) } \\
(0=\text { Small; } 1=\text { Large })\end{array}$ & & $-0.313(0.292)$ & $0.426(0.307)$ & & & $0.049(0.316)$ & $0.146(0.292)$ \\
\hline $\begin{array}{l}\text { INDUSTRY } \\
(0=\text { Manu; } 1=\text { Service })\end{array}$ & $0.141(0.203)$ & $-0.148(0.284)$ & $0.337(0.295)$ & $0.053(0.326)$ & $0.146(0.281)$ & & \\
\hline \multicolumn{8}{|l|}{ Control variables } \\
\hline $\begin{array}{l}\text { Ownership } \\
(0=\text { Others; } 1=\mathrm{IJV})\end{array}$ & $0.279(0.243)$ & $0.451(0.333)$ & $-0.043(0.384)$ & $0.297(0.396)$ & $0.198(0.331)$ & $0.264(0.362)$ & $0.244(0.353)$ \\
\hline HQs' influence & $-0.050(0.106)$ & $0.086(0.143)$ & $-0.183(0.169)$ & $0.031(0.164)$ & $-0.142(0.154)$ & $-0.050(0.156)$ & $-0.016(0.145)$ \\
\hline $\begin{array}{l}\text { Other subsidiary } \\
(0=\text { Not exist, } 1=\text { Exist })\end{array}$ & $-0.476(0.312)$ & $-0.867 * *(0.397)$ & $-0.522(0.464)$ & $-0.786 * *(0.385)$ & $-0.382(0.604)$ & $-1.193 * *(0.580)$ & $-0.368(0.376)$ \\
\hline Initial benefit & $0.267 * *(0.106)$ & $0.344 * *(0.146)$ & $0.167(0.174)$ & $0.261(0.156)$ & $0.314 *(0.156)$ & $0.454 * *(0.171)$ & $0.245(0.146)$ \\
\hline Initial dependence & $0.120(0.110)$ & $0.130(0.365)$ & $0.246(0.188)$ & $0.200(0.191)$ & $0.046(0.140)$ & $-0.196(0.188)$ & $0.261 *(0.140)$ \\
\hline \multicolumn{8}{|l|}{ Model characteristics } \\
\hline $\mathrm{R}^{2}$ & 0.18 & 0.29 & 0.14 & 0.16 & 0.30 & 0.25 & 0.25 \\
\hline Adjusted $\mathrm{R}^{2}$ & 0.11 & 0.14 & 0.01 & 0.012 & 0.17 & 0.09 & 0.14 \\
\hline F ratio & $2.39 * *$ & $1.935^{*}$ & 1.062 & 1.08 & $2.27 * *$ & 1.60 & $1.24 * *$ \\
\hline $\mathrm{N}$ & 96 & 41 & 55 & 49 & 47 & 42 & 54 \\
\hline Maximum VIF & 1.38 & 1.30 & 1.89 & 1.50 & 1.41 & 1.68 & 1.31 \\
\hline
\end{tabular}


Table 6-13d Regression results for social commitment at relationship formation

\begin{tabular}{|c|c|c|c|c|c|c|c|}
\hline & $\begin{array}{l}\text { Full-sample } \\
\text { Model 14-1 }\end{array}$ & $\begin{array}{l}\text { Asian firms } \\
\text { Model 14-2 }\end{array}$ & $\begin{array}{l}\text { Western firms } \\
\text { Model 14-3 }\end{array}$ & $\begin{array}{l}\text { Small firms } \\
\text { Model 14-4 }\end{array}$ & $\begin{array}{l}\text { Large firms } \\
\text { Model 14-5 }\end{array}$ & $\begin{array}{c}\text { Mfg firms } \\
\text { Model 14-6 }\end{array}$ & $\begin{array}{l}\text { Service firms } \\
\text { Model 14-7 }\end{array}$ \\
\hline Constant & $-0.280(0.389)$ & $-0.146(0.458)$ & $0.630 *(0.352)$ & $-0.574(0.544)$ & $-0.075(0.705)$ & $-0.704(0.708)$ & $-0.016(0.472)$ \\
\hline \multicolumn{8}{|l|}{ Explanatory variables } \\
\hline $\begin{array}{l}\text { NATIONALITY } \\
(0=\text { Asian; } 1=\text { Western })\end{array}$ & $0.470 * *(0.187)$ & & & $0.465 *(0.256)$ & $0.421(0.307)$ & $0.559 *(0.300)$ & $0.317(0.254)$ \\
\hline SIZE1 (Full-sample) & $-0.139 * *(0.122)$ & & & & & & \\
\hline $\begin{array}{l}\text { SIZE2 (Split-samples) } \\
(0=\text { Small; } 1=\text { Large })\end{array}$ & & $0.042(0.317)$ & $-0.088(0.261)$ & & & $-0.064(0.317)$ & $-0.021(0.260)$ \\
\hline $\begin{array}{l}\text { INDUSTRY } \\
\text { (0=Manu; } 1=\text { Service })\end{array}$ & $0.186(0.185)$ & $0.363(0.308)$ & $0.028(0.251)$ & $0.286(0.281)$ & $0.145(0.283)$ & & \\
\hline \multicolumn{8}{|l|}{ Control variables } \\
\hline $\begin{array}{l}\text { Ownership } \\
(0=\text { Others; } 1=\mathrm{IJV})\end{array}$ & $0.038(0.222)$ & $0.025(0.361)$ & $0.172(0.326)$ & $0.336(0.341)$ & $-0.204(0.544)$ & $0.316(0.363)$ & $-0.217(0.315)$ \\
\hline HQs' influence & $-0.012(0.097)$ & $-0.027(0.155)$ & $0.075(0.144)$ & $-0.057(0.141)$ & $-0.066(0.155)$ & $-0.151(0.157)$ & $0.127(0.129)$ \\
\hline $\begin{array}{l}\text { Other subsidiary } \\
(0=\text { Not exist, } 1=\text { Exist })\end{array}$ & $-0.374(0.285)$ & $-0.330(0.431)$ & $-0.523(0.394)$ & $-0.398(0.332)$ & $-0.737(0.608)$ & $-0.420(0.582)$ & $-0.439(0.335)$ \\
\hline Initial benefit & $0.210 * *(0.097)$ & $0.340 * *(0.158)$ & $0.246(0.148)$ & $0.164(0.134)$ & $0.340 * *(0.157)$ & $0.179(0.171)$ & $0.264 * *(0.130)$ \\
\hline Initial dependence & $0.380 * * *(0.101)$ & $0.575 * * *(0.153)$ & $0.210(0.160)$ & $0.505 * * *(0.165)$ & $0.292 * *(0.141)$ & $0.521 * * *(0.189)$ & $0.315 * *(0.125)$ \\
\hline \multicolumn{8}{|l|}{ Model characteristics } \\
\hline $\mathrm{R}^{2}$ & 0.31 & 0.38 & 0.21 & 0.31 & 0.35 & 0.36 & 0.32 \\
\hline Adjusted $\mathrm{R}^{2}$ & 0.25 & 0.24 & 0.10 & 0.19 & 0.23 & 0.23 & 0.21 \\
\hline F ratio & $5.02 * * *$ & $2.84 * *$ & 1.822 & $2.63 * *$ & $2.96 * *$ & $2.75 * *$ & $3.06 * *$ \\
\hline $\mathrm{N}$ & 96 & 41 & 55 & 49 & 47 & 42 & 54 \\
\hline Maximum VIF & 1.38 & 1.30 & 1.89 & 1.50 & 1.41 & 1.68 & 1.31 \\
\hline
\end{tabular}


Table 6-13e Regression results for norms and values at relationship formation

\begin{tabular}{|c|c|c|c|c|c|c|c|}
\hline & $\begin{array}{l}\text { Full-sample } \\
\text { Model 15-1 }\end{array}$ & $\begin{array}{l}\text { Asian firms } \\
\text { Model 15-2 }\end{array}$ & $\begin{array}{l}\text { Western firms } \\
\text { Model 15-3 }\end{array}$ & $\begin{array}{l}\text { Small firms } \\
\text { Model 15-4 }\end{array}$ & $\begin{array}{l}\text { Large firms } \\
\text { Model 15-5 }\end{array}$ & $\begin{array}{c}\text { Mfg firms } \\
\text { Model 15-6 }\end{array}$ & $\begin{array}{c}\text { Service firms } \\
\text { Model 15-7 }\end{array}$ \\
\hline Constant & $-0.989 * *(0.397)$ & $-0.209(0.492)$ & $0.515 *(0.294)$ & $-0.087(0.477)$ & $-2.035 * * *(0.729)$ & $-0.951(0.721)$ & $-0.807 *(0.452)$ \\
\hline \multicolumn{8}{|l|}{ Explanatory variables } \\
\hline $\begin{array}{l}\text { NATIONALITY } \\
(0=\text { Asian; } 1=\text { Western })\end{array}$ & $0.708 * * *(0.190)$ & & & $0.344(0.225)$ & $1.017 * * *(0317)$ & $0.989 * * *(0.306)$ & $0.416 *(0.243)$ \\
\hline SIZE1 (Full-sample) & $-0.066(0.125)$ & & & & & & \\
\hline $\begin{array}{l}\text { SIZE2 (Split-samples) } \\
(0=\text { Small; } 1=\text { Large })\end{array}$ & & $-0.531(0.340)$ & $0.189(0.219)$ & & & $-0.526(0.322)$ & $0.201(0.249)$ \\
\hline $\begin{array}{l}\text { INDUSTRY } \\
\text { (0=Manu; } 1=\text { Service) }\end{array}$ & $-0.065(0.189)$ & $0.134(0.331)$ & $-0.257(0.210)$ & $-0.456 *(0.299)$ & $0.130(0.293)$ & & \\
\hline \multicolumn{8}{|l|}{ Control variables } \\
\hline $\begin{array}{l}\text { Ownership } \\
(0=\text { Others; } 1=\mathrm{IJV})\end{array}$ & $0.303(0.227)$ & $0.589(0.387)$ & $-0.070(0.273)$ & $0.556 *(0.299)$ & $-0.072(0.344)$ & $0.539(0.369)$ & $0.038(0.301)$ \\
\hline HQs' influence & $0.062(0.099)$ & $0.255(0.166)$ & $-0.099(0.120)$ & $0.204(0.124)$ & $-0.085(0.161)$ & $0.026(0.160)$ & $0.137(0.124)$ \\
\hline $\begin{array}{l}\text { Other subsidiary } \\
(0=\text { Not exist, } 1=\text { Exist })\end{array}$ & $-0.041(0.291)$ & $-0.147(0.462)$ & $-0.168(0.330)$ & $-0.303(0.291)$ & $0.302(0.628)$ & $-0.433(0.593)$ & $0.034(0.321)$ \\
\hline Initial benefit & $0.305 * *(0.099)$ & $0.507 * * *(0.169)$ & $0.210 *(0.124)$ & $0.248 * *(0.118)$ & $0.344 * *(0.162)$ & $0.385 * *(0.175)$ & $0.280 * *(0.125)$ \\
\hline Initial dependence & $0.101(0.103)$ & $0.274(0.164)$ & $0.095(0.134)$ & $0.005(0.144)$ & $0.101(0.145)$ & $-0.007(0.192)$ & $0.120(0.120)$ \\
\hline \multicolumn{8}{|l|}{ Model characteristics } \\
\hline $\mathrm{R}^{2}$ & 0.29 & 0.40 & 0.16 & 0.33 & 0.42 & 0.41 & 0.29 \\
\hline Adjusted $\mathrm{R}^{2}$ & 0.22 & 0.27 & 0.03 & 0.22 & 0.31 & 0.29 & 0.19 \\
\hline F ratio & $4.39 * * *$ & $3.09 * *$ & 1.24 & $2.915 * *$ & $3.96 * * *$ & $3.40 * * *$ & $2.73 * *$ \\
\hline $\mathrm{N}$ & 96 & 41 & 55 & 49 & 47 & 42 & 54 \\
\hline Maximum VIF & 1.38 & 1.30 & 1.89 & 1.50 & 1.41 & 1.68 & 1.31 \\
\hline
\end{tabular}

Estimated coefficients are reported in the table. Standard errors are in parentheses. Missing values are replaced with sample means. $* \mathrm{p}<0.10 ; * * \mathrm{p}<0.05 ; * * * \mathrm{p}<0.01$.

No difference in the confidence intervals (95\%) of the control variables was found between each pair of split-samples (Asian vs. Western; Small vs. Large;

Manufacturing vs. Services) 


\subsubsection{The degree of change in economic constructs}

The degree of change in each economic construct from Time 1 to Time 2 was used as the dependent variable in regression modelling. As explained earlier, the 'initial relationship benefit' and 'initial relationship dependence' were replaced by the 'overall relationship benefit' and 'overall relationship dependence', respectively; another two control variables - relationship duration and relationship satisfaction - were added. The results for the regressions are presented in Tables 6-14a, b, c, d, e and f.

First, the degree of change in tangible economic interaction was used as the dependent variable in regression modelling. Table 6-14a shows that the coefficient associated with INDUSTRY is significantly negative $(\mathrm{p}<0.10)$ in the full-sample model, marginal to other variables. This suggests that, holding other variables constant, after relationships are formed, manufacturing firms, on average, experience greater increase in tangible economic interactions, than service firms. Relationship dependence is negatively related to the dependent variable in the full-sample based model ( $\mathrm{p}<0.05)$, and the split-sample analysis shows that similar results also exist in the models based on both Asian firms $(\mathrm{p}<0.10)$ and Western firms $(\mathrm{p}<0.05)$, as well large firms $(\mathrm{p}<0.10)$ and service firms $(\mathrm{p}<0.10)$. Further, the negative coefficient associated with relationship duration indicates the variable's explanatory power for the dependent variable in the model for the manufacturing firms $(\mathrm{p}<0.01)$, marginal to the contributions of other variables. Relationship satisfaction is positively related to the dependent variable in the fullsample model $(\mathrm{p}<0.05)$, suggesting that holding other variables constant, the more satisfactory relationships are, the greater the tangible economic interaction may increase between the two parties. According to the split-sample analysis, this result is driven by the split-samples of Western firms $(\mathrm{p}<0.05)$, small firms $(\mathrm{p}<010)$ and manufacturing firms $(0<0.05)$.

Second, the degree of change in intangible economic interaction was used as the dependent variable. Table $6-14 \mathrm{~b}$ presents the results from all the regression 
models. With regard to the explanatory variables, the positive coefficient associated with SIZE1 in the full-sample model $(\mathrm{p}<0.10)$ suggests that, in a marginal sense, the relationships of larger firms, on average, have greater increase in knowledge and technology transfer with local actors than smaller firms. The split-sample analysis reveals that this finding is mainly contributed by the group of manufacturing firms $(\mathrm{p}<0.10)$. As for the control variables, the coefficient associated with relationship dependence is negative in the full-sample model $(\mathrm{p}<0.05)$. Similar results can be seen in the split-sample modelling estimated using both Asian firms and Western firms $(\mathrm{p}<0.10)$, and large firms $(\mathrm{p}<0.01)$. Also, in the full-sample model, holding other variables constant, the presence of other subsidiary/ries is associated with a negative coefficient $(\mathrm{p}<0.10)$, indicating that firms having at least one other sister subsidiary in China, on average, have greater increase in their intangible economic interaction. Finally, based on the split-sample modelling of manufacturing firms, the coefficients associated with firms' ownership and relationship satisfaction are positive $(p<0.05$ and $p<0.10$, respectively), implying that these two control variables have explanatory power for the dependent variable, marginal to the contributions of other variables in the model.

Third, the degree of change in economic communication was used as the dependent variable for regression modelling. In Table 6-14c, NATIONALITY is associated with a negative coefficient in the model based on manufacturing firms $(\mathrm{p}<0.05)$. It indicates that with other variables being held constant in the model, Asian firms, on average, increase more greatly in economic communication with their local customers during the relationship development process. The coefficient associated with SIZE1 is positive in the full-sample model $(\mathrm{p}<0.05)$, and using SIZE2 the split-sample analysis shows that the result is contributed mainly by the group of Western firms $(\mathrm{p}<0.01)$. INDUSTRY shows marginal explanatory power for the dependent variable in the full-sample based model $(p<0.10)$. The negative coefficient means that manufacturing firms, on average, increase more in 
economic communication with local customers after relationship formation, than service firms.

With regard to the control variables, ownership is associated with a positive coefficient in the model based on large firms $(\mathrm{p}<0.01)$, suggesting that for this group of firms, international joint ventures are likely to achieve a higher degree of increase in economic communication than other ownership forms. The coefficient associated with headquarters' influence is positive in the full-sample model $(\mathrm{p}<0.10)$, and this result is driven by the split-samples of Asian firms $(\mathrm{p}<0.10)$ and large firms $(\mathrm{p}<0.05)$. As for the presence of other subsidiary/ries in China, the negative coefficients associated with this variable in the models based on large firms $(\mathrm{p}<0.05)$ and manufacturing firms $(\mathrm{p}<0.01)$ imply that for these two types of firms, those having no other subsidiary/ries in China, on average, increase more in economic communication with local customers. Moreover, relationship benefit demonstrates a positive relationship with the dependent variable in nearly all the models (at least $\mathrm{p}<0.10$ ), except for the sample of large firms. In contrast, the coefficients associated with relationship dependence are negative in all the models ( $\mathrm{p}<0.01)$, marginal to other variables. This indicates that, holding other variables constant, the more firms are dependent on the customers, the more their economic communication decreases.

Fourth, the regression results for the degree of change in competence trust are displayed in Table 6-14d. In the model based on manufacturing firms, the coefficient associated with NATIONALITY is significantly negative $(\mathrm{p}<0.01)$, marginal to other variables in the model. This implies that manufacturing firms from a Western background, on average, develop greater competence trust in their local customers, than those manufacturing firms from an Asian background. The coefficient associated with SIZE2 is positive in the model based on Western firms $(\mathrm{p}<0.10)$, indicating that holding other variables constant, larger Western firms, on average, increase more competence trust than smaller Western firms. As for the control variables, headquarters' influence is positively related to the dependent 
variable in the model based on larger firm $(\mathrm{p}<0.10)$. The coefficient associated with relationship benefit is positive in the full-sample model $(p<0.05)$, and the split-sample analysis shows that similar results can be seen in the models for both the Asian firms $(\mathrm{p}<0.05)$ and Western firms models $(\mathrm{p}<0.05)$, and smaller firms $(\mathrm{p}<0.01)$ and manufacturing firms $(\mathrm{p}<0.01)$. Relationship dependence, however, is found to be negatively related to the dependent variable in all the models (at least $\mathrm{p}<0.10)$.

Fifth, the degree of change in contractual trust was used as the dependent variable in regression modelling. As shown in Table 6-14e, NATIONALITY is associated with a negative coefficient in the model based on manufacturing firms $(p<0.10)$, implying that holding other variables constant in the model, Western manufacturing firms, on average, have less growth in their contractual trust in local customers, than Asian manufacturing firms. The coefficient associated with SIZE1 is positive in the full-sample model $(\mathrm{p}<0.10)$, marginal to other variables. This result, according to the split-sample analysis using SIZE2, is driven by the Western firms $(p<0.10)$ and service firms $(p<0.10)$. Also in the full-sample model, INDUSTRY shows its marginal explanatory power for the dependent variable $(\mathrm{p}<0.10)$, and the coefficient is negative. This means that contractual trust increases more in the relationships of manufacturing firms than service firms. The finding is mainly driven by the group of Asian firms $(\mathrm{p}<0.05)$ and small firms $(\mathrm{p}<0.05)$.

With respect to the control variables, the model estimated using manufacturing firms presents a negative coefficient associated with the presence of other subsidiary/ries $(\mathrm{p}<0.10)$, indicating that in a marginal sense, foreign manufacturing firms having no other sister-subsidiary/ries in China, on average, grow contractual trust in their relationships more greatly than those having at least one sister-subsidiary. Relationship benefit is associated with a positive coefficient in the full-sample model $(\mathrm{p}<0.05)$, marginal to other variables. Similar results can be observed in the models for Asian firms $(\mathrm{p}<0.05)$ and manufacturing firms 
$(\mathrm{p}<0.05)$. Additionally, in the model based on service firms, relationship dependence is negatively related to the dependent variable $(\mathrm{p}<0.10)$, marginal to other variables.

Sixth, the degree of change in economic commitment was used as the dependent variable for regression modelling, and the results are reported in Table 6-14f. The coefficient associated with NATIONALITY is negative in the full-sample model $(\mathrm{p}<0.10)$, marginal to other variables, which indicates that Western firms, on average, increase their economic commitment to local customers after the relationship formation stage, less than Asian firms. The split-sample analysis further suggests that this result is driven by the group of smaller firms $(\mathrm{p}<0.10)$. Also in the full-sample model, the positive coefficient associated with SIZE1 shows its explanatory power for the dependent variable $(\mathrm{p}<0.05)$, marginal to the contributions of other variables in the model. This implies that larger firms enhance their economic commitment more significantly than smaller firms. The split-sample analysis using SIZE2 suggest that the result is driven by the group of Western firms $(\mathrm{p}<0.10)$.

With regard to the control variables, the coefficients associated with the presence of other sister subsidiary in China are positive in the models based on small firms $(\mathrm{p}<0.10)$ and service firms $(\mathrm{p}<0.01)$, marginal to other variables. Relationship benefit is positively related to the dependent variable in the full-sample based model ( $\mathrm{p}<0.05)$, and the split-sample analysis shows that this result is mainly driven by the Asian firms ( $\mathrm{p}<0.05)$, both small and large firms $(\mathrm{p}<0.10)$, and manufacturing firms $(\mathrm{p}<0.01)$. In contrast, relationship dependence is negatively related to the dependent variable in all the models (at least $\mathrm{p}<0.10$ ), suggesting that the more firms are dependent on their local customers, the more their economic commitment to their customers decreases. Finally, the results in the full-sample model show that relationship satisfaction is positively related to the dependent variable $(p<0.10)$, and this result is driven by the large firms $(p<0.10)$ and manufacturing firms $(\mathrm{p}<0.05)$. 
Table 6-14a Regression results for the degree of change in tangible economic interaction

\begin{tabular}{|c|c|c|c|c|c|c|c|}
\hline & $\begin{array}{l}\text { Full-sample } \\
\text { Model 16-1 }\end{array}$ & $\begin{array}{l}\text { Asian firms } \\
\text { Model 16-2 }\end{array}$ & $\begin{array}{c}\text { Western firms } \\
\text { Model 16-3 }\end{array}$ & $\begin{array}{l}\text { Small firms } \\
\text { Model 16-4 }\end{array}$ & $\begin{array}{l}\text { Large firms } \\
\text { Model 16-5 }\end{array}$ & $\begin{array}{c}\text { Mfg firms } \\
\text { Model 16-6 }\end{array}$ & $\begin{array}{c}\text { Service firms } \\
\text { Model 16-7 }\end{array}$ \\
\hline Constant & $-0.311(0.439)$ & $0.129(0.543)$ & $-0.217(0.424)$ & $-0.354(0.612)$ & $0.167(0.816)$ & $-0.220(0.765)$ & $-0.422(0.536)$ \\
\hline \multicolumn{8}{|l|}{ Explanatory variables } \\
\hline $\begin{array}{l}\text { NATIONALITY } \\
(0=\text { Asian; } 1=\text { Western })\end{array}$ & $0.022(0.215)$ & & & $0.055(0.296)$ & $0.121(0.368)$ & $0.142(0.333)$ & $-0.011(0.287)$ \\
\hline SIZE1 (Full-sample) & $0.176(0.135)$ & & & & & & \\
\hline $\begin{array}{l}\text { SIZE2 (Split-samples) } \\
(0=\text { Small; 1=Large) }\end{array}$ & & $0.090(0.351)$ & $0.139(0.305)$ & & & $0.553(0.329)$ & $-0.097(0.291)$ \\
\hline $\begin{array}{l}\text { INDUSTRY } \\
(0=\text { Manu; } 1=\text { Service })\end{array}$ & $-0.172 *(0.197)$ & $-0.219(0.325)$ & $-0.095(0.279)$ & $0.030(0.295)$ & $-0.297(0.310)$ & & \\
\hline \multicolumn{8}{|l|}{ Control variables } \\
\hline $\begin{array}{l}\text { Ownership } \\
(0=\text { Others; } 1=\mathrm{IJV})\end{array}$ & $-0.208(0.237)$ & $-0.517(0.383)$ & $0.124(0.358)$ & $-0.397(0.360)$ & $0.018(0.386)$ & $-0.052(0.383)$ & $-0.263(0.336)$ \\
\hline HQs' influence & $0.043(0.107)$ & $0.123(0.175)$ & $0.062(0.161)$ & $0.074(0.148)$ & $-0.022(0.184)$ & $-0.032(0.164)$ & $0.046(0.752)$ \\
\hline $\begin{array}{l}\text { Other subsidiary } \\
(0=\text { Not exist, } 1=\text { Exist })\end{array}$ & $0.278(0.312)$ & $0.234(0.500)$ & $0.438(0.437)$ & $0.609(0.381)$ & $-0.203(0.662)$ & $0.594(0.610)$ & $0.274(0.365)$ \\
\hline Overall benefit & $0.149(0.110)$ & $0.022(0.203)$ & $0.265 *(0.156)$ & $0.055(0.166)$ & $0.155(0.176)$ & $0.124(0.171)$ & $0.104(0.152)$ \\
\hline Overall dependence & $-0.260 * *(0.105)$ & $-0.292 *(0.169)$ & $-0.349 * *(0.160)$ & $-0.161(0.158)$ & $-0.329 *(0.167)$ & $-0.198(0.196)$ & $-0.268 *(0.134)$ \\
\hline Duration & $-0.028(0.031)$ & $-0.044(0.066)$ & $-0.038(0.041)$ & $-0.050(0.054)$ & $0.009(0.044)$ & $-0.158 * * *(0.055)$ & $0.043(0.038)$ \\
\hline Satisfaction & $0.250 * *(0.105)$ & $0.183(0.161)$ & $0.343 * *(0.159)$ & $0.326 *(0.165)$ & $0.224(0.154)$ & $0.454 * *(0.173)$ & $0.117(0.139)$ \\
\hline \multicolumn{8}{|l|}{ Model characteristics } \\
\hline $\mathrm{R}^{2}$ & 0.19 & 0.20 & 0.23 & 0.27 & 0.18 & 0.40 & 0.17 \\
\hline Adjusted $\mathrm{R}^{2}$ & 0.09 & -0.05 & 0.08 & 0.09 & -0.02 & 0.23 & -0.01 \\
\hline F ratio & $1.95 * *$ & 0.81 & 1.50 & 1.55 & 0.88 & $2.33 * *$ & 0.94 \\
\hline $\mathrm{N}$ & 96 & 41 & 55 & 49 & 47 & 42 & 54 \\
\hline Maximum VIF & 1.36 & 1.62 & 1.51 & 1.48 & 1.54 & 1.76 & 1.44 \\
\hline
\end{tabular}

Estimated coefficients are reported in the table. Standard errors are in parentheses. Missing values are replaced with sample means. $* \mathrm{p}<0.10 ; * * \mathrm{p}<0.05 ; * * * \mathrm{p}<0.01$.

No difference in the confidence intervals (95\%) of the control variables was found between each pair of split-samples (Asian vs. Western; Small vs. Large;

Manufacturing vs. Services) 
Table 6-14b Regression results for the degree of change in intangible economic interaction

\begin{tabular}{|c|c|c|c|c|c|c|c|}
\hline & $\begin{array}{l}\text { Full-sample } \\
\text { Model 17-1 }\end{array}$ & $\begin{array}{l}\text { Asian firms } \\
\text { Model 17-2 }\end{array}$ & $\begin{array}{c}\text { Western firms } \\
\text { Model 17-3 }\end{array}$ & $\begin{array}{l}\text { Small firms } \\
\text { Model 17-4 }\end{array}$ & $\begin{array}{l}\text { Large firms } \\
\text { Model 17-5 }\end{array}$ & $\begin{array}{c}\text { Mfg firms } \\
\text { Model 17-6 }\end{array}$ & $\begin{array}{c}\text { Service firms } \\
\text { Model 17-7 }\end{array}$ \\
\hline Constant & $-0.506(0.318)$ & $-0.436(0.348)$ & $-0.050(0.327)$ & $-0.229(0.412)$ & $-0.799(0.607)$ & $-0.615(0.413)$ & $-0.241(0.458)$ \\
\hline \multicolumn{8}{|l|}{ Explanatory variables } \\
\hline $\begin{array}{l}\text { NATIONALITY } \\
(0=\text { Asian; } 1=\text { Western })\end{array}$ & $0.080(0.156)$ & & & $0.061(0.200)$ & $0.179(0.274)$ & $0.221(0.188)$ & $0.016(0.245)$ \\
\hline SIZE1 (Full-sample) & $0.159 *(0.097)$ & & & & & & \\
\hline $\begin{array}{l}\text { SIZE2 (Split-samples) } \\
(0=\text { Small; } 1=\text { Large })\end{array}$ & & $0.138(0.225)$ & $0.275(0.235)$ & & & $0.336 *(0.185)$ & $0.141(0.249)$ \\
\hline $\begin{array}{l}\text { INDUSTRY } \\
(0=\text { Manu; } 1=\text { Service })\end{array}$ & $-0.033(0.143)$ & $0.131(0.533)$ & $-0.131(0.215)$ & $0.125(0.199)$ & $-0.149(0.231)$ & & \\
\hline \multicolumn{8}{|l|}{ Control variables } \\
\hline $\begin{array}{l}\text { Ownership } \\
(0=\text { Others; } 1=\mathrm{IJV})\end{array}$ & $0.260(0.171)$ & $0.175(0.245)$ & $0.222(0.275)$ & $0.195(0.243)$ & $0.380(0.287)$ & $0.501 * *(0.216)$ & $0.170(0.287)$ \\
\hline HQs' influence & $0.055(0.078)$ & $0.139(0.112)$ & $-0.039(0.124)$ & $0.017(0.099)$ & $0.110(0.137)$ & $0.148(0.093)$ & $-0.043(0.123)$ \\
\hline $\begin{array}{l}\text { Other subsidiary } \\
(0=\text { Not exist, } 1=\text { Exist })\end{array}$ & $0.014 *(0.226)$ & $0.132(0.321)$ & $-0.046(0.336)$ & $0.000(0.256)$ & $0.438(0.493)$ & $0.123(0.339)$ & $-0.055(0.311)$ \\
\hline Overall benefit & $0.062(0.080)$ & $0.114(0.387)$ & $0.022(0.120)$ & $0.034(0.112)$ & $0.094(0.131)$ & $-0.091(0.096)$ & $0.087(0.129)$ \\
\hline Overall dependence & $-0.244 *(0.076)$ & $-0.201 *(0.108)$ & $-0.213 *(0.123)$ & $-0.143(0.107)$ & $-0.388 * * *(0.124)$ & $-0.148(0.111)$ & $-0.229 *(0.115)$ \\
\hline Duration & $0.007(0.023)$ & $0.035(0.043)$ & $0.006(0.031)$ & $-0.023(0.036)$ & $0.033(0.032)$ & $-0.026(0.031)$ & $0.209(0.032)$ \\
\hline Satisfaction & $-0.002(0.076)$ & $0.025(0.103)$ & $-0.040(0.122)$ & $-0.034(0.111)$ & $-0.008(0.115)$ & $0.194 *(0.098)$ & $-0.152(0.118)$ \\
\hline \multicolumn{8}{|l|}{ Model characteristics } \\
\hline $\mathrm{R}^{2}$ & 0.18 & 0.33 & 0.14 & 0.08 & 0.29 & 0.46 & 0.15 \\
\hline Adjusted $\mathrm{R}^{2}$ & 0.08 & 0.13 & -0.03 & -0.14 & 0.12 & 0.31 & -0.03 \\
\hline F ratio & $1.83^{*}$ & 1.67 & 0.84 & 0.37 & 1.70 & $3.05 * * *$ & 0.85 \\
\hline $\mathrm{N}$ & 96 & 41 & 55 & 49 & 47 & 42 & 54 \\
\hline Maximum VIF & 1.36 & 1.62 & 1.51 & 1.48 & 1.54 & 1.76 & 1.44 \\
\hline
\end{tabular}

Estimated coefficients are reported in the table. Standard errors are in parentheses. Missing values are replaced with sample means. $* \mathrm{p}<0.10 ; * * \mathrm{p}<0.05 ; * * * \mathrm{p}<0.01$.

No difference in the confidence intervals (95\%) of the control variables was found between each pair of split-samples (Asian vs. Western; Small vs. Large;

Manufacturing vs. Services) 
Table 6-14c Regression results for the degree of change in economic communication

\begin{tabular}{|c|c|c|c|c|c|c|c|}
\hline & $\begin{array}{l}\text { Full-sample } \\
\text { Model 18-1 }\end{array}$ & $\begin{array}{l}\text { Asian firms } \\
\text { Model 18-2 }\end{array}$ & $\begin{array}{c}\text { Western firms } \\
\text { Model 18-3 }\end{array}$ & $\begin{array}{l}\text { Small firms } \\
\text { Model 18-4 }\end{array}$ & $\begin{array}{l}\text { Large firms } \\
\text { Model 18-5 }\end{array}$ & $\begin{array}{c}\text { Mfg firms } \\
\text { Model 18-6 }\end{array}$ & $\begin{array}{c}\text { Service firms } \\
\text { Model } 18-7\end{array}$ \\
\hline Constant & $0.064(0.241)$ & $0.487(0.348)$ & $-0.187(0.194)$ & $0.608(0.364)$ & $0.438(0.333)$ & $1.121 * * *(0.325)$ & $-0.083(0.804)$ \\
\hline \multicolumn{8}{|l|}{ Explanatory variables } \\
\hline $\begin{array}{l}\text { NATIONALITY } \\
(0=\text { Asian; } 1=\text { Western })\end{array}$ & $-0.159(0.118)$ & & & $-0.268(0.176)$ & $0.176(0.150)$ & $-0.332 * *(0.142)$ & $-0.145(0.179)$ \\
\hline SIZE1 (Full-sample) & $0.216 * *(0.074)$ & & & & & & \\
\hline $\begin{array}{l}\text { SIZE2 (Split-samples) } \\
(0=\text { Small; } 1=\text { Large })\end{array}$ & & $0.112(0.225)$ & $0.468 * * *(0.140)$ & & & $0.286 * *(0.139)$ & $0.323 *(0.182)$ \\
\hline $\begin{array}{l}\text { INDUSTRY } \\
(0=\text { Manu; } 1=\text { Service })\end{array}$ & $-0.033 *(0.108)$ & $-0.183(0.208)$ & $0.051(0.128)$ & $-0.220(0.176)$ & $0.088(0.127)$ & & \\
\hline \multicolumn{8}{|l|}{ Control variables } \\
\hline $\begin{array}{l}\text { Ownership } \\
(0=\text { Others; } 1=\mathrm{IJV})\end{array}$ & $0.038(0.130)$ & $-0.103(0.245)$ & $0.084(0.164)$ & $-0.259(0.214)$ & $0.458 * * *(0.158)$ & $0.002(0.162)$ & $0.117(0.210)$ \\
\hline HQs' influence & $0.101 *(0.059)$ & $0.206 *(0.112)$ & $0.063(0.074)$ & $0.116(0.088)$ & $0.195 * *(0.075)$ & $0.054(0.070)$ & $0.125(0.090)$ \\
\hline $\begin{array}{l}\text { Other subsidiary } \\
(0=\text { Not exist, } 1=\text { Exist })\end{array}$ & $-0.277(0.171)$ & $-0.457(0.321)$ & $-0.238(0.200)$ & $-0.195(0.226)$ & $-0.925 * * *(0.270)$ & $-0.803 * * *(0.255)$ & $0.020(0.227)$ \\
\hline Overall benefit & $0.280 * * *(0.060)$ & $0.406 * * *(0.130)$ & $0.235 * * *(0.071)$ & $0.368 * * *(0.099)$ & $0.119(0.072)$ & $0.457 * * *(0.073)$ & $0.167 *(0.095)$ \\
\hline Overall dependence & $-0.301 * * *(0.057)$ & $-0.302 * * *(0.108)$ & $-0.312 * * *(0.073)$ & $-0.364 * * *(0.094)$ & $-0.257 * * *(0.068)$ & $-0.311 * * *(0.083)$ & $-0.320 * * *(0.084)$ \\
\hline Duration & $0.006(0.017)$ & $0.009(0.043)$ & $0.006(0.019)$ & $-0.006(0.032)$ & $0.011(0.018)$ & $-0.015(0.023)$ & $0.021(0.024)$ \\
\hline Satisfaction & $0.033(0.058)$ & $-0.036(0.103)$ & $0.062(0.395)$ & $-0.056(0.098)$ & $0.078(0.063)$ & $0.065(0.073)$ & $0.029(0.086)$ \\
\hline \multicolumn{8}{|l|}{ Model characteristics } \\
\hline $\mathrm{R}^{2}$ & 0.38 & 0.43 & 0.41 & 0.44 & 0.56 & 0.66 & 0.32 \\
\hline Adjusted $\mathrm{R}^{2}$ & 0.30 & 0.26 & 0.29 & 0.31 & 0.45 & 0.57 & 0.18 \\
\hline F ratio & $5.08 * * *$ & $2.50 * *$ & $3.49 * * *$ & $3.32 * * *$ & $5.13 * * *$ & $6.96 * * *$ & $2.28 * *$ \\
\hline $\mathrm{N}$ & 96 & 41 & 55 & 49 & 47 & 42 & 54 \\
\hline Maximum VIF & 1.366 & 1.62 & 1.51 & 1.48 & 1.54 & 1.76 & 1.44 \\
\hline
\end{tabular}

Estimated coefficients are reported in the table. Standard errors are in parentheses. Missing values are replaced with sample means. $* \mathrm{p}<0.10 ; * * \mathrm{p}<0.05 ; * * * \mathrm{p}<0.01$.

No difference in the confidence intervals (95\%) of the control variables was found between each pair of split-samples (Asian vs. Western; Small vs. Large;

Manufacturing vs. Services) 
Table 6-14d Regression results for the degree of change in competence trust

\begin{tabular}{|c|c|c|c|c|c|c|c|}
\hline & $\begin{array}{l}\text { Full-sample } \\
\text { Model 19-1 }\end{array}$ & $\begin{array}{l}\text { Asian firms } \\
\text { Model 19-2 }\end{array}$ & $\begin{array}{l}\text { Western firms } \\
\text { Model 19-3 }\end{array}$ & $\begin{array}{l}\text { Small firms } \\
\text { Model 19-4 }\end{array}$ & $\begin{array}{l}\text { Large firms } \\
\text { Model 19-5 }\end{array}$ & $\begin{array}{c}\text { Mfg firms } \\
\text { Model 19-6 }\end{array}$ & $\begin{array}{c}\text { Service firms } \\
\text { Model 19-7 }\end{array}$ \\
\hline Constant & $-0.053(0.317)$ & $0.082(0.405)$ & $-0.452(0.277)$ & $0.177(0.528)$ & $0.078(0.393)$ & $0.951 *(0.502)$ & $-0.414(0.402)$ \\
\hline \multicolumn{8}{|l|}{ Explanatory variables } \\
\hline $\begin{array}{l}\text { NATIONALITY } \\
(0=\text { Asian; } 1=\text { Western })\end{array}$ & $-0.232(0.155)$ & & & $-0.280(0.256)$ & $-0.046(0.177)$ & $-0.652 * * *(0.219)$ & $0.024(0.215)$ \\
\hline SIZE1 (Full-sample) & $0.168 * *(0.097)$ & & & & & & \\
\hline $\begin{array}{l}\text { SIZE2 (Split-samples) } \\
(0=\text { Small; } 1=\text { Large })\end{array}$ & & $0.206(0.262)$ & $0.354 *(0.199)$ & & & $0.332(0.134)$ & $0.252(0.219)$ \\
\hline $\begin{array}{l}\text { INDUSTRY } \\
(0=\text { Manu; } 1=\text { Service })\end{array}$ & $-0.030(0.142)$ & $-0.401(0.108)$ & $0.285(0.182)$ & $-0.005(0.255)$ & $0.019(0.149)$ & & \\
\hline \multicolumn{8}{|l|}{ Control variables } \\
\hline $\begin{array}{l}\text { Ownership } \\
(0=\text { Others; } 1=\mathrm{IJV})\end{array}$ & $-0.171(0.171)$ & $-0.099(0.285)$ & $-0.294(0.234)$ & $-0.266(0.311)$ & $0.195(0.186)$ & $-0.157(0.251)$ & $-0.254(0.252)$ \\
\hline HQs' influence & $-0.063(0.078)$ & $-0.105(0.131)$ & $-0.064(0.105)$ & $-0.185(0.127)$ & $0.164 *(0.089)$ & $-0.020(0.018)$ & $-0.100(0.108)$ \\
\hline $\begin{array}{l}\text { Other subsidiary } \\
(0=\text { Not exist, } 1=\text { Exist })\end{array}$ & $-0.016(0.225)$ & $-0.099(0.373)$ & $-0.045(0.285)$ & $-0.063(0.328)$ & $-0.105(0.319)$ & $-0.398(0.395)$ & $0.194(0.274)$ \\
\hline Overall benefit & $0.238 * *(0.079)$ & $0.310 * *(0.151)$ & $0.211 * *(0.102)$ & $0.394 * * *(0.143)$ & $0.058(0.085)$ & $0.424 * * *(0.112)$ & $0.165(0.114)$ \\
\hline Overall dependence & $-0.281 * * *(0.075)$ & $-0.390 * * *(0.126)$ & $-0.182 *(0.104)$ & $-0.247 *(0.137)$ & $-0.273 * * *(0.080)$ & $-0.267 * *(0.129)$ & $-0.292 * * *(0.101)$ \\
\hline Duration & $0.035(0.023)$ & $0.050(0.050)$ & $0.020(0.027)$ & $0.039(0.047)$ & $0.027(0.021)$ & $0.052(0.036)$ & $0.024(0.028)$ \\
\hline Satisfaction & $0.024(0.076)$ & $0.026(0.120)$ & $0.009(0.104)$ & $0.069(0.142)$ & $-0.040(0.074)$ & $-0.135(0.114)$ & $0.164(0.104)$ \\
\hline \multicolumn{8}{|l|}{ Model characteristics } \\
\hline $\mathrm{R}^{2}$ & 0.24 & 0.40 & 0.24 & 0.32 & 0.34 & 0.45 & 0.29 \\
\hline Adjusted $\mathrm{R}^{2}$ & 0.15 & 0.22 & 0.08 & 0.16 & 0.18 & 0.29 & 0.14 \\
\hline F ratio & $2.65 * *$ & $2.24 * *$ & 1.55 & $1.97 *$ & $2.15^{* *}$ & $2.90 * *$ & $1.93 *$ \\
\hline $\mathrm{N}$ & 96 & 41 & 55 & 49 & 47 & 42 & 54 \\
\hline Maximum VIF & 1.36 & 1.62 & 1.51 & 1.48 & 1.54 & 1.76 & 1.44 \\
\hline
\end{tabular}

Estimated coefficients are reported in the table. Standard errors are in parentheses. Missing values are replaced with sample means. $* \mathrm{p}<0.10 ; * * \mathrm{p}<0.05 ; * * * \mathrm{p}<0.01$.

No difference in the confidence intervals (95\%) of the control variables was found between each pair of split-samples (Asian vs. Western; Small vs. Large;

Manufacturing vs. Services) 
Table 6-14e Regression results for the degree of change in contractual trust

\begin{tabular}{|c|c|c|c|c|c|c|c|}
\hline & $\begin{array}{l}\text { Full-sample } \\
\text { Model 20-1 }\end{array}$ & $\begin{array}{l}\text { Asian firms } \\
\text { Model 20-2 }\end{array}$ & $\begin{array}{l}\text { Western firms } \\
\text { Model 20-3 }\end{array}$ & $\begin{array}{l}\text { Small firms } \\
\text { Model 20-4 }\end{array}$ & $\begin{array}{l}\text { Large firms } \\
\text { Model 20-5 }\end{array}$ & $\begin{array}{c}\text { Mfg firms } \\
\text { Model 20-6 }\end{array}$ & $\begin{array}{l}\text { Service firms } \\
\text { Model 20-7 }\end{array}$ \\
\hline Constant & $0.184(0.342)$ & $0.537(0.482)$ & $0.026(0.255)$ & $0.600(0.500)$ & $0.529(0.579)$ & $1.797 * *(0.673)$ & $-0.556 *(0.335)$ \\
\hline \multicolumn{8}{|l|}{ Explanatory variables } \\
\hline $\begin{array}{l}\text { NATIONALITY } \\
(0=\text { Asian; } 1=\text { Western })\end{array}$ & $-0.105(0.168)$ & & & $-0.245(0.242)$ & $0.128(0.261)$ & $-0.531 *(0.294)$ & $0.131(0.179)$ \\
\hline SIZE1 (Full-sample) & $0.207 *(0.105)$ & & & & & & \\
\hline $\begin{array}{l}\text { SIZE2 (Split-samples) } \\
(0=\text { Small; 1=Large) }\end{array}$ & & $0.200(0.311)$ & $0.326 *(0.184)$ & & & $0.274(0.289)$ & $0.327 *(0.182)$ \\
\hline $\begin{array}{l}\text { INDUSTRY } \\
(0=\text { Manu; } 1=\text { Service })\end{array}$ & $-0.270 *(0.154)$ & $-0.628 * *(0.288)$ & $-0.090(0.168)$ & $-0.583 * *(0.241)$ & $0.007(0.22)$ & & \\
\hline \multicolumn{8}{|l|}{ Control variables } \\
\hline $\begin{array}{l}\text { Ownership } \\
(0=\text { Others; } 1=\mathrm{IJV})\end{array}$ & $0.059(0.184)$ & $-0.057(0.339)$ & $0.096(0.215)$ & $-0.285(0.294)$ & $0.393(0.274)$ & $0.315(0.337)$ & $-0.046(0.210)$ \\
\hline HQs' influence & $-0.022(0.084)$ & $-0.119(0.156)$ & $0.086(0.097)$ & $-0.094(0.121)$ & $0.140(0.131)$ & $0.017(0.145)$ & $-0.069(0.090)$ \\
\hline $\begin{array}{l}\text { Other subsidiary } \\
(0=\text { Not exist, } 1=\text { Exist })\end{array}$ & $-0.278(0.243)$ & $-0.118(0.444)$ & $-0.362(0.263)$ & $-0.123(0.311)$ & $-0.629(0.470)$ & $-0.947 *(0.529)$ & $-0.078(0.228)$ \\
\hline Overall benefit & $0.203 * *(0.086)$ & $0.446 * *(0.180)$ & $0.007(0.094)$ & $0.165(0.135)$ & $0.146(0.125)$ & $0.342 * *(0.151)$ & $-0.070(0.095)$ \\
\hline Overall dependence & $-0.111(0.082)$ & $-0.217(0.150)$ & $-0.024(0.096)$ & $-0.119(0.129)$ & $-0.098(0.118)$ & $0.014(0.173)$ & $-0.157 *(0.084)$ \\
\hline Duration & $-0.005(0.024)$ & $-0.040(0.504)$ & $0.018(0.025)$ & $0.040(0.044)$ & $-0.029(0.031)$ & $-0.061(0.049)$ & $0.027(0.024)$ \\
\hline Satisfaction & $0.064(0.082)$ & $0.044(0.143)$ & $-0.003(0.095)$ & $0.035(0.135)$ & $0.061(0.109)$ & $0.228(0.152)$ & $-0.043(0.087)$ \\
\hline \multicolumn{8}{|l|}{ Model characteristics } \\
\hline $\mathrm{R}^{2}$ & 0.14 & 0.36 & 0.12 & 0.23 & 0.19 & 0.31 & 0.22 \\
\hline Adjusted $\mathrm{R}^{2}$ & 0.04 & 0.17 & -0.05 & 0.05 & -0.01 & 0.11 & 0.05 \\
\hline F ratio & $1.40 * *$ & $1.87 *$ & 0.70 & 1.25 & 0.94 & 1.58 & 1.33 \\
\hline $\mathrm{N}$ & 96 & 41 & 55 & 49 & 47 & 42 & 54 \\
\hline Maximum VIF & 1.36 & 1.62 & 1.51 & 1.48 & 1.54 & 1.76 & 1.44 \\
\hline
\end{tabular}

Estimated coefficients are reported in the table. Standard errors are in parentheses. Missing values are replaced with sample means. $* \mathrm{p}<0.10 ; * * \mathrm{p}<0.05 ; * * * \mathrm{p}<0.01$.

No difference in the confidence intervals (95\%) of the control variables was found between each pair of split-samples (Asian vs. Western; Small vs. Large;

Manufacturing vs. Services) 
Table 6-14f Regression results for the degree of change in economic commitment

\begin{tabular}{|c|c|c|c|c|c|c|c|}
\hline & $\begin{array}{l}\text { Full-sample } \\
\text { Model 21-1 }\end{array}$ & $\begin{array}{l}\text { Asian firms } \\
\text { Model 21-2 }\end{array}$ & $\begin{array}{l}\text { Western firms } \\
\text { Model 21-3 }\end{array}$ & $\begin{array}{l}\text { Small firms } \\
\text { Model 21-4 }\end{array}$ & $\begin{array}{l}\text { Large firms } \\
\text { Model 21-5 }\end{array}$ & $\begin{array}{l}\text { Mfg firms } \\
\text { Model 21-6 }\end{array}$ & $\begin{array}{l}\text { Service firms } \\
\text { Model 21-7 }\end{array}$ \\
\hline Constant & $-0.167(0.323)$ & $0.127(0.475)$ & $-0.541 * *(0.248)$ & $0.110(0.439)$ & $0.207(0.602)$ & $0.818(0.559)$ & $-0.310(0.385)$ \\
\hline \multicolumn{8}{|l|}{ Explanatory variables } \\
\hline $\begin{array}{l}\text { NATIONALITY } \\
(0=\text { Asian; } 1=\text { Western })\end{array}$ & $-0.213 *(0.159)$ & & & $-0.363 *(0.213)$ & $0.139(0.272)$ & $-0.302(0.244)$ & $-0.232(0.206)$ \\
\hline SIZE1 (Full-sample) & $0.176 * *(0.099)$ & & & & & & \\
\hline $\begin{array}{l}\text { SIZE2 (Split-samples) } \\
(0=\text { Small; } 1=\text { Large })\end{array}$ & & $0.000(0.307)$ & $-0.321 *(0.178)$ & & & $0.310(0.240)$ & $-0.039(0.209)$ \\
\hline $\begin{array}{l}\text { INDUSTRY } \\
(0=\text { Manu; } 1=\text { Service })\end{array}$ & $-0.038(0.145)$ & $-0.079(0.284)$ & $-0.131(0.163)$ & $0.014(0.212)$ & $-0.115(0.229)$ & & \\
\hline \multicolumn{8}{|l|}{ Control variables } \\
\hline $\begin{array}{l}\text { Ownership } \\
(0=\text { Others; } 1=I J V)\end{array}$ & $0.065(0.174)$ & $-0.032(0.334)$ & $-0.015(0.209)$ & $-0.025(0.259)$ & $0.227(0.284)$ & $0.116(0.279)$ & $0.023(0.242)$ \\
\hline HQs' influence & $0.033(0.079)$ & $0.115(0.460)$ & $-0.006(0.094)$ & $0.045(0.106)$ & $0.035(0.136)$ & $0.050(0.120)$ & $-0.065(0.104)$ \\
\hline $\begin{array}{l}\text { Other subsidiary } \\
(0=\text { Not exist, } 1=\text { Exist })\end{array}$ & $0.257(0.229)$ & $0.340(0.437)$ & $-0.248(0.255)$ & $0.506 *(0.273)$ & $-0.379(0.488)$ & $-0.489(0.439)$ & $0.735 * * *(0.262)$ \\
\hline Overall benefit & $0.275 * *(0.081)$ & $0.378 * *(0.177)$ & $-0.116(0.091)$ & $0.213 *(0.119)$ & $0.245 *(0.130)$ & $0.408 * * *(0.125)$ & $0.107(0.109)$ \\
\hline Overall dependence & $-0.360 * * *(0.077)$ & $-0.502 * * *(0.147)$ & $-0.270 * * *(0.093)$ & $-0.354 * * *(0.114)$ & $-0.362 * * *(0.123)$ & $-0.525 * * *(0.143)$ & $-0.189 *(0.097)$ \\
\hline Duration & $-0.009(0.023)$ & $-0.083(0.058)$ & $0.024(0.024)$ & $-0.015(0.039)$ & $0.000(0.032)$ & $-0.019(0.040)$ & $0.011(0.027)$ \\
\hline Satisfaction & $0.139 *(0.078)$ & $0.056(0.141)$ & $0.139(0.093)$ & $0.075(0.118)$ & $0.209 *(0.114)$ & $0.307 * *(0.126)$ & $0.044(0.100)$ \\
\hline \multicolumn{8}{|l|}{ Model characteristics } \\
\hline $\mathrm{R}^{2}$ & 0.34 & 0.44 & 0.31 & 0.42 & 0.33 & 0.56 & 0.26 \\
\hline Adjusted $\mathrm{R}^{2}$ & 0.26 & 0.28 & 0.17 & 0.28 & 0.17 & 0.44 & 0.11 \\
\hline F ratio & $4.23 * * *$ & $2.66^{* *}$ & $2.21 * *$ & $3.03 * * *$ & $2.05 *$ & $4.52 * * *$ & 1.68 \\
\hline $\mathrm{N}$ & 96 & 41 & 55 & 49 & 47 & 42 & 54 \\
\hline Maximum VIF & 1.36 & 1.62 & 1.51 & 1.48 & 1.54 & 1.76 & 1.44 \\
\hline
\end{tabular}

Estimated coefficients are reported in the table. Standard errors are in parentheses. Missing values are replaced with sample means. $* \mathrm{p}<0.10 ; * * \mathrm{p}<0.05 ; * * * \mathrm{p}<0.01$.

No difference in the confidence intervals (95\%) of the control variables was found between each pair of split-samples (Asian vs. Western; Small vs. Large;

Manufacturing vs. Services) 


\subsubsection{The degree of change in social constructs}

The degree of change in each social construct from the relationship formation to the time at the survey completion was used as the dependent variable in regression modelling. The results for the regressions are shown in Tables 6-15a, b, c, d, and e.

First, the degree of change in social interaction was used as the dependent variable. As presented in the Table 6-15a, the coefficient associated with INDUSTRY is negative in the full-sample model $(\mathrm{p}<0.10)$. This implies that holding other variables in the model constant, manufacturing firms, on average, experience greater increase in their social interaction with customers than service firms, after relationships are formed. This result is mainly driven by the group of large firms $(\mathrm{p}<0.05)$. Also, the model based on the split-sample of service firms shows a negative coefficient associated with NATIONALITY $(\mathrm{p}<0.10)$, indicating that in a marginal sense, Asian service firms, on average, increase more in socialising activities than Western service firms. As for the control variables, ownership is associated with a positive coefficient in the full-sample model $(\mathrm{p}<0.10)$, and the result mainly comes from the group of service firms $(\mathrm{p}<0.10)$. Relationship benefit is positively related to the dependent variable in the models $(\mathrm{p}<0.10)$ except for small firms and manufacturing firms. Additionally, the coefficients associated with relationship dependence are negative in all the models (at least $\mathrm{p}<0.05$ ), suggesting the explanatory power of this variable for the degree of change in social interaction, marginal to other variables included in the models.

Second, using the degree of change in social communication as the dependent variable, the regression results are displayed in Table 6-15b. In the full-sample model, the coefficient associated with INDUSTRY is significantly negative $(\mathrm{p}<0.05)$, marginal to other variables. The split-sample analysis further reveals that this result is driven by Asian firms $(p<0.10)$ and larger firms $(p<0.10)$. Also, in the model based on smaller firms, the coefficient associated with NATIONALITY is negative $(\mathrm{p}<0.05)$, implying that, with other variables being constant, smaller firms from an Asian background experience more increase in 
social communication than those from a Western background. With regard to the control variables, the table shows that headquarters' influence is positively related to the dependent variable in the model based on Asian firms $(\mathrm{p}<0.05)$. The presence of other subsidiary/ries in China has marginal explanatory power for the dependent variable in the model based on service firms $(\mathrm{p}<0.10)$. Relationship benefit is positively related to the degree of change in social communication in the full-sample model $(p<0.05)$, and similar results can be seen in the models of Western firms $(p<0.05)$, larger firms $(\mathrm{p}<0.10)$, and both manufacturing firms and service firms $(\mathrm{p}<0.05)$. In contrast, the coefficients associated with relationship dependence are negative in all the models (at least $\mathrm{p}<0.05$ ). Relationship satisfaction is positively related to the degree of change in social communication in the model of manufacturing firms $(\mathrm{p}<0.10)$, marginal to other variables.

Third, the degree of change in social trust was used as the dependent variable for regression modelling, and results are presented in Table 6-15c. The coefficient associated with INDUSTRY is negative in the full-sample model $(\mathrm{p}<0.05)$. This implies that holding other variables constant, manufacturing firms, on average, increase their social trust in local customers more greatly than service firms, after relationships are formed. Split-sample analysis shows that this result is mainly driven by the groups of Asian firms $(p<0.10)$ and larger firms $(p<0.10)$. In respect to the control variables, relationship benefit has marginal explanatory power for the dependent variable in the full-sample model $(\mathrm{p}<0.05)$. The positive coefficient indicates that relationships perceived as being more beneficial are likely to have a higher increase in social trust. According to the split-sample analysis, this result is driven by Western firms $(\mathrm{p}<0.05)$, larger firms $(\mathrm{p}<0.10)$ and manufacturing firms $(\mathrm{p}<0.10)$. Relationship dependence, however, demonstrates a negative relationship with the degree of change in social trust (at least $\mathrm{p}<0.05$ ), apart from in the model based on manufacturing firms. Relationship satisfaction has a marginal negative association with the dependent variable in the model of manufacturing firms $(\mathrm{p}<0.10)$. 
Fourth, the degree of change in social commitment was adopted as the dependent variable. In Table 6-15d, SIZE1 shows marginal contribution to the dependent variable in the full-sample model $(\mathrm{p}<0.10)$, implying that with other variables being controlled for, larger firms grow their social commitment to local customers more than smaller firms, during the relationship development process after formation. The split-sample analysis using SIZE2 suggests that this result is mainly driven by the group of Western firms $(\mathrm{p}<0.10)$. Also, in the full-sample model, INDUSTRY is associated with a significant and negative coefficient $(\mathrm{p}<0.05)$. This suggests that, with other variables in the model being constant, manufacturing firms, on average, increase social commitment to their local customers more greatly than service firms, after relationship are formed. This result is driven by the groups of Asian firms $(\mathrm{p}<0.05)$ and larger firms $(\mathrm{p}<0.05)$. With respect to the control variables, foreign headquarters' influence is significantly and positively related to the dependent variable in four models (at least $\mathrm{p}<0.10$ ). The coefficients associated with relationship benefit are positive in nearly all the models (at least $\mathrm{p}<0.05$ ), except for large firms. However, relationship dependence is negatively related to the dependent variable in all the models (at least $\mathrm{p}<0.10$ ).

Fifth, the degree of change in norms and values was used as the dependent variable in regression modelling. From Table 6-15e, it can be seen that the coefficient associated with NATIONALITY is negative in the full-sample model $(\mathrm{p}<0.10)$, suggesting that, with other variables in the model held constant, Western firms, on average, increase more greatly in norms and values than Asian firms. This result is driven by the groups of smaller firms $(\mathrm{p}<0.10)$ and manufacturing firms $(\mathrm{p}<0.01)$. SIZE1 is associated with a positive coefficient in the model based on the full-sample $(\mathrm{p}<0.05)$, suggesting that in a marginal sense, larger firms achieve a higher degree of increase in the dependent variable than smaller firms. Similar results can be also seen in the split-sample models based on Western firms $(\mathrm{p}<0.10)$ and manufacturing firms $(\mathrm{p}<0.01)$, using SIZE2 as explanatory variable. INDUSTRY shows its explanatory power for the dependent 
variable in the full-sample model $(\mathrm{p}<0.10)$, marginal to other variables. According to the split-sample analysis, this result is driven by the group of Asian firms $(\mathrm{p}<0.05)$,

As far as the control variables are concerned, in the model based on large firms, ownership has marginal explanatory power for the degree of change in norms and values $(\mathrm{p}<0.10)$. Influence from the foreign headquarters is associated with a positive coefficient in the full-sample model $(\mathrm{p}<0.10)$. The presence of other subsidiary/ries in China is associated with a negative coefficient in the model based on the manufacturing firms $(\mathrm{p}<0.10)$, implying that in this particular splitsample, holding other variables constant in the model, firms having other sister subsidiary/ries in China experience less degree of increase in common norms and values with local customers, than those having no other subsidiary/ries. Further, the significant and positive coefficients associated with relationship benefit in nearly all the models (at least $\mathrm{p}<0.05$ ) except for Asian firms show the marginal explanatory power of this variable for the dependent variable. In contrast, relationship dependence is associated with a negative coefficient in all the models (at least $\mathrm{p}<0.05$ ). Relationship duration is found to be negatively related to the dependent variable in the models based on Asian firms $(\mathrm{p}<0.05)$ and manufacturing firms $(\mathrm{p}<0.10)$, marginal to other variables in the two models. 
Table 6-15a Regression results for the degree of change in social interaction

\begin{tabular}{|c|c|c|c|c|c|c|c|}
\hline & $\begin{array}{l}\text { Full-sample } \\
\text { Model 22-1 }\end{array}$ & $\begin{array}{l}\text { Asian firms } \\
\text { Model 22-2 }\end{array}$ & $\begin{array}{l}\text { Western firms } \\
\text { Model 22-3 }\end{array}$ & $\begin{array}{l}\text { Small firms } \\
\text { Model 22-4 }\end{array}$ & $\begin{array}{l}\text { Large firms } \\
\text { Model 22-5 }\end{array}$ & $\begin{array}{c}\text { Mfg firms } \\
\text { Model 22-6 }\end{array}$ & $\begin{array}{c}\text { Service firms } \\
\text { Model 22-7 }\end{array}$ \\
\hline Constant & $-0.008(0.232)$ & $0.196(0.307)$ & $-0.037(0.213)$ & $0.117(0.318)$ & $-0.129(0.410)$ & $0.136(0.457)$ & $-0.243(0.267)$ \\
\hline \multicolumn{8}{|l|}{ Explanatory variables } \\
\hline $\begin{array}{l}\text { NATIONALITY } \\
(0=\text { Asian; } 1=\text { Western })\end{array}$ & $-0.027(0.114)$ & & & $-0.130(0.154)$ & $0.087(0.185)$ & $-0.018(0.199)$ & $-0.088 * 0.143)$ \\
\hline SIZE1 (Full-sample) & $0.083(0.071)$ & & & & & & \\
\hline $\begin{array}{l}\text { SIZE2 (Split-samples) } \\
(0=\text { Small; } 1=\text { Large })\end{array}$ & & $0.000(0.198)$ & $0.175(0.153)$ & & & $0.312(0.196)$ & $-0.123(0.145)$ \\
\hline $\begin{array}{l}\text { INDUSTRY } \\
(0=\text { Manu; } 1=\text { Service })\end{array}$ & $-0.198 *(0.104)$ & $-0.213(0.183)$ & $-0.209(0.140)$ & $-0.070(0.154)$ & $-0.379 * *(0.156)$ & & \\
\hline \multicolumn{8}{|l|}{ Control variables } \\
\hline $\begin{array}{l}\text { Ownership } \\
(0=\text { Others; } 1=\mathrm{IJV})\end{array}$ & $0.215 *(0.125)$ & $0.214(0.216)$ & $0.226(0.180)$ & $0.069(0.187)$ & $0.315(0.113)$ & $0.207(0.229)$ & $0.336 *(0.168)$ \\
\hline HQs' influence & $0.079(0.057)$ & $0.111(0.099)$ & $0.080(0.081)$ & $0.064(0.077)$ & $0.111(0.093)$ & $0.106(0.098)$ & $0.049(0.072)$ \\
\hline $\begin{array}{l}\text { Other subsidiary } \\
(0=\text { Not exist, } 1=\text { Exist })\end{array}$ & $0.075(0.165)$ & $0.029(0.283)$ & $0.086(0.219)$ & $0.138(0.198)$ & $0.329(0.332)$ & $-0.035(0.360)$ & $0.235(0.182)$ \\
\hline Overall benefit & $0.201 * *(0.058)$ & $0.227 *(0.114)$ & $0.182 * *(0.078)$ & $0.078(0.086)$ & $0.273 * * *(0.088)$ & $0.140(0.102)$ & $0.248 * * *(0.076)$ \\
\hline Overall dependence & $-0.275 * * *(0.055)$ & $-0.319 * * *(0.095)$ & $-0.277 * * *(0.080)$ & $-0.263 * * *(0.082)$ & $-0.275 * * *(0.084)$ & $-0.244 * *(0.117)$ & $-0.276 * * *(0.067)$ \\
\hline Duration & $-0.022(0.017)$ & $-0.042(0.037)$ & $-0.019(0.021)$ & $-0.010(0.028)$ & $-0.026(0.022)$ & $-0.037(0.033)$ & $-0.009(0.019)$ \\
\hline Satisfaction & $0.001(0.056)$ & $-0.094(0.091)$ & $0.079(0.080)$ & $0.011(0.086)$ & $-0.019(0.077)$ & $0.055(0.104)$ & $-0.009(0.069)$ \\
\hline \multicolumn{8}{|l|}{ Model characteristics } \\
\hline $\mathrm{R}^{2}$ & 0.34 & 0.42 & 0.30 & 0.28 & 0.49 & 0.32 & 0.41 \\
\hline Adjusted $\mathrm{R}^{2}$ & 0.26 & 0.24 & 0.16 & 0.11 & 0.37 & 0.13 & 0.28 \\
\hline F ratio & $4.35 * * *$ & $2.39 * *$ & $2.18 * *$ & 1.67 & $3.97 * * *$ & 1.68 & $3.25 * * *$ \\
\hline $\mathrm{N}$ & 96 & 41 & 55 & 49 & 47 & 42 & 54 \\
\hline Maximum VIF & 1.36 & 1.62 & 1.51 & 1.48 & 1.54 & 1.76 & 1.44 \\
\hline
\end{tabular}


Table 6-15b Regression results for the degree of change in social communication

\begin{tabular}{|c|c|c|c|c|c|c|c|}
\hline & $\begin{array}{l}\text { Full-sample } \\
\text { Model 23-1 }\end{array}$ & $\begin{array}{l}\text { Asian firms } \\
\text { Model 23-2 }\end{array}$ & $\begin{array}{l}\text { Western firms } \\
\text { Model 23-3 }\end{array}$ & $\begin{array}{l}\text { Small firms } \\
\text { Model 23-4 }\end{array}$ & $\begin{array}{l}\text { Large firms } \\
\text { Model 23-5 }\end{array}$ & $\begin{array}{c}\text { Mfg firms } \\
\text { Model 23-6 }\end{array}$ & $\begin{array}{l}\text { Service firms } \\
\text { Model 23-7 }\end{array}$ \\
\hline Constant & $0.272(0.346)$ & $0.651(0.433)$ & $-0.223(0.302)$ & $0.995 *(0.479)$ & $-0.379(0.584)$ & $1.108 *(0.618)$ & $-0.381(0.417)$ \\
\hline \multicolumn{8}{|l|}{ Explanatory variables } \\
\hline $\begin{array}{l}\text { NATIONALITY } \\
(0=\text { Asian; } 1=\text { Western })\end{array}$ & $-0.237(0.170)$ & & & $-0.526 * *(0.232)$ & $0.197(0.263)$ & $-0.391(0.269)$ & $-0.116(0.223)$ \\
\hline SIZE1 (Full-sample) & $0.074(0.106)$ & & & & & & \\
\hline $\begin{array}{l}\text { SIZE2 (Split-samples) } \\
(0=\text { Small; 1=Large })\end{array}$ & & $-0.332(0.279)$ & $0.321(0.217)$ & & & $0.301(0.265)$ & $-0.265(0.226)$ \\
\hline $\begin{array}{l}\text { INDUSTRY } \\
(0=\text { Manu; } 1=\text { Service })\end{array}$ & $-0.222 * *(0.155)$ & $-0.475 *(0.259)$ & $-0.145(0.199)$ & $-0.243(0.231)$ & $-0.436 *(0.222)$ & & \\
\hline \multicolumn{8}{|l|}{ Control variables } \\
\hline $\begin{array}{l}\text { Ownership } \\
(0=\text { Others; } 1=\mathrm{IJV})\end{array}$ & $0.030(0.186)$ & $-0.329(0.305)$ & $0.125(0.255)$ & $-0.355(0.282)$ & $0.461(0.276)$ & $-0.180(0.309)$ & $0.374(0.261)$ \\
\hline HQs' influence & $0.095(0.085)$ & $0.338 * *(0.140)$ & $-0.025(0.115)$ & $0.159(0.116)$ & $0.156(0.132)$ & $0.134(0.133)$ & $0.018(0.112)$ \\
\hline $\begin{array}{l}\text { Other subsidiary } \\
(0=\text { Not exist, } 1=\text { Exist })\end{array}$ & $0.182(0.245)$ & $0.245(0.399)$ & $0.031(0.311)$ & $0.144(0.298)$ & $0.236(0.474)$ & $-0.253(0.485)$ & $0.522 *(0.284)$ \\
\hline Overall benefit & $0.285 * *(0.087)$ & $0.220(0.161)$ & $0.279 * *(0.111)$ & $0.204(0.130)$ & $0.237 *(0.126)$ & $0.320 * *(0.138)$ & $0.241 * *(0.118)$ \\
\hline Overall dependence & $-0.396 * * *(0.082)$ & $-0.544 * * *(0.134)$ & $-0.336 * * *(0.114)$ & $-0.498 * * *(0.124)$ & $-0.291 * *(0.119)$ & $-0.459 * * *(0.158)$ & $-0.351 * * *(0.104)$ \\
\hline Duration & $-0.015(0.025)$ & $-0.080(0.053)$ & $-0.008(0.029)$ & $-0.023(0.042)$ & $-0.010(0.031)$ & $-0.056(0.045)$ & $0.015(0.029)$ \\
\hline Satisfaction & $0.080(0.083)$ & $0.043(0.128)$ & $0.092(0.113)$ & $0.135(0.129)$ & $-0.005(0.11)$ & $0.236 *(0.140)$ & $-0.020(0.108)$ \\
\hline \multicolumn{8}{|l|}{ Model characteristics } \\
\hline $\mathrm{R}^{2}$ & 0.32 & 0.51 & 0.24 & 0.46 & 0.35 & 0.44 & 0.33 \\
\hline Adjusted $\mathrm{R}^{2}$ & 0.23 & 0.36 & 0.09 & 0.33 & 0.19 & 0.28 & 0.19 \\
\hline F ratio & $3.88 * * *$ & $3.46 * * *$ & 1.61 & $3.58 * * *$ & $2.20 * *$ & $2.77 * *$ & $2.35 * *$ \\
\hline $\mathrm{N}$ & 96 & 41 & 55 & 49 & 47 & 42 & 54 \\
\hline Maximum VIF & 1.36 & 1.62 & 1.51 & 1.48 & 1.54 & 1.76 & 1.44 \\
\hline
\end{tabular}

Estimated coefficients are reported in the table. Standard errors are in parentheses. Missing values are replaced with sample means. $* \mathrm{p}<0.10 ; * * \mathrm{p}<0.05 ; * * * \mathrm{p}<0.01$.

No difference in the confidence intervals (95\%) of the control variables was found between each pair of split-samples (Asian vs. Western; Small vs. Large;

Manufacturing vs. Services) 
Table 6-15c Regression results for the degree of change in social trust

\begin{tabular}{|c|c|c|c|c|c|c|c|}
\hline & $\begin{array}{l}\text { Full-sample } \\
\text { Model 24-1 }\end{array}$ & $\begin{array}{l}\text { Asian firms } \\
\text { Model 24-2 }\end{array}$ & $\begin{array}{c}\text { Western firms } \\
\text { Model 24-3 }\end{array}$ & $\begin{array}{l}\text { Small firms } \\
\text { Model 24-4 }\end{array}$ & $\begin{array}{l}\text { Large firms } \\
\text { Model 24-5 }\end{array}$ & $\begin{array}{c}\text { Mfg firms } \\
\text { Model 24-6 }\end{array}$ & $\begin{array}{c}\text { Service firms } \\
\text { Model 24-7 }\end{array}$ \\
\hline Constant & $-0.042(0.368)$ & $0.633(0.501)$ & $-0.304(0.316)$ & $0.087(0.404)$ & $-0.265(0.793)$ & $0.525(0.692)$ & $-0.665(0.446)$ \\
\hline \multicolumn{8}{|l|}{ Explanatory variables } \\
\hline $\begin{array}{l}\text { NATIONALITY } \\
(0=\text { Asian; } 1=\text { Western })\end{array}$ & $-0.034(0.180)$ & & & $-0.177(0.196)$ & $0.156(0.358)$ & $-0.196(0.302)$ & $0.127(0.239)$ \\
\hline SIZE1 (Full-sample) & $0.131(0.113)$ & & & & & & \\
\hline $\begin{array}{l}\text { SIZE2 (Split-samples) } \\
(0=\text { Small; 1=Large) }\end{array}$ & & $0.049(0.324)$ & $0.098(0.227)$ & & & $0.469(0.297)$ & $-0.213(0.242)$ \\
\hline $\begin{array}{l}\text { INDUSTRY } \\
(0=\text { Manu; } 1=\text { Service })\end{array}$ & $-0.377 * *(0.165)$ & $-0.568 *(0.300)$ & $-0.304(0.207)$ & $-0.147(0.195)$ & $-0.562 *(0.301)$ & & \\
\hline \multicolumn{8}{|l|}{ Control variables } \\
\hline $\begin{array}{l}\text { Ownership } \\
(0=\text { Others; } 1=\mathrm{IJV})\end{array}$ & $0.086(0.198)$ & $-0.183(0.353)$ & $0.265(0.266)$ & $0.129(0.238)$ & $0.098(0.375)$ & $0.280(0.346)$ & $0.042(0.280)$ \\
\hline HQs' influence & $0.087(0.090)$ & $0.255(0.162)$ & $0.087(0.120)$ & $0.029(0.098)$ & $0.124(0.179)$ & $0.067(0.149)$ & $0.063(0.120)$ \\
\hline $\begin{array}{l}\text { Other subsidiary } \\
(0=\text { Not exist, } 1=\text { Exist })\end{array}$ & $0.214(0.261)$ & $0.081(0.462)$ & $0.391(0.325)$ & $0.326(0.252)$ & $0.500(0.643)$ & $0.039(0.544)$ & $0.382(0.304)$ \\
\hline Overall benefit & $0.237 * *(0.092)$ & $0.283(0.187)$ & $0.244 * *(0.116)$ & $0.121(0.110)$ & $0.291 *(0.171)$ & $0.268 *(0.155)$ & $0.166(0.126)$ \\
\hline Overall dependence & $-0.348 * * *(0.088)$ & $-0.294 *(0.061)$ & $-0.497 * * *(0.119)$ & $-0.250 * *(0.105)$ & $-0.410 * *(0.162)$ & $-0.261(0.177)$ & $-0.341 * * *(0.112)$ \\
\hline Duration & $-0.030(0.026)$ & $-0.094(0.136)$ & $0.000(0.030)$ & $-0.014(0.036)$ & $-0.025(0.042)$ & $-0.085 *(0.050)$ & $0.007(0.031)$ \\
\hline Satisfaction & $0.045(0.088)$ & $-0.043(0.776)$ & $0.082(0.118)$ & $0.139(0.109)$ & $-0.018(0.150)$ & $0.185(0.157)$ & $-0.029(0.115)$ \\
\hline \multicolumn{8}{|l|}{ Model characteristics } \\
\hline $\mathrm{R}^{2}$ & 0.26 & 0.29 & 0.34 & 0.30 & 0.28 & 0.31 & 0.23 \\
\hline Adjusted $\mathrm{R}^{2}$ & 0.17 & 0.08 & 0.20 & 0.13 & 0.10 & 0.12 & 0.07 \\
\hline F ratio & $2.98 * *$ & 1.38 & $2.54 * *$ & $1.81 *$ & 1.56 & 1.63 & 1.43 \\
\hline $\mathrm{N}$ & 96 & 41 & 55 & 49 & 47 & 42 & 54 \\
\hline Maximum VIF & 1.36 & 1.62 & 1.51 & 1.48 & 1.54 & 1.76 & 1.44 \\
\hline
\end{tabular}

Estimated coefficients are reported in the table. Standard errors are in parentheses. Missing values are replaced with sample means. $* \mathrm{p}<0.10 ; * * \mathrm{p}<0.05 ; * * * \mathrm{p}<0.01$.

No difference in the confidence intervals (95\%) of the control variables was found between each pair of split-samples (Asian vs. Western; Small vs. Large;

Manufacturing vs. Services) 
Table 6-15d Regression results for the degree of change in social commitment

\begin{tabular}{|c|c|c|c|c|c|c|c|}
\hline & $\begin{array}{l}\text { Full-sample } \\
\text { Model 25-1 }\end{array}$ & $\begin{array}{l}\text { Asian firms } \\
\text { Model 25-2 }\end{array}$ & $\begin{array}{c}\text { Western firms } \\
\text { Model } 25-3\end{array}$ & $\begin{array}{l}\text { Small firms } \\
\text { Model 25-4 }\end{array}$ & $\begin{array}{l}\text { Large firms } \\
\text { Model 25-5 }\end{array}$ & $\begin{array}{c}\text { Mfg firms } \\
\text { Model 25-6 }\end{array}$ & $\begin{array}{c}\text { Service firms } \\
\text { Model 25-7 }\end{array}$ \\
\hline Constant & $0.053(0.296)$ & $0.274(0.403)$ & $-0.033(0.254)$ & $0.406(0.406)$ & $-0.384(0.502)$ & $0.841(0.592)$ & $-0.675 * *(0.290)$ \\
\hline \multicolumn{8}{|l|}{ Explanatory variables } \\
\hline $\begin{array}{l}\text { NATIONALITY } \\
(0=\text { Asian; } 1=\text { Western })\end{array}$ & $-0.078(0.145)$ & & & $-0.216(0.197)$ & $0.199(0.227)$ & $-0.353(0.258)$ & $0.175(0.155)$ \\
\hline SIZE1 (Full-sample) & $0.123 *(0.091)$ & & & & & & \\
\hline $\begin{array}{l}\text { SIZE2 (Split-samples) } \\
(0=\text { Small; } 1=\text { Large })\end{array}$ & & $-0.030(0.260)$ & $0.308 *(0.183)$ & & & $0.314(0.254)$ & $-0.082(0.157)$ \\
\hline $\begin{array}{l}\text { INDUSTRY } \\
(0=\text { Manu; } 1=\text { Service })\end{array}$ & $-0.352 * *(0.091)$ & $-0.644 * *(0.012)$ & $-0.140(0.167)$ & $-0.312(0.196)$ & $-0.473 * *(0.191)$ & & \\
\hline \multicolumn{8}{|l|}{ Control variables } \\
\hline $\begin{array}{l}\text { Ownership } \\
(0=\text { Others; } 1=\mathrm{IJV})\end{array}$ & $-0.035(0.160)$ & $0.053(0.284)$ & $-0.067(0.214)$ & $-0.228(0.239)$ & $0.397(0.237)$ & $-0.154(0.296)$ & $0.053(0.182)$ \\
\hline HQs' influence & $0.173 * *(0.073)$ & $0.149(0.130)$ & $0.191 *(0.096)$ & $0.080(0.098)$ & $0.397 * * *(0.113)$ & $0.237 *(0.127)$ & $0.040(0.078)$ \\
\hline $\begin{array}{l}\text { Other subsidiary } \\
(0=\text { Not exist, } 1=\text { Exist })\end{array}$ & $0.023(0.074)$ & $0.142(0.371)$ & $-0.125(0.261)$ & $-0.121(0.253)$ & $0.394(0.407)$ & $-0.108(0.465)$ & $0.180(0.197)$ \\
\hline Overall benefit & $0.309 * * *(0.074)$ & $0.312 * *(0.150)$ & $0.287 * * *(0.093)$ & $0.397 * * *(0.110)$ & $0.165(0.108)$ & $0.379 * * *(0.132)$ & $0.234 * * *(0.082)$ \\
\hline Overall dependence & $-0.279 * * *(0.071)$ & $-0.411 * * *(0.125)$ & $-0.213 * *(0.096)$ & $-0.280 * * *(0.105)$ & $-0.242 * *(0.103)$ & $-0.463 * * *(0.152)$ & $-0.140 *(0.073)$ \\
\hline Duration & $0.003(0.021)$ & $-0.026(0.049)$ & $0.000(0.024)$ & $0.303(0.036)$ & $-0.018(0.508)$ & $-0.029(0.043)$ & $0.022(0.020)$ \\
\hline Satisfaction & $0.000(0.071)$ & $-0.062(0.119)$ & $0.054(0.095)$ & $-0.033(0.109)$ & $-0.034(0.095)$ & $0.115(0.134)$ & $-0.105(0.075)$ \\
\hline \multicolumn{8}{|l|}{ Model characteristics } \\
\hline $\mathrm{R}^{2}$ & 0.34 & 0.46 & 0.32 & 0.39 & 0.46 & 0.48 & 0.27 \\
\hline Adjusted $\mathrm{R}^{2}$ & 0.26 & 0.29 & 0.18 & 0.25 & 0.33 & 0.34 & 0.11 \\
\hline F ratio & $4.30 * * *$ & $2.78 * *$ & $2.30 * *$ & $2.70 * *$ & $3.56 * * *$ & $3.13 * * *$ & 1.74 \\
\hline $\mathrm{N}$ & 96 & 41 & 55 & 49 & 47 & 42 & 54 \\
\hline Maximum VIF & 1.36 & 1.62 & 1.51 & 1.48 & 1.54 & 1.76 & 1.44 \\
\hline
\end{tabular}

Estimated coefficients are reported in the table. Standard errors are in parentheses. Missing values are replaced with sample means. $*$ p $<0.10 ; * * p<0.05 ; * * * p<0.01$.

No difference in the confidence intervals (95\%) of the control variables was found between each pair of split-samples (Asian vs. Western; Small vs. Large;

Manufacturing vs. Services) 
Table 6-15e Regression results for the degree of change in norms and values

\begin{tabular}{|c|c|c|c|c|c|c|c|}
\hline & $\begin{array}{l}\text { Full-sample } \\
\text { Model 26-1 }\end{array}$ & $\begin{array}{l}\text { Asian firms } \\
\text { Model 26-2 }\end{array}$ & $\begin{array}{l}\text { Western firms } \\
\text { Model 26-3 }\end{array}$ & $\begin{array}{l}\text { Small firms } \\
\text { Model 26-4 }\end{array}$ & $\begin{array}{l}\text { Large firms } \\
\text { Model 26-5 }\end{array}$ & $\begin{array}{l}\text { Mfg firms } \\
\text { Model 26-6 }\end{array}$ & $\begin{array}{c}\text { Service firms } \\
\text { Model 26-7 }\end{array}$ \\
\hline Constant & $0.288(0.299)$ & $0.735 *(0.391)$ & $-0.119(0.654)$ & $0.613 *(0.344)$ & $0.409(0.615)$ & $1.723 * * *(0.496)$ & $-0.449(0.375)$ \\
\hline \multicolumn{8}{|l|}{ Explanatory variables } \\
\hline $\begin{array}{l}\text { NATIONALITY } \\
(0=\text { Asian; } 1=\text { Western })\end{array}$ & $-0.212 *(0.147)$ & & & $-0.315 *(0.167)$ & $-0.113(0.278)$ & $-0.672 * * *(0.216)$ & $0.122(0.201)$ \\
\hline SIZE1 (Full-sample) & $0.256 * *(0.092)$ & & & & & & \\
\hline $\begin{array}{l}\text { SIZE2 (Split-samples) } \\
(0=\text { Small; } 1=\text { Large })\end{array}$ & & $0.276(0.253)$ & $0.351 *(0.190)$ & & & $0.635 * * *(0.213)$ & $0.088(0.204)$ \\
\hline $\begin{array}{l}\text { INDUSTRY } \\
(0=\text { Manu; } 1=\text { Service })\end{array}$ & $-0.250 *(0.134)$ & $-0.613 * *(0.234)$ & $0.046(0.174)$ & $-0.199(0.166)$ & $-0.267(0.234)$ & & \\
\hline \multicolumn{8}{|l|}{ Control variables } \\
\hline $\begin{array}{l}\text { Ownership } \\
(0=\text { Others; } 1=\mathrm{IJV})\end{array}$ & $0.230(0.161)$ & $0.182(0.275)$ & $0.143(0.222)$ & $-0.118(0.203)$ & $0.516 *(0.291)$ & $0.245(0.248)$ & $0.332(0.235)$ \\
\hline HQs' influence & $0.125 *(0.073)$ & $0.189(0.126)$ & $0.088(0.100)$ & $0.072(0.083)$ & $0.228(0.139)$ & $0.097(0.107)$ & $0.121(0.101)$ \\
\hline $\begin{array}{l}\text { Other subsidiary } \\
(0=\text { Not exist, } 1=\text { Exist })\end{array}$ & $-0.244(0.213)$ & $-0.157(0.360)$ & $-0.223(0.272)$ & $-0.217(0.214)$ & $0.146(0.499)$ & $-0.785 *(0.390)$ & $0.069(0.255)$ \\
\hline Overall benefit & $0.275 * * *(0.075)$ & $0.242(0.146)$ & $0.296 * * *(0.097)$ & $0.212 * *(0.093)$ & $0.292 * *(0.133)$ & $0.388 * * *(0.111)$ & $0.222 * *(0.106)$ \\
\hline Overall dependence & $-0.286 * * *(0.071)$ & $-0.396 * * *(0.003)$ & $-0.284 * * *(0.099)$ & $-0.189 * *(0.089)$ & $-0.357 * * *(0.126)$ & $-0.263 * *(0.127)$ & $-0.291 * * *(0.094)$ \\
\hline Duration & $-0.028(0.021)$ & $-0.099 * *(0.048)$ & $-0.011(0.025)$ & $0.009(0.030)$ & $-0.038(0.033)$ & $-0.062 *(0.036)$ & $-0.009(0.026)$ \\
\hline Satisfaction & $-0.002(0.072)$ & $-0.050(0.116)$ & $0.021(0.099)$ & $0.027(0.774)$ & $-0.049(0.116)$ & $0.123(0.112)$ & $-0.058(0.097)$ \\
\hline \multicolumn{8}{|l|}{ Model characteristics } \\
\hline $\mathrm{R}^{2}$ & 0.33 & 0.47 & 0.24 & 0.27 & 0.40 & 0.54 & 0.22 \\
\hline Adjusted $\mathrm{R}^{2}$ & 0.25 & 0.32 & 0.09 & 0.10 & 0.25 & 0.41 & 0.06 \\
\hline F ratio & $4.05 * * *$ & $2.99 * *$ & 1.58 & 1.58 & $2.68 * *$ & $4.19 * * *$ & 1.37 \\
\hline $\mathrm{N}$ & 96 & 41 & 55 & 49 & 47 & 42 & 54 \\
\hline Maximum VIF & 1.36 & 1.62 & 1.51 & 1.48 & 1.54 & 1.76 & 1.44 \\
\hline
\end{tabular}

Estimated coefficients are reported in the table. Standard errors are in parentheses. Missing values are replaced with sample means. $*$ p $<0.10 ; * * p<0.05 ; * * * p<0.01$.

No difference in the confidence intervals (95\%) of the control variables was found between each pair of split-samples (Asian vs. Western; Small vs. Large;

Manufacturing vs. Services) 


\subsubsection{Summary of findings in the analysis of constructs}

This sub-section summarises the significant results on the explanatory variables reported in the previous four sub-sections, and underlines the main findings relating to the hypotheses. To begin with, the relationships between the explanatory variables and the initial status of each construct are summarised in Table 6-16a. The signs ' + ' and '-' are used to represent the direction and the significance level of the relationships.

The results summarised in the table reveal detailed findings relating to the hypotheses. First, with regard to the first explanatory variable - NATIONALITY - the table shows that Western firms, on average, are involved in a higher degree of tangible economic interaction and economic communication with their new local customers, and also have deeper trust in their customers' competence, than Asian firms, with other variables being held constant in the full-sample model.

The results based on the split-sample analysis further show that the difference in tangible economic interaction and competence trust exists especially for the group of large firms, defined as more than 400 employees in the sample. Also, for the group of manufacturing firms, those from a Western background generally have deeper competence trust in new local customers than those from an Asian background. Additionally, the former, on average, also have stronger contractual trust in customers in newly formed relationships, than the latter. All these findings lend support for Hypothesis 1a which predicts that Western firms form stronger economic ties than Asian firms in new business relationships. 
Table 6-16a Summary of the significant regression results for relationship formation at the construct level

\begin{tabular}{|c|c|c|c|c|c|c|c|c|}
\hline & & \multirow{2}{*}{$\begin{array}{c}\text { Full- } \\
\text { sample }\end{array}$} & \multicolumn{6}{|c|}{ Split-sample } \\
\hline & & & Asian firms & Western firms & Small firms & Large firms & Mfg firms & Service firms \\
\hline \multicolumn{9}{|c|}{ Explanatory variable: NATIONALITY } \\
\hline \multirow{11}{*}{ 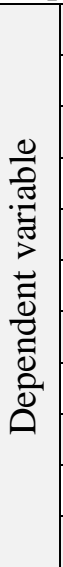 } & Tangible economic interaction at formation & + & & & & ++ & & \\
\hline & Intangible economic interaction at formation & & & & & & & \\
\hline & Economic communication at formation & ++ & & & & & & \\
\hline & Competence trust at formation & ++ & & & & + & +++ & \\
\hline & Contractual trust at formation & & & & & & + & \\
\hline & Economic commitment at formation & & & & & & & \\
\hline & Social interaction at formation & ++ & & & & & ++ & \\
\hline & Social communication at formation & ++ & & & ++ & ++ & ++ & ++ \\
\hline & Social trust at formation & +++ & & & & ++ & & + \\
\hline & Social commitment at formation & ++ & & & ++ & & ++ & \\
\hline & Norms and values at formation & +++ & & & & +++ & +++ & + \\
\hline \multicolumn{9}{|c|}{ Explanatory variable: SIZE } \\
\hline \multirow{11}{*}{ 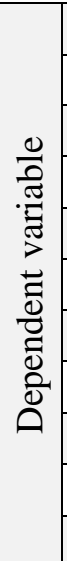 } & Tangible economic interaction at formation & & & & & & & \\
\hline & Intangible economic interaction at formation & & & & & & & \\
\hline & Economic communication at formation & & & & & & & \\
\hline & Competence trust at formation & - & & & & & & \\
\hline & Contractual trust at formation & & & & & & & \\
\hline & Economic commitment at formation & & & & & & & \\
\hline & Social interaction at formation & & & & & & & \\
\hline & Social communication at formation & - & & & & & & \\
\hline & Social trust at formation & & & & & & & \\
\hline & Social commitment at formation & -- & & & & & & \\
\hline & Norms and values at formation & & & & & & & \\
\hline
\end{tabular}




\begin{tabular}{|c|c|c|c|c|c|c|c|c|}
\hline & & \multirow{2}{*}{$\begin{array}{c}\text { Full- } \\
\text { sample }\end{array}$} & \multicolumn{6}{|c|}{ Split-sample } \\
\hline & & & Asian firms & Western firms & Small firms & Large firms & Mfg firms & Service firms \\
\hline \multicolumn{9}{|c|}{ Explanatory variable: INDUSTRY } \\
\hline \multirow{11}{*}{ 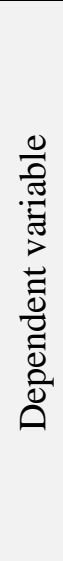 } & Tangible economic interaction at formation & & & & & & & \\
\hline & Intangible economic interaction at formation & ++ & & & & ++ & & \\
\hline & Economic communication at formation & & & & & & & \\
\hline & Competence trust at formation & & & & & & & \\
\hline & Contractual trust at formation & & & & & & & \\
\hline & Economic commitment at formation & & & - & - & & & \\
\hline & Social interaction at formation & & & & & & & \\
\hline & Social communication at formation & & & & & & & \\
\hline & Social trust at formation & & & & & & & \\
\hline & Social commitment at formation & & & & & & & \\
\hline & Norms and values at formation & & & & - & & & \\
\hline
\end{tabular}

$$
-/+(\mathrm{p}<0.10) ;--/++(\mathrm{p}<0.05) ;---/+++(\mathrm{p}<0.01)
$$


NATIONALITY has marginal explanatory power for all the social constructs at relationship formation in the models based on the full-sample. The split-sample analysis further shows that, for the split-sample of small firms, Western firms have more social communication with and more social commitment to, their new customers, than Asian firms. For the split-sample of large firms, similar difference exists in not only social communication, but also social trust and common norms and values in their local business relationships with customers. For the splitsample of manufacturing firms, the results show that Western firms, on average, have a higher degree of social interaction, social communication, social commitment and norms and values in new customer relationships, than Asian firms. Last, for the split-sample of service firms, the degree of social communication, social trust and norms and values in the relationships of Western firms is, on average, higher than in the relationships of Asian firms. All these findings contradict Hypothesis $\mathbf{1 b}$ that predicts Western firms forming weaker social bonds than Asian firms in new business relationships.

Second, with regard to firm size, the negative coefficient associated with SIZE1 in the full-sample model suggests a contradiction to Hypothesis $2 a$, which predicts that larger firms form stronger economic ties than smaller firms. As for the social constructs, table 6-16a shows that, based on the full-sample model, larger firms are engaged in less social communication and have less common norms and values with new customers, than smaller firms. These findings lend support for Hypothesis $\mathbf{2 b}$. They also show that analysis at the construct level can provide additional insight in the relationship development process, as there is no significant result for this hypothesis in the analysis of the economic ties and social bonds.

Third, the table shows that in the full-sample model, service firms have more intangible economic interaction with new customers than manufacturing firms. Similar results exist for the group of large firms. However, in the split-sample analysis of Western firms and smaller firms, the results suggest that, holding other 
variables in the models constant, service providers on average, are less economically committed to their new customers than manufacturers. These results provide an inconclusive finding for the comparison between manufacturing firms and service firms, in regard to their economic ties at relationship formation. Moreover, the split-sample analysis reveals that for the group of smaller firms in particular, service firms, on average, have a lower degree of common norms and values with their new customers than manufacturing firms, with other variables being held constant. This result contradicts Hypothesis $\mathbf{3 a}$ which predicts that service firms form stronger social bonds than manufacturing firms in new local relationships. It also supplements the analysis of social bonds, which produces no significant result regarding this hypothesis.

Drawing on the results highlighted in Table 6-16a, Table 6-16b provides further details on the findings relating to the hypotheses. The number of constructs that report significant results relating to the hypothesis is indicated in parentheses. 
Table 6-16b

Hypothesis testing results for relationship formation at the construct level

\begin{tabular}{|c|c|c|c|c|c|c|c|c|}
\hline \multirow{2}{*}{\multicolumn{2}{|c|}{ Hypothesis }} & \multirow{2}{*}{$\begin{array}{c}\text { Full- } \\
\text { sample }\end{array}$} & \multicolumn{6}{|c|}{ Split-samples } \\
\hline & & & Asian & Western & Small & Large & Mfg & Service \\
\hline H1a & $\begin{array}{l}\text { Western foreign firms form } \\
\text { stronger economic ties than Asian } \\
\text { foreign firms in their new local } \\
\text { business relationships in China. }\end{array}$ & S (3) & n.a. & n.a. & & S (2) & S (2) & \\
\hline $\mathrm{H} 1 \mathrm{~b}$ & $\begin{array}{l}\text { Western foreign firms form } \\
\text { weaker social bonds than Asian } \\
\text { foreign firms in their new local } \\
\text { business relationships in China. }\end{array}$ & C (5) & n.a. & n.a. & C (2) & C (3) & C (4) & C (3) \\
\hline $\mathrm{H} 2 \mathrm{a}$ & $\begin{array}{l}\text { Larger foreign firms form } \\
\text { stronger economic ties than } \\
\text { smaller foreign firms in their new } \\
\text { local business relationships in } \\
\text { China. }\end{array}$ & C (3) & & & n.a. & n.a. & & \\
\hline $\mathrm{H} 2 \mathrm{~b}$ & $\begin{array}{l}\text { Larger foreign firms form weaker } \\
\text { social bonds than smaller foreign } \\
\text { firms in their new local business } \\
\text { relationships in China. }\end{array}$ & S (2) & & & n.a. & n.a. & & \\
\hline $\mathrm{H} 3 \mathrm{a}$ & $\begin{array}{l}\text { Foreign service firms form } \\
\text { stronger social bonds than foreign } \\
\text { manufacturing firms in their new } \\
\text { local business relationships in } \\
\text { China. }\end{array}$ & & & & $\mathrm{C}(1)$ & & n.a. & n.a. \\
\hline
\end{tabular}

'S' means that support for the hypothesis is found based on the analysis of the constructs.

' $\mathbf{C}$ ' means that contradiction to the hypothesis is found based on the analysis of the constructs. The number of constructs that report significant results relating to the hypothesis is indicated in parentheses. n.a. means the regression modelling is not applicable for the specific split-sample.

Moreover, Table 6-17a summarises the significant results from the regression modelling pertaining to the degree of change in each economic and social construct. As indicated for Table 6-16a, the signs '+' and '-' are used to represent the direction and the significance level of relationships between the explanatory and dependent variables. 
Table 6-17a Summary of the significant regression results for the degree of change at the construct level

\begin{tabular}{|c|c|c|c|c|c|c|c|c|}
\hline & & \multirow{2}{*}{$\begin{array}{c}\text { Full- } \\
\text { sample }\end{array}$} & \multicolumn{6}{|c|}{ Split-samples } \\
\hline & & & Asian firms & Western firms & Small firms & Large firms & Mfg firms & Service firms \\
\hline \multicolumn{9}{|c|}{ Explanatory variable: NATIONALITY } \\
\hline \multirow{11}{*}{ 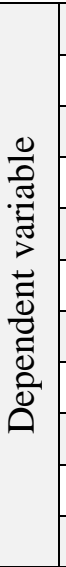 } & Degree of change in tangible economic interaction & & & & & & & \\
\hline & Degree of change in intangible economic interaction & & & & & & & \\
\hline & Degree of change in economic communication & & & & & & -- & \\
\hline & Degree of change in competence trust & & & & & & --- & \\
\hline & Degree of change in contractual trust & & & & & & - & \\
\hline & Degree of change in economic commitment & - & & & - & & & \\
\hline & Degree of change in social interaction & & & & & & & - \\
\hline & Degree of change in social communication & & & & -- & & & \\
\hline & Degree of change in social trust & & & & & & & \\
\hline & Degree of change in social commitment & & & & & & & \\
\hline & Degree of change in norms and values & - & & & - & & --- & \\
\hline \multicolumn{9}{|c|}{ Explanatory variable: SIZE } \\
\hline \multirow{11}{*}{ 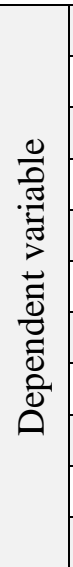 } & Degree of change in tangible economic interaction & & & & & & & \\
\hline & Degree of change in intangible economic interaction & + & & & & & + & \\
\hline & Degree of change in economic communication & ++ & & +++ & & & ++ & + \\
\hline & Degree of change in competence trust & ++ & & + & & & & \\
\hline & Degree of change in contractual trust & + & & + & & & & + \\
\hline & Degree of change in economic commitment & ++ & & - & & & & \\
\hline & Degree of change in social interaction & & & & & & & \\
\hline & Degree of change in social communication & & & & & & & \\
\hline & Degree of change in social trust & & & & & & & \\
\hline & Degree of change in social commitment & + & & + & & & & \\
\hline & Degree of change in norms and values & ++ & & + & & & +++ & \\
\hline
\end{tabular}




\begin{tabular}{|c|c|c|c|c|c|c|c|c|}
\hline & & \multirow{2}{*}{$\begin{array}{c}\text { Full- } \\
\text { sample }\end{array}$} & \multicolumn{6}{|c|}{ Split-samples } \\
\hline & & & Asian firms & Western firms & Small firms & Large firms & Mfg firms & Service firms \\
\hline \multicolumn{9}{|c|}{ Explanatory variable: INDUSTRY } \\
\hline \multirow{11}{*}{ 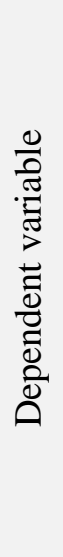 } & Degree of change in tangible economic interaction & - & & & & & & \\
\hline & Degree of change in intangible economic interaction & & & & & & & \\
\hline & Degree of change in economic communication & - & & & & & & \\
\hline & Degree of change in competence trust & & & & & & & \\
\hline & Degree of change in contractual trust & - & -- & & -- & & & \\
\hline & Degree of change in economic commitment & & & & & & & \\
\hline & Degree of change in social interaction & - & & & & -- & & \\
\hline & Degree of change in social communication & -- & - & & & - & & \\
\hline & Degree of change in social trust & -- & - & & & - & & \\
\hline & Degree of change in social commitment & -- & -- & & & -- & & \\
\hline & Degree of change in norms and values & - & -- & & & & & \\
\hline
\end{tabular}


First, with regard to nationality, the results from the full-sample based model suggest that, in a marginal sense Asian firms experience more increase than Western firms in economic commitment to their local customers, after relationships are formed. A similar result can be seen in the model based on smaller firms. Further, in the split-sample of manufacturing firms, the results show that Asian firms, on average, achieve more increase than Western firms, with respect to economic communication, competence and contractual trust. All these results contradict Hypothesis 1c which argues that Western firms have greater growth in the economic ties than Asian firms.

The results from the full-sample based model also show that, Asian firms, on average, have a higher degree of increase than Western firms in common norms and values with local customers. A similar result to this can be found in the splitsample analysis for smaller firms and manufacturing firms. The split-sample of smaller firms further shows that, in this specific group, Asian firms increase more in their social communication than Western firms, during the subsequent relationship development. Results from the model based on the service firms also reveal that Asian firms increase more in social interaction with their customers than Western firms. All these results relate to and give support for Hypothesis 1d which predicts that Western firms have less growth in their social bonds than Asian firms.

Second, with regard to firm size, the table shows that in the full-sample models, SIZE1 has marginal explanatory power for the degree of change in nearly all the economic constructs, except for tangible economic interaction. In the split-sample of manufacturing firms, the result for SIZE2 suggests that larger firms have greater increase in the intangible economic interaction and economic communication than smaller firms, after relationship formation. Likewise, in the split-sample of service firms, larger firms achieve greater increase in economic communication and contractual trust than smaller firms. In the split-sample of Western firms, larger firms, on average, increase more in economic 
communication, competence and contractual trust, than smaller firms. All these results relate to and lend support for Hypothesis $2 c$ which predicts that larger firms' relationships tend to have greater growth in economic ties than smaller firms. However, it is also noticed that in the split--sample of Western firms, the smaller firms appear to have more increase in their economic commitment to local customers, than larger firms.

In respect to the social constructs, the full-sample model suggests the marginal explanatory power of firm size for the degree of change in social commitment and norms and values. Similar results can be noticed in the split-sample based model of Western firms. Also, in the split-sample of manufacturing firms, larger firms, on average, experience a greater degree of increase in norms and values than smaller firms, during the subsequent relationship development. These results are related to the Additional Finding 1 identified from the analysis of the overall social bonds (see Section 6.3.1.5), and provide insight to the specific constructs that contribute to the finding.

Third, with regard to INDUSTRY, results from the full-sample models show that with other variables being constant, service firms, on average, achieve less increase in tangible economic interaction, economic communication and contractual trust in their relationships, than manufacturing firms. Also, in the splitsample analysis of Asian firms and smaller firms, the results show that service firms experience less increase in their contractual trust in local customers after relationship formation. These results relate to and contradict Hypothesis $\mathbf{3 b}$ which argues that service firms achieve greater growth in economic ties than manufacturing firms.

Further, results in the full-sample models show that in a marginal sense, manufacturing firms have greater degree of increase in all the social constructs than service firms. The results from the split-sample analysis of Asian firms further suggest that within this particular group, manufacturing firms, on average, 
increase their social communication, social trust, social commitment, and norms and values more than service firms. Likewise, within the group of larger firms, the split-sample analysis shows that manufacturing firms, on average have a higher degree of increase in social interaction, social communication, social trust, and social commitment than service firms. These results are consistent with the Additional Finding 2 identified from the analysis of social bonds (see Section 6.3.1.5).

Table 6-17b

Hypothesis testing results for the degree of change in relationships at the construct level

\begin{tabular}{|c|c|c|c|c|c|c|c|c|}
\hline & \multirow{2}{*}{ Hypothesis \& additional finding } & \multirow{2}{*}{$\begin{array}{c}\text { Full- } \\
\text { sample }\end{array}$} & \multicolumn{6}{|c|}{ Split-samples } \\
\hline & & & Asian & Western & Small & Large & Mfg & Service \\
\hline $\mathrm{H} 1 \mathrm{c}$ & $\begin{array}{l}\text { After relationship formation, } \\
\text { Western foreign firms have greater } \\
\text { growth in their economic ties than } \\
\text { Asian foreign firms in China. }\end{array}$ & $\mathrm{C}(1)$ & n.a. & n.a. & $\mathrm{C}(1)$ & & $\mathrm{C}(3)$ & \\
\hline H1d & $\begin{array}{l}\text { After relationship formation, } \\
\text { Western foreign firms have less } \\
\text { growth in their social bonds than } \\
\text { Asian foreign firms in China. }\end{array}$ & $S(1)$ & n.a. & n.a. & $\mathrm{S}(2)$ & & $\mathrm{S}(1)$ & $S(1)$ \\
\hline $\mathrm{H} 2 \mathrm{c}$ & $\begin{array}{l}\text { After relationship formation, larger } \\
\text { foreign firms have greater growth } \\
\text { in their economic ties than smaller } \\
\text { foreign firms in China. }\end{array}$ & $S(5)$ & & $\begin{array}{l}\text { S (3) } \\
\text { C (1) }\end{array}$ & n.a. & n.a. & $\mathrm{S}(2)$ & $S(2)$ \\
\hline A.F.1 & $\begin{array}{l}\text { After relationship formation, larger } \\
\text { foreign firms have greater growth } \\
\text { in their social bonds than smaller } \\
\text { foreign firms in China. }\end{array}$ & $S(2)$ & & $S(2)$ & n.a. & n.a. & $\mathrm{S}(1)$ & \\
\hline $\mathrm{H} 3 \mathrm{~b}$ & $\begin{array}{l}\text { After relationship formation, } \\
\text { foreign service firms have greater } \\
\text { growth in their economic ties than } \\
\text { foreign manufacturing firms in } \\
\text { China. }\end{array}$ & $\mathrm{C}(3)$ & $\mathrm{C}(1)$ & & $\mathrm{C}(1)$ & & n.a. & n.a. \\
\hline A.F. 2 & $\begin{array}{l}\text { After relationship formation, } \\
\text { foreign manufacturing firms have } \\
\text { greater growth in their social bonds } \\
\text { than foreign service firms in China. }\end{array}$ & $S(5)$ & $\mathrm{S}(4)$ & & & $\mathrm{S}(4)$ & n.a. & n.a. \\
\hline
\end{tabular}


Table $6-17 \mathrm{~b}$ concludes the findings about the hypotheses pertaining to the degree of change in relationships, including the two additional findings. The number of constructs that are found relevant to the findings is indicated in the parentheses.

\subsection{Chapter Summary}

This chapter explains the procedure of the quantitative analyses undertaken in Phase 2 and reports the multiple regression results from the analysis of the economic ties and social bonds, and the individual constructs of which these two dimensions are comprised, based on both the full-sample analysis and splitsample analysis. The results offer comprehensive insights in foreign firms' business relationship development with their important local customers in the Chinese market. Based on the marginal interpretation of the results, the hypotheses are tested by exploring the differences between Western foreign firms and Asian foreign firms, between small foreign firms and large foreign firms, and between foreign manufacturing firms and foreign service firms, in the relationship development process. Results for the control variables are also reported in this chapter.

In the following chapter, findings from both Phase 1 and Phase 2 of the study are discussed, to further address the two research questions, as well as the overarching research problem. Contributions of the study are presented, followed by the conclusions arising from the thesis. In the conclusions section, limitations of the research, recommendations for future research and implications for practitioners are noted. 


\section{Chapter Seven Discussion and Conclusions}

\subsection{Chapter Objectives}

This chapter contains two parts. First, the findings from Phase 1 and Phase 2 are discussed in depth to address the fundamental research problem: how do foreign firms operating in China develop their local business relationships with the local actors along their economic and social dimensions. The qualitative findings underpinning the two-dimensional view of the study are highlighted, showing how the relationship development process can be better understood by scrutinising the economic ties and social bonds. Then, the quantitative findings are discussed in order to shed further light on the two dimensional view and the differences between different types of foreign firms, in terms of the development of their economic and social dimensions. Contributions of the study are then discussed based on these findings. The second part of the chapter concludes the study by reiterating the key findings, acknowledging the limitations, highlighting the future research implications and directions, and outlining the managerial implications. Concluding remarks concerning the thesis are provided at the end of this chapter.

\subsection{Discussion of the Findings}

The qualitative findings and quantitative findings are discussed in this section, followed by the contributions to the relationship literature and research methodology.

\subsubsection{Discussion of the qualitative findings}

In this study, the researcher proposes that it is meaningful to analyse business relationships by distinguishing between the economic and social dimensions. One fundamental objective in Phase 1 is to seek support for this two-dimensional view, particularly in the Chinese research setting. As reported in Chapters 4 , the qualitative data show that firms may manage and develop their economic ties and social bonds differently. In Chapter 6, the quantitative data also indicate that these two dimensions could be developed unequally in a relationship. Collectively, 
these findings offer support for the two-dimensional view. Using this as the starting point, this section continues to discuss how the economic ties and social bonds evolve differently over time in the relationship development context, based on the qualitative data.

\subsubsection{Early stage in relationship development}

Two approaches undertaken by firms to form new business relationships are revealed by the qualitative data. In some cases, firms enhanced the social dimension actively via socialisation and fostering social trust and commitment. The purpose of this was to nurture a social context, facilitating them to seek business opportunities later on. Alternatively, other firms began their relationships with a strong focus on the economic aspect, involving frequent economic transactions and strong economic trust and commitment, whereas the development of social bonds was not a major consideration. Newly formed relationships resulting from these two approaches are illustrated differently in the matrix (Figure 4-2), subject to their distinct economic and social contents.

Similar findings are also reported in other qualitative research conducted in the Asian context. Nguyen et al. (2005) investigated how interfirm trust develops in Vietnam. They found that some local Vietnamese firms adopted a social-based approach to nurturing trust through social means such as personal interactions, whereas others, usually the foreign firms, undertook a more Western approach that allowed trust to emerge naturally from repeated business activities. As a result, the former type of firm was often able to nurture economic trust 'earlier' rather than the latter, because the social trust they fostered could assist them with developing the economic-based trust effectively. In comparison, despite relatively large amounts of resources involved in business transactions, economic trust in the relationships for the latter type of firm had to evolve gradually from repeated business activities, which often took a longer period of time. 
As far as the Chinese setting is concerned, the extent to which foreign firms adopt a socially-oriented approach to forming new business relationships could be considered from two angles. On one hand, the Chinese environment would be expected to encourage social-based relationship development at the early stage (Björkman and Kock, 1995), because social networking or guanxi is regarded as important while pursuing business goals. The qualitative data in Phase 1 for example, reveal that HRCONSULT obtained valuable business information from its social activities with potential clients. On the other hand, it is known that in China, nurturing 'useful' social bonds can be time-consuming and requires great patience (Chen and Chen, 2004). Also, the development of social networks is not cost-free and requires firms' input of resources (Westlund and Nillson, 2005). Hence, many foreign firms may feel reluctant to invest time and resources in forming social bonds with those local business actors they are not yet familiar with, particularly when they require immediate economic gains, and the outcomes from investing in social bonds seems to be uncertain. This is related to Nebus' (2006) statement that when forming relationships, firms face a trade-off between the expected outcome and the costs of obtaining the outcome from the relationships.

In short, the qualitative data show that foreign firms operating in China have different emphasis on the economic ties and social bonds when they initiate new relationships with local actors. This suggests the distinctive nature of these two dimensions in a relationship from the early stage of its development process.

\subsubsection{The subsequent relationship development}

The qualitative findings also shed light on the extent to which firms strengthen their relationships during the subsequent development process. The early network literature recommended firms to build strong relationships with their business partners (Jarillo, 1988). In a similar vein, nurturing the relational mechanism to govern business activities via an emphasis on social activities is always of particular interest of scholars (Jones et al., 1997). In recent years, however, this 
view has been enriched by many other scholars who become increasingly concerned about the negative effects of strong and close relationships resulting from social relations (Anderson and Jap, 2005). For example, Uzzi (1997) describes the paradox of relational embeddedness; Gargiulo and Benassi (2000), Yli-Renko et al. (2001) and Oh et al. (2004) indicate the dark-side of relational social capital; Molina-Morales and Martinez-Fernandez (2009) warn firms about the U-shape impact of social networking on firms' performance. With particular reference to the Chinese context, Chen and Chen (2009) state that close personal ties could deteriorate the outcome from a business relationship.

As a result, scholars are now recommending a more sophisticated approach to developing relationships. Peng (2002) points out that firms must stay at the appropriate 'closeness' with surrounding business actors, knowing clearly how close is too close, so that they can benefit from cooperative relationships as well as avoid the negative impacts. Molina-Morales and Martinez-Fernandez (2009) suggest that firms should develop relationships wisely. By so-called wise relationship practices, they explain that social networking should not be assumed naively as the panacea to all business-related issues; neither should it be avoided totally due to concern about potential negative effects. Rather, the question is whether a firm can find and achieve the optimal level of social bonds, so that it can not only benefit from the facilitation and safety from social ties, but retain flexibility and not be constrained.

The qualitative phase of the study provides a preliminary investigation on this issue by looking at how foreign firms in China deal with the 'appropriate closeness' or 'wise relationship management' in practice. As described in Chapter 4 , the sample firms were aware of the boundaries between economic and social dimensions. For example, the extent to which economic transactions and socialising activities were carried out in some relationships differed greatly; the degree of economic and social aspects of trust and commitment were also distinctive. Specifically, some enhanced social bonds actively, whereas others 
tried to avoid them and tightly uphold 'business is business' as their guiding principle. These findings reflect firms' sophisticated approaches to managing their relationships. They suggest that the engagement in socialisation is by no means a default option for these firms. Rather, in response to Molina-Morales and Martinez-Fernandez (2009), the social nature seems to be a key variable in firms' relationship development, and managing the degree of social bonds appears to be an important technique assisting firms with achieving the anticipated closeness or strength of relationship with various actors.

The qualitative findings also provide insight into the reasons for firms not to enhance their social bonds in the present research setting. First, managers in two firms (WATERHEAT and HOTEL) expressed their concern with potential corruption that is often intertwined with guanxi at the personal level. This is related to the negative effects of strong and close relationships, and is discussed by Luo (2008b) in his recent article. Second, firms' intention to develop social bonds seems to be driven by their expected economic outcome. Once they perceive that social bonds may not contribute additional value for their business activities, socialisation is no longer thought to be necessary. This corresponds to the networking criteria proposed by Jarillo (1988) who notes that relationship building should be carried out based on effectiveness and efficiency, serving the fundamental purpose for networking, that is, to pursue business opportunities. It is also consistent with Larson's (1992) early advice that, when discrete or arm'slength ties are enough for firms to achieve their business goals, relational and social elements may not be needed. In the specific context of China, a similar suggestion is made by Ramasamy et al. (2006). According to them, in this fast changing market, the arm's-length or less social-based relationship strategy sometimes can be a more efficient way for foreign firms to achieve business goals, because nurturing social ties requires substantial amounts of investment and time.

In conclusion, after the early stage of relationship development, the extent to which firms continue to strengthen their relationships with local actors differs. 
Particularly, social bonds are an important variable in the degree or magnitude of relationship strength. This implies that first, not every relationship will evolve toward a position with substantial economic and social contents; and, second, that the economic and social dimensions in a relationship can experience different development processes.

\subsubsection{Discussion of the quantitative findings}

After the interviews with the senior managers in eight foreign firms operating in China, the study shifted to its second stage - Phase 2. In Phase 2, the development process of relationships between foreign firms and their important local customers were investigated along the economic and social dimensions. The data for these relationships were collected with respect to the formation stage and the time of the research, which allows the researcher to further examine the degree of change in these relationships. Phase 2 first provided further empirical support for the findings in Phase 1, showing distinctive economic and social dimensions of firms' relationships, and indicating their uneven development over time. Then, in line with the hypotheses stated in Chapter 3, the Phase 2 of study compared the relationship development process between Western firms and Asian firms, between small and larger firms, and between manufacturing firms and service firms. The following sub-sections discuss the relevant results reported in Chapter 6 with regard to the hypotheses. Based on the marginal interpretations of the results, three figures ${ }^{22}$ are used to illustrate the comparisons of firms' relationship development processes, to assist with the discussion.

\subsubsection{Comparison between Western and Asian firms (Hypotheses 1a, 1b, 1c and 1d)}

As reviewed in Chapter 3, the literature suggests that Western firms place more emphasis on the economic aspect and Asian firms adopt a relatively social approach to developing business relationships. Drawing from this, four

\footnotetext{
22 Figures 7-1, 7-2 and 7-3 are only visual representations of the results. They do not reflect the actual scale, and the linear relationships are not tested in this study. Discussion on the relevant results is provided in the accompanying text.
} 
hypotheses regarding the development of economic ties and social bonds were formed and tested in this study. Hypothesis $1 \boldsymbol{a}$ predicts that Western firms tend to form stronger economic ties than Asian firms in new relationships. It gains support from the full-sample analysis of the economic ties, and the split-sample analysis based on large firms and manufacturing firms. Similar results are also found from the analysis of a number of economic constructs (i.e. tangible economic interaction, economic communication and competence trust). Hypothesis $\mathbf{l b}$ predicts that Asian firms form stronger social bonds than Western firms in new relationships. This hypothesis is not supported by the results, which, however, suggest that it is Western firms that establish stronger social bonds than Asian firms when building new relationships.

Hypothesis 1 c predicts that Western firms reinforce their economic ties more than Asian firms after the formation stage. No support is found for this hypothesis from the analysis of the economic ties, but the analysis of the economic constructs based on the full-sample shows that Asian firms tend to have greater degree of increase in economic commitment to their customers. In particular, for the splitsample of manufacturing firms, it is also noted that relationships of Asian firms may experience more growth in economic communication and competence trust, in addition to economic commitment. These results relate to the hypothesis, suggesting that Asian firms are more likely to reinforce certain aspects of the economic ties more than Western firms during the subsequent development process.

Hypothesis 1d predicts that Asian firms enhance their social bonds more than Western firms after relationships are formed. This is not supported by the results from the full-sample analysis of the social bonds. However, the split-sample analysis reveals that for the group of small firms defined in the study, those from an Asian background experience a higher degree of increase in their social bonds than those from a Western background. The analysis of the social constructs further shows that the relationships of Asian firms generally achieve a higher 
degree of growth in common norms and values than do Western firms. Particularly for the group of service firms, those from Asia tend to have a higher degree of increase in social interaction with the local customers, after relationships are formed. These results relate to Hypothesis 1d, indicating that Asian firms may reinforce certain aspects of their social bonds more than their Western counterparts.

Drawing on these findings, Figure 7-1 is presented to visually illustrate the development patterns of the economic and social dimensions of Western and Asian foreign firms in China, with respect to the time of relationship formation, and the subsequent change. According to the results related to Hypotheses 1a and $1 \mathrm{~b}$, Western foreign firms, on average, form relationships containing stronger economic ties and social bonds, whereas according to the results for Hypotheses 1c and 1d, Asian foreign firms may achieve a higher degree of increase in both dimensions during the subsequent development of the relationship.

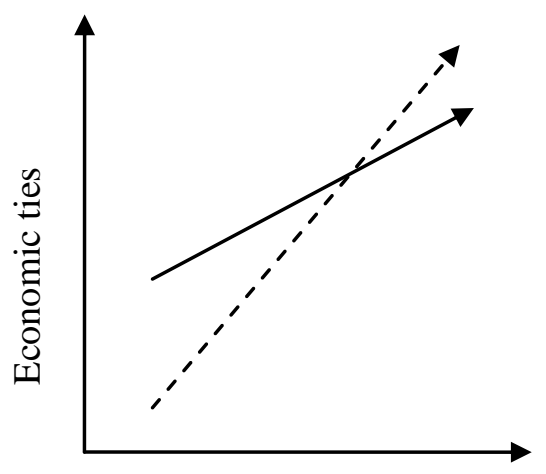

Timeline

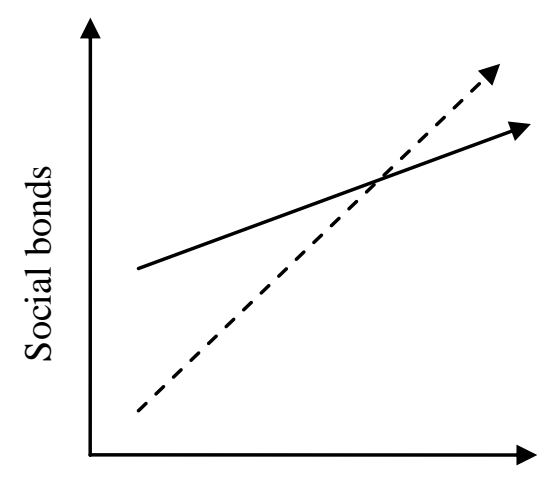

Timeline

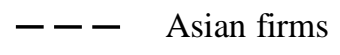

Western firms

Figure 7-1

Illustration of the relationship development patterns for Asian and Western firms

Explanation for the patterns can be drawn from the literature and other relevant findings from the study. First, the finding of Western firms' stronger economic ties is consistent with the general perception held in the literature. As Luo (1999) 
noted, most Western firms in China tend to possess advanced managerial skills, organisational capabilities and superior technology. Therefore, they may be able to enhance their economic ties efficiently from the early stage of relationship development. The qualitative data in Phase 1 also show that some Western firms executed effective assessment and evaluation of the potential relationship candidates before the initial economic exchange took place. For instance, they carried out frequent communication to clarify expectations, careful inspection of the candidates' ability, and their willingness to accomplish the requested business tasks. With such preparation, Western firms' economic ties could be better developed than Asian firms by the time that the relationships are formed.

Further, these characteristics of Western firms indicated above may help them to gain a positive image in front of Chinese firms, which can benefit them in forming new relationships in the local market. As Duanmu and Fai (2007) reported, many Chinese firms like to cooperate with Western firms, because they regard it as an opportunity to improve their own organisational performance. Hence, compared to Asian firms, Western firms may be able to start their relationships with local business actors relatively easily and with a larger scale of economic exchange. The qualitative data offer an example of this explanation. The manager at ANIMATION acknowledged that a key reason for them to be able to quickly initiate business projects with two major local players in China, with limited time and effort spent on pre-relationship negotiation and other preliminary activities like assessment and trial, was because the local partners strongly believed that American firms possessed superior technology and advanced management knowhow, and they considered this would be a great chance for learning and earning profit.

Second, it is interesting to see Western firms forming stronger social ties, because traditionally, they are often considered to be largely economic-driven and advocating a 'professional way' of managing relationships (Hitt et al., 2002), whereas it is Asian firms that are generally associated with a social approach to 
developing relationships. This finding may be explained by the evolving management philosophy of Western firms over the past two decades. As Maskell and Malmberg (1999) described, in the 1990s, managers in the West were strongly encouraged to learn how to utilise a social approach to managing businesses. Lovett et al. (1999) also predicted that Western firms would embrace a more social and less economic approach to operating their businesses. Further, this finding may reflect a type of 'culture-blend' phenomenon of Western firms in China (Batonda and Perry, 2003b). This means that Western firms operating in the Chinese market tend to adopt the local way of doing business, that is, by putting emphasis on social networks, following recent scholarly recommendations (Su et al., 2009). The Belgian Director of HRCONSULT in Phase 1, for instance, demonstrated excellent interpersonal skills to initiating business relationships through socialising activities. In fact, it is not unusual to see that the first Chinese word many Western managers in China learn is guanxi.

Western firms' strong advocacy to nurturing social bonds may also partially reflect the ongoing strategic transition of many foreign firms in China. Luo (2007) points out that, as the Chinese market becomes increasingly important to foreign MNCs' global success, these firms need to perceive themselves as not only local adaptors, but strategic insiders. He further states that the traditional concept of 'local responsiveness' is too reactive, whereas these MNCs in China must become more effective in localisation and adaptation. If foreign Western firms are experiencing such a transition, they are very likely to view developing social embeddedness as one of their strategies for the Chinese market (London and Hart, 2004). This could lead to their increasing emphasis on their social dimension in relationships with local business actors.

Third, Asian firms' greater degree of increase in both the economic and social dimensions can be considered from a cultural perspective. In the quantitative analysis, the group of Asian firms consists of foreign firms mostly from a Chinarelated cultural background, including Hong Kong, Taiwan, Singapore, South 
Korea, and Japan. Compared to Western firms, their culture is featured by higher uncertainty avoidance and long-term orientation (Luo, 1997). Hence, they may tend to adopt a relatively conservative and cautious approach to developing business relationships. Specifically, they choose not to engage in large scale economic activities with new exchange partners at the beginning, and will only grow trust in, and commitment to, the partners gradually through repeated interactions. After the relationships develop, these Asian firms are willing, however, to reinforce and maintain them for the long-term. This approach is very similar to the Chinese style of relationship management. According to Batonda and Perry (2003b), for traditional Chinese firms, it is often difficult to start new relationships because they are careful and cautious, but once the relationships are formed, they are easy to develop and maintain, and hard to terminate.

Overall, the findings suggest that Western firms in China have adapted to the Chinese environment by learning to nurture social bonds from the early stage of relationship development. Asian firms appear to retain some degree of their inherent characteristics in terms of building social-based relationships, which is reflected, for example, by their greater degree of increase in the social dimension during the subsequent development process.

\subsubsection{Comparison between small and large firms (Hypotheses $2 a, 2 b$ and $2 c$ )}

As reviewed in Chapter 3, the literature suggests that small firms tend to advocate a more social approach to building relationships, whereas large firms develop relationships formally and focus more on the economic aspect. On this basis, three hypotheses were formed and tested in Phase 2.

Hypothesis $2 a$ predicts that larger foreign firms in China form stronger economic ties than smaller firms. No support for this is found in the analysis of the overall economic ties. The analysis of the economic constructs, however, shows that relationships of small firms contain higher competence trust in the new customers. This is related to, but does not lend strong support for the hypothesis. Hypothesis 
$\boldsymbol{2} \boldsymbol{b}$ predicts that larger firms build weaker social bonds than smaller firms while initiating their local business relationships. This hypothesis gains no support in the analysis of the social bonds. However, the full-sample analysis of the social constructs shows that relationships of smaller firms tend to involve more social communication and social commitment than larger firms. These results relate to the hypothesis, suggesting the difference between small and large firms at the relationship formation stage.

Hypothesis $2 c$ predicts that larger firms would achieve greater growth in their economic ties than smaller firms during the relationship development process after formation. This gains support from the analysis of the economic ties based on the full-sample, and two split-samples of Western firms and manufacturing firms. Similar results are also found in the full-sample analysis of those economic constructs. Last, the Additional Finding 1 identified from the analyses of the social bonds and the social constructs suggests that relationships of larger firms, on average, experience a higher degree of increase in the social dimension than those of smaller firms.

In summary, the results for Hypotheses $2 \mathrm{a}$ and $2 \mathrm{~b}$ suggest that there is little difference between smaller and larger foreign firms in China in terms of initiating economic ties. Also, smaller firms possess stronger social bonds at the relationship formation stage. The results for Hypothesis $2 \mathrm{c}$ and the Additional Finding 1 suggest that larger firms, on average, tend to achieve a higher degree of increase than smaller firms in both the economic and social dimensions during the subsequent development process. The overall development patterns of economic and social dimensions for larger and smaller firms are visually illustrated in Figure 7-2. 

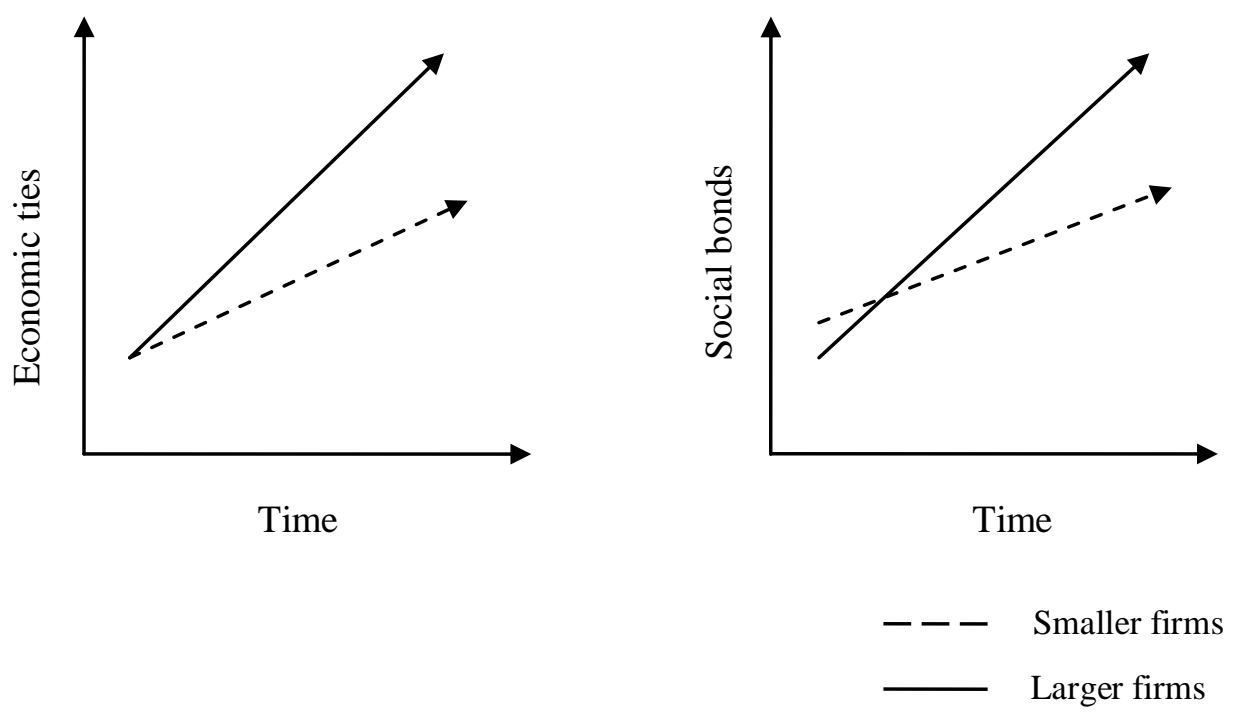

Figure 7-2

Illustration of the relationship development patterns for larger and smaller firms

A key point for discussion is why larger firms do not form stronger economic ties than smaller firms. The literature suggests that large firms can absorb more risks involved in forming new business relationships than small firms, based on their greater resource capacity. Therefore, they should be able to start relationships with, for example, a larger scale of economic exchanges than small firms (Chen et al., 2004). One way to consider this finding relates to the subsidiary background of the focal firms in the study, which suggests two possible explanations.

First, according to Johnston and Menguc (2007), the smaller the subsidiaries are, the more likely they operate with lower autonomy. This means that those smaller firms investigated in the study could receive greater managerial intervention from their foreign headquarters than larger firms. Their business decisions and market behaviours in China may, therefore, be influenced by the headquarters, rather than only determined by their own resource endowments and capabilities. Also, the tight control from headquarters could imply that smaller subsidiaries receive a relatively high degree of support from the other subsidiaries of the MNC. This might compensate their weakness and disadvantage in resources and capabilities that are associated with small size. Hence, the distinction between these 
subsidiaries and their larger counterparts in relationship building in China may become less apparent.

Second, it may be assumed that foreign MNCs with only small subsidiaries in China could be at a relatively early stage of the local market development, compared to those having larger subsidiaries. Under this circumstance, drawing on Gargiulo and Gulati's (1999) theory of network development, these MNCs are likely to undertake an exploratory approach to establish new relationships, in order to seek local business opportunities and expand their local networks quickly. As a result, their small subsidiaries, as the agents of the MNCs in the local market, could then act in a somewhat risk-taking or even aggressive manner. To be 'effective' and 'efficient' in relationship building (Jarillo, 1988), these subsidiaries' relationships with local actors might start with a prominent economic focus, associated, for example, with expectations for an immediate business outcome.

The small firm ANIMATION serves as a good example of these two explanations. As mentioned earlier, the firm entered China in 2007, and signed several big contracts with local partners in the following year, in spite of limited time spent on pre-relationship evaluation of the partners. According to the informant, part of the reason for their aggressive market development was to achieve the US headquarters' 'strategic objectives' and establish the foothold in China.

Larger firms however, reinforce their economic ties more than smaller firms in their subsequent relationship development. This may suggest that even though the intervention and support from the headquarters might help smaller firms to establish their economic ties at the early stage of relationship development, in the long term, they still face challenges. These include having to absorb risks and cope with uncertainties, due to lower resource endowments and capabilities compared to larger subsidiaries (Johnston and Menguc, 2007). On the other hand, larger firms generally have more expertise and better developed internal systems 
than small firms (Lawler, 1997). If it is assumed that the size of a subsidiary indicates the MNC's length of operation in China, then the larger firms are also likely to enjoy the benefits of greater location-specific knowledge, experience and skills. The associated advantages would allow them to deal with their local business partners more successfully, reflected by growth in the economic dimension of their relationships

The finding that smaller firms have stronger social bonds than larger firms at the relationship formation stage is consistent with the literature. It is generally considered that small firms need to rely on their networks for business development, especially in the international business context, and that specific attention should be given to the social aspects of relationships (Klang et al., 2002; Prashantham and Berry, 2004; Raudh, 2001). However, the study also shows that this finding can only be identified at the construct-level based on the split-samples, which implies that the difference between smaller and larger firms in initiating social bonds while entering relationships may be less apparent than expected in the literature. This could be because foreign firms in China are increasingly aware of the importance of social networking, regardless of their size.

Last, the results suggest that smaller firms' social bonds grow less than those of larger firms after relationship formation. This may be because the limited resource endowments and capabilities of smaller firms in the local market, compared to larger firms, make them less powerful when dealing with local actors. According to the power-dependence theory (Mainiero, 1986), when two parties are rarely equal in power in a relationship, the more powerful party may take advantage of the other for its own maximal gains (Cox, Lonsdale, Sanderson and Watson, 2004; Kim, Hoskisson and Wan, 2004). Hence, smaller firms might be more likely to encounter challenges in nurturing their social bonds, when they develop the relationships with local customers. The results presented in Table 6-16a further show that the relationships of smaller firms are formed with more social communication and social commitment, indicating these firms' particular interest 
and effort in establishing social bonds at the early stage of relationship development. This, however, does not guarantee that their social bonds will develop more than those of larger firms during relationship development.

Another explanation for smaller firms' lower degree of increase in the social bonds can be drawn from a recent study by Tam, Moon, Ng and Hui (2007). These researchers found that in the Hong Kong clothing industry small firms deliberately choose not to advocate the relational approach to networking. Unlike large firms that prefer to form a small number of strong strategic alliances, the small firms establish multiple, but weaker, business relationships. The authors explain that it is probably because small firms tend to be more short-term and profit-oriented in reality, as they are usually fragile and lack resources. Their finding is contradictory to the general perception of how small firms network, but seems to be relevant to this study.

Overall, the findings in Phase 2 suggest that the relationships formed by smaller and larger foreign firms in China do not appear to be substantially different in terms of the economic and social nature at the beginning of the relationship. However, during the subsequent development, relationships of larger firms gain stronger momentum than smaller firms in both the economic ties and social bonds.

\subsubsection{Comparison between manufacturing and service firms (Hypotheses 3a} and 3b)

As reviewed in Chapter 3, the literature suggests that service firms tend to adopt a more social approach to developing business relationships than manufacturing firms. Two hypotheses are formed on this basis. Hypothesis $\mathbf{3 a}$ predicts that service firms form stronger social bonds than manufacturing firms. No support can be found at the level of analysis of the social bonds. Further analysis at the construct level reveals that in the split-sample of smaller firms, those in the service sector may have a higher level of common norms and values with their 
local customers than manufacturers. This finding relates to the hypothesis, and provides a minimal level of support.

Hypothesis $\mathbf{3 b}$ predicts that service firms experience a higher degree of increase in economic ties than manufacturing firms. No support is found for this hypothesis in the analysis at the level of the economic ties. The full-sample analysis at the construct level reveals that manufacturing firms may experience a higher degree of increase than service firms in tangible economic interaction, economic communication, and contractual trust. Also, based on the split-samples, the analysis reveals that in the groups of Asian firms and smaller firms, manufacturers tend to increase more contractual trust in their customers than service providers. These findings all relate to, but contradict Hypothesis $3 b$.

Meanwhile, the full-sample analysis at the level of the economic ties reveals no difference between manufacturing firms and service firms at the time of relationship formation. The analysis of the economic constructs shows that service firms involve more intangible economic interaction in the newly formed relationships than manufacturing firms. However, no other significant result can be seen. Also, as described in Chapter 6, the Additional Finding 2 suggests that manufacturing firms, on average, achieve a higher degree of increase in the social dimension.

Overall, these findings suggest that there is little difference between the manufacturing and service foreign firms in terms of forming the economic ties and social bonds at relationship initiation. But the manufacturing firms, on average, tend to achieve a higher degree of increase in these two dimensions, especially with regard to the social bonds. Based on these, Figure 7-3 is produced to visually illustrate the development patterns for the economic ties and social bonds of the two types of foreign firms operating in China. 


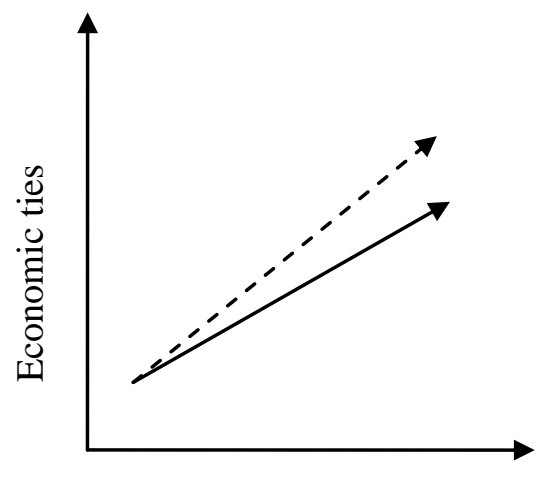

Time

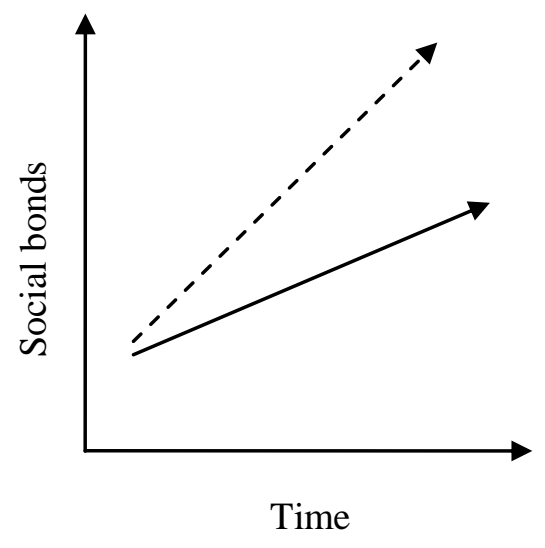

- - Manufacturing firms

Service firms

Figure 7-3

Illustration of the relationship development patterns for manufacturing and service firms

The findings on the development of economic ties may be explained as follows. First, even though the business operations of service firms traditionally involve a great deal of information sharing and learning from clients (Knight, 1999), scholars have recently noted that "manufacturers are being continually pushed towards refining their products and processes to be more responsive to and involved with customers" (Chowdhury and Miles, 2006: 127). This changing nature of manufacturing firms means that they are no longer necessarily less customer-oriented and responsive than service firms, and therefore, they could also build economic ties as strongly as service firms, based on, for instance, intensive business interactions and commitment.

Second, although service firms are more capable of customising their offerings to satisfy various customers' needs by tailoring the supplementary component of services (Lovelock and Yip, 1996), their high adaptability to various customers could result in low switching costs and dependence in their relationships. For example, the firms could seek and develop new customers quickly by tailoring their offerings, and the existing customers could obtain similar services easily 
from another provider in the market. Under such circumstances, the relationships may contain less commitment, particularly in the economic aspect (Morgan and Hunt, 1994). Relatively, manufacturing firms often need to invest considerable amount of resources to establish their distribution channels, because they heavily rely on their distribution channels to achieve consistent business performance (Fynes et al., 2005a, 2005b). Thus, they may put more emphasis on stabilising their relationships, especially the economic ties.

The third explanation for service firms' weaker economic ties may draw on the firms' business operation models. As identified in Phase 1, many service firms' relationships with their clients are based on projects that last only a short-term, like several months. Once a project is completed, the relationship could become less active, or even dormant, until the customer requests more services, initiating a new project. Such a style of business operation could hinder the development of economic ties, because the short time period for a project may not be adequate for both parties to nurture strong mutual economic trust and commitment. In comparison, manufacturing firms tend to deal with their customers frequently and on a regular basis. Their economic ties are more likely to experience continuous growth over time.

The second and third explanations mentioned above may also help in understanding the findings on the development of social bonds. As indicated earlier, although the literature suggests that service firms should build highly relational customers relationships through such means as intensive interpersonal contact (Eriksson et al., 1999; Knight, 1999), the results failed to show they form stronger social bonds than manufacturers. In line with the second explanation, it may be argued that the perceived low switching cost and dependence associated with the relationships could affect service firms' intentions around nurturing the social bonds with their customers. Likewise, from the customers' point of view, the interest in fostering social bonds could also be low for similar reasons; rather, they might prefer to keep the relationships largely contractual, and functioning as 
arm's-length ties, so that they could switch to competitive alternatives freely without being constrained by the social attachment. Meanwhile, in line with the third explanation, the short time period of many service firms' projects could disadvantage their development of social bonds, compared to the manufacturing firms that build relationships on a continuous basis.

Service firms' weaker social bonds may be also explained by the present research setting. Unlike the manufacturing industry in China, the Chinese service sector only began to open for foreign investors after the country's WTO accession in 2001. Foreign firms operating in this sector are therefore, generally at an early stage after their market entry, and may not have a well-established embeddedness mechanism to provide them with guidance for local network development, a factor noted by Gulati and Gargiulo (1999). In theory, network development in such a situation is likely to be exploratory and dynamic, reflected by frequent creation and deletion of relationship (Koka et al., 2006). The relationship building behaviours of foreign service firms with local actors, therefore, could be turbulent, contain more uncertainty, and bear low tolerance to underperforming partners, so that social elements can be difficult to emerge and sustain. Taking ANIMATION from Phase 1 as an example again, the firm actively sought to cooperate with local actors shortly after its arrival in China, but two out of the three major projects they were engaged with in 2007/8 failed within a half year. Also, given the limited presence in the local market, the firm could not decide whether it should shift from the current B2B business mode to B2C in a near future. This uncertainty had a big impact on the firm's local network development, resulting in only short-term or temporary commitment to its existing alliances.

Overall, the study shows that manufacturing and service firms are not substantially different in their economic ties and social bonds when they enter business relationships with local Chinese actors; however, the former is likely to achieve more growth in the economic ties during the subsequent relationship development. 


\subsubsection{Control variables}

The control variables adopted in the quantitative analysis pertain to two aspects: the firms and the focal relationships. Regression results for the control variables provide additional insight into foreign firms' relationship development process in the Chinese market.

To begin with, the coefficients associated with firms' ownership are not significant in the models used for analysing the economic ties and social bonds. In the analysis of economic and social constructs, significant coefficients are found in only a few models. The results suggest that overall, the distinction between joint ventures and other forms of ownership, mainly wholly-owned subsidiaries, may exist but does not appear to be very prominent in the present research setting. Hence, firms' ownership has some, but limited, marginal explanatory power for the development of their relationships. This finding is interesting because it is often considered that international joint ventures in China tend to act more locallike than wholly-owned subsidiaries, with regard to relationship building, because of the direct involvement of Chinese partners (Luo, 1997).

One explanation for this finding may be drawn from the increasing strategic importance of the Chinese market that is recognised by foreign MNCs (Luo, 2007). If the foreign partners in joint ventures generally deepen their local adaptation, not only in production and technology, but also more comprehensively in such aspects as business operations and local network development ( $\mathrm{Su}$ et al., 2009), then the distinction between joint ventures and wholly-owned subsidiaries in relationship development due to the ownership variable could become less noticeable. Also, another control variable, HQs' managerial influence, is found to be significantly and positively related to the degree of increase in social bonds, based on the full-sample model. This could imply that the foreign headquarters encourages its China-based subsidiaries to emphasise social bonds in their local relationship development, which may contribute to the explanation about ownership. 
The analysis of the social bonds at relationship formation reports a negative coefficient associated with the presence of other subsidiary/ries in China, based on the split-sample of small firms. The analysis of social trust at relationship formation also shows that this control variable is associated with negative coefficients in the split-samples of Asian firms, small firms and manufacturing firms. Collectively, these results imply that foreign firms having other sister subsidiary/ries in China form relationships with lower social content at the early development stage, compared with those having no sister subsidiary in the market. One plausible explanation for this finding is that the number of subsidiaries could indicate the degree to which a foreign firm has been engaged in the local market. Therefore, foreign firms with more China-based subsidiaries are likely to have more experience and knowledge of the local market and business environment. These firms, as Ramasamy et al. (2006) recommended, may be able to opt for a less social-based approach to build relationships in China. Such an approach could be more effective in achieving economic objectives, but can only be implemented well by those who possess adequate local specific knowledge and skills.

From the transaction cost perspective, firms' relationships are fundamentally driven by their expected profit and other types of organisational outcomes (Williamson, 1985). Relationship benefit, therefore, is often considered as an important antecedent of relationships (Morgan and Hunt, 1994). In line with the previous literature, the analysis of the economic ties and social bonds report significant and positive coefficients associated with this variable, suggesting its role in foreign firms' relationship building in China. Nonetheless, the constructlevel analysis reveals that this variable is not significantly related to contractual trust, social trust and social commitment at relationship formation, and the degree of change in tangible and intangible economic interaction, in a number of models based on split-samples. These results suggest that the perceived benefit may only encourage firms to enter relationships by initiating economic exchanges, whereas it may not directly contribute to firms' psychological attachment to the new 
partners. Also, the perceived benefit may not guarantee the growth of the economic exchanges after firms enter relationships, because the subsequent development needs to be based on the outcome and firms' satisfaction with the prior cooperation (Ring and Van de Ven, 1994). In short, these results of relationship benefit enrich the current body of knowledge about this variable in the relationship development context.

Relationship dependence essentially deals with the firms' perceived reliance on another party due to the degree to which the party can be replaced by others. Results show that, first, firms' dependence on their partners is not significantly related to the economic ties at the formation stage. Second, relationship dependence has the marginal explanatory power for the social bonds at relationship formation, and the analysis at the construct level reveals similar findings with regard to social commitment. Third, for most of the models for the degree of change in economic ties and social bonds, as well as in the respective constructs, relationship dependence shows significant and negative coefficients. This suggests a negative relationship between firms' perceived dependence on a local customer, and the growth of the relationship in both the economic and social dimensions.

A starting point to explain these findings is to look into the nature of dependence. Dependence between two parties in a relationship needs to be considered along with its direction, because "although both actors are mutually dependent on an exchange, it does not mean that they are always equally dependent on each other" (Kim et al., 2004: 618). In other words, equal dependence is very rare in reality. As indicated earlier, from the power-dependence perspective, unequal dependence indicates the power status of the two parties in a relationship (Mainiero, 1986). The more dependent a party is on its partner, the less power it holds in the relationship. In such a relationship, according to Cox et al. (2004), the less dependent party could behave adversarially and is likely to exploit its power to take advantage of the dependent counterpart. 
Hence, the results about relationship dependence in this study might reflect a cautious and sophisticated approach undertaken by foreign firms in dealing with local actors that are powerful, resourceful and on whom they could be highly dependent potentially. Firms may be reluctant to initiate such business relationships, because this will expose them to the risk of being taken advantage of by the more powerful actors. If the relationships are established, however, firms tend to be committed to nurturing the social bonds, in order to create a cooperative atmosphere to secure their business transactions, as well as minimise the likelihood of partners' opportunistic behaviour. But, they may still be unwilling to develop these power-imbalanced relationships quickly, not only because of the dependence issue that they are concerned about, but also the risk associated with potential relationship failure. After all, reinforcing relationships would require intensive investment of resources and efforts by firms, even, to some extent, sacrifice of freedom and autonomy (Oliver, 1990).

Other research provides insights that are relevant to the above discussion. For example, Gounaris (2005) reported that strong calculative commitment (similar to economic commitment defined in this study) can have a negative impact on firms' relationship strength. He explains that this is mainly because of firms' intention to avoid a locked-in situation that is often associated with 'important' business partners. The quotation from the Director of EVENT in Phase 1 helps to further illustrate this issue:

"I know it would be great if we could work with them (a large company) and become their sole (advertising) agent. But, this can be very dangerous for us as well, because we will have to invest a considerable amount of time and resources, even give up many our existing customers to free some extra capacity. However, what if something goes wrong with this client? In that case, we will lose their contract, and our reputation can be damaged in the market. So, the consequences can be severe and fatal. For this type of large 
customer, I would rather be patient. If I have a good chance, I'd like to start the relationship from some small project, and then develop it carefully and slowly only if everything looks fine."

The analysis at the level of overall economic ties and social bonds does not report significant results for relationship duration. The analysis at the level of the constructs show negative coefficients associated with this variable in only a few split-sample based models. Overall, there seems to be little association between a relationship's duration and its development. This contradicts the general perception that time is necessary for developing strong and quality relationships in the Chinese context (Jansson, Johanson and Ramstrom, 2007). However, similar findings are reported by previous researchers who failed to find support for the hypothesis that relationship duration is related to trust (e.g. Armstrong and Yee, 2001; Doney and Cannon, 1997). It could be argued that relationship development is fundamentally driven by firms' economic goals and, therefore, may be largely determined by the relationship outcome, rather than the duration of the relationship. This argument also relates to the findings about the last control variable, relationship satisfaction. It is found that relationship satisfaction is positively related to the degree of change in economic ties, suggesting that firms are more likely to develop the economic dimension when they feel satisfied with the performance of their partners.

\subsubsection{Contributions to the literature}

Drawing on all the findings, the study contributes to the literature in four main ways. First, the two-dimensional view provides a lens to better understand the complex nature of interfirm business relationships. Second, based on the twodimensional view and the research findings, the study suggests relationship development as a dynamic process involving changes in the economic and social dimensions over time. Third, the study provides a number of economic and social constructs for examining business relationships more in-depth. The fourth contribution is that the study offers timely insights into foreign firms' relationship 
development process with local actors in China, a topic which has received little research attention to date, particularly in the context of the relationship features studied in this thesis. These contributions are discussed in the following four subsections.

\subsubsection{Understanding the two-dimensional nature of business relationships}

The present study shows that, while clearly interrelated, a relationship's economic ties and social bonds can be developed unevenly and unequally - that is, to different extents and at different rates over time. It is, therefore, meaningful to examine them separately, in order to gain insights into the diverse and complex nature of business relationships. The two-dimensional view presented in this study advances the existing approaches to addressing the economic and social aspects of business relationships. As mentioned earlier in the thesis, although the coexistence of economic ties and social bonds is acknowledged in the literature (Forsgren, 2005; McAllister, 1995), many scholars consider these two aspects as being tightly intertwined (Larson, 1992), which implies little need to differentiate between them while analysing relationships.

To further understand the contribution of the two-dimensional view, it is helpful to refer to another emerging stream of literature - relationship typology. Scholars in this field argue that defining relationships by polar-types terms, like 'strong' as opposed to 'weak', 'discrete' as opposed to 'relational', and measuring them along such a continuum, limits our knowledge about relationships, because little effort has gone into identifying and investigating the 'intermediary' type of relationship that seemingly exists 'between' those two polar types (Hausman, 2001). For instance, the 'economically close but adversarial' (Mudambi and Mudambi, 1995) and 'durable arm's-length' relationships (Dyer et al., 1998) identified in empirical studies, illustrate this point. To tackle this issue, these scholars tend to delineate the structure of relationships, usually along two separate dimensions through which multiple types of relationships can be defined 
(Donaldson and O’Toole, 2000; Schijns and Schroder, 1996; Tangpong et al., 2008).

This study adds to this small, but increasing body of literature. It confirms the value of delineating relationships, and its two-dimensional view demonstrates an enhancement of the work done by other scholars. The two dimensions, economic ties and social bonds, are two fundamental themes in the relationship lifecycle (Larson and Starr, 1993), and each of them is defined by behavioural and psychological factors that are most commonly studied in the literature. The four types of business relationships identified on this basis, as illustrated in the matrix (Figure 4-2), are characterised with substantially distinct economic and social strength. This representation of relationship types, drawing on the distinct and dynamic interplay between economic ties and social bonds, may help to advance our understanding of the nature of business relationships more comprehensively, especially in the Chinese setting where the social bonds deserve specific attention.

The rationale for the two-dimensional view may be also discussed from a network point of view, as relationships are embedded in the network context. Business networks can be perceived as the integration or overlapping of economic networks and social networks (Lechner et al., 2006). To analyse such complex network settings, scholars acknowledge that the only conceptually meaningful strategy is to distinguish each network by its content and analyse it separately (Fombrun, 1982). Arguably, the two-dimensional view is an extension of this perceptive at the relational level of networks. Following the same logic, since firms' business relationships are constructed from both economic ties and social bonds, an effective strategy to analyse relationships is to differentiate between the two dimensions.

Additionally, by separating the economic and social dimensions in the analysis of relationships, the study corresponds to an early concern with regard to relationship strength. When Granovetter (1973) first proposed his concept of relationship 
strength, he reminded future researchers of the multiple situations where relationships could be strong and weak - an aspect that does not appear to have attracted very much attention in the mainstream literature. Lately, for example, some scholars continue to define strong relationships as being strong in both the economic and social dimensions, and weak relationships as being weak in both the dimensions as well (e.g. Perry-Smith and Shalley, 2005). The present study helps to refocus academic attention to Granovetter's concern. Its findings reveal that relationships can be strong and weak in different ways, for instance, a relationship being economically strong and socially weak, and vice versa.

Overall, the study suggests that business relationships should be examined by measuring the economic and social aspects separately. This will allow researchers to better understand the complex nature of relationships as well as the dynamics involved in relationship development. Specifically, this two-dimensional view may have value with regard to the Chinese market, because firms in China often pay specific attention to social networks (Björkman and Kock, 1995), implying the importance of studying social bonds separately from economic ties.

\subsubsection{Considering relationship development from the two-dimensional perspective}

The study further contributes to the literature by providing a novel way to unfold the dynamic relationship development process. The two-dimensional view suggests that relationship development as a process is constituted by changes in the economic and social dimensions of the relationship. The qualitative data in the study suggest that changes in these two dimensions do not have to be identical; rather, they can differ, not only by the degree of change, but also by the direction of change, i.e. being opposite. On this basis, the study conceptualises that the development of a relationship within a given time period can consist of diverse changes in its economic ties and social bonds, described as an increase, decrease, or maintenance situation, subject to the degree and direction of change. Specifically, an increase means a positive growth for a dimension, a decrease 
implies a negative decline for a dimension, and maintenance refers to the situation where neither an increase nor a decrease occurs. In reality, for example, a small increase in economic ties could occur along with a large increase in social bonds; a large increase in economic ties could occur along with a large decrease in the social bonds; a decrease in economic ties could occur along with social bonds being maintained.

Hence, relationship development, from the two-dimensional view, may be depicted as a process whereby a firm constantly adjusts its economic ties and social bonds with another exchange partner. This can be illustrated conceptually in Figure 7-4.

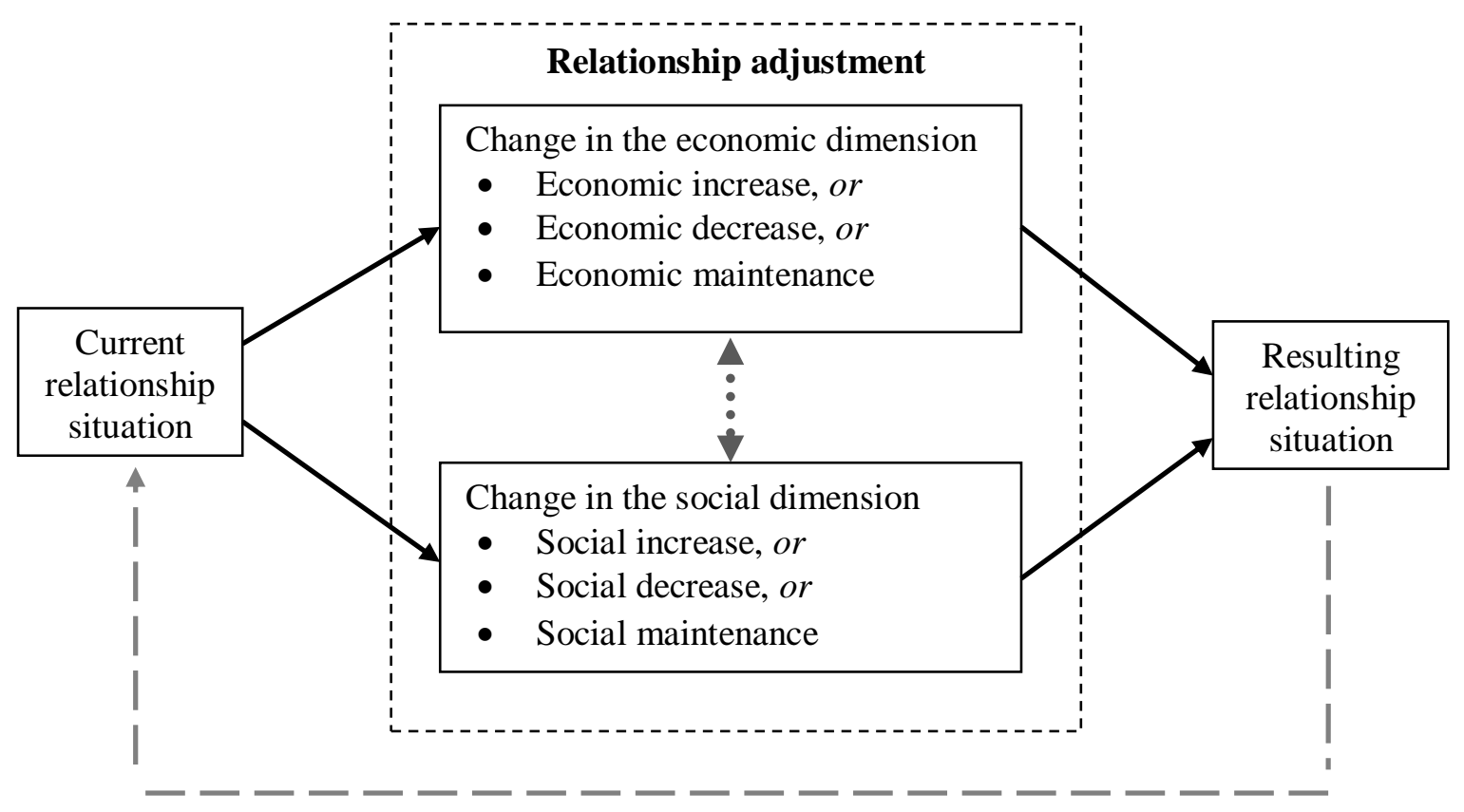

Figure 7-4

Conceptual framework illustrating the relationship development process via changes in the economic and social dimensions

As illustrated in the framework, during the relationship development process, firms analyse the current relationship situation and make decisions on whether to increase, decrease or maintain the economic ties and social bonds, as the means of 
developing the relationships toward the next step. After these adjustments in the economic and social dimensions, the relationships achieve the expected composition, which in turn will become the basis for the firms to make decisions for subsequent relationship development. This framework does not preclude each dimension being linked in some way to the other, as noted in the previous literature. Rather, it proposes that firms could put different emphasis on each dimension, and this will be reflected by consequent change in the relative strength of that dimension.

This framework sheds light on firms' deliberate development of economic ties and social bonds, and echoes some recent studies that argue relationship development as being a "more tentative, and iterative reality" other than a "process of search and decision in a series of logical phases" (Emberson and Storey, 2006: 243). Two distinct theoretical contributions arise from this. First, the framework is flexible and provides a conceptual understanding of the 'atypical' findings about relationship development reported in previous empirical research. For example, it is found that some relationships may 'linger' for a while, meaning that the economic cooperation between two firms can remain fairly active, despite having declining social elements (Jap and Anderson, 2007). Or, some relationships remain largely social, even though the economic activities between two firms drop significantly (Batonda and Perry, 2003a). These findings, which feature asymmetric evolution of the economic and social contents, cannot be sufficiently explained by traditional theories like the stages model (Dwyer et al., 1987; Ford, 1980). The framework can, however, accommodate these atypical findings by acknowledging the potentially asymmetric development of the economic and social nature in relationships.

Second, the framework provides a fundamental platform on which to consider other studies in the extant literature. For example, from a managerial point of view, the development of relationships has to be largely subject to firms' satisfaction based on regular assessment of the relationship (Ring and Van de Ven, 
1994). Also, firms' intention of strengthening the economic and social aspects of relationships may be dependent on the market situation (Zerbini and Castaldo, 2007): if being cooperative is more important than competing, then the social content needs to be nurtured, for example. Thus, variables such as relationship satisfaction and market environment could be incorporated into the conceptual framework, and investigated for their role as determinants of firms' relationship adjustment activities. As a result, a more comprehensive understanding of relationship development process may be developed.

In short, in response to the suggestion of Turnbull et al. (1996: 46), rather than simplistically suggesting that "they (relationships) can or should develop along a single continuum between 'distant' and 'close', 'good' and 'bad'", the framework derived from the conceptual basis of the study and the research findings presents a flexible view of relationship development. It does this largely by considering the separate contributions of the economic and social dimensions in relationship formation and subsequent relationship development. This also reflects a theorybuilding contribution to the existing relationship development research, an aspect that has been called for in the literature (Whetten, 1989).

\subsubsection{Relationship constructs and measurement}

The study identified a number of constructs for the economic and social dimensions. This responds to an emerging research interest in refining previously defined relationship constructs by their economic and social aspects, for the purpose of more detailed investigation of relationships. As indicated earlier in the thesis, the multifaceted nature of many relationship constructs is not new to the literature, but it has not yet drawn enough attention from researchers to date. A number of constructs reflect both economic and social perspectives, a feature on which this study is drawn. Trust has been distinguished by, for example, by cognitive and affective trust McAllister (1995), and structural and social trust (Madhok, 1995). Commitment is distinguished by calculative and attitudinal commitment (Mathieu and Zajac, 1990), and calculative and affective 
commitment (Geyskens et al., 1996). However, scholars point out that one limitation of previous research is that, with only a few exceptions and notwithstanding the mulitdimensional nature of these constructs, they are always treated as being unidimensional (Clarke, 2006). In other words, the operationalisation of the constructs does not seem to match the conceptualisation. As Clarke (2006) notes, however, differentiating between the distinct aspects of these constructs could be an important step forward, allowing scholars to understand them more comprehensively at the inter-organisational level.

The recent literature, therefore, witnesses an increasing awareness of the need to distinguish between the economic and social aspects of a number of relationship constructs. Trust and commitment, perhaps the two most frequently investigated constructs in the literature, draw the most attention. Relevant research has appeared in the field of international business. For instance, in comparing Chinese managers and US managers, Chua et al. (2009) found that the former are more likely to differentiate between the calculative commitment and affective commitment when developing their business relationships, than the latter. Their findings strongly suggest the need for analysing these two types of commitment separately for a better understanding of the overall commitment in relationships. Likewise, Styles et al. (2009) demonstrate a thorough investigation of not only these two types of commitment, but also economic and social based trust, separately. Other researchers shed light on the behavioural aspects of relationship constructs by distinguishing socialising activities from transactional exchanges (Molina-Morales and Martinez-Fernandez, 2009; Noorderhaven and Harzing, 2009). These studies all produce valuable insights into relationships that are not well reported in previous research.

The present study provides contributions to this emerging research stream. A number of economic and social constructs in the Chinese business setting have been developed and examined. The study acknowledges the potential correlation between some of these economic and social constructs. But arguably, from a 
theoretical perspective, and as others also note, these constructs represent distinct aspects of business relationships and need to be investigated separately, in order to obtain a detailed understanding of relationships. In addition, these constructs may be particularly meaningful for conducting context-specific research in China, because the Chinese culture is considered to place a specific emphasis on the social dimension with regard to the relationship development process.

\subsubsection{Relationship development of foreign firms in China}

In Phase 2, the relationship development process of foreign firms with their important local customers in China is investigated. Specifically, the study compares the relationship formation and development processes between Western firms and Asian firms, between large and small firms, and between manufacturing and service firms. The literature has outlined differences within these groups in their networking approaches, assuming that one type generally takes a more social approach than the other in building business relationships. However, as discussed earlier, not all the relevant assumptions are supported in this study. The results of the study contribute to the literature on relationship development in the context of China, a setting that is gaining considerable research interest for foreign MNE activities. The study contributes in the following ways.

First, the study suggests that the traditional perception of Asian firms being advocated toward a more social approach to networking than Western firms (Hitt et al., 1997) needs to be reconsidered, at least in the Chinese context. The results show that foreign firms from a Western background actually possess stronger social bonds than those from an Asian background at the early stage of relationship development. The finding may be explained by Western firms' strong adaptation to the local market. This is consistent with Li's (2005) statement that interfirm networking of Western firms in China is a sophisticated integration of social based managerial ties and modern management philosophies. Further, the finding relates to Peng and Luo (2000) argument that firms' network approach is determined by the institutional environment. This implies that the social and 
relational network approach should not simply be regarded as the domain of Chinese or Asian culture, because Western firms operating in an Asian context are likely to become socially oriented, as a result of the influence of the surrounding institutional factors. Also, the finding echoes the predications made earlier by Lovett et al. (1999) that, Western firms would gradually become more social oriented in developing their business networks, whereas Asian firms, particularly those in China, may put increasing emphasis on exchange partners' market competence and capabilities.

Second, by comparing large and small foreign firms operating in China, the study enriches the body of knowledge relating to 'subsidiary size', a variable that has been rarely investigated in the literature (Johnston and Megnuc, 2007). The results suggest that the size of a subsidiary can be a factor explaining MNCs' relationship development in a local market. But, it must be noted that the general perception of firm size regarding relationship development may not be totally applicable to subsidiaries in their MNC context. Specifically, the study shows that smaller subsidiaries, on average, do not form any stronger social bonds in China than larger subsidiaries; and they also achieve a lower degree of increase in social bonds during the subsequent development. This seemingly contradicts the literature, which regards small firms as usually embracing a more social and relational approach to building network relationships. As discussed earlier, this may partially result from the intervention and support that subsidiaries obtain from their headquarters, thus minimising the distinction due to subsidiary size.

Another explanation for this could be the lack of power of smaller subsidiaries while dealing with local actors, relative to larger subsidiaries. Drawing on powerdependence theory, this explanation may elicit an interesting question for scholars. As already noted, the literature has strongly encouraged small firms to foster social capital and achieve social embeddedness when exploring international markets. However, these arguments tend to be largely driven by theories that highlight the benefits from social networking, such as relational marketing, social 
capital and social embeddedness, whereas relatively little effort has gone to investigating the difficulty for small firms to achieve this in practice. For example, Tam et al.'s (2007) recent study shows that smaller firms may actually develop more arm's-length relationships than larger firms. Thus, there is a need for the literature to pay more attention to the practical aspect of small firms developing relationships.

Third, the comparison between manufacturing firms and service firms, from various aspects, has attracted interest from scholars from a range of fields over recent years (Altomonte and Pennings, 2009; Buckley et al., 1992; Habib and Victor, 1991; Prajogo, 2006; Song et al., 1999; Yoon and Choi, 2002). However, similar interest is rarely seen in the field of network studies. In international business, early research has pointed out that service firms tend to advocate a more social approach to networking than manufacturing firms, due to the high demand for their localisation ( $\mathrm{Li}$ and Guisinger, 1992); however, empirical investigation remains limited. With regard to the Chinese context, likewise, only recently have researchers begun to suggest using comparative analysis to examine how foreign manufacturing and service firms may differ in terms of local networking and relationship building (Mu et al., 2007; Wu and Choi, 2004).

The above research gap is addressed to some extent in this study, and the results show that first, these two types of firms do not appear to be substantially different in respect to their initial economic ties and social bonds when forming the business relationships. This seems to relate to Chowdhury and Miles's (2006: 121) concern that "there has been a blurring of the differences between the processes of modern service and manufacturing firms and the question can be raised as to whether treating service firms as distinct from manufacturing purely based on primary output is still appropriate". Second, the results show that it is the manufacturing firms that achieve a higher degree of increase in the social bonds in the development phase of their relationships. As identified by Hastings and Perry (2000) in the context of Australian manufacturing and service exporters, the 
findings from this study appear to contradict the general perception that service firms would generally be more socially-oriented than manufacturing firms when dealing with clients and managing relationships (Knight, 1999; O'Farrell et al., 1998). In short, the study can be regarded as making a contribution toward reconfirming the distinction between manufacturing and service firms (Lotti, 2007) from a relationship development perspective, particularly in the Chinese context.

Overall, the analysis of the three pairs of comparisons of foreign firms operating in China provides up-to-date findings about these firms' relationship development processes. The study also offers relevant insight into the difference between each pair of the comparison firms with regard to their social embeddedness with local customers, which is an important strategic issue for MNCs (London and Hart, 2004). However, it is important to note that the discussion on the degree to which the economic and social dimensions are developed in firms' relationships must be understood in a relative, not an absolute sense, given that the data were analysed using a comparative approach.

\subsubsection{Contributions to research methodology}

Contributions of the study from the methodological aspect are mainly concerned with ways to examine the relationship development process and the Chinese research setting. They are discussed in the following three sub-sections.

\subsubsection{Relationship development from a process-based view}

The study draws on Van de Ven's (1992) definitions of process and, in correspondence to Turnbull et al.'s (1996) recommendation, unfolds the development process of relationship by focusing on their evolving nature per se. To begin with, it complements the literature because although relationships have been studied for decades, most research in this field is concerned with the antecedents and consequences of relationship development (Borgatti and Foster, 2003). Since relationship development is essentially a process-based concept (Hite and Hesterly, 2001; Larson and Starr, 1993), the evolving nature of relationships 
clearly deserves more attention. The study, therefore, begins to address what has been identified in the literature as an under-researched topic; that is, the evolution of network dynamics (Coviello, 2006). It extends this knowledge base by focusing on the dynamics of the relationship development process itself and on the nature of the ties and bonds that make up the relationships in this process.

Further, focusing on the evolving nature of relationships, the study examines relationship development in terms of the formation and subsequent growth of relationships. This methodological approach enriches, but does not depart entirely from the previous literature. It is in line with Todeva's (2006) recommendation that researchers could utilise the stages model as a guide to trace changes of relationships over time, rather than asserting the definite stages in the development process. The findings, as already discussed in this chapter, provide a clear picture of how relationships evolve along their economic and social dimensions.

Overall, the process approach underpins the exploratory nature of the study, and the resulting findings advance more contemporary views of relationship development. The study, therefore, contributes to the research which more recently challenges traditional views on the relationship development process of firms, and where much of the research has been descriptive and interpretative.

\subsubsection{The two-phase research design}

The study employs a two-phase design combining both the qualitative and quantitative approaches to address the fundamental research problem. This is similar to some previous network and relationship studies conducted in China (e.g. Park and Luo, 2001; Peng and Luo, 2000; Zhou et al., 2007). Notably, a strong linkage is established between the two phases. As outlined in Chapter 3, Phase 1 consolidates the conceptual basis on which the hypotheses tested in Phase 2 are formed. In addition, the rich and contextual qualitative data benefit the study in terms of offering insights in relation to the economic and social elements, and 
helping make sense of some of the quantitative findings, as shown in this chapter. This echoes Peng and Luo's (2000) comments that the qualitative phase can usually provide valuable input to the subsequent quantitative research. Overall, the study shows that a two-phase design may assist the researcher with obtaining an in-depth understanding of the research problem.

Meanwhile, the two-phase design is embedded with abduction logic, i.e. an integrative logic of deduction and induction, because the two-dimensional view is initially drawn on the existing literature, and then examined empirically. According to Eriksson and Kovallainen (2008), abduction logic can help researchers to investigate complex research problems. In this study, the abduction approach has been valuable in assisting the researcher in addressing the relationship development process in the Chinese setting.

\subsubsection{Data collection in China}

Multiple techniques were employed in this study to collect the qualitative and quantitative data from foreign firms operating in China. The qualitative sample in Phase 1 was achieved by approaching firms identified from public sources, and through the help from local intermediaries. The quantitative sample in Phase 2 was achieved through a combination of a random postal survey, a referral-based approach to accessing firms, and collaboration with a local university. The random postal survey only produced a small number of responses. In comparison, the referral-based approach and collaboration with the local university contributed the majority of the quantitative sample.

The outcome from the referral-based approach supports Cycyota and Harrison's (2006) argument that, in survey research, sponsorship by an organisation or person in the informants' social networks can significantly increase the response rate. With regard to the Chinese context in particular, this approach can be effective because it essentially relates to the exchange of favours, or face, among three parties: the researcher, the referee and the informant. This type of social 
exchange remains as the central value of Chinese culture - guanxi. Also, collaborating with local research institutions like universities could be a reliable method for collecting valid data in emerging economies such as China (Zhou et al., 2010). In this study, it has allowed the researcher to take advantage of the abundant resources and manpower of the university.

In short, the study adds to the base of knowledge on data collection methods in China. Consistent to the studies summarized in Table 5-19, it shows the importance of adopting multiple techniques for firm-level data collection in this market, where standard Western methods could often fail. Also, as noted in Chapter 5, it is important that certain measures are taken to ensure that the responses and data are genuine, as with a standard post data collection procedure.

\subsubsection{Section summary}

Overall, the study is undertaken to provide results and insights that contribute to addressing the broad Research Problem: How do foreign firms operating in China develop business relationships with local actors? This section has focused on a discussion of the findings from the two phases of the study. First, the discussion of the qualitative findings in Phase 1 highlights the nature of the relationships, particularly of the economic ties and social bonds in the relationship development context. It addresses Research Question (1): Do foreign firms operating in China emphasise their economic ties and social bonds differently in developing business relationships? It enhances the understanding of the two dimensional view, and further consolidates the conceptual basis for the quantitative part of the study. Second, the discussion of the quantitative findings in Phase 2 primarily addresses Research Question (2): Are there any differences in the relationship development processes of firms that have different nationality and size, and which operate in different industry sectors, with respect to the economic ties and social bonds? It outlines the patterns of these firms' relationship development process with regard to the economic and social dimensions, and interprets them in the context of the existing literature and the 
qualitative data from the prior phase. Additionally, the quantitative results for the control variables used in the multiple regression modelling are discussed to provide a comprehensive understanding of firms' relationship development. Finally, this section sheds light on the contributions derived from these findings, as well as the methodological approach taken for the study. It is argued that the study may advance the current body of knowledge about relationships and relationship development, particularly in the Chinese setting. Recommendations for others who may embark on research related to business relationships and China are also provided.

\subsection{Conclusions of the Study}

This section concludes the present study by reiterating the key findings, and acknowledging the limitations of the study, as well as recommendations for future research. Then, the practical implications for managers in foreign firms operating in China are discussed, followed by brief concluding remarks on the thesis.

\subsubsection{Summary of key research findings}

In this study, both qualitative and quantitative approaches are employed to explore the relationship development processes of foreign firms operating in China. In Phase 1, interviews with the senior managers in eight foreign firms generated valuable qualitative data and produced many interesting findings regarding business relationships with a variety of local business actors (see Chapter 4). A central argument drawn on these findings is that studying relationships by viewing their economic and social dimensions separately helps the researcher to understand the nature of relationships in more depth. With regard to the relationship development context, this means that the economic ties and social bonds of a relationship may evolve differently. The strength of these dimensions may be asymmetric at the early stage of relationship formation, and they may also evolve separately during the subsequent development process. This lends support for the two-dimensional view presented in the study, and provides a conceptual 
basis for the further quantitative investigation of the relationship development processes in Phase 2.

In Phase 2, a survey was conducted in China and multiple techniques were adopted to recruit firms. In the questionnaire, each respondent provided data for a business relationship with one of his/her firm's most important local customers. The local customers, as explained earlier, broadly refer to the actors that directly purchase, distribute or utilise firms' products or services. They can be, for instance, sales agents, distributors and end-users, which are generally regarded as $k e h u$ in Chinese. The final sample comprised responses from managers in 96 foreign firms. Based on these data, the hypotheses were tested by multiple regression modelling. The results reveal the differences between Western firms and Asian firms, between small firms and large firms, and between manufacturing firms and service firms, in terms of the development of the economic ties and social bonds in their focal business relationships.

Specifically, based on the marginal interpretation of the results, it was found that Western firms tend to emphasise both the economic and social dimensions more than Asian firms at the formation stage, whereas Asian firms might subsequently achieve a higher degree of increase in these two dimensions. Larger foreign firms form slightly weaker social dimension than smaller firms, and no significant difference is noticed with regard to the economic dimension. However, it is the larger firms that gain stronger momentum in both these dimensions during the following relationship development process. Foreign manufacturing firms and service firms in the sample do not appear to be significantly different in their economic ties and social bonds when initiating the relationships. But, the former grow more rapidly in both these dimensions, particularly the social bonds. In addition to these, a number of control variables adopted in the quantitative analysis show explanatory power for the development of relationships. 
Overall, the study demonstrates a comprehensive investigation of foreign firms' relationship development process, with a particular focus on the evolution of the economic and social dimensions. The results yielded from both the qualitative and quantitative analysis provide an up-to-date and vivid picture about how foreign firms operating in China develop their relationships with local actors, especially with regard to their important customers.

\subsubsection{Limitations and future research}

The study has a number of limitations. These are noted in this section, along with recommendations for future research. First, the study adopts a process-based approach to examine the evolving nature of business relationships. Although it unveils the dynamic changes of relationships during the development process, relatively less attention is paid to the antecedents that influence those changes (Van de Ven, 1992). In Phase 2, the researcher sheds light on the three organisational level explanatory variables (i.e. nationality, size and industry sector) and takes into consideration a number of control variables in the regression modelling for relationship development. However, other variables could also play a role in foreign firms' relationship development in China, including, for example, firms' strategic orientation (Li, 2005), market competition (Kim et al., 2006; Luo, 2003), and market uncertainty (Gulati and Gargiulo, 1999; Koka et al., 2006). Future research should address this issue by exploring how these variables are related to changes in the economic and social dimensions, for a more comprehensive understanding of the relationship development process. Additionally, in this study firm size is measured by the number of full-time employees. Future research is recommended to consider other resource-based variables that more directly reflect firm advantages and capabilities (Chiao et al., 2008) with respect to relationship development, which could provide supplementary insights.

Second, in Phase 2, the study focuses on one important customer relationship of each firm. Although this sampling method is justifiable (see Section 5.2), it 
unavoidably overlooks other types of business relationships of firms, including those with local suppliers. Also, because the relationships investigated were 'important' and 'active' at the time of the survey, the sample could be biased towards those relationships that were relatively 'cooperative', 'successful', or, at least, still in an active form, and experienced growth since their initial formation. Future research should address these aspects, by first focusing on multiple categories of relationships in firms' networks (Peng and Luo, 2000), and second, by paying attention to declining or failing relationships. Analysis of these relationships would enrich the findings of the present study, and also contribute to the body of knowledge on relationship dissolution, which is now receiving increased research interest in the literature (Beloucif et al., 2006). Additionally, the study examines relationships from the focal firms' perspective. Despite this being a common approach undertaken by many researchers, future research could consult both parties in a dyadic relationship, in order to gain more in-depth understanding of the relationship development process, based on the potentially different story told by each party (Mohr and Spekman, 1994).

Third, in the quantitative Phase 2, the relationship development process is examined by assessing the economic ties and social bonds at the formation stage, and the degree of change in both the dimensions. One limitation associated with this approach is that, while the overall changes of the relationships are captured by the analysis process, the ups-and-downs occurring within the focal timeframe (as described by Johnston and Hausman, 2006) are not able to be detected. Or, when respondents tried to recall historical events, they might tend to idealise the past, which could lead to biased data. Future research could address this by adopting either a longitudinal methodology or a multiple-round survey to track the changes in relationships over time. Measuring ups-and-downs in relationships could offer interesting insights into their dynamic changes, for example, opposite changes occurring in the economic and social dimensions. Another limitation is that the study does not directly address the 'pre-relationship stage' (Ford, 1980), even though the status of the economic and social dimensions at formation could reflect 
the effort that firms have invested in the relationship to that stage. Future research should address this issue, because the findings could contribute to our understanding of the relationship emergence phenomenon, a topic that remains under-researched (Nebus, 2006).

Fourth, the study has a relatively small sample size, with eight firms being interviewed in Phase 1, and 96 useable questionnaires being collected in Phase 2 from 96 firms. It is well-known that firm-level research can be very difficult to conduct in China, especially for students who have limited professional connections and financial resources to draw on. Future research should strive to obtain larger sample sizes, particularly for the quantitative component of the investigation. A more substantial dataset would also allow some additional quantitative analyses to be performed. For instance, confirmatory factor analysis could be carried out to explore the constructs developed in this study.

Fifth, with regard to the research setting, the study was conducted in a single country context - China - and data were collected from foreign firms located mainly in the Shanghai region. Hence, generalisation of the findings of the study to other cultural contexts or even different regions in China needs to be undertaken carefully. It would be also interesting to see a similar study conducted in different settings such as countries with predominantly Western-backgrounds, where business networks are generally considered to be more economic-based and involve less social elements, or in other areas in China that may be less economically developed or Westernised than Shanghai. The results from such research could examine the extent to which the two-dimensional view remains meaningful and applicable across different contexts, and, therefore, contribute a more robust conceptual framework for relationship development.

Sixth, the researcher is aware of two issues that are often associated with surveybased studies using self-reported perception measures: social desirability and common method variance. Social desirability generally refers to a respondent's 
propensity for fabricating the data to look good (Ganster, Hennessey and Luthans, 1983); common method variance occurs if a respondent has "a propensity to provide consistent answers to survey questions that are otherwise not related" (Chang et al., 2010: 178). Both these two issues could cause data contamination and result in measurement errors, although they may be "attributable to the measurement method rather than to the constructs the measures represent" (Podsakoff, MacKenzie, Lee and Podsakoff, 2003: 879). As described in Chapter 5 , in the survey instrument, the respondents in Phase 2 were assured of anonymity and confidentiality, and were informed that only the appropriate answers were expected; the order for all the questions for the economic and social dimensions was also randomised. Further, great care was taken during the questionnaire development procedure, for example, by inviting both academics and practitioners to preview the questionnaire to help avoid ambiguity of the survey instrument. These activities, as Chang et al. (2010) recommend, might have assisted in reducing the potential bias caused by common method variance, and also social desirability. Also, it is worth noting that the explanatory variables employed in Phase 2 are based on the factual information provided by the respondents, rather than their perceptions, which may lower the likelihood of common method variance occurring in the results - as suggested by Podsakoff and Organ (1986). However, the researcher acknowledges that these issues are a potential limitation in the study.

Furthermore, the outcomes of the study may suggest other research avenues. First, the four types of business relationships identified from the qualitative findings warrant more research attention. Future research could utilise other quantitative data analysis techniques, such as cluster analysis to affirm this typology. It would also be interesting to establish the linkage between these types of relationships and performance measures, such as the profitability of the relationships, and consider the strategic implications for firms' relationship building. Second, the study presents a descriptive framework for relationship development (see Figure 7-4), based on the conceptualisation and empirical investigation of the economic 
and social dimensions. This framework could guide future research in exploring the circumstances in which firms undertake specific economic and social adjustments in the course of their relationship development activities. Third, the economic and social constructs developed in the study may assist researchers in examining relationships in more depth and further exploring the internal causal features of relationships (Ivens and Blois, 2004).

\subsubsection{Implications for Practitioners}

The study has revealed a number of managerial implications for foreign firms in China, with regard to developing business relationships in the local market. These implications are drawn from the two-dimensional view and the research findings with respect to the three sets of hypotheses.

\subsubsection{Manage relationships by the economic and social dimensions}

In line with the fundamental conceptualisation of the study - the two-dimensional view - managers must be aware of the multidimensional nature of business relationships. As defined in this study, relationships are constructed on their economic ties and social bonds. The former are associated with firms' business activities and exchange of resources, and the latter are supplementary and may assist firms with pursuing business goals, but could also result in a negative effect. These two dimensions are related and also distinguishable.

Managers need to first learn to take advantage of the interrelated nature of the economic and social dimensions, using one to leverage the other. For example, if firms are willing to deepen their business cooperation with others, but find it difficult to reinforce strong economic ties at the start, then focusing on the social bonds can be a facilitating approach, as the social elements could act as the lubricant for the business operations. Second, managers must be aware that strong social bonds are not necessarily good for relationships, because they can lead to series of negative effects that may potentially damage firms and their relationships (Andeson and Jap, 2005; Gargiulo and Benassi, 2000). This also explains why the 
recent literature has been shifting away from the traditional perception of building strong and relational ties toward 'good networking' (Luo, 2003) and 'wise relationship management' practices (Molina-Morales and Martínez-Fernández, 2009). The latest view is that firms should situate with the appropriate closeness to their business actors in every relationship (Peng, 2002), so that they may create an interfirm context that continually fosters cooperation between the exchange partners, and simultaneously guard against the potential hazards of opportunism (Lado, Dant and Tekleab, 2008). Since not all relationships need to be very strong (Golicic et al., 2003), managers are expected to carry out regular assessment of their relationship portfolio, and make sure that for each of them, the degree of the economic ties and social bonds is appropriate. This further leads to the third recommendation that managers must remain alert to either of these two dimensions becoming inadequately or overly developed during the relationship development process. They can then make decisions on whether to strengthen, maintain or diminish them, as illustrated in Figure 7-4.

Overall, the study suggests that by considering relationships from their economic and social dimensions, managers could better assess their relationships with other business actors, and therefore be able to develop their relationships more successfully. This is particularly meaningful for foreign firms operating in China, because, even though some research has shown that social bonds may not be necessarily be developed to a high level, they could still play an important role in China's business environment (Björkman and Kock, 1995; Xin and Pearce, 1996; Luo, 1997). Hence, managers of foreign firms need to pay close attention to social and economic dimensions in their relationships and develop both of them strategically.

\subsubsection{Relationship development for foreign Western and Asian firms in}

\section{China}

The study shows that Western foreign firms in China form both stronger economic ties and social bonds in new relationships than do Asian firms. This 
implies that these firms partially draw on the traditional Western style of relationship development, having a clear focus on the economic aspect. In addition, they become adapted to the local environment by emphasising the social aspect. One managerial recommendation drawn from these findings is that managers in Western firms in China could consider more carefully the degree to which their social bonds should be enhanced while building new relationships with local business actors. This is because developing social elements is not costfree, but requires considerable investment of resources and time. From a managerial perspective, the development of social bonds needs to be appropriate to the business purpose. Also, as emphasised elsewhere in the thesis, strong social bonds do not necessarily bring greater benefits to firms in some relationship situations.

The results also suggest that managers in Western firms should pay close attention to the early evaluation of new exchange partners. Although Western firms generally perform well in this respect, as the qualitative data suggest, their relatively deep economic involvement in new relationships makes this fairly crucial. Another issue that managers of Western firms need to consider is why their economic and social dimensions with customers increase less than those of Asian firms during the subsequent development process. This phenomenon could imply that in the long term, Asian firms are likely to achieve overall stronger relationships than Western firms, which in turn, suggests that Western firms may fundamentally still follow a 'weak-ties' based network strategy, as noted by early scholars (Hitt et al., 1997).

The findings also imply that Asian foreign firms tend to undertake a relatively conservative approach to initiating business relationships, as indicated by their lower level of economic and social content at the formation stage. During the subsequent development of the relationship, however, they aim to achieve higher degree of increase in both dimensions. Based on these findings, managers in foreign Asian firms are recommended to reconsider whether their approach to 
developing relationships is effective and efficient, and whether such a gradual approach would hinder their local market development. First, given the fact that stronger relationships help firms to avoid conflicts and then are less likely to fail (Nelson, 1989), Asian firms' tendency to have relatively weak relationships at the early stage of development could lead to a high rate of relationship failure with new customers, compared to Western firms. Second, the modern Chinese market changes rapidly. Under such a circumstance, relationship development may be fast paced. Therefore, in dealing with new customers, if Asian firms are willing to form strong relationships only after both parties become familiar with each other, they may be disadvantaged relative to competitors, such as Western firms, that form strong relationships earlier.

\subsubsection{Relationship development for foreign small and large firms in China}

It is generally regarded that larger firms tend to have greater ability to absorb risks in relationship building, based on their resource strength and market capabilities, compared to their smaller counterparts. The study, however, does not find any evidence showing that these two types of firms differ significantly in initiating their economic ties. Managers in the larger firms, therefore, are recommended to explore the possibility of further enhancing the economic dimension at the beginning of their relationship development, based on their inherent advantages as mentioned above; this could help them to outperform the smaller firms in terms of local relationships development and local networking. Two possible approaches to achieve this are: first, managers could consider allowing more economic exchanges to take place at the early stage, so that deeper economic integration between them and the new local business partners could be achieved; second, managers need to nurture their economic trust and commitment in the relationships more effectively at the early stage, as this is crucial for creating the right inter-firm context for economic exchanges. In addition, since the results show that larger firms, on average, have weaker social bonds than smaller firms at the relationship formation stage, managers might also need to develop their social bonds more proactively, because these can also facilitate business activities. 
Further, larger firms' economic ties increase more than those of smaller firms over time. This might indicate that these firms exploit their inherent advantages during the subsequent relationship development process. With regard to this, managers in the larger firms need to keep in mind that the fast growth of the economic dimension could increase the potential damage resulting from possible relationship failure. Therefore, they must be very cautious when making decisions to deepen their economic cooperation with local actors. The key is constant evaluation of the relationship outcome and overall performance, as, from the economic perspective, relationships can only grow when expectations of both parties are met.

As far as smaller firms are concerned, managers need to be aware that their business relationships may, over time, become weaker than those of larger firms in both the economic and social dimensions. Two recommendations are provided in this respect. First, SMEs in China are often at the low end of the power spectrum (Wu and Leung, 2005), and this could create difficulty for them in nurturing their social bonds, especially with powerful exchange partners. Therefore, managers must try to overcome this challenge by learning to nurture the social elements in their relationships more effectively. In fact, as indicated earlier, the results in Phase 2 (see Table 6-16a) show that smaller firms did invest greater effort in socialisation than larger firms at the early relationship development stage. Managers should then, understand that nurturing social networks and social ties in China is a time-consuming task (Chen and Chen, 2004). They should continue emphasising this in their later relationship development, and strive to nurture social elements with the partner firms, through such means as interpersonal contacts and social events. Second, because small firms often lack resources and are more susceptible to failure, they sometimes tend to be more short-term and profit-oriented in developing relationships than larger firms (Tam et al., 2007). In the light of the study's findings, managers are, however, strongly recommended to change such a mindset. Rather, despite potential difficulty in 
practice, they should develop stronger relationships as well as a more stable network, by, for instance, seeking assistance from their foreign headquarters and other units in the MNC. As suggested in the literature (e.g. Carlisle and Flynn, 2005; Rowden, 2001; Rutashobya and Jaensson, 2004; Shaw, 2006), small firms should leverage their network resources to compensate their own resource limitations.

\subsubsection{Relationship development for foreign service firms in China}

The study provides recommendations for managers of foreign service firms in China. To begin with, the results provide no evidence showing service firms forming stronger social bonds than manufacturing firms when initiating business relationships. Managers are, therefore, suggested to pay more attention to the social dimension at the early stage of relationship development. This is because, although the boundaries between manufacturing and service firms are now thought to be somewhat blurry, as discussed earlier, there is still a reason to argue that service firms should aim at a higher level of social bonds in relationships, especially with their customers. In particular, service firms tend to have more frequent face-to-face interpersonal contacts with their customers than do manufacturing firms. Even prior to relationship formation, socialising activities with potential customers, including both social interactions and social communication, could yield important business information for service firms. As noted by the Director of HRCONSULT, this could help the firm to develop appealing business proposals and further successfully establish the business relationships.

Moreover, the study identified that, for certain types of services, customers may perceive low switching costs for replacing their current service provider, due to the highly adaptable nature of their service offerings. This implies a relatively high likelihood for the economic dimension to be discontinued by the existing customers, leading to potential relationship termination. The qualitative data reveal that some service firms noticed this phenomenon and accepted it as being 
'common' in China. For instance, EVENT's customers usually shifted to alternative service providers after two or three years, because, as the Director explained, they wanted to experience some different services. This was described by the Director as a normal 'lifecycle' of their customers.

In order to prolong relationships and retain customers, service firms can deepen the level of economic integration with their existing customers, by providing highly customised services as well as identifying their underlying demands for new business opportunities. This type of business strategy is reported in other empirical research (Liu et al., 2005; Myhal, Kang and Murphy, 2008), and also undertaken by DATABASE in the present study. In addition, managers must emphasise the development of their social bonds, because this could assist them with obtaining up-to-date business information about customers. This type of information helps firms to address potential problems in the development of relationships with their customers. As identified in Phase 1, EVENT was unable to retain a client that had a sudden personnel change in the top management team. However, it may be argued that if EVENT could predict this change in advance and prepare for the potential risks, it might be able to secure the relationship through dialogue with the new managers and nurturing mutual trust. Particularly, in such a circumstance, social interaction and social communication need to be emphasised, because critical business information can generally be obtained via informal communication channels.

Another reason for service firms to enhance their social bonds is that, in China, they can last regardless of the status of economic ties (Batonda and Perry, 2003a). With the existence of strong social bonds, even though customers may move to an alternative service provider, firms could still retain the option of revitalising the business relationship at certain point in the future, as long as the customers have demand for their services. A relevant example is that, after the completion of every project, or in between two projects, managers in DATABASE tried to maintain a reasonable level of socialisation with their clients, in order to sustain 
long-term relationships and make sure they would 'come back' sometime in the future. Additionally, managers in service firms must learn to nurture social bonds effectively, because many service firms' business operations are based on projects that usually last for only several months, leaving limited time for relationship development.

\subsubsection{Concluding remarks}

The research project was initially triggered by a fairly broad research problem how do foreign firms operating in China develop their business relationships in the local market? Unlike previous research that often focuses on the antecedents and consequences of networks and relationships, the present study investigates the evolving nature of relationships. In particular, the researcher argues that the nature of business relationships is defined by their distinguishable economic and social contents. Such a two-dimensional view has been indicated by the findings from a number of previous studies, but it has not yet been made explicit in the literature. Neither does it appear to be operationalised in the context of relationship development, and in the context of MNCs' subsidiaries in foreign markets.

Hence, in this study, the researcher first investigates foreign firms' relationship development in China with respect to the economic and social dimensions. This is achieved by seeking evidence of these two dimensions in interfirm relationships, and of their unequal development through a qualitative approach, which also allows the researcher to further examine and justify the two-dimensional view in the Chinese research setting. Then, the researcher undertakes this twodimensional view to investigate quantitatively the relationship development process of foreign firms with their local customers. Specifically, in the quantitative analysis, three groups of comparisons are made between Western firms and Asian firms, between smaller firms and larger firms, and between manufacturing firms and service firms. The results reveal in-depth findings about these firms relationship building approaches in a relative sense. Interestingly, some of the findings appear to be different from the perceptions traditionally held 
in the literature. The results provide insights into relationship development in the Chinese context, and also point to further research implications.

Overall, the study demonstrates an in-depth investigation of foreign firms' relationship development with local business actors in China, from a twodimensional view and using a process-based approach. The findings suggest that the two-dimensional view offers an effective angle to analyse business relationships, compared with other methods that do not differentiate between, or operationalise, the economic and social aspects. The study makes a number of contributions to the literature, and recommends future research opportunities. In addition, the results lead to managerial implications that broadly encourage firms to consider the respective roles of the economic ties and social bonds in their approaches to developing relationships. This is crucial because relationship building is the foundation for network development, and the successful management of business relationships with network actors is key to firms' business performance and survival, especially in the Chinese market. 


\section{REFERENCES:}

Adler, P.S. and Kwon, S.W. (2002) 'Social capital: prospects for a new concept', Academy of Management Review 27(1): 17-40.

Acquaah, M. (2007) 'Managerial social capital, strategic orientation, and organisational performance in an emerging economy', Strategic Management Journal 28(12): 1235-1255.

Allen, N.J. and Meyer, J.P. (1990) 'The measurement and antecedents of affective, continuance and normative commitment to the organization', Journal of Occupational Psychology 63(1): 1-18.

Altomonte, C. and Pennings, E. (2009) 'Domestic plant productivity and incremental spillovers from foreign firect investment', Journal of International Business Studies 40(7): 1131-1148.

Alon, I and McKee, D. (1999) 'The internationalisation of professional business service franchises', The Journal of Consumer Marketing 16(1): 74-85.

Anderson, E. and Jap, S.D. (2005) 'The dark side of close relationships', MIT Solan Management Review 46(3): 75-82.

Andersson, U. (2003) 'Managing the transfer of capabilities within multinational corporations: the dual role of the subsidiary', Scandinavian Journal of Management 19(4): 425-442.

Andersson, U. and Forsgren, M. (1996) 'Subsidiary embeddedness and control in the multinational corporation', International Business Review 5(5): 487-508.

Andersson, U. and Forsgren, M. (2000) 'In search of centre of excellence: network embeddedness and subsidiary roles in multinational corporations', Management International Review 40(4): 329-350.

Andersson, U., Forsgren, M. and Holm, U. (2001) 'Subsidiary embeddedness and competence development in MNCs - a multi-level analysis', Organisation Science 22(6): 1013-1034.

Andersson, U., Forsgren, M. and Holm, U. (2002) 'The strategic impact of external networks: subsidiary performance and competence development in the multinational corporation', Strategic Management Journal 23(10): 979-996. 
Andersson, U., Forsgren, M. and Holm, U. (2007) 'Balancing subsidiary influence in the federative MNC: a business network view', Journal of International Business Studies 38(5): 802-818.

Andersson, J.C., Hakansson, H. and Johanson, J. (1994) 'Dyadic business relationships within a business network context', Journal of Marketing 58(1): 115.

Armstrong, R.W. and Yee, S.M. (2001) 'Do Chinese trust Chinese? A study of Chinese buyers and sellers in Malaysia', Journal of International Marketing 9(3): 63-86.

Bagozzi, R.P. (1975) 'Social exchange in marketing', Journal of the Academy of Marketing Science 3(3/4): 314-327.

Barringer, B.R. and Harrison, J.S. (2000) 'Walking a tightrope: creating value through interorganisational Relationships', Journal of Management 26(3): 367403.

Batonda, G. and Perry, C. (2003a) 'Approaches to relationships development processes in inter-firm networks', European Journal of Marketing 37(10): $1457-1484$.

Batonda, G. and Perry, C. (2003b) 'Influence of culture on relationship development processes in overseas Chinese/Australian networks', European Journal of Marketing 37(11/12): 1548-1574.

Baum, J.A. and Oliver, C. (1992) 'Institutional embeddedness and the dynamics of organisational populations', American Sociological Review 57(4): 540-559.

Beloucif, A., Donaldson, B. and Waddell, M. (2006) 'A systems view of relationship dissolution', Journal of Financial Services Marketing 11(1): 30-48.

Bian, Y., Breiger, R., Davis, D. and Galaskiewicz, J. (2005) 'Occupation, class, and social networks in urban China', Social Forces 83(4): 1443-1468.

Björkman, I. and Kock, S. (1995) 'Social relationships and business networks: the case of Western companies in China', International Business Review 4(4): 519535 .

Blois, K.J. (1999) 'Trust in business to business relationships: an evaluation of its status', Journal of Management Studies 36(2): 197-215. 
Blois, K.J. and Ivens, B.S. (2006) 'Measuring relational norms: some methodological issues', European Journal of Marketing 40 (3/4): 352-365.

Borgatti, S.P. and Foster, P.C. (2003) 'The network paradigm in organisational research: a review and typology', Journal of Management 29(6): 991-1013.

Bove, L.L. and Johnson, L.W. (2001) 'Customer relationships with service personnel: do we measure closeness, quality or strength', Journal of Business Research 54 (2): 189-197.

Brass, D.J., Galaskiewicz, J., Greve, H.R. and Tsai, W. (2004) 'Taking stock of networks and organisations: a multilevel perspective', Academy of Management Journal 47(6): 795-817.

Brislin, R. W. (1980), 'Translation and Content Analysis of Oral and Written Material," in H. C. Triandis and J. W. Berry (eds.) Handbook of Cross-Cultural Psychology, Vol.1, Allyn \& Bacon: Boston.

Buckely, P.J., Pass, C.L. and Prescott, K. (1992) 'The internationalisation of service firms: a comparison with the manufacturing factories', Scandinavian International Business Review 1(1): 39-56.

Bueno, E., Salmador, M.P. and Rodriguez, O. (2004) 'The role of social capital in today's economy', Journal of Intellectual Capital 5(4): 556-574.

Burkhardt, M.E. and Brass, D.J. (1990) 'Changing patterns or patterns of change: the effects of a change in technology on social network structure and power', Administrative Science Quarterly 35(1): 104-127.

Burt, R.S. (1992) Structural Holes: The Social Structure of Competition, Harvard University Press: Cambridge, MA.

Burt, R.S. (1997) 'The contingent value of social capital', Administrative Science Quarterly 42(2): 339-365.

Burt, R.S. (2005) Brokerage and Closure: An Introduction to Social Capital, Oxford University Press: Oxford, the UK.

Cannon, J.P. and Perreault, W.D. (1999) 'Buyer-seller relationship in business markets', Journal of Marketing Research 36(4): 439-460. 
Carlisle, E. and Flynn, D. (2005) 'Small business survival in China: guanxi, legitimacy, and social capital', Journal of Developmental Entrepreneurship 10(1): 79-96.

Carman, J.M. and Langeard, E. (1980) 'Growth strategies for service firms', Strategic Management Journal 1(1): 7-22.

Chan, R.Y.K., Cheng, L.T.W. and Szeto, R.W.F. (2002) 'The dynamics of guanxi and ethics for Chinese executives', Journal of Business Ethics 41(4): 327-336.

Chang, S., van Witteloostuijn, A. and Eden, L. (2010) 'From the editors: common method variance in International Business research', Journal of International Business Studies 41(2): 178-184.

Chen, H. and Chen, T. (1998) 'Network linkages and location choice in foreign direct investment', Journal of International Business Studies 29(3): 445-467.

Chen, X. and Chen, C.C. (2004) 'On the intricacies of the Chinese guanxi: a process model of guanxi development', Asia Pacific Journal of Management 21(3): 305-324.

Chen, C.C. and Chen, X.P. (2009) 'Negative externalities of close guanxi within organisations', Asia Pacific Journal of Management 26(1): 37-53.

Chen, T., Chen, H. and Ku. Y.H. (2004) 'Foreign direct investment and local linkages', Journal of International Business Studies 35(4): 320-333.

Cheung, F.S.L. and Leung, W.F. (2007) 'International expansion of transnational advertising agencies in China: an assessment of the stages theory approach', International Business Review 16(2): 251-268.

Chiao, Y., Yu, C.J., Li, P. and Chen, Y. (2008) 'Subsidiary size, internationalisation, product diversification, and performance in an emerging market', International Marketing Review 25(6): 612-633.

Chowdhury, S. and Miles, G. (2006) 'Customer-induced uncertainty in predicting organisational design: empirical evidence challenging the service versus manufacturing dichotomy', Journal of Business Research 59(2): 121-129.

Chua, R.Y., Morris, M. W. and Ingram, P. (2009) 'Guanxi vs. networking: distinctive configuration of affect- and cognition-based trust in the networks of 
Chinese vs. American managers', Journal of International Business Studies 40(3): 490-508.

Clarke, N. (2006) 'The relationships between network commitment, its antecedents and network performance', Management Decision 44(9): 11831205 .

Coase, R.H. (1937) 'The nature of the firm', Economica 4(6): 386-405.

Cohen, J., Cohen, P., West, S.G. and Aiken, L.S. (2003) Applied Multiple Regression / Correlation Analysis for the Behavioural Sciences, $\left(3^{\text {rd }}\right.$ eds.) Lawrence Erlbaum Associates: Mahwah, NJ.

Coleman, J.S. (1984) 'Introducing social structure into economic analysis', The American Economic Review 74(2): 84-88.

Coleman, J.S. (1988) 'Social capital in the creation of human capital', The American Journal of Sociology 94(1): 95-120.

Coleman, J.S. (1990) Foundations of Social Theory, Harvard University Press: the U.S.

Contractor, N.S., Wasserman, S. and Faust, K. (2006) 'Testing multitheoretical, multilevel hypotheses about organisational networks: an analytic framework and empirical example', Academy of Management Review 31(3): 681-703.

Cooper, D.R. and Schindler, P.S. (2002) Business Research Methods, $\left(8^{\text {th }}\right.$ Eds.) McGraw-Hill Companies: New York.

Coviello, N. E. and Munro, H.J. (1995) 'Growing the entrepreneurial firm: networking for international market development', European Journal of Marketing 29(7): 49-61.

Coviello, N.E. and Munro, H.J. (1997) 'Network relationships and the internationalisation process of small software firms', International Business Review 6(4): 361-386.

Coviello, N. E. (2006) 'The network dynamics of international new ventures', Journal of International Business Studies 37(5): 713-731.

Cox, A., Lonsdale, C., Sanderson, J. and Watson, G. (2004) Business Relationships for Competitive Advantage: Managing Alignment and 
Misalignment in Buyer and Supplier Transactions, Palgrave Macmillan: New York.

Creswell, J. W. (1994) Research Design: Qualitative and Quantitative Approaches, Sage: Thousand Oaks, CA.

Creswell, J.W. and Clark, V.L. (2007) Designing and Conducting Mixed Methods Research, Sage: Thousand Oaks, CA.

Cycyota, C. S. and Harrison, D. A. (2006) 'What (not) to expect when surveying executives: a meta-analysis of top manager response rates and techniques over time', Organizational Research Methods 9(2): 133-160.

Dacin, M.T., Ventresca, M.J. and Beal, B.D. (1999) 'The embeddedness of organisations: dialogue and directions', Journal of Management 25(3): 317-356.

Denscombe, M. (2007) The Good Research Guide: for Small-scale Social Research Projects, ( ${ }^{\text {rd }}$ eds.), Open University Press: New York.

Denzin, N.K. and Lincoln,Y.S. (2000) 'Introduction: The Discipline and Practice of Qualitative Research', in N.K. Denzin and Y.S. Lincoln (eds.) Handbook of Qualitative Research, Sage: Thousand Oaks, CA.

Dhanaraj. C., Lyles, M., Steensma, H.K. and Tihanyi, L. (2004) 'Managing tacit and explicit knowledge transfer in IJVs: the role of relational embeddedness and the impact on performance', Journal of International Business Studies 35(5): 428-442.

Donaldson, B. and O'Toole, T. (2000) 'Classifying relationships structures: relationship strength in industrial markets', Journal of Business \& Industrial Marketing 15(7): 491-506.

Doney, P.M. and Cannon, J.P. (1997) 'An examination of the nature of trust in buyer-seller relationships', Journal of Marketing 61(1): 35-51.

Douglas, S. P. and Craig, C. S. (2007) 'Collaborative and iterative translation: an alternative approach to back translation', Journal of International Marketing 15 (1), 30-43.

Doz, Y.L. (1996) 'The evolution of cooperation in strategic alliances: initial conditions or learning processes', Strategic Management Journal 17(1): 55-83. 
Duanmu, J. and Fai, F.M. (2007) 'A processual analysis of knowledge transfer: from foreign MNEs to Chinese suppliers', International Business Review 16(4): 449-473.

Duschek, S. (2004) 'Inter-firm resources and sustained competitive advantage', Management Revue 15(1): 53-73.

Dwyer, F.R., Schurr, P.H. and Oh, S. (1987) 'Developing buyer-seller relationships', Journal of Marketing 51(2): 11-27.

Dyer, J.H., Cho, D.S. and Chu, W. (1998) 'Strategic supplier segmentations: the next 'best practices' in supply chain management', California Management Review 40(2): 57-77.

Dyer, J.H. and Chu, W. (2000) 'The determinants of trust in supplier-automaker relationships in the U.S., Japan, and Korea', Journal of International Business Studies 31(2): 259-285.

Dyer, J.H. and Singh, H. (1998) 'The relational view: cooperative strategy and sources of interorganisational competitive advantage', Academy of Management Review 23(4): 660-679.

Edmondson, A.C. and McManus, S.E. (2007) 'Methodological fit in management field research', Academy of Management Review 32(4): 1155-1179.

Eisenhardt, K.M. (1989) 'Building theories from case study research', Academy of Management Review 14(4): 532-550.

Eisenhardt, K.M. and Graebner, M.E. (2007) 'Theory building from cases: opportunities and challenges', Academy of Management Journal 50(1): 25-32.

Eisingerich, A.B. and Bell, S.J. (2008) 'Managing networks of interorganisational linkages and sustainable firm performance in business-to-business service contexts', Journal of Services Marketing 22(7): 494-504.

Elg, U. (2000) 'Firms' home-market relationships: their role when selecting international alliance partners', Journal of International Business Studies 31(1): 169-177.

Ellis, P. (2000) 'Social ties and foreign market entry', Journal of International Business Studies 31(3): 443-469. 
Ellis, P. and Pecotich, A. (2001b) 'Social factors influencing export initiation in small and medium-sized enterprises', Journal of Marketing Research 38 (1): 119-130.

Emberson, C. and Storey, J. (2006) 'Buyer-supplier collaborative relationships: beyond the normative accounts', Journal of Purchasing \& Supply Management 12(5): 236-245.

Eriksson, K., Majkgård, A. and Sharma, D.D. (1999) 'Service quality by relationships in the international market', Journal of Services Marketing 13(4/5): 361-377

Eriksson, P. and Kovalainen, A. (2008) Qualitative Methods in Business Research, Sage: London.

Erramilli, M.K. (1990) 'Entry mode choice in service industries', International Marketing Review 7(5): 50-62.

Erramilli, M.K. and Rao, C.P. (1993) 'Choice of foreign market entry modes by service firms: role of market knowledge', Management International Review 30(2): $135-50$.

Ferrell, O.C. and Zey-Ferrell, M. (1977) 'Is all social exchange marketing?' Journal of the Academy of Marketing Science 5(4): 307-314.

Field, A. (2005) Discovering Statistics Using SPSS, Sage: London.

Finlay, W. and Coverdill, J.E. (2000) 'Risk, opportunism, and structural holes', Work and Occupations 27(3): 377-405.

Fischer, H.M. and Pollock, T.G. (2004) 'Effects of social capital and power on surviving transformational change: the case of initial public offerings', Academy of Management Journal 47(4): 463-481.

Florin, J., Lubatkin, M. and Schulze, W. (2003) 'A social capital model of highgrowth ventures', Academy of Management Journal 46(3): 374-384.

Fombrun, C. (1982) 'Strategies for network research in organisations', Academy of Management Review 7(2): 280-291.

Ford, D. (1980) 'The development of buyer-seller relationships in industrial markets', European Journal of Marketing 14(6): 339-354. 
Forsgren, M. (2004) 'The use of network theory in MNC research', in V. Mahnke and T. Pedersen (eds.) Knowledge Flows, Governance and the Multinational Enterprise: Frontiers in International Management Research. Palgrave MacMillan: New York.

Forsgren, M., Holm, U. and Johanson, J. (2005) Managing the Embedded Multination: A Business Network View. Edward Elgar Publishing Ltd: Cheltenham UK.

Freeman, S. and Sandwell, M. (2008) 'Professional service firms entering emerging markets: the role of network relationships', Journal of Service Marketing 22(3): 198-212.

Fynes, B. and Voss, C. (2002) 'The moderating effect of buyer-supplier relationships on quality practices and performance', International Journal of Operations \& Production Management 22(5/6): 589-613.

Fynes, B., Voss, C. and de Búrca, S. (2005a) 'The impact of supply chain relationship quality on quality performance', International Journal of Production Economics 96(3): 339-354.

Fynes, B., Voss, C. and de Búrca, S. (2005b) 'The impact of supply chain relationship dynamics on manufacturing performance', International Journal of Operations \& Production Management 25(1): 6-19.

Galaskiewicz, J. (1985) 'Interorganisational relations', Annual Review of Sociology 11: 281-304

Gall, J. G., Gall, M. D. and Borg, W. R. (1999) Applying Educational Research: A Practical Guide, Longman: New York.

Ganesan, S. (1994) 'Determinants of long-term orientation in buyer-seller relationships', Journal of Marketing 58(April):1-19.

Ganster, D.C., Hennessey, H.W. and Luthans, F. (1983) 'Social desirability response effects: three alternative models', Academy of Management Journal 26(2): 321-331.

Gargiulo, M. and Benassi, M. (2000) 'Trapped in your own net? Network cohesion, structural holes, and the adaptation of social capital', Organisation Science 11(2): 183-196. 
Gay, L. R. and Airasian, P. (2000) Educational Research: Competencies for Analysis and Application (6th eds.), Prentice Hall: Upper Saddle River, NJ.

Geyskens, I., Steenkamp, J. E. M., Scheer, L.K. and Kumar, N. (1996) 'The effects of trust and interdependence on relationship commitment: a tran-Atlantic study', International Journal of Research in Marketing 13(4): 303-317.

Geyskens, I., Steenkamp, J.E.M. and Kumar, N. (1998) 'Generalisations about trust in marketing channel relationships using meta-analysis', International Journal of Research in Marketing 15(3): 223-248.

Ghauri, P. (2004) 'Designing and conducting case studies in international business research', in R. Marschan-Piekkari and C. Welch (eds.), Handbook of Qualitative Research Methods for International Business, Edward Elgar: Cheltenham.

Ghoshal, S. and Bartlett, C.A. (1990) 'The multinational corporation as an interorganisational network', Academy of Management Review 15(4): 603-25.

Gnyawali, D.R. and Madhavan, R. (2001) 'Cooperative networks and competitive dynamics: a structural embeddedness perspective', Academy of Management Review 26(3): 431-445.

Golicic, S.L., Foggin, J.H. and Mentzer, J.T. (2003) 'Relationship magnitude and its role in interorganisational relationship structure', Journal of Business Logistics 24(1): 57-74.

Gordon, G.L., Kaminski, P.F., Calantone, R.J. and di Benedetto, C.A. (1993) 'Linking customer knowledge with successful service innovation', Journal of Applied Business Research 9(2): 129-139.

Gounaris, S.P. (2005) 'Trust and commitment influences on customer retention: insights from business-to-business services', Journal of Business Research 58(2): 126-140.

Granovetter, M.S. (1973) 'The strength of weak ties', American Journal of Sociology 78(6): 1360-1380.

Granovetter, M.S. (1985) 'Economic action and social structure: the problem of embeddedness', American Journal of Sociology 91(3): 481-510. 
Granovetter, M.S. (1990) 'Interview with Mark Granovetter', in R. Swedberg (eds.) Economics and Sociology: Redefining Their Boundaries: Conversations with Economics and Sociologists, Princeton University Press: New Jersey.

Griffith, D.A. and Harvey, M.G. (2004) 'The influence of individual and firm level social capital of marketing managers in a firm's global network', Journal of World Business 39(3): 244-254.

Griffith, D.A., Cavusgil, S. T. and Xu, S. (2008) 'Emerging issues in international business research', Journal of International Business Studies 39(7): 1220-1235.

Grönroos, C. (1999) 'Internationalisation strategies for services', Journal of Services Marketing 13(4/5): 290-297.

Gruen, T.W. (1995) 'The outcome set of relationship marketing in consumer markets', International Business Review 4(4): 447-469.

Gu, F.F., Hung, K. and Tse, D.K. (2008) 'When does guanxi matter? Issues of capitalisation and its dark sides', Journal of Marketing 72 (4): 12-28.

Gulati, R. (1998) ‘Alliances and networks', Strategic Management Journal 19(4): 293-317.

Gulati, R. and Gargiulo, M. (1999) 'Where do interorganisational networks come from?' The American Journal of Sociology 104(5): 1439-1493.

Gulati, R. and Higgins, M.C. (2003) 'Which ties matter when? The contingent effects of interorganisational partnerships on IPO Success', Strategic Management Journal 24(1): 127-144.

Gundlach, G.T. and Achrol, R.S. (1993) 'Governance in exchange: contract law and its alternatives', Journal of Public Policy \& Marketing 12(2): 141-55.

Habib, M.M. and Victor, B. (1991) 'Strategy, structure, and performance of U.S. manufacturing and service MNCs: a comparative analysis', Strategic Management Journal 12(8): 589-606.

Hagedoorn, J. (2006) 'Understanding the cross-level embeddedness of interfirm partnership formation', Academy of Management Review 31(3): 670-680.

Hair, J.D., Anderson, R.E., Tatham, R.L. and Black, W.C. (1998) Multivariate Data Analysis ( $5^{\text {th }}$ Eds.), Prentice-Hall, Inc: New Jersey. 
Håkansson, H. and Ford, D. (2002) 'How should companies interact in business networks?' Journal of Business Research 55(2): 133-139.

Halfpenny, P. (1979) 'The analysis of qualitative data', Sociological Review 27: 799-825.

Harris, S. and Wheeler, C. (2005) 'Entrepreneurs' relationships for internationalisation: functions, origins and strategies', International Business Review 14(2): 187-207.

Hastings, K. and Perry, C. (2000) 'Do service exporters build relationships? Some qualitative perspectives', Qualitative Market Research 3(4): 207-214.

Hausman, A. (2001) 'Variations in relationship strength and its impact on performance and satisfaction in business relationships', The Journal of Business \& Industrial Marketing 16(6/7): 600-616.

Healy, M., Hastings, K., Brown, L. and Gardiner, M. (2001) 'The old, the new and the complicated - a typology of marketing relationships', European Journal of Marketing 35(1/2): 182-193.

Heide, J.B. (1994) 'Interorganisational governance in marketing channels', Journal of Marketing 58(1): 71-85.

Heracleous, L. and Murray, J. (2001) 'Networks, interlocking directors and strategy: toward a theoretical Framework', Asia Pacific Journal of Management 18(2): 137-160.

Hite, J.M. (2003) 'Patterns of multidimensionality among embedded network ties: a typology of relational embeddedness in emerging entrepreneurial firms', Strategic Organisation 1(1): 9-49.

Hite, J.M. (2005) 'Evolutionary processes and paths of relationally embedded network ties in emerging entrepreneurial firms', Entrepreneurship Theory and Practice 29(1): 113-139.

Hite, J.M. and Hesterly, M.S. (2001) 'The evolution of firm networks: from emergence to early growth of the firm', Strategic Management Journal 22(3): 275-286. 
Hitt, M.A., Dacin, B.B., Tyler, B.B. and Park, D. (1997) 'Understanding the differences in Korean and U.S. executives' strategic orientations', Strategic Management Journal 18(1): 159-167.

Hitt, M.A., Lee, H. and Yucel, E. (2002) 'The importance of social capital to the management of multinational enterprises: relational networks among Asian and Western Firms', Asia Pacific Journal of Management 19(2/3): 353-372.

Hofstede, G. (1980) Culture's Consequences: International Differences in WorkRelated Values, Sage: Beverly Hills/London.

Hofstede, G. (1994) 'Management scientists are human', Management Science 40(2): 4-13.

Hofstede, G. and Bond, M.H. (1988) 'The Confucius connection: from cultural roots to economic growth', Organisational Dynamics 16(4): 4-21.

Holden, M.T. and O’Toole, T. (2004) 'A quantitative exploration of communication's role in determining the governance of manufacturer - retailer relationships', Industrial Marketing Management 33(6): 539-548.

Holm, D.B., Eriksson, K. and Johanson, J. (1996) 'Business networks and cooperation in international business relationships', Journal of International Business Studies 27(5): 1033-1053.

Hult, G.T., Ketchen, D.J., Griffith, D.A. Finnegan, C.A. et al. (2008) 'Data equivalence in cross-cultural international business Research', Journal of International Business Studies 39(6): 1027-1044.

Iacobucci, D. and Ostrom, A. (1996) 'Commercial and interpersonal relationships: using the structure of interpersonal relationships to understand individual-toindividual, individual-to-firm, and firm-to-firm relationships in commerce', International Journal of Research in Marketing 13(1): 53-72.

IMP Group (2002) 'An interaction approach’, in D. Ford (eds.), Understanding Business Markets, Thompson Learning: London.

Inkpen, A.C. and Tsang, E.W.K. (2005) 'Social capital, networks, and knowledge transfer', Academy of Management Review 30(1): 146-165.

Isobe, T., Makino, S. and Montgomery. D.B. (2000) 'Resource commitment, entry timing, and market performance of foreign direct investments in emerging 
economies: the case of Japanese international joint ventures in China', Academy of Management Journal 43(3): 468-484.

Ivens, B. and Blois. K.J. (2004) 'Relational exchange norms in marketing: a critical review of Macneil's Contribution', Marketing Theory 4(3): 239-263.

Jap, S.D. and Anderson, E. (2007) 'Testing a life-cycle theory of cooperative interorganisational relationships: movement across stages and performance', Management Science 53(2): 260-275.

Jarillo, J.C. (1988) 'On strategic networks', Strategic Management Journal 9(1): $31-41$.

Jansson, H., Johanson, M. and Ramstrom, J. (2007) 'Institutions and business networks: a comparative analysis of the Chinese, Russian and West European Markets', Industrial Marketing Management 36 (7): 955-967.

Johanson, J. and Mattsson, L. (1987) 'Interorganisational relations in industrial systems - a network approach compared with the transaction cost approach', International Studies of Management \& Organisation 17(1): 34-48.

Johanson, J. and Mattsson, L. (1988) 'Internationalisation in industrial systems - a network approach', in Hood and Vahlne (eds.), Strategies in Global Competition, Croom Helm: New York.

Johanson, J. and Vahlne, J. (1990) 'The mechanism of internationalisation', International Marketing Review 7(4): 11-24.

Johnson, J.L. (2006) Book Review, Academy of Management Review 31(3): 757759.

Johnston, S. and Menguc, B. (2007) 'Subsidiary size and the level of subsidiary autonomy in multinational corporations: a quadratic model investigation of Australian subsidiaries', Journal of International Business Studies 38(5): 802818.

Johnston, W.J. and Hausman, A. (2006) 'Expanding the marriage metaphor in understanding long-term business relationships', Journal of Business \& Industrial Marketing 21(7): 446-452. 
Jones, C., Hesterly, W.S. and Borgatti, S.P. (1997) 'A general theory of network governance: exchange conditions and social mechanisms', Academy of Management Review 22(4): 911-945.

Keeble, D., Lawson, C., Smith, H.L., Moore, B. and Wilkinson, F. (1998) 'Internationalisation processes, networking and local embeddedness in technology-intensive small firms', Small Business Economics 11(4): 327-342.

Kenis, P. and Knoke, D. (2002) 'How organisational field networks shape interorgansational tie-formation rates', Academy of Management Review 27(2): 275-293.

Kim, H., Hoskisson, R.E. and Wan, W.P. (2004) 'Power dependence, diversification strategy, and performance in keiretsu member firms', Strategic Management Journal 25(7): 613-636.

Kim, T.Y., Oh, H, and Swaminathan, A. (2006) 'Framing interorganisational network change: a network inertia perspective', Academy of Management Review 31(3): 704-720.

Klang, M., Ihlstrom, C. and Olsson, S. (2002) 'Overcoming barriers: why SMEs should consider networks', International Journal of Service Technology and Management 3(1): 68-81.

Knight, G. (1999) 'International services marketing: review of research 19801998', Journal of Services Marketing 13(4/5): 347-360.

Koka, B.R., Madhavan, R. and Prescott, J.E. (2006) 'The evolution of interfirm networks: environmental effects on patterns of network change', Academy of Management Review 31(3): 721-737.

Kostova, T. and Roth, K. (2003) 'Social capital in multinational corporations and a micro-macro model of its formation', Academy of Management Review 28(2): 297-317.

Koza, M.P. and Lewin, A.Y. (1998) 'The co-evolution of strategic alliances', Organisation Science 9(3): 255-264.

Koza, M.P. and Lewin, A.Y. (1999) 'The coevolution of network alliances: a longitudinal analysis of an international professional service network', Organisation Science 10(5): 638-653. 
Kwon, Y.C. (2008) 'Antecedents and consequences of international joint venture partnerships: a social exchange perspective', International Business Review 17(5): 559-573.

Lado, A.A., Dant, R.R. and Tekleab, A.G. (2008) 'Trust-opportunism paradox, relationalism, and performance in interfirm relationships: evidence from the retail industry', Strategic Management Journal 29(4): 401-423.

Larson, A. (1992) 'Network dyads in entrepreneurial settings: a study of the governance of exchange relationships', Administrative Science Quarterly 37(1): 76-104.

Larson, A. and Starr, J.A. (1993) 'A network model of organisation formation', Entrepreneurship Theory and Practice 17(2): 5-15.

Lawler, E.E. (1997) 'Rethinking organisation size', Organizational Dynamics 26(2): 24-35.

Leana, C.R. and Van Buren, H.J. (1999) 'Organisational social capital and employment practices', Academy of Management Review 24(3): 538-555.

Lechner, C., Dowling, M. and Welpe, I. (2006) 'Firm networks and firm development: the role of the relational mix', Journal of Business Venturing 21(4): 514-540.

Lee, G.K. (2007) 'The significance of network resources in the race to enter emerging product markets: the convergence of telephony communications and computer networking, 1989-2001', Strategic Management Journal 28(1): 17-37.

Lee, D.J., Pae, J.H. and Wong, Y.H. (2001) 'A model of close business relationships in China (guanxi)', European Journal of Marketing 35(1/2): 51-69.

Levin, D.Z. and Cross, R. (2004) 'The strength of weak ties you can trust: the mediating role of trust in effective knowledge transfer', Management Science 50(11): 1477-1490.

Li, J.J. (2005) 'The formation of managerial networks of foreign firms in China: the effects of strategic orientations', Asia Pacific Journal of Management 22(4): 423-443.

Li, J. and Guisinger, S. (1992) 'The globalisation of service multinationals in the triad regions', Journal of International Business Studies 23(4): 675-696. 
Li, L. (2001) 'Networks, transactions, and resources: Hong Kong trading companies' strategic position in the China market', Asia Pacific Journal of Management 18(3): 279-293.

Li, L.Y. (2004) 'An examination of the foreign market knowledge of exporting firms based in the People's Republic of China: its determinants and effects on export intensity', Industrial Marketing Management 33(7): 561-572.

Ling, F.Y., Ibbs, C.W. and Cuervo, J.C. (2005) 'Entry and business strategies used by international architectural, engineering and construction firms in China', Construction Management and Economics 23 (5): 509-520.

Liu, A.H., Leach, M.P. and Bernhardt, K.L. (2005) 'Examining customer value perceptions of organisational buyers when sourcing from multiple vendors', Journal of Business Research 58(5): 559-568.

Liu, X., Wang, C. and Wei, Y. (2009) 'Do local manufacturing firms benefit from transactional linkages with multinational enterprises in China?' Journal of International Business Studies 40(7): 1113-1130.

Lo, T. W. and Yung, A. (1988) 'Multinational service firms in centrally-planned economies: foreign advertising agencies in the PRC', Management International Review 28(1): 26-31.

London, T. and Hart, S. (2004) 'Reinventing strategies for emerging markets: beyond the transnational model', Journal of International Business Studies 35(5): 350-370.

Lotti, F. (2007) 'Firm dynamics in manufacturing and services: a broken mirror?' Industrial and Corporate Change 16(3): 347-369.

Lovelock, C.H. (1999) 'Developing marketing strategies for transnational service operations', Journal of Services Marketing 13(4/5): 278-289.

Lovelock, C.H. and Yip, G.S. (1996) 'Developing global strategies for service businesses', California Management Review 38(2): 64-86.

Lovett, S., Simmons, L.C. and Kali, R. (1999) 'Guanxi versus the market: ethics and efficiency', Journal of International Business Studies 30(2): 231-247.

Lu, J.W. and Beamish, P.W. (2001) 'The internationalisation and performance of SMEs', Strategic Management Journal 22(6/7): 565-586. 
Luo, Y. (1997) 'Guanxi and performance of foreign-invested enterprises in China: an empirical inquiry', Management International Review 37(1): 51-70.

Luo, Y. (1998) 'Joint venture success in China: how should we select a good partner?' Journal of World Business 33(2): 145-166.

Luo, Y. (1999) 'Dimensions of knowledge: comparing Asian and Western MNCs in China', Asia Pacific Journal of Management 16(1): 75-93.

Luo, Y. (2003) 'Industrial dynamics and managerial networking in an emerging market: the case of China', Strategic Management Journal 24(12): 1315-1327.

Luo, Y. (2007) 'From foreign investors to strategic insiders: shifting parameters, prescriptions and paradigms for MNCs in China', Journal of World Business 42(1): 14-34.

Luo, Y. (2008a) 'Structuring interorganisational cooperation: the role of economic integration in strategic alliances', Strategic Management Journal 29(6): 617637.

Luo, Y. (2008b) 'The changing Chinese culture and business behaviour: the perspective of intertwinement between guanxi and corruption', International Business Review 17(2): 188-193.

Macneil, I. (1980) The New Social Contract, Yale University Press: New Haven.

Madhavan, R., Koka, B.R. and Prescott, J.E. (1998) 'Networks in transition: how industry events (re)shape interfirm relationships', Strategic Management Journal 19(5): 439-459.

Madhok, A. (1995) 'Revisiting multinational firms' tolerance for joint ventures: a trust-based approach', Journal of International Business Studies 26(1): 117-137.

Mainiero, L.A. (1986) 'A review and analysis of power dynamics in organisational romances', Academy of Management Review 11(4): 750-762.

Maitland, I., Bryson, J. and Van de Ven, A. (1985) 'Sociologists, economists, and opportunism', Academy of Management Review 10(1): 59-65.

Marshall, C. and Rossman, G.B. (1999) Designing Qualitative Research (3 ${ }^{\text {rd }}$ eds.), Sage: Thousand Oaks, CA.

Maskell, P. and Malmberg, A. (1999) 'Localised learning and industrial competitiveness', Cambridge Journal of Economics 23(2): 167-185. 
Mason, J. (2002) Qualitative Researching, Sage: London.

Mathieu, J.E. and Zajac. D.M. (1990) 'A review and meta-analysis of the antecedents, correlates, and consequences of organisational commitment', Psychological Bulletin 108(2): 171-194.

Mattsson, L.G. and Johanson, J. (2006) 'Discovering market networks', European Journal of Marketing 40(3/4): 259-275.

McAllister, D. J. (1995) 'Affect- and cognition-based trust as foundations for interpersonal cooperation in organisations', Academy of Management Journal 38(1): 24-59.

Miles, M.B. and Huberman, A.M. (1994) Qualitative Data Analysis: An Expanded Source Book, (2 $2^{\text {nd }}$ eds.), Sage: Thousand Oaks, CA.

Mohr, J. and Spekman, R. (1994) 'Characteristics of partnership success: partnership attributes, communication behaviour, and conflict resolution techniques', Strategic Management Journal 15(2): 135-152.

Molina-Morales, F.X. and Martínez-Fernández, M.T. (2009) 'Too much love in the neighbourhood can hurt: how an excess of intensity and trust in relationships may produce negative effects on firms', Strategic Management Journal 30(9): 1013-1023.

Moran, P. (2005) 'Structural vs. relational embeddedness: social capital and managerial performance', Strategic Management Journal 26(12): 1129-1151.

Moran, P. and Ghoshal, S. (1999) 'Markets, firms, and the process of economic development', Academy of Management Review 24(3): 390-412.

Morgan, R.M. and Hunt, S.D. (1994) 'The commitment-trust theory of relationship marketing', Journal of Marketing 58(3): 20-38.

Mouzas, S. and Naude, P. (2007) 'Network mobiliser', Journal of Business \& Industrial Marketing 22(1): 62-71.

Mu, S.H., Gnyawali, D.R. and Hatfield, D.E. (2007) 'Foreign subsidiaries' learning from local environment: an empirical test', Management International Review 47(1): 79-102. 
Mudambi, R. and Mudambi, M. (1995) 'From transaction cost economics to relationship marketing: a model of buyer-supplier relations', International Business Review 4(4): 419-433.

Myhal, G.C., Kang, J. and Murphy, J.A. (2008) 'Retaining customers through relationship quality: a service business marketing case', Journal of Services Marketing 22(6): 445-453.

Nahapiet, J. and Ghoshal, S. (1998) 'Social capital, intellectual capital, and the organisational advantage', Academy of Management Review 23(2): 242-266.

Nebus, J. (2006) 'Building collegial information networks: a theory of advice network generation', Academy of Management Review 31(3): 615-637.

Nelson, R.E. (1989) 'The strength of strong ties: social networks and intergroup conflict in organisations', Academy of Management Journal 32(2): 377-401.

Nes, E.B., Solberg, C.A. and Silkoset, R. (2007) 'The impact of national culture and communication on exporter - distributor relations and on export performance', International Business Review 16(4): 405-424.

Nguyen, T.V., Weinstein, M., and Meyer, A.D. (2005) 'Development of trust: a study of interfirm relationships in Vietnam', Asia Pacific Journal of Management 22(3): 211-235.

Nicoulaud, B. (1988) 'Problems and strategies in the international marketing of services', European Journal of Marketing 23(6): 55-66.

Nielsen, B.B. (2005) 'The role of knowledge embeddedness in the creation of synergies in strategic alliances', Journal of Business Research 58(9): 1194-1204.

Nohria, N. (1992) 'Introduction: is the network perspective a useful way of studying organisations?' In N. Nohria and R. Eccles (eds.), Networks and Organisations: Structure, Form and Action, Harvard Business School Press: Boston, MA.

Noorderhaven, N. and Harzing, A. (2009) 'Knowledge-sharing and social interaction within MNEs', Journal of International Business Studies 40 (5): 719-740. 
O'Farrell, P.N., Wood, P.A. and Zheng, J. (1998) 'Regional influences on foreign market development by business service companies: elements of a strategic context explanation', Regional Studies 32(1): 31-48.

O'Farrell, P.N. and Wood, P.A. (1999) 'Formation of strategic alliances in business services: towards a new client-oriented conceptual framework', The Service Industries Journal 19(1): 133-151.

Oh, H., Chung, M.H., and Labianca, G. (2004) 'Group social capital and group effectiveness: the role of informal socialising ties', Academy of Management Journal 47(6): 860-875.

Oliver, C. (1990) 'Determinants of interorganisational relationships: integration and future directions', The Academy of Management Review 15(2): 241-265.

Ouchi, W.G. (1981) Theory Z: How American Business Can Meet the Japanese Challenge, Addison-Wesley: Reading, MA.

Parkhe, A., Wasserman, S. and Ralston, D.A. (2006) 'New frontiers in network theory development', Academy of Management Review 31(3): 560-568.

Park, S.H. and Luo, Y. (2001) 'Guanxi and organisational dynamics: organisational networking in Chinese Firms', Strategic Management Journal 22(5): 455-477.

Parnell, M.F. (2005) 'Chinese business guanxi: an organisation or nonorganisation', Organisational Transformation and Social Change 2(1): 29-47.

Peng, M.W. (2002) 'Towards and institution-based view of business strategy', Asia Pacific Journal of Management 19(2/3): 251-267.

Peng, M.W. (2003) 'Institutional transitions and strategic choices', Academy of Management Review 28(2): 275-296.

Peng, M.W. and Heath, P.S. (1996) 'The growth of the firm in planned economies in transition: institutions, organisations, and strategic choice', Academy of Management Review 21(2): 492-528.

Peng, M.W. and Luo, Y. (2000) 'Managerial ties and firm performance in a transition economy: the nature of a micro-macro link', Academy of Management Journal 43(3): 486-501. 
Peng, M.W. and Zhou, J.Q. (2005) 'How network strategies and institutional transitions evolve in Asia', Asia Pacific Journal of Management 22(4): 321-336.

Perry-Smith, J.E. and Shalley, C.E. (2003) 'The social side of creativity: a static and dynamic social network perspective', Academy of Management Review 28(1): 89-106.

Pittaway, L., Robertson, M., Munir, K., Denyer, D. and Neely, A. (2004)

'Networking and innovation: a systematic review of the evidence', International Journal of Management Reviews 5(3/4): 137-168.

Podsakoff, P.M., MacKenzie, S.B., Lee, J.Y. and Podsakoff, N.P. (2003) 'Common method biases in behavioural research: a critical review of the literature and recommended remedies', Journal of Applied Psychology 88(5): 879-903.

Podsakoff, P.M. and Organ, D.W. (1986) 'Self-reports in organisational research: problems and prospects', Journal of Management 12(4): 531-544.

Pollock, T.G., Porac, J.F. and Wade, J.B. (2004) 'Constructing deal networks: brokers as network "architects" in the U.S. IPO market and other examples', Academy of Management Review 29(1): 50-72.

Prahalad, C. and Doz, Y. (1981) 'An approach to strategic control in MNCs', Sloan Management Review 22(4): 5-14.

Prajogo, D.I. (2006) 'The relationship between innovation and business performance - a comparative study between manufacturing and service firms', Knowledge and Process Management 13(3): 218-225.

Prashantham, S. and Berry, M.M. (2004) 'The small knowledge-intensive firm: a conceptual discussion of its characteristics and internationalisation', International Journal of Entrepreneurship and Innovation Management 4(2/3): 150-158.

Provan, K.G., Fish, A. and Sydow, J. (2007) 'Interorganisational network at the network level: a review of the empirical Literature on whole networks', Journal of Management 33(3): 479-516.

Punch, K.F. (2005) Introduction to Social Research: Quantitative and Qualitative Approaches, (2 ${ }^{\text {nd }}$ eds.), Sage: London. 
Ramasamy, B., Goh, K.W. and Yeung, C.H. (2006) 'Is guanxi a bridge to knowledge transfer?' Journal of Business Research 59(1): 130-139.

Rauch, J.E. (2001) 'Business and social networks in international trade', Journal of Economic Literature 39(4): 1177-1203.

Reardon, J.R., Erramilli, M.K. and Dsouza, D. (1996) 'International expansion of service firms: problems and strategies', Journal of Professional Service Marketing 15(1): 31-46.

Ren, B., Au., K.Y. and Birtch, T.A. (2009) 'China's business network structure during institutional transitions', Asia Pacific Journal of Management 26(2): 219-240.

Ring, P.S. and Van de Ven, A.H. (1992) 'Structuring cooperative relationships between organisations', Strategic Management Journal 13(7): 483-498.

Ring, P.S. and Van de Ven, A.H. (1994) 'Developmental processes of cooperative interorganisational relationships', Academy of Management Review 19(1): 90118.

Ritter, T. (2007) 'A framework for analysing relationship governance', Journal of Business \& Industrial Marketing 22(3): 196-201.

Robson, M.J. and Katsikeas, C.S. (2005) 'International strategic alliance relationships within the foreign investment decision process', International Marketing Review 22(4): 399-419.

Rowden, R.W. (2001) 'Research note: how a small business enters the international market', Thunderbird International Business Review 43(2): 257268.

Rowley, T. (1997) 'Moving beyond dyadic ties: a network theory of stakeholder influences', Academy of Management Review 22(4): 867-910.

Rundh, B. (2001) 'International market development: new patterns in SMEs international market development', Marketing Intelligence \& Planning 19(5): 319-329.

Rutashobya, L. and Jaensson, J. (2004) 'Small firms' internationalisation for development in Tanzania: exploring the network Phenomenon', International Journal of Social Economics 31(1/2):159. 
Ruyter, K., Moorman, L. and Lemmink, J. (2001) 'Commitment and trust in customer-supplier relationships in high technology markets', Industrial Marketing Management 30 (3): 271-286.

Schijns, J.M. and Schroder, G.J. (1996) 'Segment selection by relationship strength', Journal of Direct Marketing 10(3): 70-79.

Schmitt, N.W. and Klimoski, R.J. (1991) Research Methods in Human Resources Management, South-Western Publishing Co. Ltd: Cincinnati, Ohio.

Schurr, P.H. (2007) 'Buyer-seller relationship development episodes: theories and methods', Journal of Business \& Industrial Marketing 22(3): 161-170.

Schutjens, V. and Stam, E. (2003) 'The evolution and nature of young firm networks: a longitudinal perspective', Small Business Economics 21(2):115-134.

Shamdasani, P.N. and Balakrishnan, A.A. (2000) 'Determinants of relationship quality and loyalty in personalised services', Asia Pacific Journal of Management 17(3): 399-423.

Shaw, E. (2006) 'Small firm Networking', International Small Business Journal 24(1): 5-29.

Shipilov, A. (2006) 'Network strategies and performance of Canadian investment banks', Academy of Management Journal 49(3): 590-604.

Sikorski, D. and Menkhoff, T. (2000) 'Internationalisation of Asian business', Singapore Management Review 22(1): 1-17.

Song, X.M., Di Benedetto, C.A. and Zhao, Y.L. (1999) 'Pioneering advantages in manufacturing and service industries: empirical evidence from nine countries', Strategic Management Journal 20(9): 811

Stern, R.N. (1979) 'The development of an interorganisational control network: the case of intercollegiate athletics', Administrative Science Quarterly 24 (2): 242-267.

Styles, C., Patterson, P.G. and Ahmed, F. (2008) 'A relational model of export performance', Journal of International Business Studies 39(5): 880-900.

Su, C., Yang, Z., Zhuang, G., Zhou, N. and Dou, W. (2009) 'Interpersonal influence as an alternative channel communication behaviour in emerging 
markets: the case of China', Journal of International Business Studies 40(4): 668-689.

Svejenova, S. (2006) 'How much does trust really matter? Some reflections on the significance and implications of Madhok's trust-based approach', Journal of International Business Studies 37(1): 12-20.

Swedberg, R. (1990) 'Introduction', in R. Swedberg (eds.), Economics and Sociology: Redefining Their Boundaries: Conversations with Economics and Sociologists, Princeton University Press: New Jersey.

Sydow, J., van Well, B. and Windeler, A. (1997) 'Networked networks - financial services networks in the context of their industry', International Studies of Management \& Organisation 27(4): 47-75.

Tam, F.Y., Moon, K.L., Ng, S.F. and Hui, C.L. (2007) 'Production sourcing strategies and buyer-supplier relationships - a study of the differences between small and large enterprises in the Hong Kong clothing industry', Journal of Fashion Marketing and Management 11(2): 297-306.

Tang, F. and Xi, Y. (2006) 'Exploring dynamic multi-level linkages in interorganisational networks', Asia Pacific Journal of Management 23(2): 187-208.

Tangpong, C., Michalisin, M.D. and Melcher, A.J. (2008) 'Towards a typology of buyer-supplier relationships: a study of the computer industry', Decision Sciences 39(3): 571-593.

Thorelli, H.B. (1986) 'Networks: between markets and hierarchies', Strategic Management Journal 7(1): 37-51.

Tichy, N.M., Tushman, M.L. and Fomburn, C. (1979) 'Social network analysis for organisations', Academy of Management Review 4(4): 507-519.

Todeva, E. (2006) Business Networks: Strategy and Structure, Routledge: New York.

Trimarchi, M. and Tamaschke, R. (2004) 'Coordinations in business interactions between Hong Kong Chinese, Mainland Chinese, and Western Actors', International Business Review 13(3): 331-357.

Tsai, W. and Ghoshal, S. (1998) 'Social capital and value creation: the role of intrafirm social capital', Academy of Management Journal 41(4): 464-476. 
Tsai, W.P. (2000) 'Social capital, strategic relatedness and the formation of intraorganisational linkages', Strategic Management Journal 21(9): 925-939.

Tse, D.J., Lee, K. Vertinsky, I. and Wehrung, D.A. (1988) 'Does culture matter? A cross-cultural study of executives' choice, decisiveness, and risk adjustment in international marketing', Journal of International Marketing 52 (2): 81-95.

Turnbull, P., Ford, D. and Cunningham, M. (1996) 'Interaction, relationships and networks in business markets: an evolving perspective', Journal of Business \& Industrial Marketing 11(3/4): 44-62.

Turnbull, P. and Valla J. (1986) Strategies for International Industrial Marketing, Croom Helm: London

Tyler, K., Stanley, E. and Brady, A. (2006) 'Relationship development in a multinational utilities network', Journal of Service Marketing 20(5): 333-345.

Uzzi, B. (1996) 'The sources and consequences of embeddedness for the economic performance of organisations: the network effect', American Sociological Review 61(4): 674-698.

Uzzi, B. (1997) 'Social structure and competition in interfirm networks: the paradox of embeddedness', Administrative Science Quarterly 42(1): 35-67.

Uzzi, B. and Gillespie, J.J. (2002) 'Knowledge spillover in corporate financing networks: embeddedness and the firm's debt performance', Strategic Management Journal 23(7): 595-618.

Uzzi, B. and Lancaster, R. (2003) 'Relational embeddedness and learning: the case of bank loan managers and their clients', Management Science 49(4): 383399.

Vandaele, D., Rangarajan, D., Gemmel, P. and Lievens, A. (2007) 'How to govern business services exchanges: contractual and relational Issues', International Journal of Management Reviews 9(3): 237-258.

Van de Ven, A. (1976) 'On the nature, formation, and maintenance of relations among organisations', Academy of Management Review 1(4): 24-36.

Van de Ven, A. (1992) 'Suggestions for studying strategy process: a research note', Strategic Management Journal 13(2): 169-188. 
Van Wijk, R., Van den Bosch, R., and Volberda, H.W. (2003) 'Knowledge and networks', in M. Easterby-Smith and M.A. Lyles (eds.), The Blackwell Handbook of Organisational Learning and Knowledge Management, Blackwell Publishing: MA, USA.

Venhatraman, N. and Lee, C.H. (2004) 'Preferential linkage and network evolution: a conceptual model and empirical test in the U.S. video game sector', Academy of Management Journal 47(6): 876-892.

Walker, G., Kogut, B. and Shan, W. (2005) 'Social capital, structural holes and the formation of an industry network', Organisation Science 8(2): 109-125.

Warren, D.E., Dunfee, T.W. and Li, N. (2004) 'Social exchange in China: the double-edged sword of guanxi', Journal of Business Ethics 55(4): 355-372.

Welch, D., Welch, L., Wilkinson, I.F. and Young, L.C. (1996) 'Network analysis of a new export grouping scheme: the role of economic and non-economic relations', International Journal of Research in Marketing 13 (5): 463-477.

Welch, K. and Wilkinson, I. (2004) 'The political embeddedness of international business networks', International Marketing Review 21(2): 216-231.

Westlund, H. and Nilsson, E. (2005) 'Measuring enterprises' investments in social capital: a pilot study', Regional Studies 39(8): 1079-1094.

Whetten, D. A. (1989) 'What constitutes a theoretical contribution?' Academy of Management Review 14(4): 490-495.

Whitener, E.M., Brodt, S.E., Korsgaard, M.A. and Werner, J.M. (1998) 'Manager as initiators of trust: an exchange relationship framework for understanding managerial trustworthy behaviour', Academy of Management Review 23(3): 513-530.

Widen-Wulff, G. and Ginman, M. (2004) 'Explaining knowledge sharing in organisations through the dimensions of social capital', Journal of Information Science 30(5): 448-458.

Williamson, O.E. (1979) 'Transaction-cost economics: the governance of contractual relations', Journal of Law and Economics 22(2): 233-261.

Williamson, O.E. (1985) The Economic Institutions of Capitalism: Firms, Markets and Relational Contracting, Free Press: New York. 
Williamson, O.E. (1991) 'Comparative economic organisation: the analysis of discrete structural alternatives', Administrative Science Quarterly 36(2): 269296.

Williamson, O.E. (1998) 'Transaction cost economics: how it works; where it is headed', De Economist 146(1): 23-58.

Wilkinson, I.F. (2006) 'The evolution of an evolutionary perspective on B2B business', Journal of Business \& Industrial Marketing 21(7): 458-465.

Wong, P.L. and Ellis, P. (2002) 'Social ties and partner identification in SinoHong Kong international joint ventures', Journal of International Business Studies 33(2): 267-289.

Wong, A., Tjosvold, D. and Zhang, P. (2005) 'Developing relationships in strategic alliances: commitment to quality and cooperative interdependence', Industrial Marketing Management 34(7): 722-731.

Wu, W.P. (2004) 'Transaction cost, social capital and firms' synergy creation in Chinese business networks: an integrative approach', Asia Pacific Journal of Management 21(3): 325-343.

Wu, W.P. (2008) 'Dimensions of social capital and firm competitiveness improvement: the mediating role of information sharing', Journal of Management Studies 45(1): 122-146.

Wu, W.P. and Choi, W.L. (2004) 'Transaction cost, social capital and firms' synergy creation in Chinese business networks: an integrative approach', Asia Pacific Journal of Management 12(3): 325-343.

Wu, W.P. and Leung, A. (2005) 'Does a micro-macro link exist between managerial value of reciprocity, social capital and firm performance? The case of SMEs in China', Asian Pacific Journal of Management 22(4): 445-463.

Xin, K.R. and Pearce. J.L. (1996) 'Guanxi: connections as substitutes for formal institutional support', Academy of Management Journal 39(6): 1641-1658.

Yeung, Y. and Li, X. (2000) 'Transnational corporations and local embeddedness: company case studies from Shanghai, China', Professional Geographer 52(4): 624-635. 
Yeung, I.Y.M. and Tung, R.L. (1996) 'Achieving business success in Confucian societies: the importance of guanxi (connections)', Organisational Dynamics 25(2): 54-65.

Yin, R.K. (1994) Case Study Research: Design and Methods, (2 ${ }^{\text {nd }}$ eds.), Sage: CA.

Yin, R.K. (1981) 'The case study crisis: some answers', Administratively Science Quarterly 26(1): 58-65.

Yiu, D. W., Lau, C. and Bruton, G.D. (2007) 'International venturing by emerging economy firms: the effects of firm capabilities, home country networks, and corporate entrepreneurship', Journal of International Business Studies 38(4): 519-540.

Yli-Renko, H., Autio, E. and Sapienza, H.J. (2001) 'Social capital, knowledge acquisition, and knowledge exploitation in young technology-based firms', Strategic Management Journal 22(6/7): 587-613.

Yoon, S.J. and Choi, Y.G. (2002) 'Comparison of marketing performance between manufacturing and service sector firms in Korea', Journal of Asian Pacific Marketing 1(2): 63-87.

Young, C.S. (2005) 'Top management teams' social capital in Taiwan: the impact on firm value in an emerging economy', Journal of Intellectual Capital 6(2): 177-190.

Zaheer, A. and Bell, G.G. (2005) 'Benefiting from network position: firm capabilities, structural holes, and performance', Strategic Management Journal 26(9): 809-825.

Zerbini, F. and Castaldo, S. (2007) 'Stay in or get out the Janus? The maintenance of multiplex relationships between buyers and sellers', Industrial Marketing Management 36(7): 941-954.

Zhao, X., Yeung, A.C. and Lee, T.S. (2004) 'Quality management and organisation context in selected service industries of China', Journal of Operations Management 22(6): 575-587.

Zhou, K.Z. and Poppo, L. (2010) 'Exchange hazards, relational reliability and contracts in China: the contingent role of legal enforceability', Journal of International Business Studies 40(9): 861-881. 
Zhou, L., Wu, W. and Luo, X. (2007) 'Internationalisation and the performance of born-global SMEs: the mediating role of social networks', Journal of International Business Studies 38 (4): 673-690.

Zhou, Y, and Xin, T. (2003) 'An innovative region in China: interaction between multinational corporations and local firms in a high-tech cluster in Beijing', Economic Geography 79(2): 129-152.

Zhou, X., Zhao, W., Li, Q. and Cai, H. (2003) 'Embeddedness and contractual relationships in China's transitional economy', American Sociological Review 68 (1): $75-102$. 


\title{
Appendix 1
}

\author{
VICTORIA UNIVERSITY OF WELLINGTON \\ Te Whare Wananga o te Upoko o te Ika a Maui
}

\section{if \\ INTRODUCTION ON THE RESEARCH PROJECT \\ Business Relationship Development of Foreign Firms Operating in China}

\begin{abstract}
The researcher:
Yang (Cruise) $\mathrm{Yu}$ is a doctoral student at Victoria University of Wellington in New Zealand. $\mathrm{He}$ is doing a research project on foreign multinational corporations (MNCs) operating in China. He plans to conduct the research from February 2008 to January 2009.

Telephone: +64 (4) 4636920; Cell phone: +64 21 490498; Email: Cruise.Yu@ vuw.ac.nz
\end{abstract}

\author{
Supervisors: \\ Associate Professor Val Lindsay, School of Marketing and International Business \\ Victoria University of Wellington, P.O. Box 600. Wellington, New Zealand \\ Tel.+64 (4) 4636915; Email: Val.Lindsay@vuw.ac.nz \\ Dr. Elizabeth Rose, School of Marketing and International Business \\ Victoria University of Wellington, P.O. Box 600. Wellington, New Zealand \\ Email: Elizabeth.Rose@ vuw.ac.nz
}

\section{Overview}

This research is conducted as part of a doctoral thesis at Victoria University of Wellington. The research looks at foreign firms in China, and investigates how the firms develop their business relationships in the local market. To gain insight into firms' approaches to building and managing relationships, this research pays attention to both the economic and social aspects of business relationships.

Your company is one that the researcher invites to participate in this study. This will include talking with the CEO or a senior manager, regarding the development process of a number of company's business relationships in China. The interview is expected to take up to 1 hour. The raw data will be available only to the researcher and his supervisors. The researcher will write up a report as the thesis. The data collected in this research will be also for other academic use, such as conference presentations and journal submissions.

\section{How will you be affected?}

- The researcher is looking for a range of views and experiences from the CEO or manager who agrees to participate.

- Information provided in the interview will be treated in confidence, and will not be attributed to you in the research report. Information from companies in the study will be aggregated and no interviewed company will be identified.

- Everyone involved will sign an agreement outlining the way the information will be handled.

- The researcher will be asking you about the network relationship development of your company in the Chinese market since your firm's initial entry into China, and some related practical issues.

- The researcher will present the findings and feedback in report form back to participants in the organisation if requested. 


\title{
Appendix 2
}

\author{
VICTORIA UNIVERSITY OF WELLINGTON \\ Te Whare Wananga o te Upoko o te Ika a Maui
}

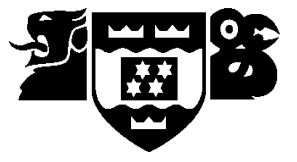

\section{CONSENT FORM}

- This is a consent form between you and the researcher, Yang Yu.

- Your interview will be confidential: that is, your name will not be used, and your company will not be identified.

- The researcher will take notes during the interview, and will ask your permission for the interview to be taped. You will be able to see the notes or any transcripts, if you wish.

- Only the researcher and supervisors will have access to the notes and tapes (if used).

- The research results may be published in the academic literature, and the final report, in form of a thesis, will be deposited in the Victoria University of Wellington library.

- The information gained will be used only for the purpose stated and will not be used for any commercial purposes or passed on in non-aggregated form to any competitor in the market.

- You may request further information about the project by contacting the researcher.

- You may withdraw at anytime during the interview.

\section{Participant's statement}

I am satisfied with the information provided on the project. I realise I can decide not to be involved at any time during the interview without having to say why.

I have read and understood the information sheet and have had opportunity to ask questions.

I would like to be informed of the research results by being sent a copy of a report.

\section{Participant:}

Name:

Signature:

Date:

\section{The researcher:}

Yang Yu is a doctoral student at Victoria University of Wellington in New Zealand. He is doing a research project on foreign firms operating in China. He plans to be doing the research from February 2008 to January 2009.

Telephone: +64 (4) 4636920

Cell phone: +6421490498

Email: Cruise.Yu@vuw.ac.nz

\section{Supervisors:}

Associate Professor Val Lindsay, School of Marketing and International Business

Victoria University of Wellington, P.O. Box 600. Wellington, New Zealand

Tel. +64 (4) 4636915; Email: Val.Lindsay@ vuw.ac.nz

Dr. Elizabeth Rose, School of Marketing and International Business

Victoria University of Wellington, P.O. Box 600. Wellington, New Zealand

Email: Elizabeth.Rose@vuw.ac.nz 


\section{Appendix 3}

\section{Background of the Interviewed Firms in Phase 1}

In this appendix, contextual information about the eight interviewed firms is provided.

WATERHEAT was the only manufacturing firm in the sample. Its parent company, which has been operating in the US market for nearly a century, first entered in China in 1998 by setting up a representative office. In 2000, WATERHEAT was established as a wholly-owned-subsidiary, after the parent's initial attempt to build a joint venture with a local party failed. The firm began operations in China with 300 employees, and has been experiencing significant growth in the past. By the time of the interview, WATERHEAT has already become the market leader in China's water heater industry, with 3,000 employees and approximately 20 per cent market share. Apart from some key components imported from the US, the majority of WATERHEAT's materials and components were sourced from local Chinese suppliers. All the finished products were sold in China through two major domestic chain-store distributors and many regional sales agents. As the Director considered, this well-established distribution channel was an important source of the firm's competitive advantages in the market.

DATABASE offered business services including credit reporting, debt collection, and marketing services based on its commercial database. It was originally established as a wholly-owned subsidiary in 2005 by its US parent, two years after operating in China as a representative office. In 2007, this subsidiary merged with a local competitor, and became a joint-venture. DATABASE was responsible for its US parent's business operations in the entire Chinese market. Its clients were mostly large foreign and local companies. Given the fast growth of China's economy, DATABASE has been developing rapidly, and, as the Marketing Director described, was still at an exploratory stage.

VIDEOCON developed online communication programmes that could be used for video conferencing and instant data exchange. It US parent initially entered China in 2001, setting up a research and development (R\&D) centre only. From 2005, due to the increasing local demand, the centre was expanded to become a fully functioning whollyowned-subsidiary with production and sales force - this is VIDEOCON - which also became the Asia-Pacific regional headquarters of the MNC a year later. 
HRCONSULT was specialised in executive management consulting, providing human resource related services such as training and recruitment. It was founded in Shanghai in 2003, as the expansion of a Belgian family business. Although the firm was a member of an international industry association, its operations in China were highly independent. Its customers mostly were foreign MNCs in China. Much of the firm's early business was developed from the Belgian owner's personal social networks, which continued playing an active role by the time of the interview.

HOTEL was a subsidiary of a well-known hotel management group based in the US. The parent company has been very successful globally and operates hundreds of hotels around the world. The main responsibility of HOTEL was to manage the existing hotels in China and seek investors for building new hotels. Due to the nature of its business, the firm dealt frequently with many local suppliers including interior designers and construction companies.

EVENT provided business services on event management and corporation image consultation. It was established in China in 2006, by its German parent that operates in many European and Asian countries. At the time of the research, EVENT was at the early exploratory stage, and faced challenges in a number of aspects. For instance, according to the Director, the firm experienced difficulty in nurturing similar business values and visions with its local clients. This was however, essential for the firm's market development.

ANIMATION was specialised in computer animation services. Its clients were mostly website and online game operators. The firm was established in 2006 as a wholly-ownedsubsidiary, only two years after its US parent was born. This was because the parent company was funded by venture capital, and the investors insisted on China as a 'mustcompete' market. ANIMATION has however, encountered great challenges since its early entry into China. In 2007, two of its three major projects with other local companies failed. One of the main causes, according to the Marketing Director, was that the top management team, which consisted of all American expatriates, lacked adequate local knowledge about the Chinese market. 
SOFTWARE was originally Hong Kong-based, and then strategically shifted its market focus to Shanghai in 2005, because of the limited market capacity of Hong Kong compared to the mainland China. The firm's business operations in China, however, have not been very successful. In 2007, SOFTWARE reformed its corporate strategy and became dedicated to a new niche market - developing computer programmes for managing daily administration and documentation. This significant change also led to a dramatic downsize of the firm, from previously 30 employees to 12 . By the time of the interview, SOFTWARE was completing a major project with a well-known Japanese multinational company. This project, as the Director described, was expected to be an important reference case for the firm's future market development. 
Appendix 4

\section{VICTORIA UNIVERSITY OF WELLINGTON \\ Te Whare Wananga o te Upoko o te Ika a Maui}

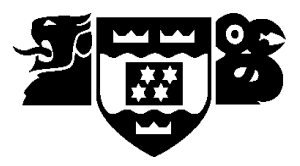

Interview Guideline

\section{Objectives:}

1. Explore foreign firms' business relationship in China with respect to the economic and social aspects

\section{Potential interviewees:}

CEOs and senior managers of foreign firms in China

Theme of interview:

1. Characteristics of relationships

2. Firms' managerial approaches to developing relationships

\section{Section 1 General information about the interviewee and the firm (5-10 min)}

- Interviewee's position

- Background of the firm and its foreign and Chinese parents

- Firm's growth, size, major products/services

- Challenges / opportunities for the firm

- Etc.

Section 2 Overall perceptions about business relationships in China (15-20 min)

- How does the firm view business relationships in China?

- What are the 'good' / 'bad' relationships from the firm's point of view?

- What are the common problems associated with developing relationships in China?

\section{Section 3 Address specific relationships with local business actors (30-40 min)}

- Who are the firm's main buyer(s), supplier(s) and other business partners in China? How important are they?

- When and how the relationships with these actors were initially formed?

- How have these relationships been developed over time? In terms of:

- Economic exchanges

- Socialising activities

- Information sharing

- Mutual trust and commitment

- Etc.

- What are the prospects for these relationships?

- Were there any critical events during the development process of these relationships? If yes, please describe.

- How does the firm usually manage conflicts in these relationships? 


\section{Appendix 5: Factor analysis results for the economic constructs used in the study}

\begin{tabular}{|c|c|c|c|c|c|c|c|c|c|}
\hline \multirow{2}{*}{\multicolumn{2}{|c|}{ Constructs }} & \multicolumn{4}{|c|}{ Time 1} & \multicolumn{4}{|c|}{ Time 2} \\
\hline & & $\begin{array}{c}\text { Factor } \\
\text { loadings }\end{array}$ & KMO & $\begin{array}{l}\text { Variance } \\
\text { explained }\end{array}$ & $\begin{array}{c}\text { Cronbach } \\
\text { alpha }\end{array}$ & $\begin{array}{l}\text { Factor } \\
\text { loadings }\end{array}$ & KMO & $\begin{array}{l}\text { Variance } \\
\text { explained }\end{array}$ & $\begin{array}{c}\text { Cronbach } \\
\text { alpha }\end{array}$ \\
\hline \multicolumn{2}{|c|}{ Tangible economic interaction } & & 0.747 & 63.58 & 0.80 & & 0.676 & 58.96 & 0.75 \\
\hline Item 1 & $\begin{array}{l}\text { We have large volume of transactions with this } \\
\text { customer }\end{array}$ & 0.88 & & & & 0.86 & & & \\
\hline Item 2 & We have frequent transactions with this customer & 0.87 & & & & 0.84 & & & \\
\hline Item 3 & We work on multiple projects with this customer & 0.73 & & & & 0.69 & & & \\
\hline \multicolumn{2}{|c|}{ Intangible economic interaction } & & 0.612 & 60.46 & 0.67 & & 0.632 & 59.45 & 0.65 \\
\hline Item 1 & $\begin{array}{l}\text { We share resources related to production, } \\
\text { distribution and personnel with this customer. }\end{array}$ & 0.68 & & & & 0.71 & & & \\
\hline Item 2 & $\begin{array}{l}\text { We transfer our product-related technology to this } \\
\text { customer. }\end{array}$ & 0.79 & & & & 0.78 & & & \\
\hline Item 3 & $\begin{array}{l}\text { We transfer our management know-how to this } \\
\text { customer. }\end{array}$ & 0.85 & & & & 0.82 & & & \\
\hline Item 1 & $\begin{array}{l}\text { This customer and our company have frequent } \\
\text { business meetings and visits. }\end{array}$ & 0.81 & & & & 0.67 & & & \\
\hline Item 2 & $\begin{array}{l}\text { We understand this customer's demands and } \\
\text { expectations of us, in terms of price. }\end{array}$ & 0.84 & & & & 0.79 & & & \\
\hline Item 3 & $\begin{array}{l}\text { We understand this customer's demands and } \\
\text { expectations of us, in terms of quality. }\end{array}$ & 0.86 & & & & 0.80 & & & \\
\hline Item 4 & $\begin{array}{l}\text { We understand this customer's demands and } \\
\text { expectations of us, in terms of due dates for } \\
\text { delivery. }\end{array}$ & 0.82 & & & & 0.81 & & & \\
\hline Item 5 & $\begin{array}{l}\text { We inform this customer about new developments } \\
\text { regarding our joint project(s). }\end{array}$ & 0.68 & & & & 0.75 & & & \\
\hline Item 6 & We inform this customer about business-related & 0.73 & & & & 0.73 & & & \\
\hline
\end{tabular}




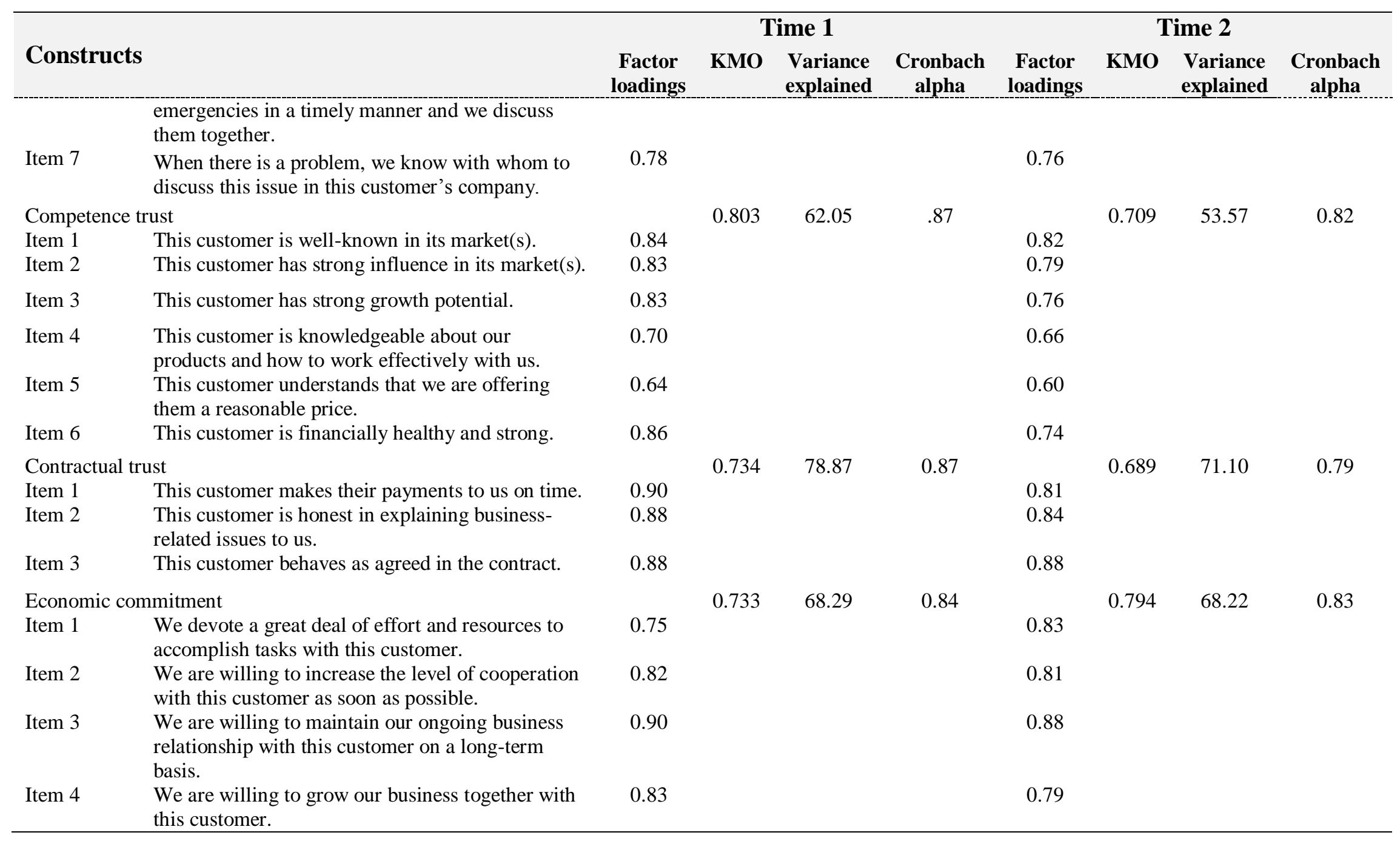




\section{Appendix 6: Factor analysis results for the social constructs used in the study}

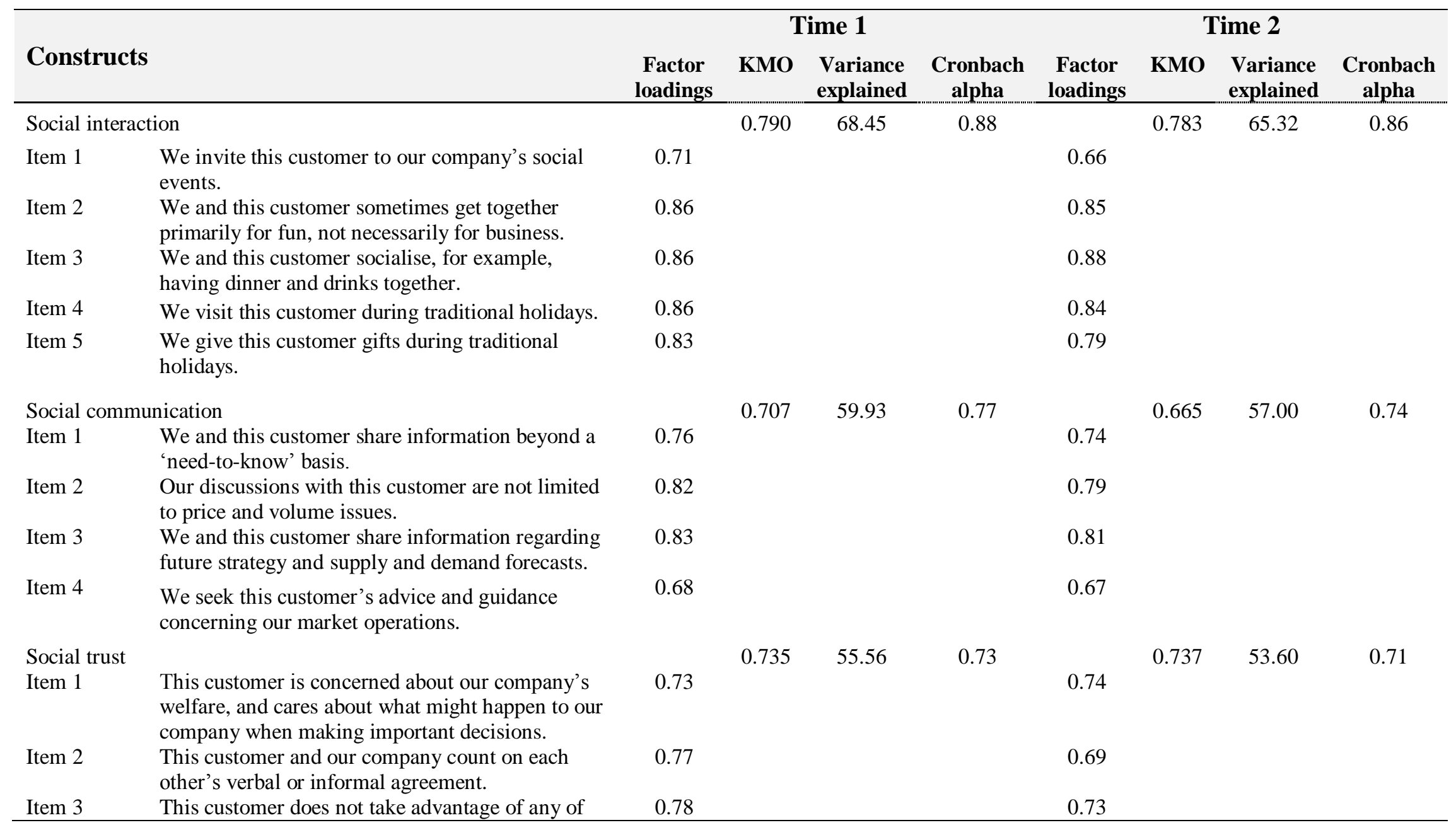




\begin{tabular}{|c|c|c|c|c|c|c|c|c|c|}
\hline \multirow{2}{*}{ Constructs } & & \multicolumn{4}{|c|}{ Time 1} & \multicolumn{4}{|c|}{ Time 2} \\
\hline & & $\begin{array}{c}\text { Factor } \\
\text { loadings }\end{array}$ & KMO & $\begin{array}{l}\text { Variance } \\
\text { explained }\end{array}$ & $\begin{array}{l}\text { Cronbach } \\
\text { alpha }\end{array}$ & $\begin{array}{c}\text { Factor } \\
\text { loadings }\end{array}$ & KMO & $\begin{array}{l}\text { Variance } \\
\text { explained }\end{array}$ & $\begin{array}{c}\text { Cronbach } \\
\text { alpha }\end{array}$ \\
\hline \multirow[b]{2}{*}{ Item 4} & $\begin{array}{l}\text { our weaknesses in business negotiations, for their } \\
\text { own gain. }\end{array}$ & & & & & \multirow[b]{2}{*}{0.77} & & & \\
\hline & $\begin{array}{l}\text { This customer will not replace our company with a } \\
\text { competitor, in order to achieve small benefits. }\end{array}$ & 0.71 & & & & & & & \\
\hline \multicolumn{2}{|c|}{ Social commitment } & & 0.666 & 61.59 & 0.79 & & 0.694 & 54.91 & 0.70 \\
\hline Item 1 & $\begin{array}{l}\text { If this customer makes mistakes, we are willing to } \\
\text { forgive them and then continue the relationship. }\end{array}$ & 0.80 & & & & 0.80 & & & \\
\hline Item 2 & $\begin{array}{l}\text { We are willing to make sacrifices for this } \\
\text { customer, to keep the relationship intact. }\end{array}$ & 0.85 & & & & 0.82 & & & \\
\hline Item 3 & $\begin{array}{l}\text { We are willing to modify terms for this customer, } \\
\text { in response to changes in the market. }\end{array}$ & 0.82 & & & & 0.76 & & & \\
\hline Item 4 & $\begin{array}{l}\text { If the relationship with this customer has to be } \\
\text { terminated, we tend to maintain a social bond with } \\
\text { them. }\end{array}$ & 0.67 & & & & 0.56 & & & \\
\hline \multicolumn{2}{|c|}{ Norms and values } & & 0.765 & 57.78 & 0.85 & & 0.792 & 55.78 & 0.83 \\
\hline Item 1 & $\begin{array}{l}\text { We are willing to 'sink or swim' together with this } \\
\text { customer. }\end{array}$ & 0.78 & & & & 0.69 & & & \\
\hline Item 2 & We consider this customer to be 'one of us'. & 0.77 & & & & 0.72 & & & \\
\hline Item 3 & $\begin{array}{l}\text { We and this customer have similar business } \\
\text { philosophies. }\end{array}$ & 0.79 & & & & 0.80 & & & \\
\hline Item 4 & $\begin{array}{l}\text { We and this customer have similar views of the } \\
\text { Chinese market. }\end{array}$ & 0.85 & & & & 0.86 & & & \\
\hline Item 5 & $\begin{array}{l}\text { We and this customer have compatible economic } \\
\text { goals. }\end{array}$ & 0.71 & & & & 0.75 & & & \\
\hline Item 6 & $\begin{array}{l}\text { We and this customer have similar approaches to } \\
\text { dealing with many business issues. }\end{array}$ & 0.64 & & & & 0.63 & & & \\
\hline
\end{tabular}




\title{
Appendix 7: Research Information Sheet
}

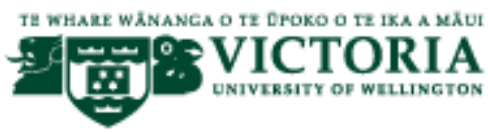

\author{
PO Box 600 \\ Wellington, New Zealand \\ Date: ---- \\ Dear -----------
}

My name is Yang Yu, and I am currently pursuing a PhD in International Business at Victoria University of Wellington, New Zealand. I am writing to ask for your assistance in helping me complete my doctoral studies by responding to the enclosed survey.

Firms are not operating in a vacuum, but interacting with many other market actors including such as suppliers, buyers, strategic alliances, etc. to achieve business goals. The cooperation between firms and their business partners has become not only a concern of practitioners, but a critical issue for academic researchers. My study focuses on foreign firms operating in China in particular, given the significance of foreign direct investment (FDI) as well as multinational corporations (MNCs) in China's economy. Specifically, it attempts to find out how firms cooperate with customers, by emphasising on two primary aspects of business relationships: i.e. economic linkage and social attachment.

As suggested in a number of preliminary interviews conducted in Shanghai recently, insights from managers knowledgeable about companies' operations are particularly valuable. The enclosed survey in this letter will be consulting your perceptions on how your company forms relationships with new customers and manages them afterwards in the local Chinese market. To obtain sufficient data, I am expecting to gain support from about 200 companies. Considering the difficulty with this respect, your response, therefore, will be extremely important for me to accomplish this challenging task. This survey is a vital part of my doctoral study. I would be very grateful if you would assist me by completing the questionnaire and return it in the enclosed, selfaddressed, postage-paid envelope, by $25^{\text {th }}$ December, 2008.

The survey should take no more than 30 minutes to complete, and neither proprietary nor personal information has been requested in this questionnaire. All responses that you provide will be held in strictest anonymity, and under no circumstance will a respondent or the respondent's company be identified as having provided a particular response. For your information, following the established procedure for research involving human subjects at Victoria University of Wellington, this study has been assessed and approved by the Faculty of Commerce and Administration's Human Ethics Committee. Please respond to all the survey items as objectively as you can. There is no correct or incorrect response to any of the items. Also, please feel free to make any additional explanatory or qualifying comments regarding any of the questions, if you feel that such comments will help to clarify your response. Last but not least, the data collected from this questionnaire will be kept for 3 years and then destroyed upon completion of this study. If you have any questions or concerns, please feel free to contact me (see the business card attached) or my supervisors Associate Professor Val Lindsay (Val.Lindsay@vuw.ac.nz), and Dr. Elizabeth Rose (Elizabeth.Rose@vuw.ac.nz).

Sincerely

Yang Yu

PhD candidate http://www.victoria.ac.nz/smib/staff/cruise-yu/index.aspx

School of Marketing and International Business 


\section{Appendix 8: Survey Questionnaire}

\section{RELATIONSHIP DEVELOPMENT OF FOREIGN FIRMS OPERATING IN CHINA}

\section{Important Information for Participants - Please Read!}

I. This questionnaire contains three sections. Section 1 asks for some basic information about you, and Section 2 asks for some information about your company. Section 3 asks you to consider one important local customer - with whom your company deals with directly at the present time - and then explore your company's relationship with this customer.

II. In this questionnaire, 'China' refers to mainland China, and 'your company' refers to a company that is established in mainland China and which you are working with at the present time.

III. Defining 'Customers': For this questionnaire, 'customers' are broadly defined to be parties that directly purchase, utilise, or distribute your company's products or services. These might be sales agents, distributors, or end-users. In Section 3 of the questionnaire (Question 17, page 3), you will be asked to select one of your company's important customers in the Chinese market, and then respond to the following questions with regard to this particular customer. The selected customer needs to be a local firm.

TV. Answering the questionnaire: Please tick the approrpirate box(es) to respond to questions, and feel free to write other information, as you feel it is appropriate. If you are not sure of an answer, please check 'D/K' (Don't know); if a question does not apply to your company, please check 'N/A' (Not applicable).

V. Feedback Report: We will be very happy to send you a report that will include a summary of the results of this study, based on data collected from all of the companies responding to this questionnaire. Please express your interest here:

$$
\text { Yes, I would like to have a report. } \quad \square \text { No, I do not need a report. }
$$

\section{Section One About You}

The following questions are about you. Please take the time to respond to them, as this will help us to understand more about the participants in this study.

1. Your gender: $\square$ Male $\square$ Female

2. Are you a Chinese national (of mainland China)?

$$
\square \text { Yes (Please go to Question 5.) } \quad \square \text { No }
$$

3. If you are not a mainland Chinese national, please specify your nationality:

4. How long have you been working in China? Years

5. How long have you been working in this China-based company? Years

6. What is your position in this China-based company? (Please check all that apply.)

\section{CEO / General manager}

Chief representative in China

Marketing manager / director $\square$ Production manager / director

$\square$ Other (please specify): 


\section{Section Two About Your Company}

In this section, 'your company' refers to the company, which is established and based in mainland China, and with which you are working at the present time.

7. In what year was your company officially established in China? Please write the year here:

8. In which region is your company registered in China? (Please check one only.)
$\square$ Beijing
$\square$ Shanghai
$\square$ Guangdong
Other (please specify):

9. In what industry does your company operate in China? (Please check all that apply.)
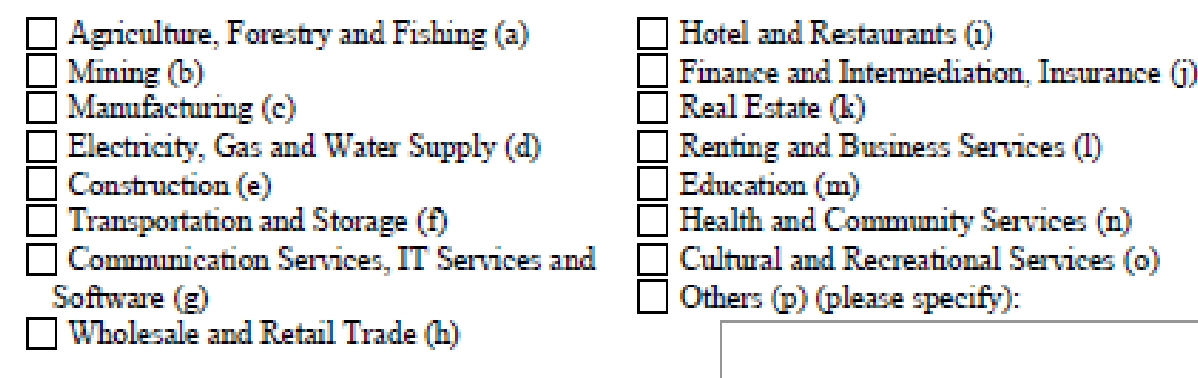

If you checked multiple industries in the above list, please indicate the letter associated with your company's primary industry:

10. How many full-time employees does your company have in China at the present time? (Please check one only.) Please count two part-time employees as one full-time-equivalent employee.
1-19
$20-49$
$\square$ 50-99 $\square$ 100-199
200-399
$400-599$
600-999 $\square \geq 1,000$

11. Approximately what was your company's sales volume in fiscal year 2007, in million RMB? (Please check one only.)
$\square<1$
$1-5$
$\square 6-9$
$\square$ 10-19
20-49
50-99
$\square \geq 100$ million

12. What is your company's annual sales growth rate in the Chinese market, since its establishment? (Please check one only.)
$0-5 \%$
6-9\%
$10-19 \%$
$20-39 \%$
$40-59 \%$
60-99\%
$\square \geq 100 \% \square \mathrm{D} / \mathrm{K}$

13. What is the present ownership of your company? (Please check one only.)
$\square$ Wholly-owned subsidiary of a foreign company
Foreign representative office
$\square$ Equity joint venture (Please specify the ratio of imestment from the foreign partner):

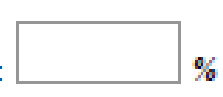
$\square$ Other (please specify):

14. Where is the headquarters of your company's foreign parent / partner located? (Please check one only.)
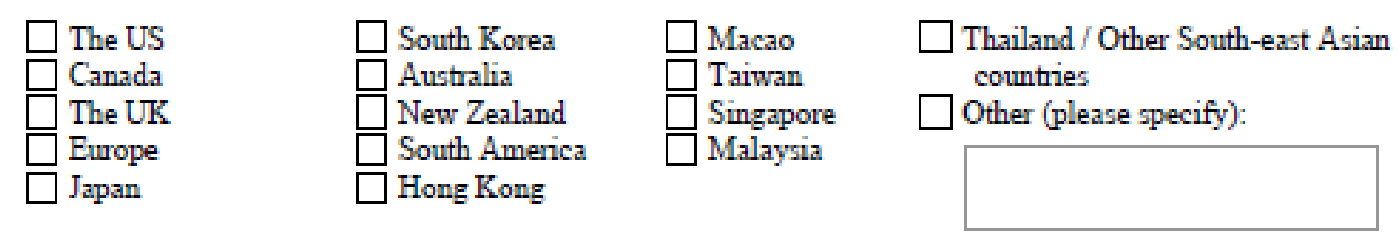

15. Not counting your company, how many other wholly-owned subsidianies and joint ventures does this foreign parent / partner company currently have in China? (Please check one only.)
$\square 0$
$\square 1 \square 2$
$\square 3$
$\square 4 \quad \square 5$
$\square 6$
$\square 7 \quad \square 8$
$\square 9 \quad \square 10$
$\square 10 \quad \square>10$
$\square / \mathrm{K}$ 
16. Please indicate the extent to which you agree or disagree with the following statements. (Please check one box for each statement.)

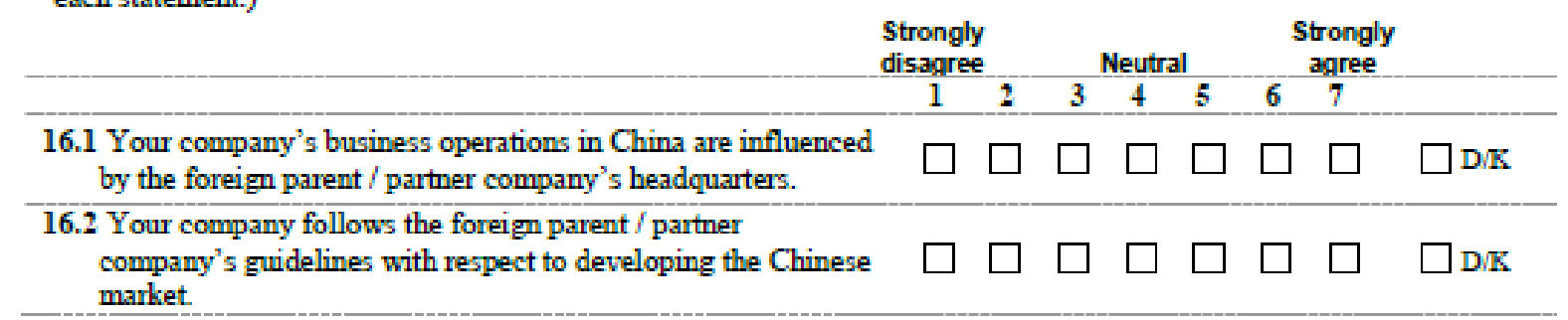

\section{Section 3 Relationship with a Customer}

As noted in the instructions, for the purpose of this questionnaire, 'CUSTOMERS' are parties who directly purchase, utilise, or distribute your company's products/services (including sales agents, distributors, or endusers).

In order to respond to the questions that follow, please think of ONE IMPORTANT LOCAL

CUSTOMER - IN CHINA - with whom your company is CURRENTLY dealing. Please also make sure that you are familiar with the way in which this customer's relationship with your company has developed. from the very start of the relationship. Then, please answer all the questions in this section with respect to ONLY THIS PARTICULAR CUSTOMER.

17. How would you characterise this customer, relative to your company? (Please check all that apply.)

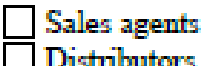

Distributors

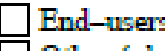

Other (please specify)

18. For how many years has your company been working with this customer in China? (Please check one only.)
$\square 1$
$\square 2$
$\square 3$
$\square 4 \square 5$
D 6
$\square 7$
$\square 8$
$\square 9$
$\square 10 \square>10$ Years

19. Please indicate the extent to which you agree or disagree with each of the following statements regarding your company's relationship with this customer. (Please check one box for each statement)

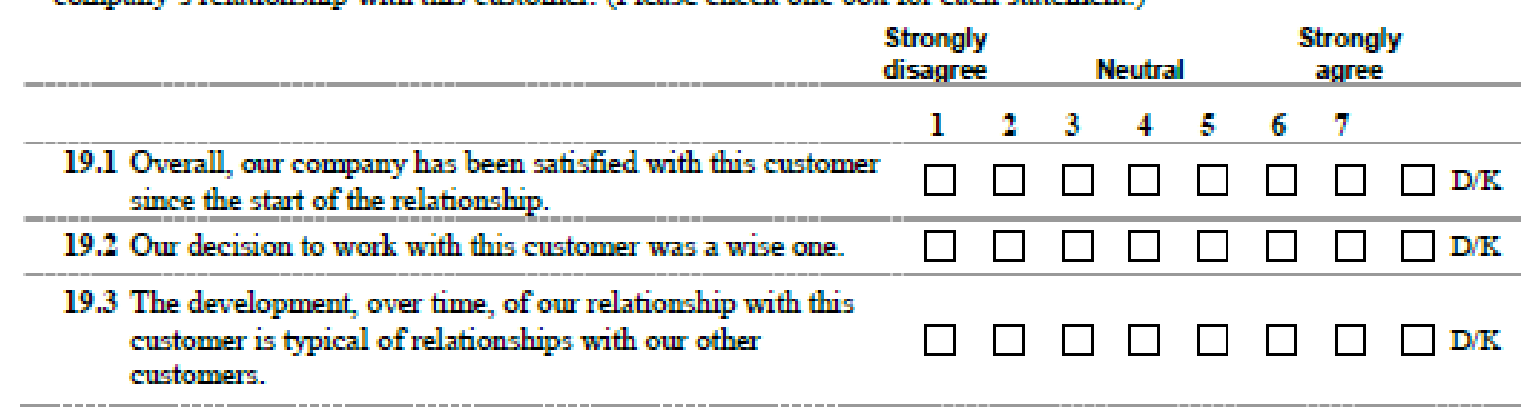

The next few pages contain statements that relate to relationships between companies and their customers. We are very interested in the extent to which you agree or disagree with each statement, regarding the particular customer you have in mind. Please, first recall the very early stage of this relationship when it was formed (i.e. when your company and this customer had just started doing business together in China, e.g., carrying out the first contract, or during the first few months of the relationship); second, consider this relationship at present. Then, provide your view on each statement for BOTH time periods, by ticking one box for the very early stage (the middle column), and one box for the present (the right column). If you are not sure of an answer, please check ' $D / K$ ' (Don't know); if a question does not apply to your company, please check 'N/A' (Not applicable). 


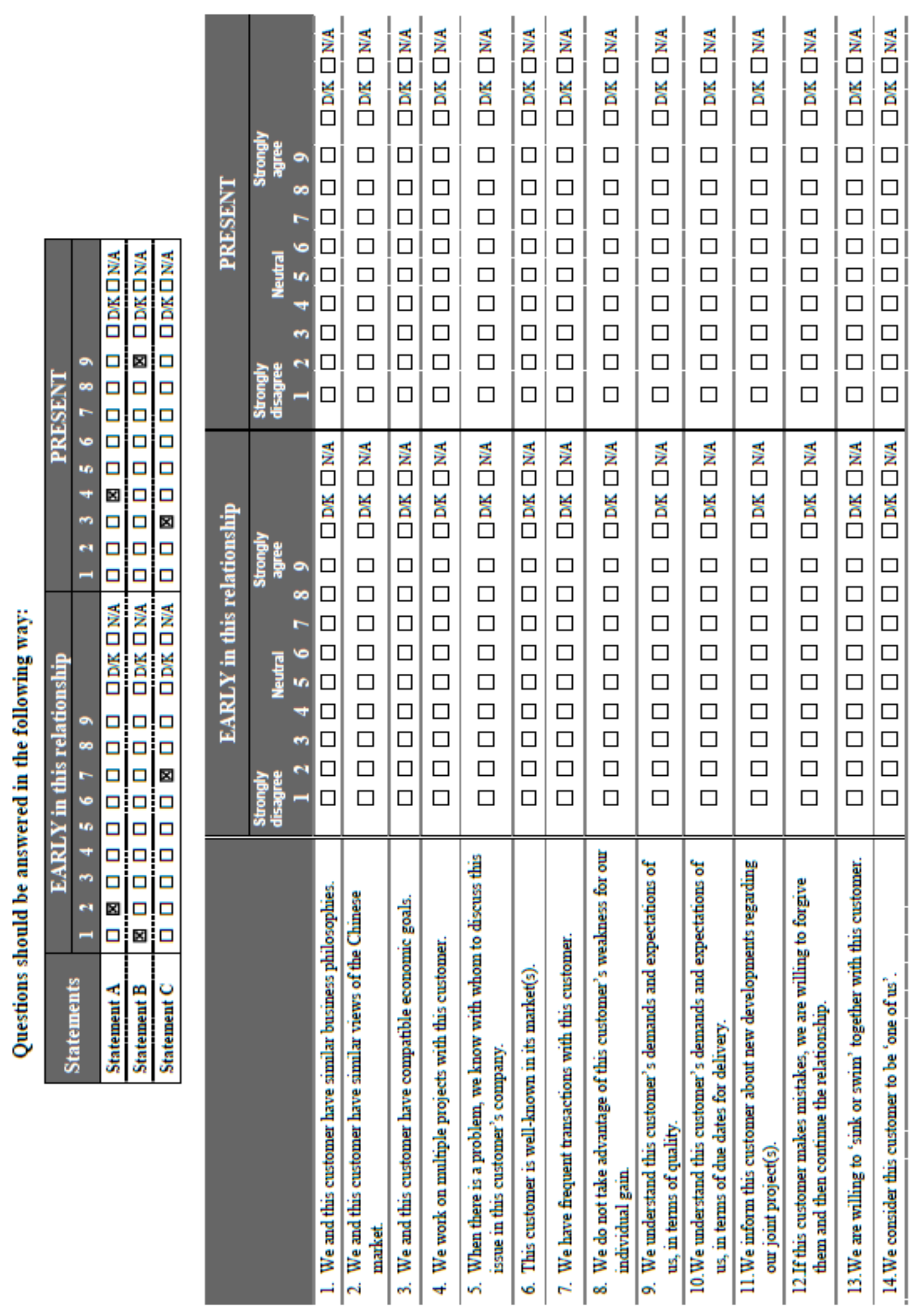




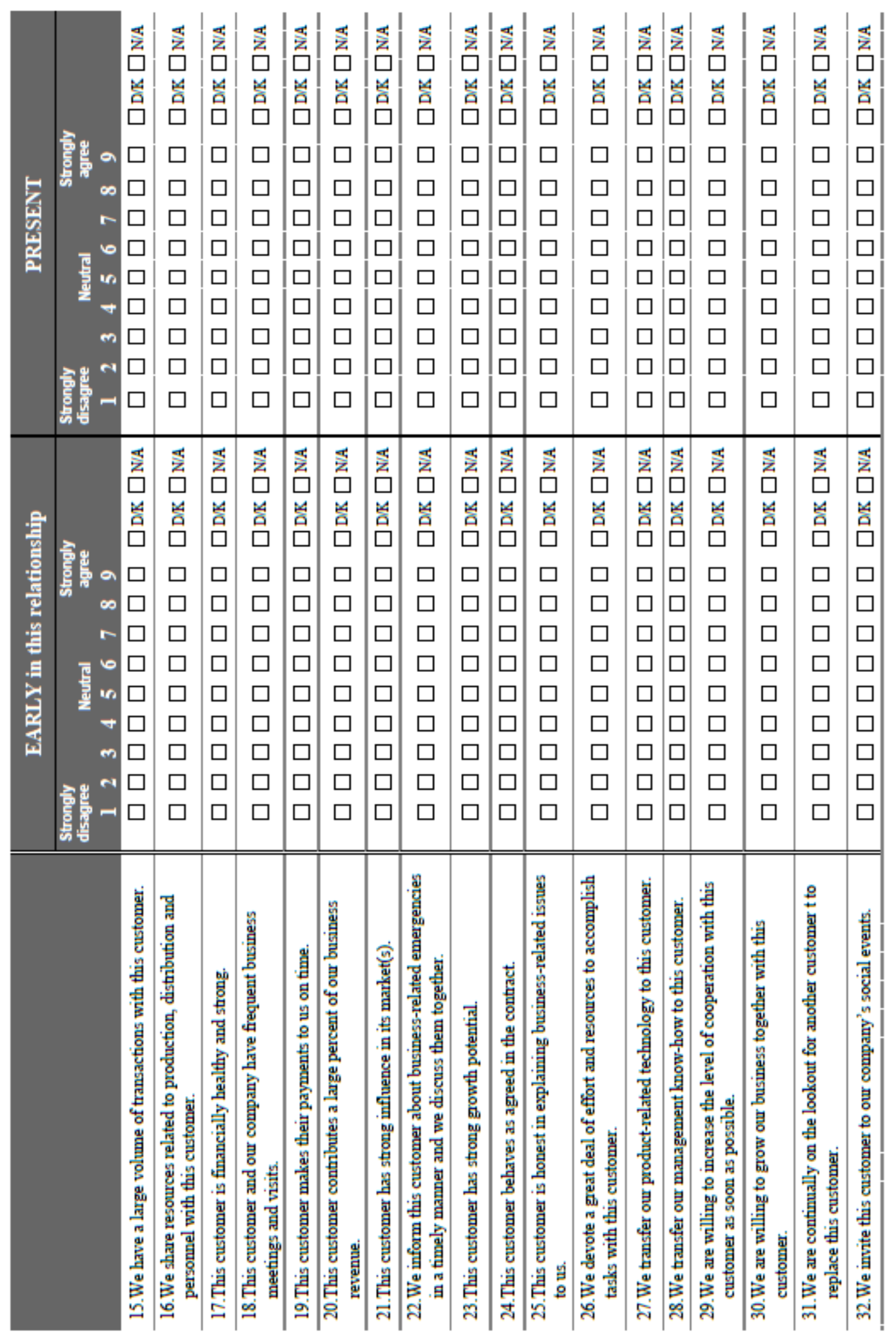




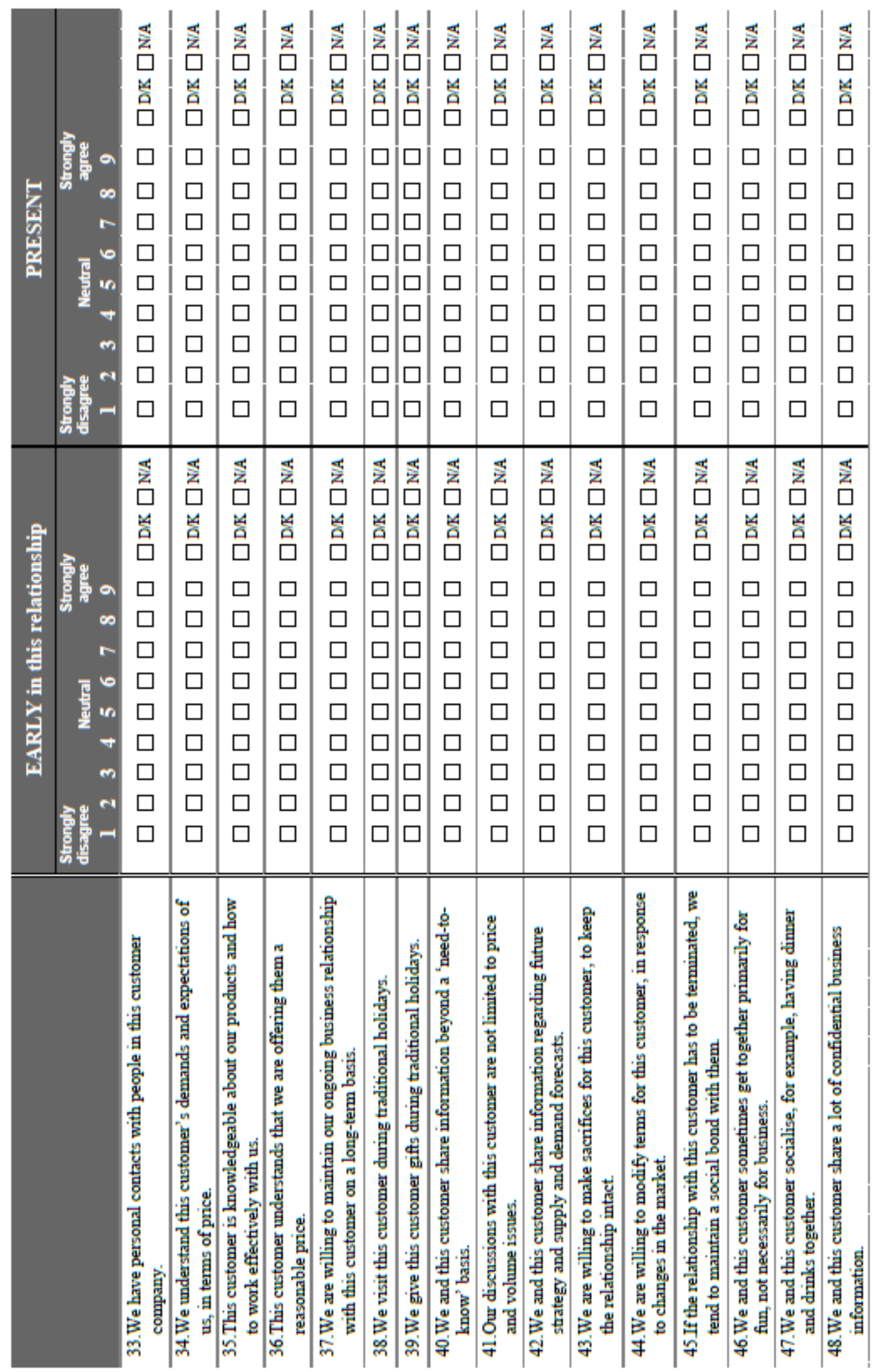




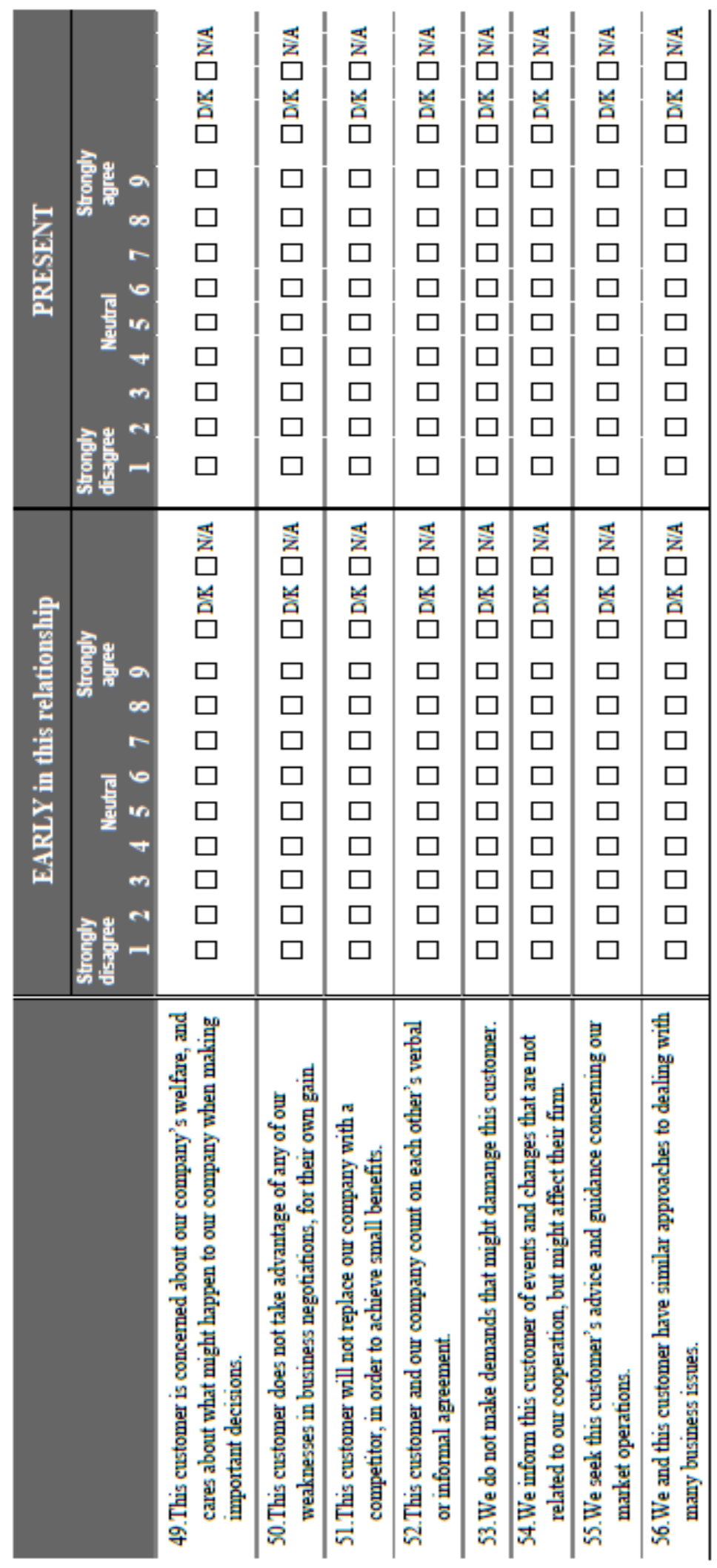



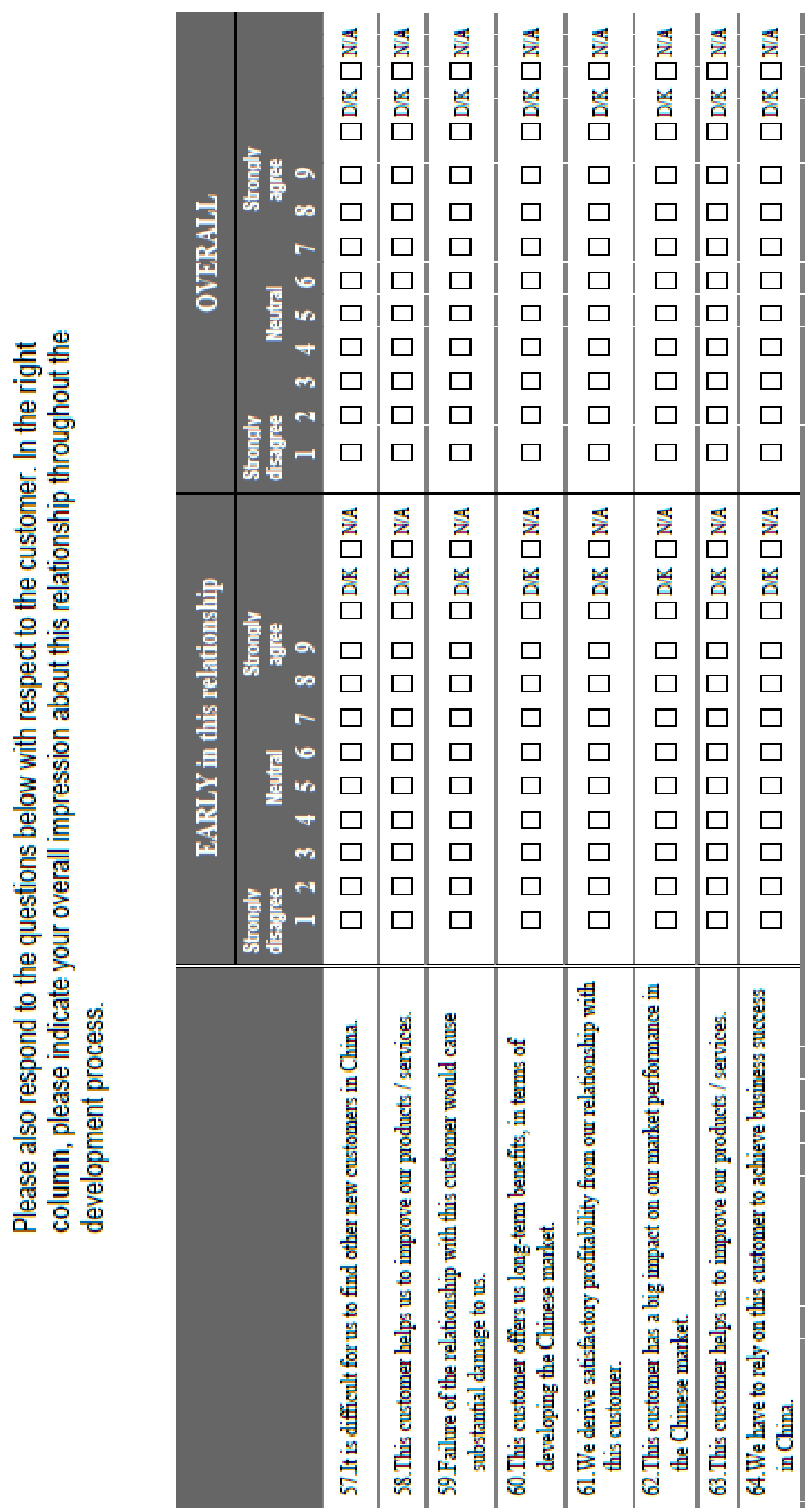
Appendix 9 Summary statistics and correlation matrix

\begin{tabular}{|c|c|c|c|c|c|c|c|c|c|c|c|c|c|c|c|c|c|c|}
\hline Variables & Mean & d. Dev. & 1 & 2 & 3 & 4 & 5 & 6 & 7 & 8 & 9 & 10 & 11 & 12 & 13 & 14 & 15 & 16 \\
\hline 1 Nationality & 0.57 & 0.50 & 1 & & & & & & & & & & & & & & & \\
\hline 2 Size 1 & 1.84 & 0.80 & $0.201 *$ & 1 & & & & & & & & & & & & & & \\
\hline 3 Size 2 & 0.49 & 0.50 & $0.214 *$ & $0.822 * *$ & 1 & & & & & & & & & & & & & \\
\hline 4 Industry & 0.56 & 0.50 & 0.130 & 0.038 & -0.060 & 1 & & & & & & & & & & & & \\
\hline 5 Ownership & 0.22 & 0.42 & -0.053 & 0.072 & 0.087 & -0.143 & 1 & & & & & & & & & & & \\
\hline 6 HQs' influence & 4.69 & 1.81 & 0.128 & 0.064 & 0.054 & 0.045 & -0.081 & 1 & & & & & & & & & & \\
\hline 7 Presence of other subsidiary & 0.84 & 0.37 & 0.034 & $0.312 * *$ & $0.249 *$ & -0.090 & 0.158 & $0.286 * *$ & & & & & & & & & & \\
\hline 8 Early relationship benefit & 5.76 & 1.59 & 0.122 & -0.090 & -0.100 & 0.058 & -0.116 & 0.136 & 0.160 & 1 & & & & & & & & \\
\hline 9 Present relationship benefit & 6.71 & 1.26 & 0.124 & -0.084 & -0.120 & -0.064 & 0.060 & 0.152 & $0.243 *$ & $0.623 * * 1$ & 1 & & & & & & & \\
\hline 11 Present relationship dependence & 5.61 & 1.67 & 0.092 & -0.027 & -0.011 & -0.146 & -0.034 & $0.283 * *$ & $* 0.309 * *$ & $0.333 * *$ & $0.516^{* *}$ & $0.728 * *$ & 1 & & & & & \\
\hline 12 Relationship duration & 4.94 & 3.46 & $0.320 * *$ & $0.297 * *$ & $0.302 * *$ & 0.136 & 0.017 & $0.276 * *$ & $* 0.125$ & 0.076 & 0.063 & 0.060 & 0.116 & 1 & & & & \\
\hline 13 Relationship satisfaction & 5.34 & 1.19 & $0.253 *$ & 0.014 & 0.003 & 0.012 & -0.012 & $0.264 *$ & 0.131 & 0.179 & $0.263 *$ & 0.068 & 0.188 & 0.191 & 1 & & & \\
\hline 14 Early economic ties & 6.23 & 1.30 & $0.267 * *$ & -0.075 & -0.044 & 0.006 & -0.039 & 0.161 & 0.136 & $0.657 * *$ & $0.481 * *$ & $0.491 * *$ & $0.327 * *$ & $0.238 *$ & $0.322 * *$ & 1 & & \\
\hline 15 Change in economic ties & 0.75 & 0.87 & -0.116 & $0.225^{*}$ & 0.157 & -0.042 & 0.071 & 0.013 & 0.057 & $-0.491 * *($ & 0.026 & $-0.443 * *$ & -0.087 & 0.002 & 0.082 & $-0.624 * *$ & 1 & \\
\hline 16 Early social bonds & 5.81 & 1.33 & $0.391 * *$ & -0.045 & -0.025 & 0.072 & 0.021 & 0.142 & 0.046 & $0.464 * *$ & $0.357 * *$ & $0.526 * *$ & $0.357 * *$ & $0.208 *$ & $0.274 * *$ & $0.764 * *$ & $-0.486^{* *}$ & 1 \\
\hline 17 Change in social bonds & 0.61 & 0.99 & -0.191 & 0.080 & 0.043 & $-0.229 *$ & 0.146 & 0.088 & 0.130 & $-0.326 * *($ & 0.182 & $-0.340 * *$ & 0.017 & -0.100 & 0.062 & $-0.452 * *$ & $0.781 * *$ & $-0.508 * *$ \\
\hline
\end{tabular}

Significance levels: * Correlation is significant at the 0.05 level (2-tailed); $* *$ Correlation is significant at the 0.01 level (2-tailed) 